\title{
RISK FACTORS FOR INTIMATE PARTNER VIOLENCE VICTIMISATION
}

\author{
A thesis \\ Submitted in fulfilment of \\ the requirements for the degree of \\ Master of Science in Statistics \\ by
}

Fleur McLaren

School of Mathematics, Statistics \& Computing

Victoria University of Wellington

P.O. Box 600

Wellington

New Zealand

Victoria University of Wellington

9th May 2008 


\section{Abstract}

Intimate partner violence (IPV) is a significant issue in New Zealand. Reported rates of IPV for New Zealand over a lifetime are estimated at $26 \%$ for women $18 \%$ for men. Over a 12 month period reported rates of IPV was reported at three percent for women and one point eight percent for men (Morris and Reilly, 2003).

This thesis set out to answer the following research questions:

1. What factors are strong predictors for intimate partner violence victimisation?

2. Is victim ethnicity factored out when variables such as SES, income and/or employment status are taken into account?

This thesis analysed complex survey data from New Zealand National Survey of Crime and Victimisation Survey 2001 (NZNSCV). Logistic regression analysis was use to investigate the risk factors for victimisation reported over a lifetime and reported in the previous 12 month period (2000). Explanatory variables were selected from existing research that identified key variables for analysis.

In answer to the research questions:

1. The strong predictors for IPV over a lifetime were Māori, people aged 25-39 years, females, solo parents, over-crowded households, those on social welfare benefits, and those divorced or separated. For 12 month prevalence of IPV strong predictors were those aged 15-24 years, Māori, lower NZSEI groups, solo parents with children, those in defacto relationships and those who do not own or rent a house.

2. Ethnicity is strongly significant in explaining victimisation even when other variables are factored into the model. In particular Māori reported to be twice as likely to be victims of IPV over a lifetime and three-and-a-half times more likely over the past 12 month period (Morris and Riley). This difference in reporting was not as large when other factors where factored in, however Māori remained at a significantly higher rate of reporting IPV than other ethnic groups, even when other variables are factored in.

This thesis adds to the body of evidence on risk factors and strengthens the New Zealand data available, as well as highlighting factors for prevention and areas that policy should be aimed at. 


\section{Acknowledgements}

My biggest thanks to my amazing supervisor, Dr Megan Clark. Megan has been a rock throughout this process and has provided knowledge, guidance, support and friendship throughout.

This thesis was also made possible by the Ministry of Justice who allowed me the use of the data from the New Zealand National Survey of Crime Victims (2001). I would also like to thanks those who participated in the survey and have provided valuable information about their own personal experiences of intimate partner violence.

I also gratefully acknowledge the Ministry of Social Development who have supported me through the process of this work especially Luisa Beltran-Castillon, who was only ever positive and supportive.

Finally my family. To my husband, Jason McLaren and my parents, Raewyn and Christopher Janes for all the support, encouragement, cuddles and meals that saw me get to the end. And Baxta, for your endless cuddles and kisses, for listening to my ramble, responding silently with a tilt of the head and a paw on my knee, I think you get me! And my amazing Grandpa, Colin Fleury, for your interest in my work and for the tireless reviewing of this monster. 


\section{Contents}

Chapter One - Introduction .............................................................................. 9

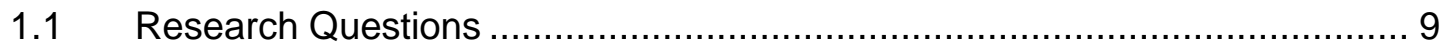

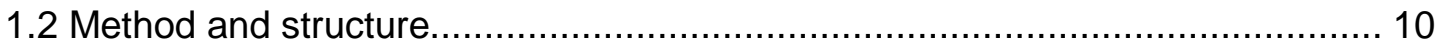

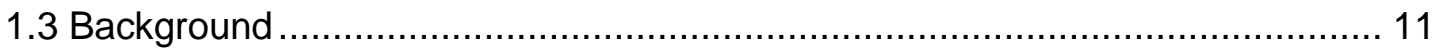

1.3.1 Intimate Partner Violence, definition for this survey ............................... 11

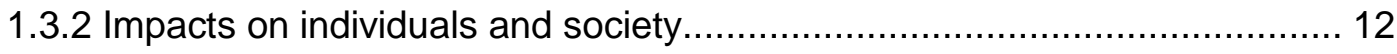

1.3.3 Disclosure of Intimate Partner Violence ................................................. 13

1.3.4 Why Survey Crime Victims ........................................................... 14

1.4 New Zealand National Survey of Crime Victims............................................ 15

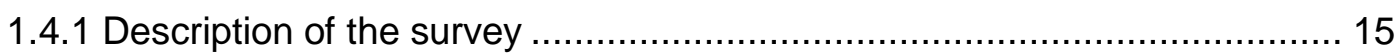

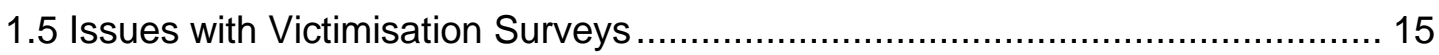

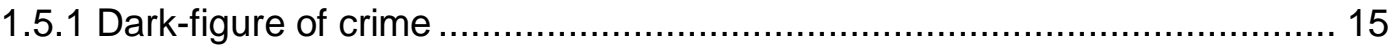

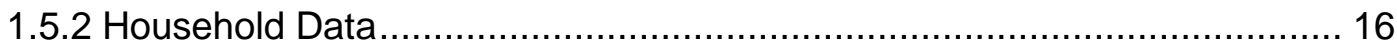

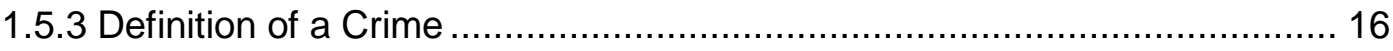

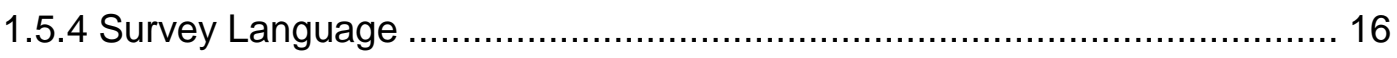

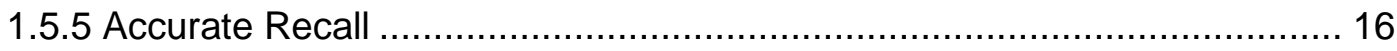

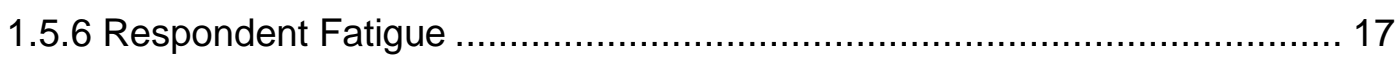

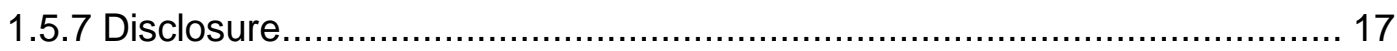

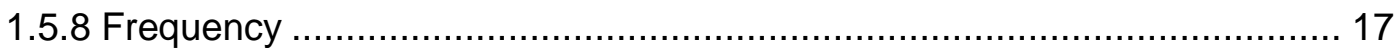

1.5.9 Group Difference in Disclosure .......................................................... 17

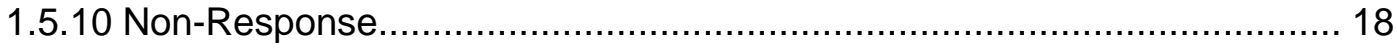

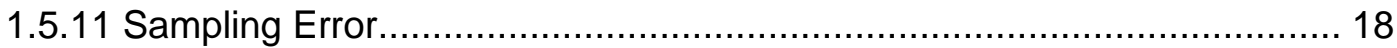

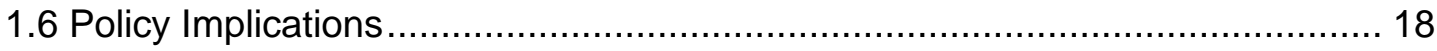

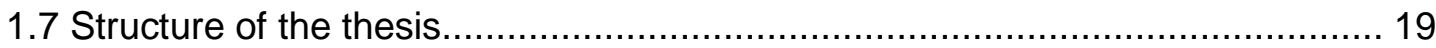

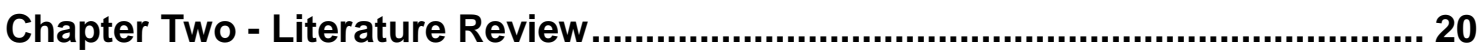

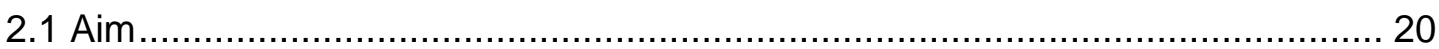

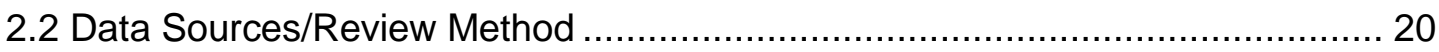

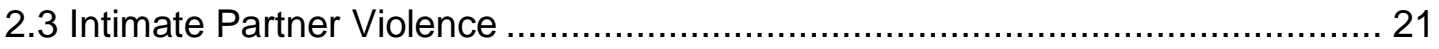

2.3.1 Incidence and Prevalence of Intimate Partner Violence ............................ 22

2.3.2 The Cost of Intimate Partner Violence .................................................... 29

2.3.3 Definition of Intimate Partner Violence ................................................. 30

2.4 Measuring Intimate Partner Violence ................................................................ 32

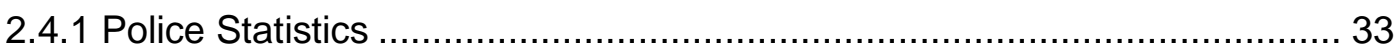




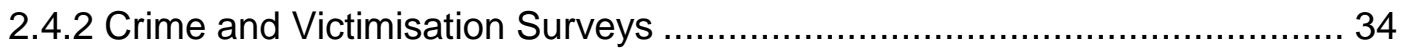

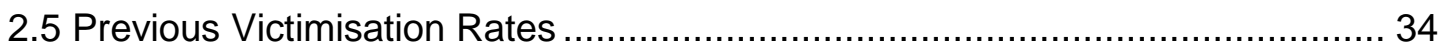

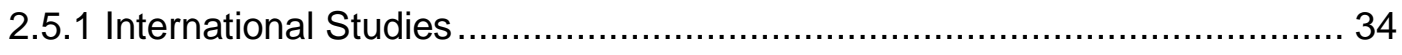

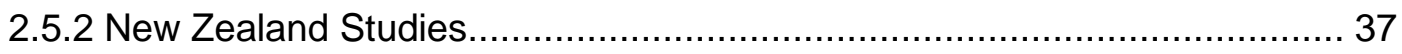

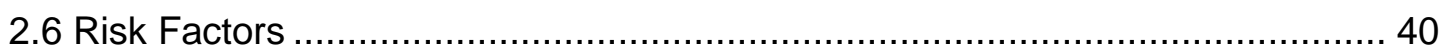

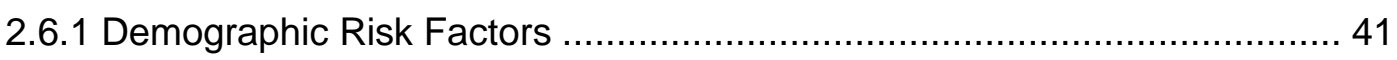

2.6.2 Socio-economic Risk Factors .......................................................... 45

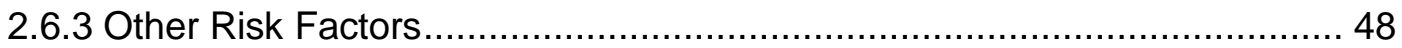

2.6.4 Health Effects ................................................................................... 54

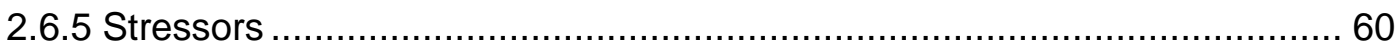

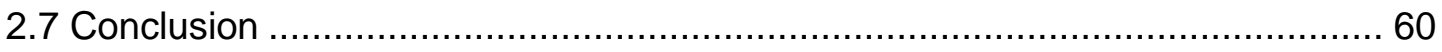

Chapter Three - Description of the New Zealand National Survey of Crime Victims

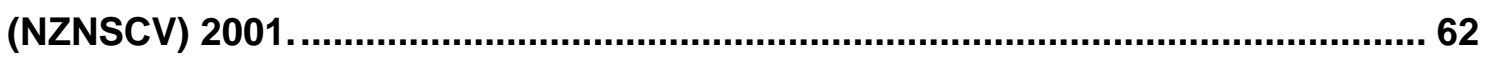

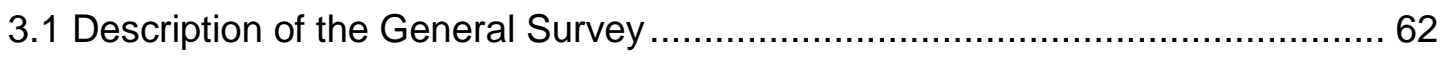

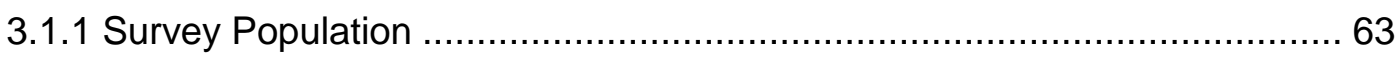

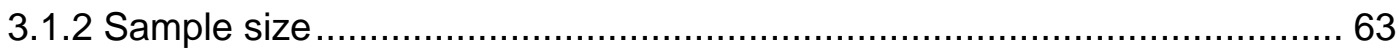

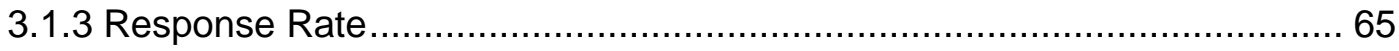

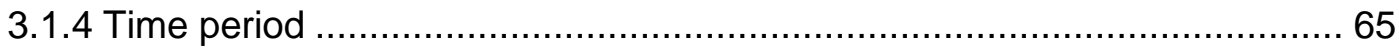

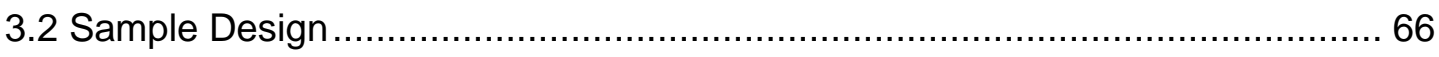

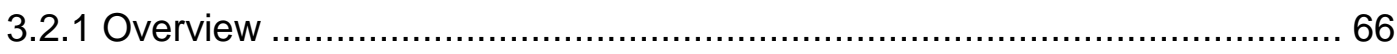

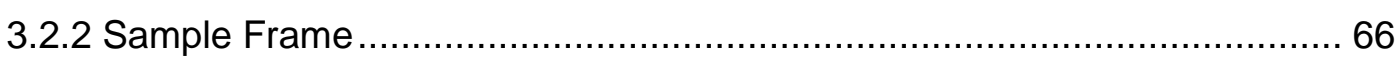

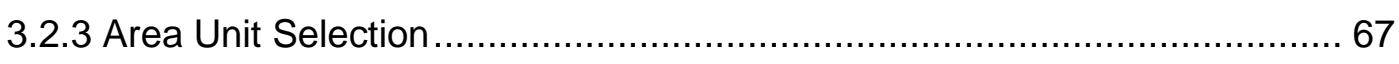

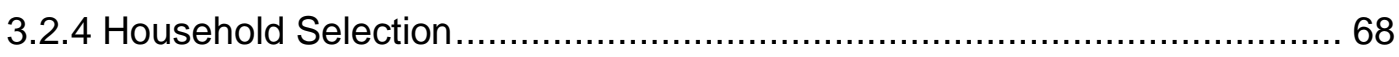

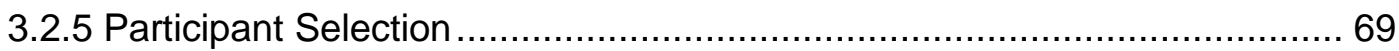

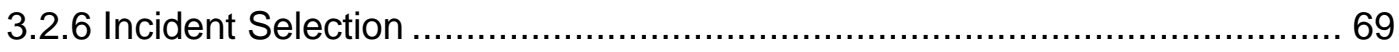

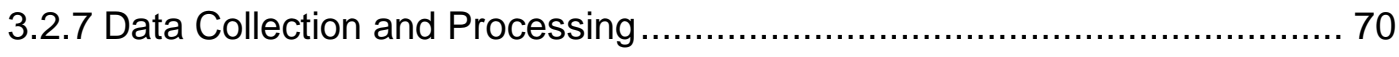

3.2.8 Questionnaire design and development.............................................. 70

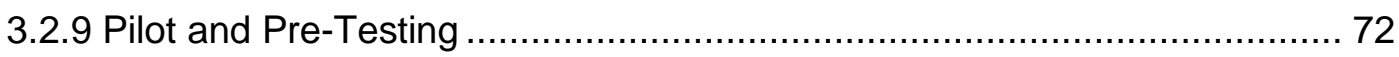

3.2.10 Description of the Database ....................................................... 72

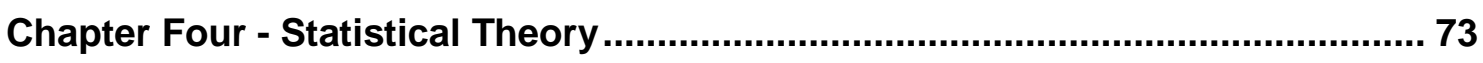

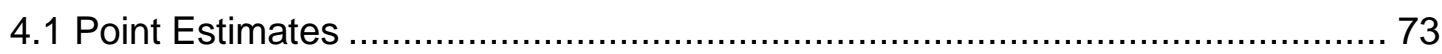

4.1.1 Estimators of point estimates ............................................................. 73

4.1.2 Dealing with items of non-response ................................................ 74

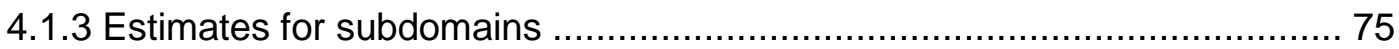

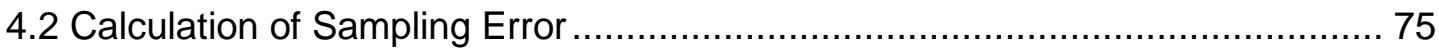




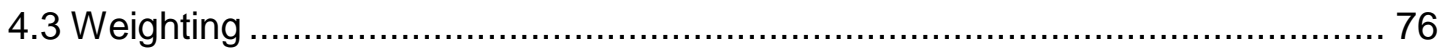

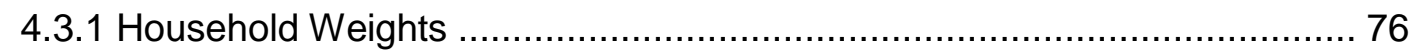

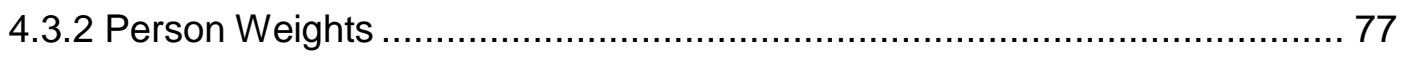

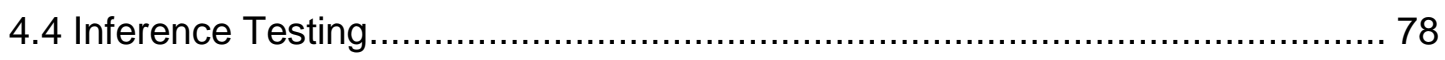

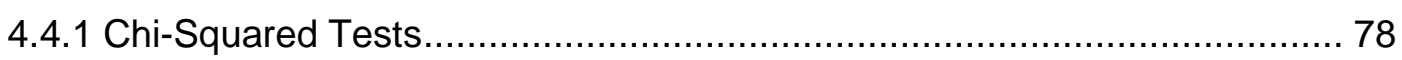

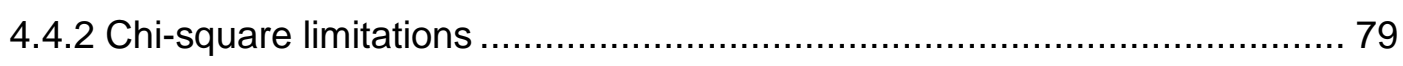

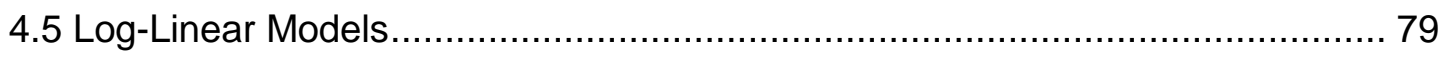

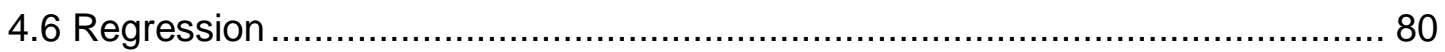

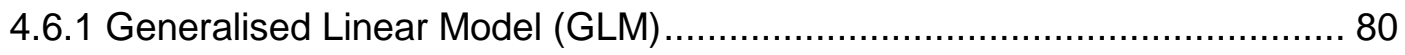

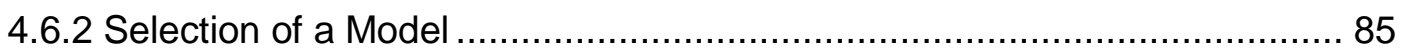

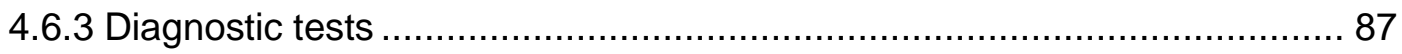

4.6.4 Sparse data ………

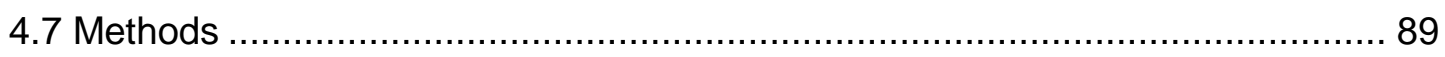

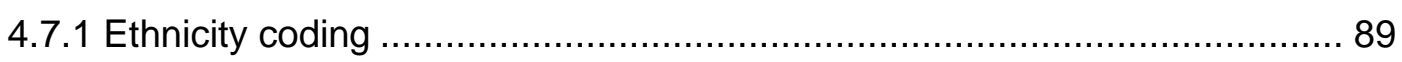

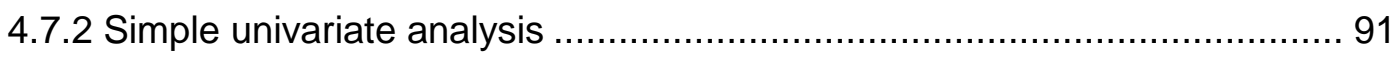

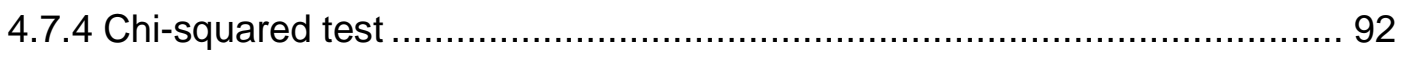

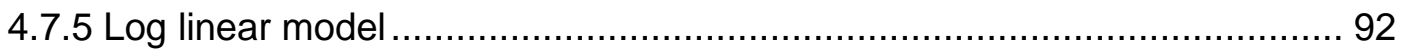

4.7.6 Logistic Regression analysis methodology ……................................... 92

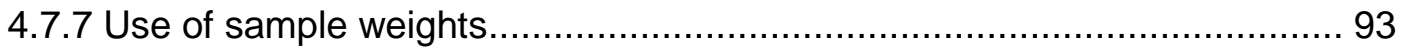

4.7.8 Modelling Intimate Partner Violence against risk factors ............................ 93

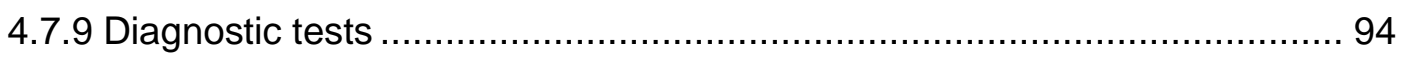

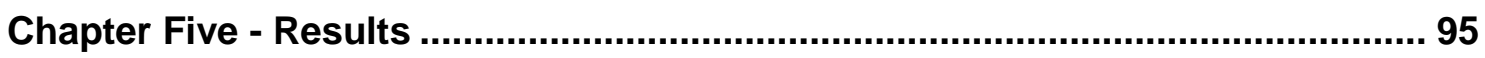

5.1 Intimate Partner Violence Victimisation ...................................................... 95

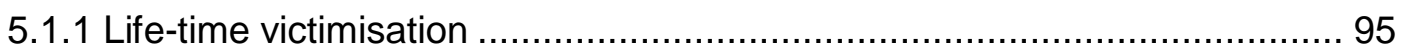

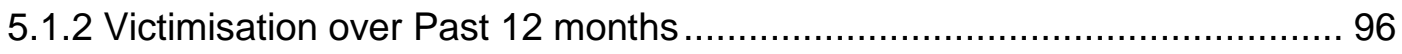

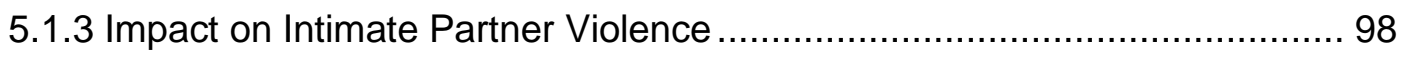

5.2 Risk factors for Intimate Partner Violence over a lifetime............................... 100

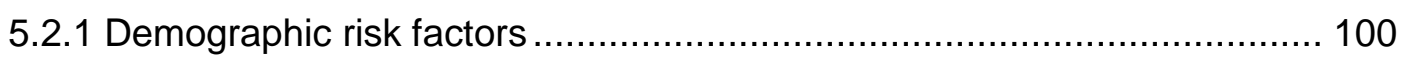

5.3 Risk factors for Intimate Partner Violence over a 12 month period................... 105

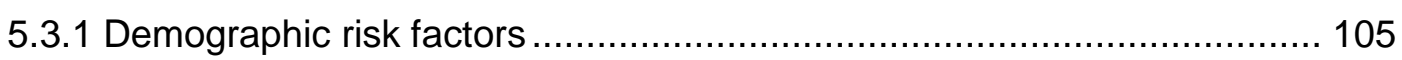

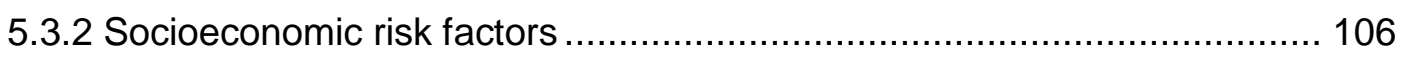

5.4 Multivariate Analysis for Intimate Partner Violence Victims risk ..................... 109

5.4.1 Log Linear results for lifetime and 12 month data ................................. 109

5.4.2 Logistic Regression results ........................................................... 110 


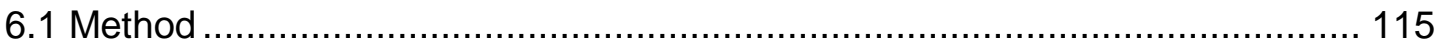

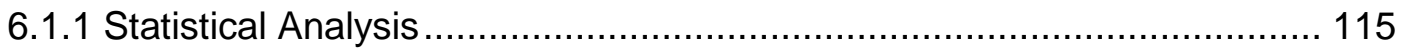

6.1.2 Violence by a Partner section of survey .......................................... 116

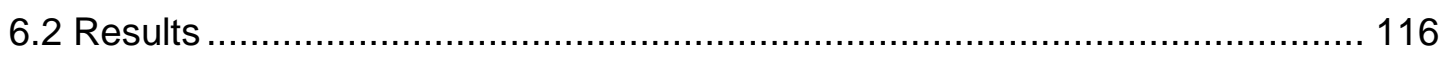

6.2.1 Risk factors for Intimate Partner Violence ........................................ 116

6.2.2 Intimate Partner Violence victimisation comparison with 1996 ................. 123

6.2.3 Comparison with previous New Zealand surveys.................................. 124

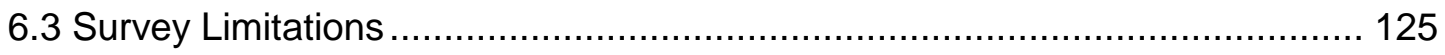

6.3.1 Disclosure of Intimate Partner Violence ........................................... 127

6.3.2 Definition of Intimate Partner Violence............................................ 127

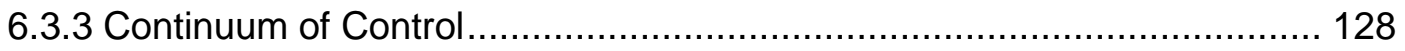

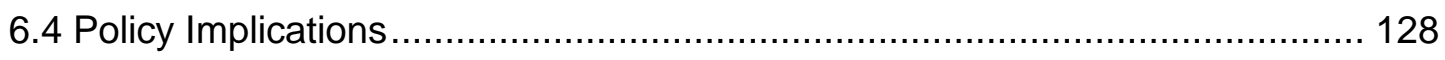

6.4.1 Ethnic Specific Policy.................................................................. 129

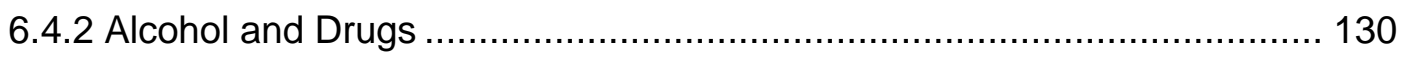

6.4.3 Levels of Stress ............................................................................ 130

6.4.4 Changing Attitudes and Behaviours ................................................ 130

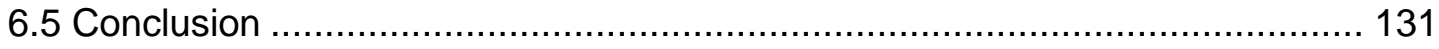

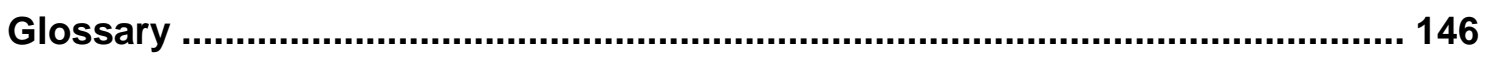

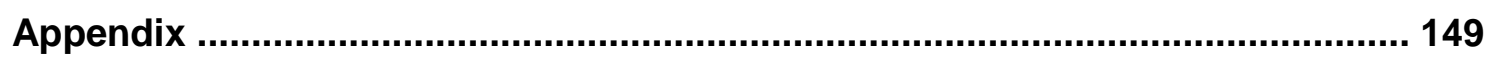

Appendix A - Victimisation section from the New Zealand National Survey of Crime

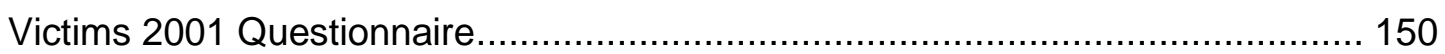

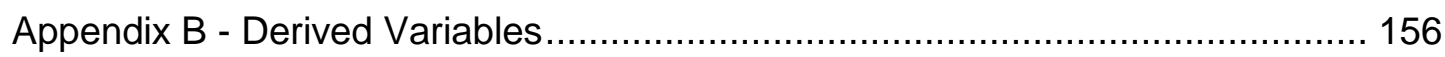

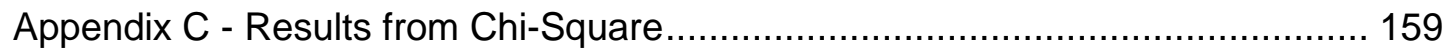

Appendix D - Results from Chi-Square - Mixed vs. Sole- Māori .......................... 182

Appendix E - Results from Log Linear Model..................................................... 185

Appendix F - Results from Logistic Regression ............................................ 192 


\section{List of Tables}

2.1 Type of violence for males and females ever experienced by a partner (in a heterosexual relationship)

2.2 Type of violence by heterosexual partners of 'ever partnered' people, by age lifetime prevalence: percentages.

2.3: Type of Violence by heterosexual partners of 'ever partnered' people, by socioeconomic status - lifetime prevalence percentages

2.4: Type of Violence by heterosexual partners of 'ever partnered' people, by ethnicity

- lifetime prevalence percentages.

2.5 Type of violence for males and females by a current partner (in a heterosexual relationship) in 2000 . 28

2.6: The Socio-Economic Costs of Violence: a Typology 29

2.7: Comparing the NZNSCV and Police recorded crime in New Zealand. 33

2.8: Recorded rates of domestic violence against women around the world. 35

2.9: Summary of New Zealand studies 38

2.10: Associations of lifetime physical violence and health outcomes reported by ever partnered women.

2.11: Women who had contact with healthcare professionals, or were hospitalised ... 58

2.12: Mental health effects of violence on women 59

3.1 Expected and actual sample sizes 64

3.2: Actual sample size used for this thesis, by ethnicity 64

3.3: The number of area units selected by each stratum for the main sample, Maori and Pacific booster samples 68

4.3: Actual sample size used for this thesis, by ethnicity ....................................... 90

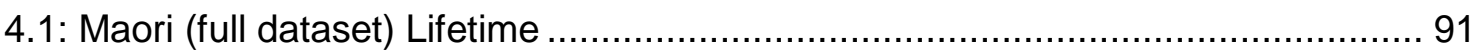

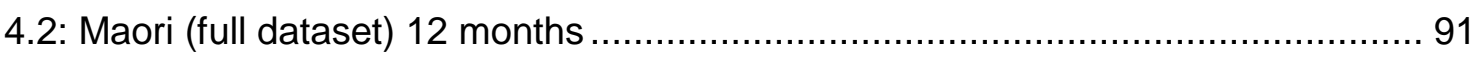

5.1 Frequency of victimisation for assault by current partner in 2000 ........................ 98

5.2: Summary of Risk factors for Intimate Partner Violence over a lifetime ................ 104

5.3: Summary of Risk factors for Intimate Partner Violence over a 12 month period 108

5.4 Risk factors for victimisation over a lifetime: logistic regression results 112

5.5 Risk factors for victimisation: logistic regression results 114

Difference in response rates for certain variables in the NZNSCV (2001) compared to the New Zealand population. 126 


\section{List of Figures}

2.1: Typology of Interpersonal Violence

2.2: Ecological model of factors associated with partner abuse.

2.3: Rates of Physical Partner Violence in three studies.

2.4: Rates of involvement in physical partner violence by relationship type (Dunedin males and females)

2.5: Rates of Victimisation reported by Dunedin Women.

2.6 Health Outcomes of Intimate Partner Violence

2.7: Rates of mental illness among Dunedin perpetrators and victims of severe physical abuse

5.1 Type of violence for males and females ever experienced by a partner 96

5.2 Type of violence for males and females by a current partner (in a heterosexual relationship) in 2000 .

5.3: Overall effects of violence by current heterosexual partners on the victim where some reaction, by sex: percentages

5.4 Victims' reactions to violent incidents by current heterosexual partners, by sex:

percentages reporting each reaction 


\section{Chapter One}

\section{Introduction}

This thesis will examine whether certain social and demographic factors are stronger predictors in intimate partner violence victimisation than other factors once all factors such as social economic status (SES), income and employment status are controlled for (for both for female and male victims).

This thesis is specifically looking at intimate partner violence (IPV) which includes violence committed by:

- a spouse

- a defacto partner/boyfriend or girlfriend

- an ex-partner.

Victimisation was recorded for both males and females who had been or were currently in a heterosexual relationship.

\subsection{Research Questions}

Using the data from the New Zealand National Survey of Crime Victims (NZNSCV) 2001 the following research questions are explored:

1. What factors are strong predictors for intimate partner violence victimisation?

2. Does victim ethnicity insignificant when variables such as SES, income and/or employment status are taken into account?

I will carry out univariate statistical analysis to identify significant factors and then use a logistic regression model to establish whether there is a relationship between the outcome variable (being a victim of intimate partner violence) and a set of predictors. If a relationship is found between certain factors then further analysis will be carried out in order to simplify the model by eliminating predictors that may not be important in 
predicting whether or not someone is likely to become a victim of intimate partner violence, while still maintaining a strong predictive relationship.

\subsection{Method and structure}

The data set used was obtained from the 2001 NZNSCV survey to look at what factors best predict intimate partner violence (IPV). This survey collected data from both female and male victims of IPV. The factors that will be considered in this analysis include respondent's age and ethnicity, the number of people in the household, household tenure, respondent's employment status, main income earner, income source, their occupation and marital status. Data from the self-completion section on 'violence by your heterosexual partner' will be used to identify those who identify as victims of IPV or not.

This thesis will investigate what the underlying factors may be that account for the higher representation of certain groups in IPV statistics. The focus on this topic is because of the implications that it has on policy making and in the design and implementation of intervention and prevention strategies to help combat the high levels of IPV that occur in New Zealand. By identifying those factors that account for being a victim of IPV we will be more able to direct policy to where it is needed. For intervention and prevention programmes to work effectively they need to be targeted at the appropriate people in the appropriate circumstances.

As identified in the NZNSCV 2001 report (Morris and Reilly, 2003) those who identified as being young Māori females were significantly more likely to report experiencing some form of violence by an intimate partner. If this is the case, when all other variables are factored in, then it has serious implications for prevention and intervention strategies to combat violence in families in New Zealand.

Using the NZNSCV (2001) data provides a New Zealand specific context for developing this research. Analysis of the NZNSCV allows us to add statistical support to build on overseas literature on risk factors. This analysis may provide the basis for the formation of New Zealand specific policy in the development of effective strategies for prevention of violence against intimate partners in New Zealand. 


\subsection{Background}

Violence cuts across culture, class, ethnicity, age and income in every country (UNICEF, 2000). Intimate partner violence is committed by many individuals, not just by those who are perceived as abnormal or those who are psychologically disturbed. IPV is perhaps the most pervasive form of violence within families (Pickup, Williams and Sweetman, 2001).

The phenomenon surrounding IPV is complex. It sits along a continuum ranging from mild to severe violence; it arises from contextual factors as well as intrapersonal and interpersonal factors and takes many forms (Pritchard, 2005).

The most commonly reported IPV was wife abuse which, in the past, was rendered socially acceptable by existing laws that only regulated the extent of physical violence husbands could use as a way of expressing disapproval to their wives. It was not until the 1960's and 1970's that IPV was recognised as a social problem that required social research.

This research is hindered by the hidden nature of this crime that often occurs in private residences (Browns and Hendricks, 1998; Pickup et al, 2001). For couples and families the place where they should feel safest, the home, is often the place of greatest danger (UNICEF, 2000).

More recently research has identified the complexity of IPV including more focus on violence initiated by female intimate partners and mutual violence occurring in couple relationships (Goodyear-Smith's, 2004; National Family Violence Survey, 1975 and 1985 in Straus and Gelles, 1986). This quote from a participant in this study illustrates mutual violence, where both partners engage in perpetrating IPV:

"We had an argument. I yelled; he hit; I retaliated".

\subsubsection{Intimate Partner Violence, definition for this survey}

There are many terms used in the literature to describe the phenomenon of this type of violence including domestic violence, intimate partner violence and family violence. This study refers to intimate partner violence which is not just reported physical violence but also psychological violence (threats and controlling behaviour). This study 
will also be using data that includes women as victims of intimate partner violence as well as men who report being victims of intimate partner violence. Data covers the experiences of victims over the previous 12 months (2000) as well as their lifetime experience of intimate partner violence by a heterosexual relationship.

The specific questions used to identify victims of intimate partner violence in the NZNSCV (Morris and Reilly, 2003) were:

- Has a current partner actually used force or violence on you, such as deliberately hit, kicked, pushed, grabbed or shoved you, or deliberately hit you with something, in a way that could have hurt you?

- Has a current partner threatened to use force or violence on you, such as threatened to hit, kick, push, grab or shove you, in a way that actually frightened you?

- Has a current partner deliberately destroyed, damaged or harmed something belonging to you, or threatened to do any of these things, in a way that actually frightened you?

- Has a current partner used a weapon against you, or threatened to use a weapon against you, such as a knife or a gun or any other weapon?

\subsubsection{Impacts on individuals and society}

Since the 1970s the phenomenon of intimate partner violence (IPV) has shifted from being considered a private family matter to being considered a social problem as researchers and practitioners have worked together. This shift in thinking has, in part, occurred as evidence indicated the negative social and psychological consequences that IPV has on victims, including pain and trauma, depression, loss of self-esteem, fear and helplessness as well as mental health problems such as depression and suicidal tendencies (Giles-Sims, 1998; Mahoney, Williams and West, 2001). There was also increasing evidence of the severe social and community cost of IPV on society and resources. Other intimate partner violence correlates include behaviours such as drinking and drug abuse (Giles-Sims, 1998; Cleveland, Herrear and Stuewig, 2003).

Intimate partner violence also impacts on a victims ability to seek and retain employment (Cram, Pihama, Jenkins and Karehana, 2002), and low self-esteem combined with high levels of depression has been demonstrated as playing a major 
role in a victims lack of ability to remove themselves from the destructive relationship (Cleveland et al, 2003).

\subsubsection{Disclosure of Intimate Partner Violence}

Accurately measuring IPV is difficult due to the predominantly private nature of the crime (Mouzos and Makkai, 2004). Victims are more likely to deal with the IPV experience themselves and to talk to family and friends rather than to seek external support. This can be a result of fear, shame, lack of support and social isolation (Mulroney, 2003).

In the NZNSCV (Morris and Rilley, 2003) the most common reason for not reporting crime to the Police was the perceived triviality of the event. The picture is quite different when looking only at those who experience violence by an intimate partner, where over $60 \%$ of respondents said they did not report the incident to the Police as it was a "private, personal or family matter" while almost $40 \%$ said they had or would deal with the matter themselves. Only about $25 \%$ of participants who reported IPV said the matter was not worth reporting or was too trivial for the Police (Morris and Reilly, 2003).

An individual's ability to recognise their situation as intimate partner violence is also a factor in non-disclosure, when the incidents are normalised by the victims (Fogarty, Burge and McCord, 2002). Some other barriers to the disclosure of intimate partner violence include:

- tendency to minimise the abuse (denial)

- cultural/ethnic/religious beliefs

- fear of reprisal

- belief that the abuse is deserved

- love for the perpetrator

- belief that he will change

- financial dependence

- concern about children

- previous negative experience with disclosure

(Fogarty, Burge and McCord, 2002). 


\subsubsection{Why Survey Crime Victims}

Victimisation surveys have greatly influenced our knowledge of victimisation and they significantly add to the information we have around the nature and extent of crime. What these surveys routinely show is that a large proportion of crimes are not reported and, likewise, that not all reported crimes are recorded by the Police in their official statistics, or that if they are recorded by the Police they can be subject to being coded incorrectly. This is often referred to as the 'dark figure of crime' by criminologists and those working in the area of crime (Mayhew and Reilly, 2007), that is, offences that do not come to the attention of the Police and are therefore unknown crimes (in terms of official Police reporting).

Those crimes that are reported to the Police also become problematic when looking into victimisation as there is little, to no, information about the context or experience of the victim/s (Morris and Reilly, 2003; Johnson 1998; O'Donnell, Smith and Madison, 2002).

For this reason victimisation surveys allow a range of information to be gathered from the victims about their circumstances and their experiences using a set of detailed robust questions. This provides us with rich contextual information unable to be captured through Police statistics due to non-reporting or the lack of information collected by Police. Questions can also be asked to ascertain consequences and impacts that the event has had on the victim and information about any resources that they, as victims, accessed as a result of the incident. This in-depth information gained through victimisation surveys provides strength in influencing policy directions as well as impacting on theoretical ideas surrounding crime and victims (Morris and Reilly, 2003; Johnson, 1998).

To date national victimisation surveys have been conducted in approximately 20 countries throughout Europe, Asia, the Middle East as well as in the United States, Britain and Canada (O'Donnell et al, 2002). 


\subsection{New Zealand National Survey of Crime Victims}

This thesis used the data from the NZNSCV 2001. It provides further analysis to that carried out by the Ministry of Justice (Morris and Reilly), published in 2003.

\subsubsection{Description of the survey}

The New Zealand National Survey of Crime Victims (NZNSCV) was commissioned by the Ministry of Justice, in collaboration with the New Zealand Police, the Department of Courts and the Ministry of Social Development in order to provide more information about responses to and effects of victimisation as well as a need for improved measures of the incidents and prevalence of victimisation in New Zealand. The fieldwork took place from mid-July to the end of November 2001.

The NZNSCV included a section on victimisation by a current or former heterosexual partner (ever partnered and over the past 12 months). Four questions were used to identify if a participant had experienced such behaviours (see section 1.3.1), if they answered yes to one or more of the four screening questions, further questions were asked about their experience of the incidents of intimate partner violence.

\subsection{Issues with Victimisation Surveys}

Surveys of crime victimisation have, in the past, been preferred to Police statistics as they were perceived to be more reliable. However victimisation surveys, like Police statistics, provide only a partial picture of the true extent of victimisation, although as a result of different methodologies and reporting practices, both forms of information have their strengths in some areas while both provide only limited pictures of victimisation overall (Morris and Reilly, 2003).

\subsubsection{Dark-figure of crime}

The term the 'dark-figure of crime' is widely used in the field of Criminology to describe crime that is unknown to the Police. Victimisation surveys still have a dark figure of crime (i.e. crime not measured by the survey) as they do not cover business or organisational crime, or crimes such as murder (as the victim is no longer living), or of those under 15 years of age. There are also those participants who will not disclose 
incidents of intimate partner violence in the survey. Thus victimisation surveys invariably underestimate the total extent of victimisation (Morris and Reilly, 2003; Mayhew and Reilly, 2007).

\subsubsection{Household Data}

Victimisation surveys tend to be surveys of households which means the omission of certain parts of the population from the survey such as the homeless, those living in boarding houses, student halls of residence, nursing homes and so on. Some of these groups tend to feature highly as victims especially those in shelters, the homeless, elderly, those in hospitals and those in penal institutions. This results again in the under-estimation in the measure of the occurrence of crime victimisation (Morris and Reilly, 2003).

\subsubsection{Definition of a Crime}

Victimisation surveys can also result in the over-estimation of incidents. Participants report on what they define as an event, consequently some of the incidents that are reported may not come within the legal definition of a particular crime, but are still recorded as such. This is also a reason why not all incidents reported to the Police are recorded, as the Police may deem the event not recordable due to a lack of seriousness or not meeting the definition of a crime (Morris and Reilly, 2003).

\subsubsection{Survey Language}

Survey estimates may be affected by the language used in the survey. By using the same definitions and legal terms as the Police, comparisons are easer between data, but may inhibit respondent's ability to report in the survey as they may not understand the meaning of the language. Some acts of violence, such as rape or IPV, can be seen as 'normal' within some relationships. In these situations the extent of crime becomes under-estimated (Morris and Reilly, 2003).

\subsubsection{Accurate Recall}

The timing of an incident can cause a problem as it is often hard for respondents to accurately recall the incident and if it occurred in the appropriate time frame the survey 
is referring to. Getting the timing correct allows contrasts to be made with Police statistics or other surveys carried out in the same time period. Under-estimation, again, can occur if participants fail to include an incident in the time period surveyed. Conversely those who include incidents in the time frame but occurred earlier will lead to an over-estimation of the extent of victimisation. Accurate recall can also be severely distorted by alcohol and drug use and the use of such substances are reportedly present in a large percentage of IPV incidents (Morris and Reilly, 2003).

\subsubsection{Respondent Fatigue}

Surveys can be quite time consuming and invasive. The average length of time to complete the NZNSCV survey was 40-50 minutes, which can put individuals off participating in the survey. It may also be that some participants began to answer questions in a way that will allow the survey to go faster. For example individuals may say they have not experienced violence at the hand of a partner to avoid the lengthy answering that would follow a positive response. This creates a bias in the responses, as not all incidents are recorded accurately.

\subsubsection{Disclosure}

The unwillingness of some participants to disclose certain incidents is another source of under-estimation of victimisation. While participants may recall an event they may be reluctant to disclose it to the interviewer due to feelings of fear or shame, or in a bid to protect their partner or themselves (Morris and Reilly, 2003).

\subsubsection{Frequency}

For crimes that occur frequently for some participants, for example violence that occurs in the home, it may be hard for participants to be able to accurately recall the number or occurrence of incidence, particularly if they view some of the incidences as not significant or important (Morris and Reilly, 2003).

\subsubsection{Group Difference in Disclosure}

Recall may also differ between groups of participants, for example across gender, ethnicity and socio-economic status. Cultures that view shame as very important may thus under-report incidents to save face for them or their family. This means that levels 
of victimisation may appear to be different amongst certain groups, which may be due their willingness or unwillingness to disclose incidents (Morris and Reilly, 2003).

\subsubsection{Non-Response}

When people decide not to take part in victimisation surveys, inaccuracy can occur if the missing data is significantly different from the data collected from those who do choose to take part in the survey. As data is not available from non-respondents we are unable to know how different the group of non-respondents is from those that do respond, and are therefore unaware of the exact impact of any inaccuracies. By using various weighting techniques some potential inaccuracies can be eliminated as a result from non-response (Morris and Reilly, 2003).

\subsubsection{Sampling Error}

As surveys use only a sample of the population there is an inherent sampling error. This means that we are reporting on estimates not exact numbers. Even if under or over-estimation did not exist, survey results would still be affected by random sampling variation. The level of sampling error can however be calculated, summarised in confidence intervals and used to conduct significance tests (Morris and Reilly, 2003).

\subsection{Policy Implications}

The complexity of IPV means that no one strategy will reduce the incidences of IPV in all situations. Intimate partner violence can occur in different social contexts, and the strategies needed would require an understanding of the degree to which a certain society or community sanctions IPV (UNICEF, 2000).

Considering the interconnectedness between factors such as social structure, power relations and economic systems, strategies and interventions must be designed with these in mind. Strategies with multiple layers that address IPV, while also providing immediate services to victims, ensure a potential to eliminate victimisation and will be sustainable (UNICEF, 2000).

Such strategies are useful and necessary in order to alter circumstances and lower the risk to victims in vulnerable situations and to enable them to prepare strategies to deal 
with impending situations. By identifying which demographic characteristics contribute to increased risk of being a victim of IPV we can inform developers of social policy and intervention programmes (O'Donnell et al, 2002).

\subsection{Structure of the thesis}

This Chapter (One) has introduced the topic of intimate partner violence and victimisation surveys.

Chapter Two covers the review of literature in the area of victimisation and theory around intimate partner violence, predictors and risk factors. The literature review focuses specifically on:

- family violence, intimate partner violence, domestic violence

- risk factors

- family strengths and family wellbeing

- prevalence and incidence of intimate partner violence

- Māori and Pacific specific research.

Chapter Three describes the New Zealand National Survey of Crime Victims 2001 from which the data was drawn.

In Chapter Four, a detailed review is included outlining the statistical methods considered for this study as well as an explanation of the final methodology used.

Chapter Five presents the results from this thesis, starting with the reporting of the NZNSCV (2001) survey results of prevalence and incidence of IPV and then on to the specific results from the analysis in this thesis on risk factors for IPV.

Chapter Six provides an in-depth discussion on the findings of this study, with policy implications and a final conclusion of these specific findings.

All quotes in this thesis are in italics and come from the NZNSCV report (Morris and Reilly, 2003).

A glossary of key terms can be found at the end of this report. 


\section{Chapter Two}

\section{Literature Review}

\subsection{Aim}

This literature review aims to identify and critically review previous studies on intimate partner violence (IPV) victimisation. This review will provide a research-based context for this present study. A review is also included of other international and New Zealand specific victimisation surveys, and provides prevalence and incidence data in order to make comparisons with the NZNSCV (2001) findings. The review of previous research provides useful insight into the limitations of victimisation surveys as well as the complexity of the area of intimate partner violence victimisation, defining and measuring.

\subsection{Data Sources/Review Method}

This literature review used mainly peer-reviewed literature from electronic databases.

The following electronic databases and search engines were used:

- Family violence clearinghouse database

- Psyclnfo

- ProQuest

- Google

- MSD library database.

The literature search focused on two main domains of recent research most of which had been published since 2000 on intimate partner violence risk factors and prevention implications. An analysis on the findings and conclusions from each domain was used to identify key risk factors for intimate partner violence victimisation and explanations for these findings on policy. 
The search covered the following key words and topics:

- family violence

- intimate partner violence

- domestic violence

- risk factors

- family strengths and family wellbeing

- prevalence and incidence of intimate partner violence

- Māori and Pacific specific research.

\subsection{Intimate Partner Violence}

Irrespective of gender, age, ethnicity, level of education, income or occupation, IPV can be experienced at any stage of a relationship (Lievore and Mayhew, 2007). While anyone can potentially be a victim of IPV there is an uneven distribution of victimisation as only a very small percentage of the population are victims, but at high rates for these individuals. The majority of Western society has little exposure to real-life violence but for some it is very common (Goodyear-Smith, 2004).

In the mid-90's the prevalence rate of violence within families in New Zealand was estimated to be at 14\% (March 1994). Under the Domestic Violence Act 1995, 28,755 applications for protection orders were made between July 1996 and June 2000. More recently, studies in New Zealand have indicated that around six percent of individuals experience intimate partner violence (Morris and Reilly, 2003; Fleming, Watson, Robinson, Ameratunga, Dixon, Clark and Crengle, 2007; Fanslow and Robinson, 2004) and in 2006 Police call outs for family violence exceeded 71,000 (Women's Refuge, 2007).

Now more research is focusing on the different forms of IPV violence that can occur and revealing the true complexity of defining and measuring IPV. The main focus of research is partner violence perpetrated by men with the intention to punish and control their partner. This instrumental violence accounts for only five to ten percent of IPV in New Zealand. The largest group of aggressive relationships tends to occur where both partners are involved (common couple violence). While common couple violence is more common in relationships where violence is occurring, it does tend more to be mild to moderate in nature, while instrumental violence tends to be more severe in harm (Pritchard, 2005). 


\subsubsection{Incidence and Prevalence of Intimate Partner Violence}

\subsubsection{Lifetime Experience}

A number of New Zealand studies have measured lifetime prevalence rates of violence by a partner (Fanslow and Robinson, 2004; Koziol-McLain, Gardiner, Batty, Rameka, Fyfe and Giddings, 2004; Morris and Reilly, 2003). The prevalence and incidence figures vary across surveys, which is possibly due to the effect of different measurements and definitions of violence.

Table 2.1 shows the lifetime prevalence of violence by a heterosexual partner for both men and women, found in the NZNSCV (Morris and Reilly, 2003). This table shows that around $20 \%$ of female participants experience each of these behaviours while over one in four females had experienced more than one of these violent acts in their lifetime. The experience of violence reported by males was lower for each item of violent behaviour. However $18 \%$ reported experiencing one or more incidents in their lifetime.

There is no directly comparable data from overseas but the 1996 British Crime Survey reported that $23 \%$ of females and $15 \%$ of males ever partnered (aged 16-59) reported being physically assaulted by a current or former partner. The American National Violence Against Women Survey (Tjaden and Thoennes, 2000) had similar results for women participants with $20 \%$ of women and seven percent of men ever partnered reporting being physically assaulted by a current or former partner in their lifetime (Tjaden and Thoennes, 2000).

From the Auckland and Waikato study (Fanslow and Robinson, 2004), lifetime rates of physical and/or sexual violence by an intimate partner were estimated to affect one in three ever partnered women.

The 1996 Australian Women's Safety Survey (Mulroney, 2003) found that current or former partners were responsible for one in five assaults against females and $33 \%$ of women who reported IPV reported more than one event. 
Table 2.1: Type of violence for males and females ever experienced by a partner (in a heterosexual relationship)

\begin{tabular}{|l|c|c|}
\hline Behaviours & $\begin{array}{c}\text { Ever } \\
\text { partnered } \\
\text { women }\end{array}$ & $\begin{array}{c}\text { Ever } \\
\text { partnered } \\
\text { men }\end{array}$ \\
\hline $\begin{array}{l}\text { Has any partner EVER actually used force or violence on } \\
\text { you, such as deliberately hit, kicked, punched, grabbed or } \\
\text { shoved you, or deliberately hit you with something, in a way } \\
\text { that could have hurt you? }\end{array}$ & 21.2 & 14.4 \\
\hline $\begin{array}{l}\text { Has any partner EVER threatened to use force or violence } \\
\text { on you, such as threatened to hit, kick, push, grab or shove } \\
\text { you, in a way that actually frightened you? }\end{array}$ & 19.5 & 8.0 \\
\hline $\begin{array}{l}\text { Has any partner EVER deliberately destroyed, damaged or } \\
\text { harmed something belonging to you, or threatened to do any } \\
\text { of these things, in a way that actually frightened you? }\end{array}$ & 18.8 & 9.8 \\
\hline $\begin{array}{l}\text { Has any partner EVER used a weapon against you, or } \\
\text { threatened to use a weapon against you, such as a knife or } \\
\text { gun or any other weapon? }\end{array}$ & 6.2 & 3.4 \\
\hline Experienced none of these & $\mathbf{7 1 . 4}$ & $\mathbf{7 9 . 0}$ \\
\hline Experienced one or more of these & $\mathbf{2 6 . 4}$ & $\mathbf{1 8 . 2}$ \\
\hline Refused to complete & 2.2 & 2.7 \\
\hline Sample Size & 2526 & 1721 \\
\hline
\end{tabular}

Morris and Reilly (2003).

It would be expected that lifetime prevalence would be higher for those in older age groups as they have experienced a longer life span. Table 2.2 shows that there is the expected age gradient in lifetime prevalence up to age 40, however after age 40 prevalence rates drop. Table 2.2 shows that almost a fifth to a quarter of each age group, except those aged 60 and over, had experienced some form of violence by a heterosexual partner.

This may be due to the reluctance of older people to disclose such incidents out of shame or embarrassment, or that they have forgotten experiences from many years ago. Another possible explanation for the decline in prevalence for older age groups is the effect of early mortality in against victims of IPV, which would mean there would be lower IPV rates in older age groups, although this effect is unlikely to be large. 
A further explanation for this reporting pattern is younger age groups may actually experience more intimate partner violence than previous generations (Morris and Reilly, 2003).

Table 2.2: Type of violence by heterosexual partners of 'ever partnered' people, by age - lifetime prevalence: percentages

\begin{tabular}{|c|c|c|c|c|c|}
\hline Behaviours & $\begin{array}{l}15 \\
\text { and } \\
16\end{array}$ & 17-24 & 25-39 & $40-59$ & $\begin{array}{l}60 \\
\text { and } \\
\text { Older }\end{array}$ \\
\hline $\begin{array}{l}\text { Has any partner EVER actually used force or } \\
\text { violence on you, such as deliberately hit, } \\
\text { kicked, punched, grabbed or shoved you, or } \\
\text { deliberately hit you with something, in a way } \\
\text { that could have hurt you? }\end{array}$ & 17.7 & 22.4 & 26.6 & 17.5 & 6.6 \\
\hline $\begin{array}{l}\text { Has any partner EVER threatened to use } \\
\text { force or violence on you, such as threatened } \\
\text { to hit, kick, push, grab or shove you, in a way } \\
\text { that actually frightened you? }\end{array}$ & 8.7 & 17.6 & 21.2 & 14.0 & 4.3 \\
\hline $\begin{array}{l}\text { Has any partner EVER deliberately } \\
\text { destroyed, damaged or harmed something } \\
\text { belonging to you, or threatened to do any of } \\
\text { these things, in a way that actually frightened } \\
\text { you? }\end{array}$ & 4.9 & 14.6 & 21.6 & 14.9 & 5.4 \\
\hline $\begin{array}{l}\text { Has any partner EVER used a weapon } \\
\text { against you, or threatened to use a weapon } \\
\text { against you, such as a knife or gun or any } \\
\text { other weapon? }\end{array}$ & 0.0 & 7.1 & 7.5 & 4.7 & 1.3 \\
\hline Experienced none of these & 72.4 & 63.1 & 66.5 & 75.7 & 88.3 \\
\hline Experienced one or more of these & 18.5 & 27.8 & 32.0 & 22.7 & 8.9 \\
\hline Refused to complete & 9.1 & 9.1 & 1.5 & 1.6 & 2.8 \\
\hline Sample Size & 26 & 268 & 1322 & 1495 & 1035 \\
\hline
\end{tabular}

Morris and Reilly (2003). 
Apart from the New Zealand Socio-economic Index (NZSEI) 30-39 group, little difference was found in prevalence rates across socio-economic groups in New Zealand (see table 2.3) (Morris and Reilly, 2003). The prevalence of IPV in the 'unspecified group' is almost two to three times higher than the other NZSEI groups, although it is not know what accounts for this big difference in reporting.

Table 2.3: Type of Violence by heterosexual partners of 'ever partnered' people, by socio-economic status - lifetime prevalence percentages

\begin{tabular}{|c|c|c|c|c|c|c|c|}
\hline Behaviours & $\begin{array}{l}\text { NZSEI } \\
\text { Unspeci } \\
\text { fied }\end{array}$ & $\begin{array}{l}\text { NZSEI } \\
10-29\end{array}$ & $\begin{array}{l}\text { NZSEI } \\
30-39\end{array}$ & $\begin{array}{l}\text { NZSEI } \\
40-49\end{array}$ & $\begin{array}{l}\text { NZSEI } \\
50-59\end{array}$ & $\begin{array}{l}\text { NZSEI } \\
60-74\end{array}$ & $\begin{array}{l}\text { NZSEI } \\
75-90\end{array}$ \\
\hline $\begin{array}{l}\text { Has any partner EVER actually used } \\
\text { force or violence on you, such as } \\
\text { deliberately hit, kicked, punched, } \\
\text { grabbed or shoved you, or deliberately } \\
\text { hit you with something, in a way that } \\
\text { could have hurt you? }\end{array}$ & 35.2 & 16.1 & 21.5 & 17.2 & 17.3 & 13.5 & 14.0 \\
\hline $\begin{array}{l}\text { Has any partner EVER threatened to } \\
\text { use force or violence on you, such as } \\
\text { threatened to hit, kick, push, grab or } \\
\text { shove you, in a way that actually } \\
\text { frightened you? }\end{array}$ & 28.7 & 14.0 & 17.9 & 14.1 & 12.7 & 9.1 & 8.0 \\
\hline $\begin{array}{l}\text { Has any partner EVER deliberately } \\
\text { destroyed, damaged or harmed } \\
\text { something belonging to you, or } \\
\text { threatened to do any of these things, in } \\
\text { a way that actually frightened you? }\end{array}$ & 27.2 & 13.4 & 19.3 & 14.6 & 12.4 & 11.4 & 7.8 \\
\hline $\begin{array}{l}\text { Has any partner EVER used a weapon } \\
\text { against you, or threatened to use a } \\
\text { weapon against you, such as a knife or } \\
\text { gun or any other weapon? }\end{array}$ & 16.2 & 5.8 & 5.9 & 4.5 & 4.2 & 1.2 & 2.0 \\
\hline Experienced none of these & 53.4 & 78.3 & 71.0 & 76.8 & 75.5 & 78.5 & 81.7 \\
\hline Experienced one or more of these & 40.2 & 20.4 & 26.7 & 21.6 & 20.8 & 19.2 & 17.4 \\
\hline Refused to complete & 6.3 & 1.3 & 2.3 & 1.6 & 3.7 & 2.3 & 0.9 \\
\hline Sample Size & 308 & 749 & 750 & 880 & 733 & 608 & 219 \\
\hline
\end{tabular}

Morris and Reilly (2003). 
Māori reported twice as many incidences of partner violence over their lifetime than did non-Māori participants (shown in table 2.4). Looking at the age of Māori and non-Māori respondents, lifetime prevalence was higher for women, both for New Zealand European and Māori women, and overall highest reported rate was for Māori women, with almost half of them reporting such behaviours at least once in their lifetime (Morris and Reilly, 2003).

Table 2.4: Type of Violence by heterosexual partners of 'ever partnered' people, by ethnicity - lifetime prevalence percentages

\begin{tabular}{|l|c|c|c|c|}
\hline Behaviours & $\begin{array}{l}\text { NZ } \\
\text { European }\end{array}$ & Māori & $\begin{array}{l}\text { Pacific } \\
\text { Peoples }\end{array}$ & Other \\
\hline $\begin{array}{l}\text { Has any partner EVER actually used force or } \\
\text { violence on you, such as deliberately hit, } \\
\text { kicked, punched, grabbed or shoved you, or } \\
\text { deliberately hit you with something, in a way } \\
\text { that could have hurt you? }\end{array}$ & 17.3 & 31.7 & 12.3 & 13.2 \\
\hline $\begin{array}{l}\text { Has any partner EVER threatened to use force } \\
\text { or violence on you, such as threatened to hit, } \\
\text { kick, push, grab or shove you, in a way that } \\
\text { actually frightened you? }\end{array}$ & 13.1 & 27.6 & 11.7 & 9.0 \\
\hline $\begin{array}{l}\text { Has any partner EVER deliberately destroyed, } \\
\text { damaged or harmed something belonging to } \\
\text { you, or threatened to do any of these things, in } \\
\text { a way that actually frightened you? }\end{array}$ & 13.6 & 24.8 & 12.1 & 13.7 \\
\hline $\begin{array}{l}\text { Has any partner EVER used a weapon against } \\
\text { you, or threatened to use a weapon against } \\
\text { you, such as a knife or gun or any other } \\
\text { weapon? }\end{array}$ & 4.1 & 12.2 & 3.3 & 3.4 \\
\hline Experienced none of these & $\mathbf{2 1 . 4}$ & $\mathbf{3 9 . 3}$ & $\mathbf{1 7 . 3}$ & $\mathbf{1 7 . 6}$ \\
\hline $\begin{array}{l}\text { Experienced one or more of these } \\
\text { Refused to complete }\end{array}$ & 3114 & 755 & 522 & 3.4 \\
\hline Sample Size & & & & \\
\hline
\end{tabular}

Morris and Reilly (2003). 
In the 2001 NZNSCV, lifetime prevalence data was collected and participants were asked if they had experienced violence by a partner at all in their life. They were not asked how often this happened or how serious the occurrences were. This may cause problems as participants may not recall events from their whole lifetime but perhaps only in the relatively relevant past (Morris and Reilly, 2003).

\subsubsection{Experience over a 12 month period}

In the NZNSCV (2001), participants were asked if they had experienced an event of violence by a partner in the previous 12 months beginning 1 January 2000. Of those who currently had partners three percent reported at least one of these types of violent behaviours (refer to table 2.5).

Findings from the Australian Bureau of Statistics (1996, in Morris and Reilly, 2003)) found that of the 6300 women they surveyed three percent reported experiencing at least one incident of violence in their current married or de facto relationship over the past 12 months.

In the British Crime Survey, Mirrlees-Black and Byron (1999) found that in the prior 12 months four percent of women reported being physically assaulted by a former or current partner which increased to six percent when frightening threats were added (Morris and Reilly, 2001).

A United States survey (Tjaden and Thoennes, 2000) of almost 6000 women found that almost one and a half percent reported violence by a current or former partner including rape, physical assault or stalking. This figure is somewhat smaller than that from the 2001 NZNSCV, especially since it included former partners; however this probably reflects the different methodology between surveys (Morris and Reilly, 2003).

While a majority of IPV is recorded as having female victims, looking at table 2.5 it can be seen that there is a relative closeness in reporting of violence between partners for both men and women, one point eight percent and three percent respectively. Other research indicates that men and women experience similar levels of intimate partner violence. In the British Crime Survey (Mirlees-Black, Mayhew and Percy, 1996) four percent of men reported being physically assaulted by a female partner, this rose to five percent when threats were added (Morris and Reilly, 2003). 
Table 2.5: Type of violence for males and females by a current partner (in a heterosexual relationship) in 2000

\begin{tabular}{|c|c|c|c|c|}
\hline \multirow{2}{*}{ Behaviour } & \multicolumn{2}{|c|}{$\begin{array}{c}\text { Currently partnered } \\
\text { women }\end{array}$} & \multicolumn{2}{|c|}{$\begin{array}{c}\text { Currently partnered } \\
\text { men }\end{array}$} \\
\hline & Incidence & Prevalence & Incidence & Prevalence \\
\hline $\begin{array}{l}\text { Since } 1 \text { January } 2000 \text {, has a current } \\
\text { partner actually used force or violence } \\
\text { on you, such as deliberately hit, } \\
\text { kicked, punched, grabbed or shoved } \\
\text { you, or deliberately hit you with } \\
\text { something, in a way that could have } \\
\text { hurt you? }\end{array}$ & 4.1 & 2.0 & 3.3 & 1.2 \\
\hline $\begin{array}{l}\text { Since } 1 \text { January } 2000, \text { has a current } \\
\text { partner threatened to use force or } \\
\text { violence on you, such as threatened } \\
\text { to hit, kick, push, grab or shove you, } \\
\text { in a way that actually frightened you? }\end{array}$ & 6.0 & 2.3 & 1.3 & 0.8 \\
\hline $\begin{array}{l}\text { Since } 1 \text { January } 2000, \text { has a current } \\
\text { partner deliberately destroyed, } \\
\text { damaged or harmed something } \\
\text { belonging to you, or threatened } \\
\text { to do any of these things, in a way } \\
\text { that actually frightened you? }\end{array}$ & 3.2 & 1.4 & 0.8 & 0.6 \\
\hline $\begin{array}{l}\text { Since } 1 \text { January } 2000, \text { has a current } \\
\text { partner used a weapon against you, } \\
\text { or threatened to use a weapon } \\
\text { against you, such as a knife or gun or } \\
\text { any other weapon? }\end{array}$ & 0.5 & 0.2 & 0.5 & 0.4 \\
\hline Experienced none of these & \multicolumn{2}{|c|}{97.0} & \multicolumn{2}{|c|}{98.2} \\
\hline Experienced one or more of these & \multicolumn{2}{|c|}{3.0} & \multicolumn{2}{|c|}{1.8} \\
\hline Sample Size & \multicolumn{2}{|c|}{1606} & \multicolumn{2}{|c|}{1327} \\
\hline
\end{tabular}

Morris and Reilly (2003). 


\subsubsection{The Cost of Intimate Partner Violence}

Estimating the cost of IPV is a way to demonstrate the impact IPV has on society, and adds to the evidence and information that influences policy makers and creates awareness about the importance of creating and investing in IPV interventions. It can also aid in the assessment of effective IPV intervention strategies and programmes (Injury Prevention Centre CDC, 2003). Below is a table (2.6) from UNICEF (2000) which looks at the socio-economic areas that intimate partner violence impacts on in society.

Table 2.6: The Socio-Economic Costs of Violence: a Typology

\begin{tabular}{|c|c|c|}
\hline Direct costs & $\begin{array}{l}\text { Value of goods and services used } \\
\text { in treating or preventing violence }\end{array}$ & $\begin{array}{ll}\text { - } & \text { Medical } \\
\text { - } & \text { Police } \\
\text { - } & \text { Criminal justice system } \\
\text { - } & \text { Housing } \\
\text { - } & \text { Social services }\end{array}$ \\
\hline $\begin{array}{l}\text { Non-monetary } \\
\text { costs }\end{array}$ & Pain and Suffering & $\begin{array}{ll}\text { - } & \text { Increased morbidity } \\
\text { - } & \text { Increased mortality via } \\
& \text { homicide and suicide } \\
\text { - } & \text { Abuse of alcohol and drugs } \\
\text { - } & \text { Depressive disorders }\end{array}$ \\
\hline $\begin{array}{l}\text { Economic } \\
\text { multiplier effects }\end{array}$ & $\begin{array}{l}\text { Macro-economics, labour market, } \\
\text { inter-generational productivity } \\
\text { impacts }\end{array}$ & $\begin{array}{ll}\text { - } & \text { Decreased labour market } \\
\text { - } & \text { participation } \\
\text { - } & \text { job } \\
\text { - } & \text { Lower earnings } \\
\text { - } & \text { Increased absenteeism } \\
\text { - Intergenerational productivity } \\
\text { impacts via grade repetition } \\
\text { and lower educational } \\
\text { attainment of children } \\
\text { - Decreased investment and } \\
\text { - } \text { Savings } \\
\text { Capital flight }\end{array}$ \\
\hline $\begin{array}{l}\text { Social multiplier } \\
\text { effects }\end{array}$ & $\begin{array}{l}\text { Impact on interpersonal relations } \\
\text { and quality of life }\end{array}$ & $\begin{array}{ll}\text { - } & \text { Intergenerational } \\
& \text { transmission of violence } \\
\text { - } & \text { Reduced quality of life } \\
\text { - } & \text { Erosion of social capital } \\
\text { - } & \text { Reduced participation in } \\
& \text { democratic process }\end{array}$ \\
\hline
\end{tabular}

Buvinic et al, 1999 in UNICEF (2000). 
In New Zealand in 1994 the reported cost of domestic violence was estimated at NZD\$1.2 billion, NZD\$140.7 million per annum under vote Health and a further NZD\$16.5 million per annum in costs directly incurred by victims (Tipu, 2003). The economic cost per person in the New Zealand population in 1994 equalled an estimated NZD\$33,241.03 (Snively, 1994 in Cram, Pihama, Jenkins and Karehana, 2002).

In a Canadian Study (in UNICEF, 2000) the cost of IPV was estimated at CDN\$1 billion per annum, this included both within and outside of the house including police time and services, criminal justice involvement and counselling and training.

In the USA the National Institute of Justice reported that $15 \%$ of the cost of crime was due to domestic violence (Giles-Sims, 1998). According to other US studies estimates range between USD $\$ 5$ and USD $\$ 10$ billion per annum (referring to direct services related costs, not human costs) (UNICEF, 2000).

These differences in findings reflect that, like the incidence and prevalence of IPV, the economic cost remains relatively unknown but again is likely to underestimate the true impact on the economy (Injury Centre CDC 2003).

\subsubsection{Definition of Intimate Partner Violence}

Intimate partner violence is a complex area to define. Below is a framework used by the World Health Organisation (2002) (Figure 2.1) to help unpack this complex picture from a holistic point of view. IPV includes one, some or all of the following acts:

- physical

- sexual

- psychological

- involving deprivation or neglect.

The term interpersonal violence is also used interchangeably by some researchers with domestic violence, family violence, intimate partner violence, battery and spousal abuse and also child abuse and elder abuse (Injury Centre CDC 2003). 


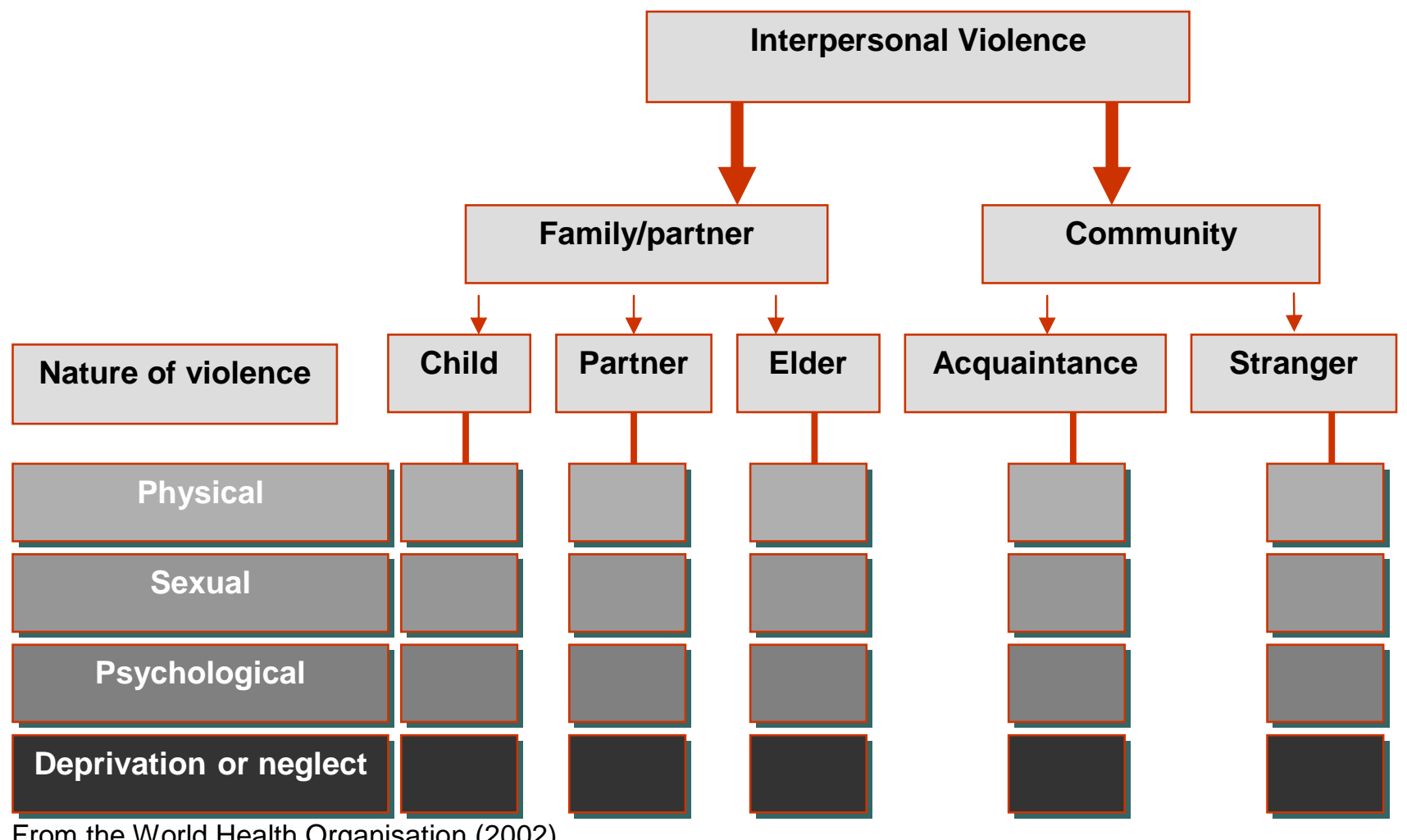

From the World Health Organisation (2002).

The New Zealand definition of violence within the family, under the Domestic Violence Act 1995, extended its definition in what was described as a "philosophical shift" in the way the justice system perceives and addresses domestic violence (Cram et al, 2002). The original Domestic Protection Act was drafted in 1982 and provided added legislation to protect victims of IPV, this Act also gave Police powers to become involved and able to arrest for such offences. However by 1993 the Department of Justice provided a range of reforms as the 1982 Act was seen as too restrictive. As a result the 1995 Domestic Violence Act took effect on 1 July 1996 providing changes to how protection orders were obtained and enforced.

The "philosophical shift" moved to include "children and young people, siblings, parents, members of the same whanau or culturally-recognised family groups, boyfriends and girlfriends, and people in same gender relationships" (www.corrections.govt.nz/publilc). The grounds for granting a protection order were also extended by increases to the scope of behaviour that the Act covered. 
The object of the 1995 Domestic Violence Act is to reduce and prevent violence in family relationships by:

- recognising that violence in the family, in all its forms, is unacceptable behaviour

- ensuring that, where violence in families occurs, there is effective legal protection for its victims

(Barwick, Gray and Macky, 2000).

The United Nations definition of violence against women (World Health Organisation, 2002) includes acts that cause physical, sexual or psychological harm or suffering including threats, coercion or deprivation of liberty both in public and/or private life (McWilliams, 1998).

While it may appear to be an easy task to provide a legal definition for violence by a partner, a recent study by Hendricks (1992) found that in the United States there is no one unified definition of violence in the family. Five states did not have a legal definition of violence in the family with 45 other states providing definitions that all differed in the degree to which harm is inflicted on the victim. And for some states physical harm was not included in the definition.

The definition in this thesis refers to intimate partner violence which is not just reported physical violence but also psychological violence (threats and controlling behaviour) committed by an intimate spouse. This study will use data that includes women as victims of intimate partner violence as well as men who report being victims of intimate partner violence.

\subsection{Measuring Intimate Partner Violence}

For those engaged in attempting to reduce violence in families knowing how much violence occurs, the severity of it and the nature of the relationship between the victim and the offender is crucial. Studies in New Zealand, the United States, Canada, Britain and other countries have served to document the severity and prevalence of intimate partner violence; however findings and theoretical explanations for these rates differ considerably across studies (Kaufman-Kantor and Jasinski, 1998). 


\subsubsection{Police Statistics}

Police statistics provide one picture of the nature and extent of crime; however victimisation surveys show that a large number of crimes go unreported and undetected by Police, or not recorded as an offence. Police statistics also provide little or no information about the experiences of victims and the context of the offence. Victimisation surveys on the other hand can provide this additional information (Morris and Reilly, 2003). Table 2.7 (from Mayhew and Reilly, 2007) shows the differences between Police statistics and victimisation surveys.

Table 2.7: Comparing the NZNSCV and Police recorded crime in New Zealand

\begin{tabular}{|c|c|}
\hline $\begin{array}{l}\text { The New Zealand National Survey of Crime } \\
\text { Victims (NZNSCV) }\end{array}$ & Offences recorded by the Police \\
\hline $\begin{array}{l}\text { - Starting in 1996, it measures both } \\
\text { reported and unreported crime. } \\
\text { - The survey is less frequent than the } \\
\text { release of Police statistics. } \\
\text { - Measures are based on estimates from a } \\
\text { sample of the population. They are } \\
\text { therefore subject to sampling error and } \\
\text { other methodological limitations. }\end{array}$ & $\begin{array}{l}\text { - These have been collected since 1878. They } \\
\text { measure offences reported to the Police that } \\
\text { are recorded by them. } \\
\text { - Police figures are published every six } \\
\text { months. } \\
\text { - They are a good measure of Police workload. }\end{array}$ \\
\hline $\begin{array}{l}\text { Does not include crimes against: } \\
\circ \text { those under } 15 \\
\circ \text { commercial establishments or public } \\
\text { sector agencies } \\
\circ \text { those in institutions } \\
\circ \text { the homeless. }\end{array}$ & $\begin{array}{l}\text { - Includes crimes against: } \\
\circ \text { those under } 15 \\
\circ \text { commercial establishments or public } \\
\text { sector agencies } \\
\circ \text { those in institutions } \\
\circ \text { the homeless. }\end{array}$ \\
\hline $\begin{array}{l}\text { - Measures crimes not reported to the } \\
\text { Police. }\end{array}$ & $\begin{array}{l}\text { - Does not measure: } \\
\text { o crimes the Police do not hear about } \\
\circ \text { reported incidents the Police do not } \\
\text { record. }\end{array}$ \\
\hline $\begin{array}{l}\text { - Does not measure: } \\
\text { victimless crimes (e.g. drug and } \\
\text { alcohol misuse) } \\
\text { crimes where a victim is no longer } \\
\text { available for interview (e.g. murder) } \\
\text { fraud (because the victim may not be } \\
\text { aware of the fraud) } \\
\text { sexual offences well (though } \\
\text { information is collected) }\end{array}$ & $\begin{array}{l}\text { - Does measure: } \\
\circ \quad \text { victimless crimes (e.g. immigration, } \\
\text { perjury, drugs and alcohol misuse) } \\
\circ \text { murder and manslaughter } \\
\circ \text { fraud } \\
\circ \text { sexual offences (consensual and non- } \\
\text { consensual). }\end{array}$ \\
\hline $\begin{array}{l}\text { - Collects information on what happens in } \\
\text { crime (e.g. injury and property loss) but } \\
\text { not afterward. }\end{array}$ & $\begin{array}{l}\text { - Collects information about the number of } \\
\text { apprehensions, who is apprehended, the } \\
\text { number of crimes resolved, and other details } \\
\text { where relevant. }\end{array}$ \\
\hline $\begin{array}{l}\text { - Provides information about how the risks } \\
\text { of crime vary for different groups. }\end{array}$ & $\begin{array}{l}\text { - Does not currently show which groups of the } \\
\text { population are most at risk of victimisation. }\end{array}$ \\
\hline
\end{tabular}




\subsubsection{Crime and Victimisation Surveys}

In 1992 New Zealand took part in the International Crime Survey along with 13 other countries (Van Dijk and Mayhew, 1992). Following this, in 1996 the New Zealand Justice department conducted the first New Zealand National Survey of Crime Victims (Morris, 1997).

The extra information collected in the $\operatorname{NZNSCV}(1996,2001)$ on IPV incidents included the sort of resources used or needed as well as any consequences of the violent incident. The information collected from non-reported incidents (to the Police) gives researchers a picture of that group and any specific reasons or barriers to nonreporting. This extra information is valuable and has considerable impact on policy direction and the theoretical debate (Morris and Reilly, 2003).

However, like police statistics, crime surveys also have a 'dark figure' although smaller. Questions may not be answered fully, if at all, or answered incorrectly out of fear or embarrassment, or memory lapse. There is also the issue of non-response including those groups of people who are not able to be contacted (e.g. with no phone or transient) (Young, 1999). Nonetheless, the findings from the crime victimisation surveys contribute to a more complete picture of crime and victims than would otherwise be possible.

\subsection{Previous Victimisation Rates}

\subsubsection{International Studies}

Many studies have been carried out around the world to gauge the prevalence of IPV, risk factors and the impacts IPV has on individuals, families and communities. Together these studies add to the body of literature that creates a picture of the nature and extent of intimate partner violence in society while raising questions about the prevalence rates, differing definitions and differences found in certain countries. Table 2.8 lists different IPV rates for female victims recorded both in developed and undeveloped countries around the world. 
Table 2.8: Recorded rates of intimate partner violence against women around the world.

\begin{tabular}{|c|c|}
\hline \multicolumn{2}{|c|}{ Industrialised Countries } \\
\hline Canada & $\begin{array}{l}29 \% \text { of women (a nationally representative sample of } 12,300 \text { women) } \\
\text { reported being physically assaulted by a current or former partner since } \\
\text { the age of } 16 \text {. }\end{array}$ \\
\hline Switzerland & $\begin{array}{l}20 \% \text { of } 1,500 \text { women reported being physically assaulted according to } \\
\text { a } 1997 \text { survey. }\end{array}$ \\
\hline United Kingdom & $\begin{array}{l}25 \% \text { of women (a random sample of women from one district) had been } \\
\text { punched or slapped by a partner or ex-partner in their lifetime. }\end{array}$ \\
\hline United States & $\begin{array}{l}28 \% \text { of women (a nationally representative sample of women) reported } \\
\text { at least one episode of physical violence from their partner. }\end{array}$ \\
\hline \multicolumn{2}{|l|}{ Asia and Pacific } \\
\hline Cambodia & $\begin{array}{l}16 \% \text { of women (a nationally representative sample of women) reported } \\
\text { being physically abused by a spouse; } 8 \% \text { report being injured. }\end{array}$ \\
\hline India & $\begin{array}{l}\text { Up to } 45 \% \text { of married men acknowledged physically abusing their } \\
\text { wives, according to a } 1996 \text { survey of } 6,902 \text { men in the state of Uttar } \\
\text { Pradesh. }\end{array}$ \\
\hline Korea & $\begin{array}{l}38 \% \text { of wives reported being physically abused by their spouse, based } \\
\text { on a survey of a random sample of women. }\end{array}$ \\
\hline Thailand & $\begin{array}{l}20 \% \text { of husbands (a representative sample of } 619 \text { husbands) } \\
\text { acknowledged physically abusing their wives at least once in their } \\
\text { marriage. }\end{array}$ \\
\hline \multicolumn{2}{|l|}{ Middle East } \\
\hline Egypt & $\begin{array}{l}35 \% \text { of women (a nationally representative sample of women) reported } \\
\text { being beaten by their husband at some point in their marriage. }\end{array}$ \\
\hline Israel & $\begin{array}{l}32 \% \text { of women reported at least one episode of physical abuse by their } \\
\text { partner in the previous year, according to a } 1997 \text { survey of } 1,826 \text { Arab } \\
\text { women. }\end{array}$ \\
\hline \multicolumn{2}{|l|}{ Africa } \\
\hline Kenya & $\begin{array}{l}42 \% \text { of } 612 \text { women surveyed in one district reported having been } \\
\text { beaten by a partner; of those } 58 \% \text { reported that they were beaten often } \\
\text { or sometimes. }\end{array}$ \\
\hline Uganda & $\begin{array}{l}41 \% \text { of women reported being beaten or physically harmed by a } \\
\text { partner; } 41 \% \text { of men reported beating their partner (representative } \\
\text { sample of women and their partners in two districts). }\end{array}$ \\
\hline
\end{tabular}




\begin{tabular}{|l|l|}
\hline Zimbabwe & $\begin{array}{l}32 \% \text { of } 966 \text { women in one province reported physical abuse by a family } \\
\text { or household member since the age of 16, according to a 1996 survey. }\end{array}$ \\
\hline Latin America and the Caribbean \\
\hline Chile & $\begin{array}{l}26 \% \text { of women (representative sample of women from Santiago) } \\
\text { reported at least one episode of violence by a partner, 11\% reported at } \\
\text { least one episode of severe violence and 15\% of women reported at } \\
\text { least one episode of less severe violence. }\end{array}$ \\
\hline Colombia & $\begin{array}{l}19 \% \text { of } 6,097 \text { women surveyed have been physically assaulted by their } \\
\text { partner in their lifetime. }\end{array}$ \\
\hline Mexico & $\begin{array}{l}30 \% \text { of } 650 \text { women surveyed in Guadalajara reported at least one } \\
\text { episode of physical violence by a partner; 13\% reported physical } \\
\text { violence within the previous year, according to a 1997 report. }\end{array}$ \\
\hline Nicaragua & $\begin{array}{l}52 \% \text { of women (representative sample of women in León) reported } \\
\text { being physically abused by a partner at least once; 27\% reported } \\
\text { physical abuse in the previous year, according to a 1996 report. }\end{array}$ \\
\hline Central and Eastern Europe/ClS/Baltic States \\
\hline Estonia & $\begin{array}{l}29 \% \text { of women aged 18-24 fear domestic violence, and the fear rises } \\
\text { with age, affecting 52\% of women } 65 \text { or older, according to a 1994 } \\
\text { survey of 2,315 women. } \\
\text { their ex-husbands; an additional } 25 \% \text { reported repeated violence. }\end{array}$ \\
\hline & $\begin{array}{l}60 \% \text { of divorced women surveyed in 1993 by the Centre for the } \\
\text { Eoland }\end{array}$ \\
\hline
\end{tabular}

Unicef (2000).

Further studies by Pilchman (1992, in Mahoney et al, 2001) reported that between 1979 to 1990, across 22 studies in the Unites States, rates of physical violence in an intimate partner relationship ranged between nine percent and 53\%, likewise Stark and Flitcraft (1988) found in their review of United States studies, that reported rates of IPV ranged from $20 \%$ to $25 \%$ of adult women, that is between 12 and 15 million women. 


\subsubsection{New Zealand Studies}

In 1995 Leibrich, Paulin and Ransom reported that 35\% of men in their study used physical violence and $62 \%$ of the males in the study reported using psychological abuse against female partners.

In 1996 a sample of 500 women was selected from the NZNSCV (1996) as part of the Women's Safety Survey (Morris, 1997). On a combined measure of physical and sexual abuse by a current or recent partner, over a two year period, $31 \%$ of women reported experiencing some form of physical and/or sexual violence, and/or threatening behaviour. Those with current partners were less likely to report violence compared to those women with a recent partner (who were three times more likely to be victims). In the previous two years $51 \%$ of the sample also reported some form of power and controlling behaviour by their partner.

The Dunedin Longitudinal Study (in Moffitt and Caspi, 1999) used a selection of questions from the Domestic Conflict Scale (Margolin, Burman, John, and O'Brien) and the Conflict Tactic Scale (Straus, 1979). Of nine hundred and ninety-one respondents in this sample $27 \%$ of the women and $24 \%$ of the men in the study reported being physically abused by their partner. Thirty-seven percent of women reportedly had initiated the violence and $22 \%$ of men had. What this study was also able to do was to compare responses by the victims to that of their partners (the perpetrators) to determine whether both members of the couple agreed that violence was occurring. Agreement about specific events was low, but when participants summarised their experience to having ever been abused by their partner, agreement by both partners was between $70 \%$ to $80 \%$.

In a study of ever partnered women in Auckland and Waikato (Fanslow and Robinson, 2004) results showed that over a lifetime $32 \%$ of women reported physical violence and $16 \%$ reported experiencing sexual violence over the previous year (2003).

Using data collected from the Youth 2000 survey (Fleming et al, 2007) of 9,699 Year nine to 13 students around New Zealand, reported rates of students experiencing adults in their home physically hurting each other over the last 12 months was six percent of the sample with just over one percent of the sample reporting that the adults in their home had physically hurt each other three or more times in the last 12 months. 
In 2007 Paterson, Percival, Schluter, Sundborn, Abbott, Carter, Cowley-Malcolm, Borrows and Gao reported additional findings from their study of 1,095 Pacific mothers living in New Zealand. The Pacific women had given birth within the past 12 months and reported being in a current intimate partner relationship. Findings showed that the prevalence of verbal aggression experienced by these women was $77 \%$, with $21 \%$ of the sample reporting "minor" physical violence, and 11\% reporting "severe" physical violence.

This study (Paterson et al, 2007) also asked the women of their level of perpetration. The results from this show that a large number of women report being verbally aggressive to their partner ( $90 \%$ of the sample) and that $35 \%$ of the women reported perpetrating "minor" physical violence, and 19\% reported perpetrating "severe" violence towards their partner. The most significant factors associated with victimization for this group of Pacific mothers was ethnicity, maternal education, marital status and household income.

Table 2.9 provides a summary of this New Zealand research including the period of victimisation measured, the sample composition and size and the measures used to define IPV.

Table 2.9: Summary of New Zealand studies

\begin{tabular}{|c|c|c|c|c|}
\hline Study & Sample Size & Measured & $\begin{array}{l}\text { Period of } \\
\text { Violence }\end{array}$ & Findings \\
\hline $\begin{array}{l}\text { Leibrich, } \\
\text { Paulin and } \\
\text { Ransom } \\
\text { (1995) }\end{array}$ & $\begin{array}{l}\text { Sample of } 2000 \\
\text { men with more } \\
\text { intensive } \\
\text { interviews with } \\
200 \text { of the men }\end{array}$ & $\begin{array}{l}\text { Questionnaire } \\
\text { and } \\
\text { interviewing }\end{array}$ & $\begin{array}{l}\text { Over the } \\
\text { preceding } \\
\text { one year } \\
\text { period }\end{array}$ & $\begin{array}{l}\text { - } 35 \% \text { of men reported using } \\
\text { physical violence and } 62 \% \text { of the } \\
\text { males reported using psychological } \\
\text { abuse against female partners. }\end{array}$ \\
\hline $\begin{array}{l}\text { Women's } \\
\text { Safety Survey } \\
\text { (Morris, 1996) }\end{array}$ & $\begin{array}{l}\text { Sample of } 500 \\
\text { women } \\
\text { selected from } \\
\text { the NZNSCV } \\
(1996)\end{array}$ & $\begin{array}{l}\text { Combined } \\
\text { measure of } \\
\text { physical and } \\
\text { sexual abuse } \\
\text { by a current } \\
\text { or recent } \\
\text { partner }\end{array}$ & $\begin{array}{l}\text { Over the } \\
\text { preceding } \\
\text { two year } \\
\text { period }\end{array}$ & $\begin{array}{l}\text { - } 31 \% \text { of women reported } \\
\text { experiencing some form of physica } \\
\text { and/or sexual violence, and/or } \\
\text { threatening behaviour. } \\
\text { - } 51 \% \text { of the sample also reported } \\
\text { some form of power and controlling } \\
\text { behaviour by their partner. }\end{array}$ \\
\hline $\begin{array}{l}\text { Dunedin } \\
\text { Longitudinal } \\
\text { Study (Moffitt } \\
\text { and Caspi, } \\
\text { 1999) }\end{array}$ & $\begin{array}{l}\text { Sample of } 991 \\
\text { respondents } \\
\text { were surveyed }\end{array}$ & $\begin{array}{l}\text { Domestic } \\
\text { Conflict Scale } \\
\text { and the } \\
\text { Conflict Tactic } \\
\text { Scale }\end{array}$ & $\begin{array}{l}\text { At } 21 \text { years } \\
\text { old } \\
\text { (longitudinal } \\
\text { sample) }\end{array}$ & $\begin{array}{l}\text { - } 27 \% \text { of women and } 24 \% \text { of men } \\
\text { reported being physically abused } \\
\text { by their partner. } \\
\text { - } 37 \% \text { of women reportedly initiated } \\
\text { the violence and } 22 \% \text { of men. }\end{array}$ \\
\hline
\end{tabular}




\begin{tabular}{|c|c|c|c|c|}
\hline Study & Sample Size & Measured & $\begin{array}{l}\text { Period of } \\
\text { Violence }\end{array}$ & Findings (Continued). \\
\hline $\begin{array}{l}\text { New Zealand } \\
\text { National } \\
\text { Survey of } \\
\text { Crime Victims } \\
\text { (Morris and } \\
\text { Reilly, 2003) }\end{array}$ & $\begin{array}{l}\text { Sample of } 5000 \\
\text { men and } \\
\text { women } 15 \\
\text { years and older } \\
\text { at the time of } \\
\text { the interview }\end{array}$ & $\begin{array}{l}\text { Face-to-face } \\
\text { questionnaire }\end{array}$ & $\begin{array}{l}\text { Over their } \\
\text { lifetime and } \\
\text { over the } \\
\text { preceding } \\
12 \text { month } \\
\text { period (in } \\
2000 \text { ) }\end{array}$ & $\begin{array}{l}\text { - One point eight percent of men and } \\
\text { three percent of women reported } \\
\text { experiencing IPV behaviours over } \\
\text { the past } 12 \text { months. } \\
\text { - Nearly } 20 \% \text { of men and } 25 \% \text { of } \\
\text { women reported experiencing IPV } \\
\text { behaviours over their lifetime. }\end{array}$ \\
\hline $\begin{array}{l}\text { Fanslow and } \\
\text { Robinson } \\
\text { (2004) }\end{array}$ & $\begin{array}{l}\text { Sample of } 2855 \\
\text { ever partnered } \\
\text { women aged } \\
18-64 \text { years }\end{array}$ & $\begin{array}{l}\text { Face-to-face } \\
\text { interviews }\end{array}$ & $\begin{array}{l}\text { Over their } \\
\text { lifetime and } \\
\text { over the } \\
\text { preceding } \\
\text { month } \\
\text { period }\end{array}$ & $\begin{array}{l}\text { - } 32 \% \text { of women reported that over a } \\
\text { lifetime they experienced physical } \\
\text { violence. } \\
\text { - } 16 \% \text { of women reported } \\
\text { experiencing sexual violence over } \\
\text { the previous year. }\end{array}$ \\
\hline $\begin{array}{l}\text { Youth } 2000 \\
\text { (Fleming, } \\
\text { Watson, } \\
\text { Robinson, } \\
\text { Ameratunga, } \\
\text { Dixon, Clark } \\
\text { and Crengle, } \\
\text { 2007) }\end{array}$ & $\begin{array}{l}\text { Sample of } 9699 \\
\text { Year 9-13 } \\
\text { students }\end{array}$ & $\begin{array}{l}\text { CASI } \\
\text { questionnaire: } \\
\text { online 'game' }\end{array}$ & $\begin{array}{l}\text { Over the } \\
\text { preceding } \\
12 \text { months }\end{array}$ & $\begin{array}{l}\text { - Six percent experienced adults in } \\
\text { their home physically hurting each } \\
\text { other. } \\
\text { - Just over one percent reported that } \\
\text { the adults in their home had } \\
\text { physically hurt each other three or } \\
\text { more times. }\end{array}$ \\
\hline $\begin{array}{l}\text { Paterson, } \\
\text { Percival, } \\
\text { Schluter, } \\
\text { Sundborn, } \\
\text { Abbott, } \\
\text { Carter, } \\
\text { Cowley- } \\
\text { Malcolm, } \\
\text { Borrows and } \\
\text { Gao (2007) }\end{array}$ & $\begin{array}{l}\text { A cohort of } \\
1,095 \text { Pacific } \\
\text { mothers living } \\
\text { in New Zealand }\end{array}$ & $\begin{array}{l}\text { Pacific } \\
\text { women who } \\
\text { had given } \\
\text { birth in the } \\
\text { past } 12 \\
\text { months, and } \\
\text { who were } \\
\text { married or } \\
\text { living with a } \\
\text { partner as } \\
\text { married. }\end{array}$ & $\begin{array}{l}\text { Over the } \\
\text { preceding } \\
12 \text { month } \\
\text { period }\end{array}$ & $\begin{array}{l}\text { - } 21 \% \text { reported experiencing "minor" } \\
\text { physical violence in the past } 12 \\
\text { months. } \\
\text { - } 11 \% \text { reported experiencing } \\
\text { "severe" physical violence in the } \\
\text { past } 12 \text { months. } \\
\text { - } 35 \% \text { reported perpetrating "minor" } \\
\text { physical violence towards their } \\
\text { partner in the past } 12 \text { months. } \\
\text { - } 19 \% \text { reported perpetrating" severe" } \\
\text { violence towards their partner in the } \\
\text { past } 12 \text { months. }\end{array}$ \\
\hline $\begin{array}{l}\text { New Zealand } \\
\text { Crime and } \\
\text { Safety survey } \\
\text { (Mayhew and } \\
\text { Reilly, 2007) }\end{array}$ & $\begin{array}{l}\text { Sample of } 5000 \\
\text { men and } \\
\text { women } 15 \\
\text { years and older } \\
\text { at the time of } \\
\text { the interview }\end{array}$ & $\begin{array}{l}\text { Face-to-face } \\
\text { questionnaire }\end{array}$ & $\begin{array}{l}\text { Over the } \\
\text { preceding } \\
12 \text { month } \\
\text { period (in } \\
2005 \text { ) }\end{array}$ & $\begin{array}{l}\text { - Six percent of men and seven } \\
\text { percent of women reported } \\
\text { experiencing IPV behaviours over } \\
\text { the past } 12 \text { months (2005). } \\
\text { - Incidents reported (number of } \\
\text { incidents per } 100 \text { ) was } 18 \text { for men } \\
\text { and } 26 \text { for women }\end{array}$ \\
\hline
\end{tabular}




\subsection{Risk Factors}

Intimate partner violence occurs across both heterosexual and homosexual relationships and often is a repeated crime (Injury Centre CDC 2003). A number of demographic variables have been identified over the past 10 years as risk factors of becoming a victim of violence by a partner including being a young woman, involvement in alcohol and drug use and those with mental illness or disabilities (O'Donnell et al, 2002, Ministry of Health, 2006).

Figure 2.2 from Population Reports (2001) outlines the ecological factors linked with intimate partner violence, from a number of research studies.

Figure 2.2: Ecological model of factors associated with partner abuse.

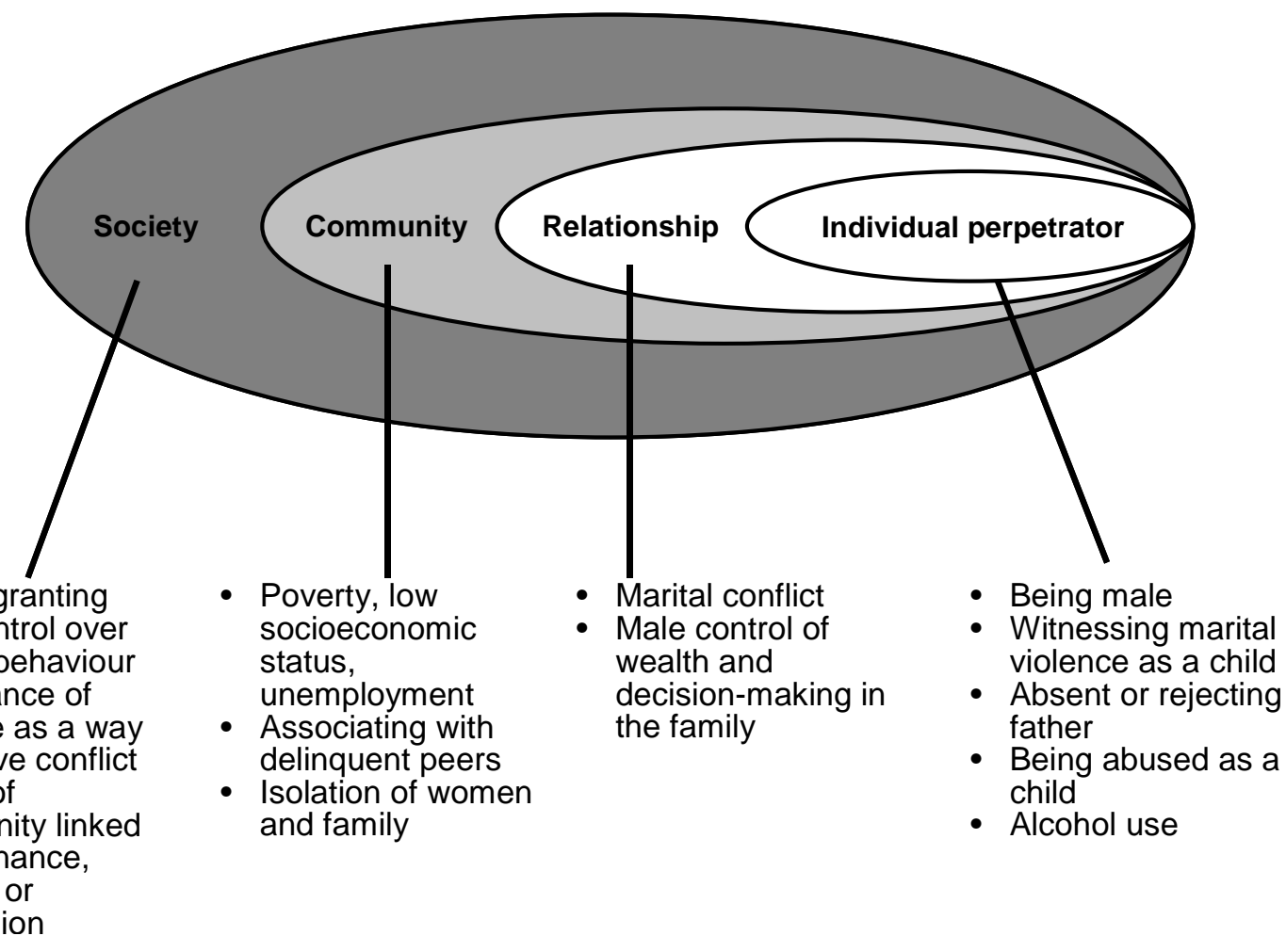

From Population Reports. 2001. 


\subsubsection{Demographic Risk Factors}

\subsubsection{Gender}

Gender issues in IPV have become more controversial with contradictory evidence linking gender with IPV victimisation, causing a shift in focus by some researchers to mutual couple violence (both partners being abusive in the relationship). Most research has indicated gender as a risk factor of aggression with women being more at risk of severe harm and of experiencing fear (Romans, Forte, Cohen, Du Mont and Hyman, 2007).

Johnson and Bunge (2001) report that women are more likely to report IPV than men. These findings have also been shown in other international studies (Rennison, 2003; Tjaden and Thoennes, 2000; Moffit and Caspi, 1999; Fagan and Browne, 1994; Elliott, Huizinga and Morse, 1985).

However, Moffit and Caspi (1999) reported findings from the Dunedin Multidisciplinary Health and Development study that men and women report violence by their partner at a similar rate. Figure 2.3 shows the comparison of findings from three studies Including the Dunedin Multidisciplinary Health and Development study) and the consistent finding of women being victims at a similar rate to men.

Goodyear-Smith's (2004) study also indicated that victimisation was experienced in similar percentages for both males and females. These findings are consistent with the National Family Violence Survey (1975, 1985 in Straus and Gelles, 1986) which reported that women assaulted their partners at the same rates as men. 


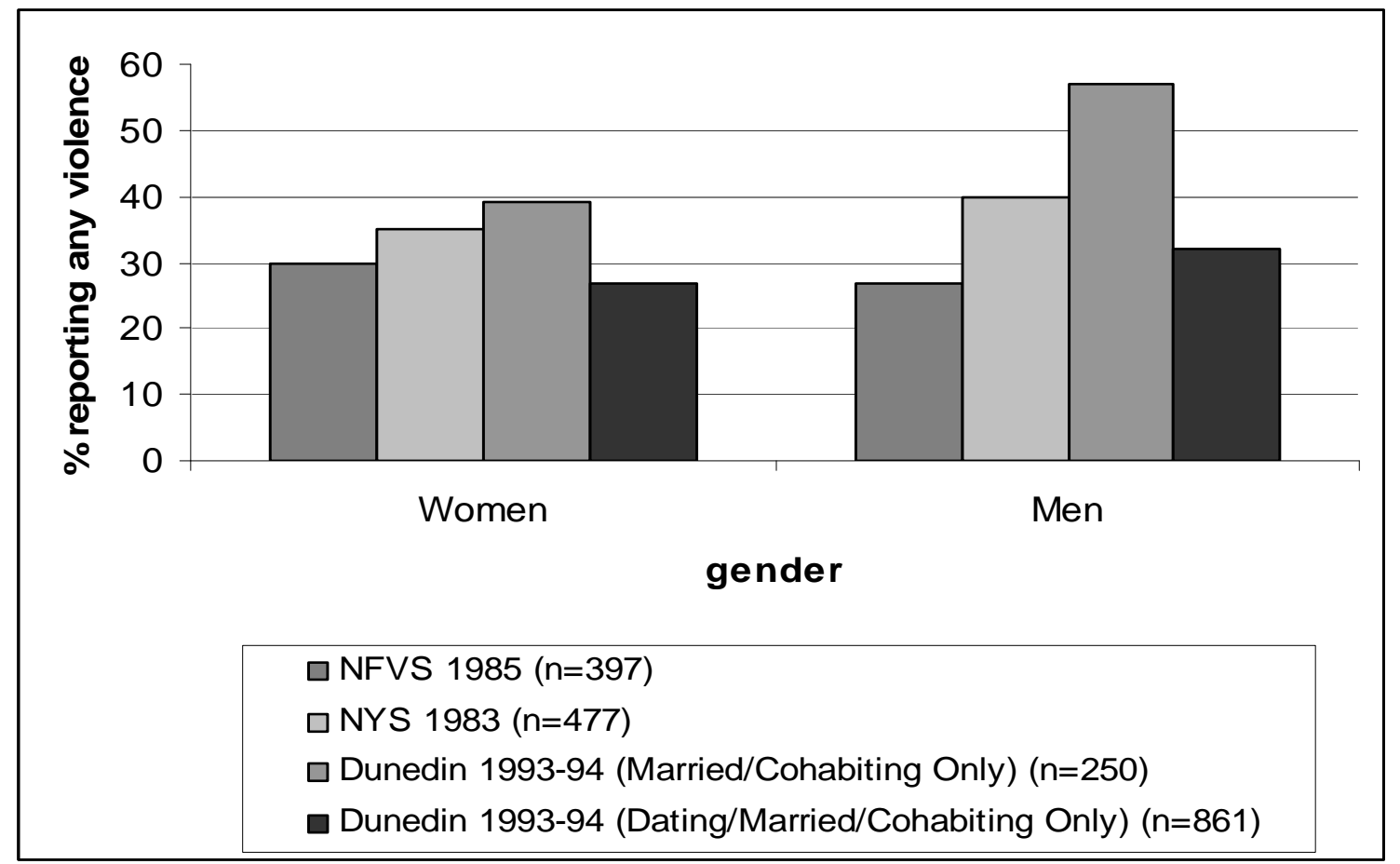

The three studies are the National Family Violence Survey (NFVS), the National Youth Survey (NYS), and the Dunedin Multidisciplinary Health and Development Study. In Moffit and Caspi (1999).

An explanation for differences in the effect of gender on IPV victimisation could be explained by the types of violence experienced. Romans et al (2007) found that women were more likely than men to report severe physical and sexual violence compared to more moderate violence.

Another major difference in gender lies in the impact of the violence and the severity of injury. Kimmel (2002, in Romans et al, 2007) urged society to recognise that women can be perpetrators of IPV, but to understand how the use of violence differs between men and women. Kaufaman-Kantor and Jasinski (1998) furthered this statement by adding their findings that violence by women was less injurious and was less likely to be used as a way to assert control.

Straus et al. (1990) found that medical care was required for women several times more than men after IPV was experienced and women were significantly more likely to experience negative psychological effects than male victims of IPV. 


\subsubsection{Age}

Age has been identified as a major factor in the likelihood of both experiencing and committing IPV. Those under 30 years old are shown to be significantly more likely to report IPV, while those above 30 years old report experiencing less IPV (O'Donnell et al. 2002, West 1998).

This may be influenced by the high rate of IPV in young dating and cohabiting couples where violence is estimated to occur in $30 \%$ of these relationships (Pritchard, 2005). Mouzos and Makkai (2004) also found a pattern of IPV perpetration occurring more in younger males and found that higher rates of IPV victimisation were experienced by younger women when compared to women in older age categories.

\subsubsection{Ethnicity}

Ethnicity primarily refers to an individual's heritage and is associated also with a group's culture, language, religion and self-perception. This term however, is continually being debated by academics and as a result there is no consistent definition internationally (Meares, 2001).

Being a member of an ethnic minority has been linked with an increase in victimisation at a rate that is disproportional to that group's representation in the population (Meares, 2001). This over-representation of ethnic minorities as victims has been demonstrated around the world (Malley-Morrison and Hines 2004; Barak, Leighton, and Flavin 2006).

This has been seen in New Zealand with a disparity in the proportions of individuals of Māori descent both as victims and as perpetrators (Hughes, 2004). Comparisons between Māori and non- Māori suggest that Māori are two to four times more likely to be involved in violent behaviour (Fergusson, 2003). Māori are also reported to be at a greater risk of being in the category of having lower educational attainment and higher rates of poverty and health problems than non-Māori (Fergusson, 2003).

Explanations as to why, in Western cultures, specific ethnic groups are reported to be involved in and be victims of IPV at a disproportionately higher rate have been posited by a number of researchers (Meares, 2001). Fergusson (2003) states that official statistics can demonstrate biases against certain ethnic groups as a result of the Justice system and the processes by which individuals come to the attention of the 
Justice System and officials. Minority groups represented in the criminal justice statistics throughout the Western world tend to be both socially and economically disadvantaged and often are involved in ongoing historical discrimination or associated with recent migrant groups (Meares, 2001).

A USA study (West, 2004) that compared IPV rates between White Americans and African Americans found consistently higher rates of IPV victimisation for African Americans, however when factors such as social class and other structural inequalities were factored in to the model, it seemed that ethnicity became a proxy for these inequalities and when economic and social factors were taken into account ethnic differences become less pronounced.

Cazehare and Straus's findings (1990, in West, 1998) from the First National Family Violence Survey also showed that when social class was factored into the statistics ethnic differences for IPV often disappeared and in one instance found that African Americans experienced less IPV than White Americans.

West (1998) adds to this by stating that where rates of IPV are higher for African Americans it may be the underlying result of racial oppression and the effects that has on mental stress and tension independently from other social and economical factors. As well as other factors such as childhood abuse, witnessing of community violence and loss.

This may be the case for New Zealand Māori whose history has included pressure from change in language and culture as a result of colonisation which has also led to a loss of land and economic power and the impact of urbanisation of Māori (Duff, 1993; Walker, 1996; Fergusson, 2003). These changes are likely to have added to stress and pressure within Māori families and increased the likelihood of dysfunction as a result of the over-representation in a number of statistics of disadvantage and violence (Fergusson, 2003).

Other explanations of the difference in rates of IPV in some ethnic groups are explained as a result of cultural ideologies. Mukherjee (1999) argues that traditions from home countries can explain some of the differences in offending and victimisation rates. Some cultural ideologies provide a legitimised excuse for men using violence against women. Traditions, both religious and historical, justify such behaviours under 
the belief of entitlement and ownership. These concepts legitimise control of women through violence (UNICEF, 2000).

The definition of ethnicity is also problematic when measuring differences in IPV rates. Apparent difference may be an artefact of how an individual identifies their ethnicity. It may also be a result of the grouping together of individuals whose country of origin, language and/or cultural heritage may be quite different. For example in many studies Indian and Chinese are put in a category of 'Asian' but these cultural groups are very different in experiences and ideologies. Sub-groups with large representative samples need to be created to allow for more meaningful statistics around IPV so the differences can be measured in prevalence of IPV and also the impact IPV has on different ethnic groups (Meares, 2001).

\subsubsection{Socio-economic Risk Factors}

Vulnerability to IPV and an inability to move from such situations has been said to be underpinned by a lack of economic resources (UNICEF, 2000). The risk of domestic IPV increases as socio-economic status (SES) decreases although the impact of low SES varies across ethnic groups and gender (Cunradi, Caetano and Schafer, 2002). Garrison, Gold, Wilson and Kannel (1993) found that education and employment levels contributed at a greater rate to the likelihood of perpetration and victimisation by either partner than any other variables.

\subsubsection{Education}

Educational attainment has been linked to IPV prevalence but the research is inconsistent and complex. In a review of over 400 studies and reports, it was found that while lower reporting of IPV was found amongst those with greater education attainment; other research has also indicated little effect of education attainment on levels of IPV. Rolling and Oheneba-Sakyi (1990 in Kaufman-Kantor and Jasinski, 1998) found no differences based on education levels and families reporting IPV. Likewise a Canadian study found that IPV levels did not vary by education levels (Rogers 1994 in O'Donnell et al, 2002).

More recently Cleveland et al (2003) found that for females with higher grades there was a reduced risk of being involved in violence. Downs, Miller and Panek (1993) also found that both moderate and severe IPV was more common amongst those without 
college educations. This perhaps indicates the importance that education has with the link to an individual's ability to gain employment in a well-paying and stable job (Kaufman et al, 1998).

\subsubsection{Employment}

For families where the male partner is unemployed or working part-time, increased rates of IPV have been reported across many studies. Kaufman et al (1998) found that blue-collar (working class manual labour job) families reported IPV twice as much as while-collar (salaried professional or a job that is clerical in nature) families. Data from the National Family Violence Survey in the United States (1975, in Straus and Gelles, 1986) also showed that those men in blue-collar employment had IPV rates at nine point two percent compared to five point four percent of white-collar employees. Adding in low income increased the rate for blue-collar IPV rates to $16.4 \%$ (Cunradi et al, 2002).

Balzer, Haimona, Henare and Matchitt (1997) found that men employed for less than 30 hours per week or who were unemployed reported an increase in IPV, but noted that employment and income were not necessarily the main cause of IPV but increased the risk along with other contributing factors.

While for males, employment status and income levels seem to be associated with levels of reported assault and IPV, for women it appears that their level of employment does not significantly affect the risk of IPV as measured by hospital admissions by Dowd, Langley, Koepsell, Soderberg and Rivara (1996; O'Donnell et al, 2002), perhaps indicating that for males, lack of employment and lower income may create greater stress increasing the risk of IPV.

This lack of correlation between women's employment and their experience of victimisation by a partner was also found by Patterson et al (2007) in a sample of Pacific mothers. Kaukinen (2004) found that correlates of socio-demographic variables along with variables relating to lack of mechanisms to deal with stress increased the risk of aggression. 


\subsubsection{Income}

Annual household income appears to impact greatly on the likelihood of IPV occurring. Cunradi et al (2002) found that while the impact of income varied in magnitude amongst different ethnic groups and by gender, household income was found to have an impact consistently across models.

Strays and associates (1980, in Kaufman et al, 1998) found that IPV rates increased by $500 \%$ for families earning below USD $\$ 20,000$. Cunradi et al (2002) found that the annual assault rate on wives for those households earning below USD $\$ 9,000$ was $16.4 \%$ compared to three point five percent for those above USD $\$ 22,500$.

The impact of low income may add to family stress, as the ability to access resources is limited. When low income levels interact with other factors, the risk of IPV is increased (Kaufman et al, 1998). Consistent with these findings, O'Donnell et al (2002) reported an increased risk of IPV for women in low income families, and also that women's income alone affected the risk of being a victim. This has been demonstrated in a number of other studies (Dal Grande, Hickling, Taylor and Woolacott, 2003; Dearwater, Coben, Campbell, Nah, Glass and McLoughlin, 1998; Vest, Catlin, Chen and Brownson, 2002).

Women who themselves earn little to no income have limited choices when wanting to leave a violent relationships and may face barriers to entering into secure housing and support as a result of the associated cost of leaving a relationship (Pickup et al. 2001). While it may seem the solution for a woman experiencing violence to leave the violent relationship, it may be that doing so will leave them worse off economically.

Added to this is the impact of IPV on a women's employment itself. In a USA study the direct result of being a victim of IPV saw $30 \%$ of these women report having lost their job. Women who do not face IPV have also been estimated to earn over two times as much per month as those women facing severe IPV (UNICEF, 2000).

\subsubsection{Socio-economic Status}

While IPV occurs amongst all social classes, consistent links have been found between low socio-economic status (SES) and the risk of IPV. Cunradi et al. (2002) found that although IPV rates varied across ethnic groups, SES was associated with increased 
risk in IPV. It may be that those in lower SES groups have more chance of being exposed to childhood violence and may be more likely to resort to violence to resolve marital conflict putting low SES families at greater risk of IPV.

West (1998) reported that family culture is shaped by economic marginalisation and as a result of low education levels, as well as limited access to employment; these individuals become economically marginalised and as a result are more likely to engage in IPV as access to appropriate non-violent coping mechanisms may be limited.

\subsubsection{Other Risk Factors}

There are also many other factors that have been identified in the literature as risk factors or confounding factors for IPV victimisation including children witnessing violence in the family, alcohol and drug use, marital status and pregnancy and young families.

\subsubsection{Childhood exposure}

Children who do witness or are victims of violence in the family context are more likely to display conduct problems which is a strong indicator for future violence. Children who witness IPV are also more at risk of becoming a victim of adolescent dating violence (Pritchard, 2005). This quote from one respondent in this study highlights the phenomenon of child witnesses of IPV and the stress that is created for a parent who is trying to protect their children:

"He threw a chair at me and I had to pretend that we were playing because my children were frightened".

Evidence supporting the idea of IPV across generations has been consistently found (Brown and Hendricks, 1998). Childhood experiences can influence attitudes in adulthood as violence experienced and witnessed as a child may be seen as normal in a family.

Research has suggested that both victims and perpetrators of IPV have a greater probability of having been raised as children in an abusive family, thus creating a greater tolerance to such behaviour. Murrell, Christoff and Henning (2007) found that 
men who were abused as children were at greater risk of abusing children themselves as adults and the impact of witnessing IPV in childhood increased the likelihood of perpetration in adulthood. This violent home environment teaches some children that violence is the answer to dealing with conflict and problems while other children in such environments develop a distorted self-concept and the belief that abuse is acceptable and that they cannot change this (Brown and Hendricks, 1998).

These findings of generational violence are challenged by research such as that by Pickup et al. (2001) who commented that while violence is said to be learnt in the household as children grow up and being a victim of violence puts an individual at greater risk of offending, statistics show that the majority of childhood violence is experienced by girls (three to six times higher than for boys) and yet this does not account for the fact that abuse is more likely to be committed by males as adults, indicating that witnessing violence as a child does impact on adult relationships but are themselves gendered, as well as based on personality, coping strategies and other factors. In other words not all those who witness violence as a child will themselves become perpetrators or victims as adults, and those who are not witnesses or victims as children can offend as adults or become victims as adults, although research strongly suggests that such experiences of witnessing violence as a child will increase the risk of IPV (Kaufman et al. 1998).

\subsubsection{Alcohol and drug use}

Alcohol and drug-use are consistently found to be associated with many violent incidents across cultures (Jasinski, 2001; Mahoney et al, 2001; McNeil, Von Dadelzen, Gray, Duituturanga, Good and Ash, 1988). A Moscow study revealed that excessive alcohol consumption was associated with half of all IPV cases (UNICEF, 2000). Mouzos and Makkai (2004) found that IPV increased three fold if a male partner got drunk several times a month but also found that the male's level of controlling behaviour was a significant risk factor, which increased the risk of IPV over six times (Jasinski, 2001).

In a study by Fals-Stewart (2003) a group of men with a history of violence were referred to a drug and alcohol treatment programme. On the days the participants drank alcohol they were eleven times more likely to hit their partners than on the days they did not drink. Findings from a study of young couples also showed that they were 
eight times more likely to hit each other on days they drank alcohol, than on days they did not drink (Relationship Services, in Pritchard, 2005).

Like alcohol, drugs also work as dis-inhibitors. Studies looking at the effects of drugs and alcohol range in effect suggesting that between six percent and $85 \%$ of intimate violence incidents involve the use of alcohol and drugs. In a New Zealand study Balzer et al (1997) reported that of the 51 men on the HAIP Māori Men's programme, 22 admitted drinking excessive alcohol while nine had been using drugs, both contributing factors to IPV.

\subsubsection{Marital Status and Marital Dependency}

Reported levels of violence in the family have been found to differ according to marital status (Mouzos and Makkai, 2004). O'Donnell et al. (2002) reported a higher risk of IPV for women in a defacto relationship. In a United States study between three and six percent of women in a defacto relationship reported IPV while only two point three percent of married women reported being victims of IPV (Mouzos and Makkai, 2004). Figures for couples in counselling or therapy are even higher with more then $50 \%$ of couples reporting IPV in the previous year. Figure 2.4 shows findings from Moffitt and Caspi (1999) who conclude that intimate partner violence is "most prevalent among cohabitating couples".

Figure 2.4: Rates of involvement in physical partner violence by relationship type (Dunedin males and females).

Going Out Cohabiting Married

Dark grey shows those participants who reported that they had been victims of intimate partner violence. Moffitt and Caspi (1999). 
Consistent with Moffitt and Caspi (1999), Johnson (1998) found in his Canadian study that married women were less likely to report IPV than those women in cohabiting/defacto relationships.

Fletcher (2002, in Pritchard, 2007) estimated that approximately $16 \%$ of married couples experienced physical violence in the previous year, while reports of instrumental violence (IPV perpetrated by men) at a mild level is present in one out of eight relationships each year. A statement from a male participant in this study was:

"My wife hit me repeatedly about the head due to [the] frustrations she was having in the marriage".

For those in relationships, there are a number of correlates to IPV including income, education, ethnicity and social class. The traditional higher status of men often places women in a position of greater IPV risk.

For those women where the economic balance is not in their favour, it may be harder to leave abusive relationships, suggesting that a traditional relationship places greater risk of IPV in marriage. Research on divorce suggests this, as divorce rates are higher for couples with similarly dependent spouses, where both spouses are earning a similar wage (status parity) (Kaukinen, 2004). Research also suggests that where the male has greater 'status parity' in the relationship it is harder for a women to leave and this creates a greater risk of violence occurring. This emphasises the idea that the male power in a relationship (especially financially) can impact on violence used by the male to gain or maintain control (Kaufman, 1998).

For individuals in abusive relationships the act of leaving is not always a realistic option when they continue to have an emotional attachment to the batterer or to the life they may leave behind (Martin, Berenson, Griffing, Sage, Madry, Bingham and Primm, 2000). This sentiment over-ride theory may account, in part, for the willingness of some victims to stay in a relationship with a partner whose behaviour is abusive or violent as perception of a partner's regard may have a stronger effect than the partner's actual behaviour (Gottman, Coan, Carrere and Swanson, 1998).

However the reverse argument has gained some support as some research is finding IPV in relationships where women's economic involvement and independence is seen 
as a threat to male partners, where the 'status parity' is tipped in the women's favour (Unicef, 2000).

\subsubsection{Pregnancy and Children}

Research has demonstrated a pattern in the transitions to, and through parenthood which have a substantial impact on relationship satisfaction and stress. Couple relationship satisfaction tends to drop after the birth of the first child, rises when children attend primary school, declines when children are adolescent and rises again when children leave home (Bradbury, 2003, in Pritchard, 2007).

Ahlborg and Strandmark (2006) identified several factors seen to affect the quality of intimate relationships for first-time parents, these included:

- coping by adjustment to parental role - mutual support as new parents

- couple's intimacy, togetherness and love - placing priority on the couple relationship - the most important predictor of stability and satisfaction

- coping by communication - verbal and non-verbal confirmation

- coping by seeking social support.

New Zealand findings (in Moffitt and Caspi, 1999) show that those most likely to be victims of IPV had children of their own. Ten percent of the women in the study had given birth by the age of 21 and these young mothers were two times more likely to be abused by their male partners than those of the same age with no children (see figure 2.5). In a US study the number of children and the age of the children were found to be risk factors in becoming a victim of IPV (O'Donnell et al. 2002). 
Figure 2.5: Rates of Victimisation reported by Dunedin Women

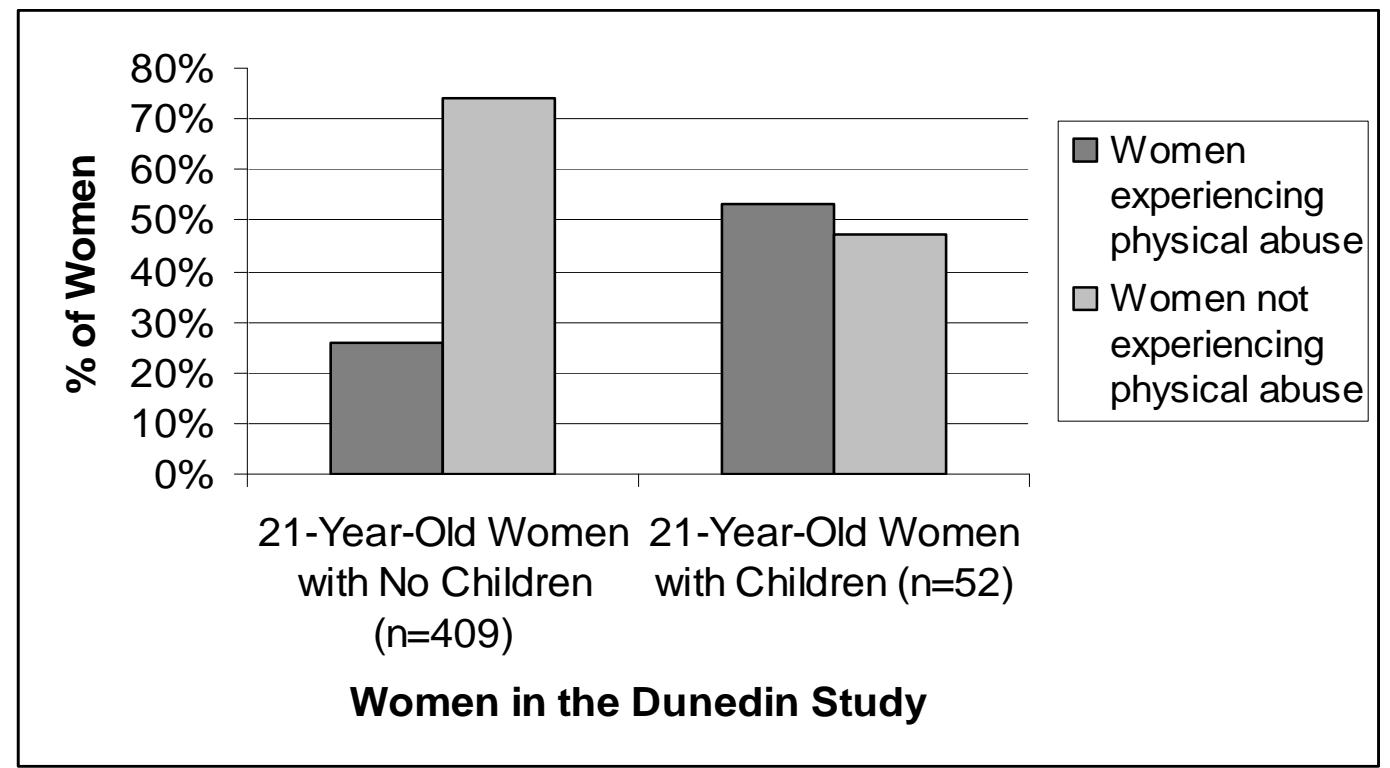

Moffitt and Caspi (1999).

For those women who are pregnant, hospital data suggests that this is again a time where IPV can increase. A quote from a woman in this study highlights the risk of pregnancy and IPV:

"I was very pregnant and he pushed my stomach then shoved me to the floor".

In New Zealand five point seven percent of women reported IPV while pregnant, with higher rates amongst those that were teenagers. Charles and Perreira (2007) report that $33 \%$ of mothers and $40 \%$ of fathers experienced IPV during the period from pregnancy to one year after the child's birth. However Kaufman et al. (1998) found the age of the parents to be more significant than being a parent.

Regardless of whether rates in IPV differ for those who are, or are not pregnant, for those that are pregnant the outcomes of violence include stillbirths, premature labour and birth, low birth weight, maternal low weight gain, foetal injury, infections and anaemia, and when violence increases in an intimate relationship, so does the likelihood of child abuse (Charles and Perreira, 2007; World Health Organisation, 2002). 


\subsubsection{Health Effects}

Violence is a key personal and public health issue and a source of serious mental and physical injuries for women (O'Donnell et al, 2002). Intimate partner violence has been recognised internationally as a significant factor to ill-health, even after the violence has ceased. In New Zealand, significant attention has been placed by Government on IPV as a priority area (Fanslow and Robinson, 2004). Hospital admissions in New Zealand show about 400 women present in hospital with injury from IPV each year, with about 11 deaths, as a results of IPV (Ministry of Health, 2001a).

Individuals in abusive intimate relationships experience disproportionate deterioration in physical health as well as a greater occurrence of mental health problems such as depression, suicide attempts and drug and alcohol abuse. The experience of women as victims increases the likelihood of use of medications as a result of increased levels of pain, depression and sleep problems (Fanslow and Robinson, 2004). Intimate partner violence may cause short-term injuries but frequently causes long-term mental and social problems as the effects of IPV last long after the violence has stopped (Miller, Cohen and Rossman, 1993; Golding, 1996; Kessler, McGonagle, Zhao, Nelson, Hughes and Eshleman, 1994; Kaslow, Thompson, Meadows, Jacobs, Chance and Gibb, 1998).

Figure 2.6 from the Ministry of Health (2001a) shows the types of health outcomes for non-fatal incidences of IPV. 
Figure 2.6: Health Outcomes of Intimate Partner Violence

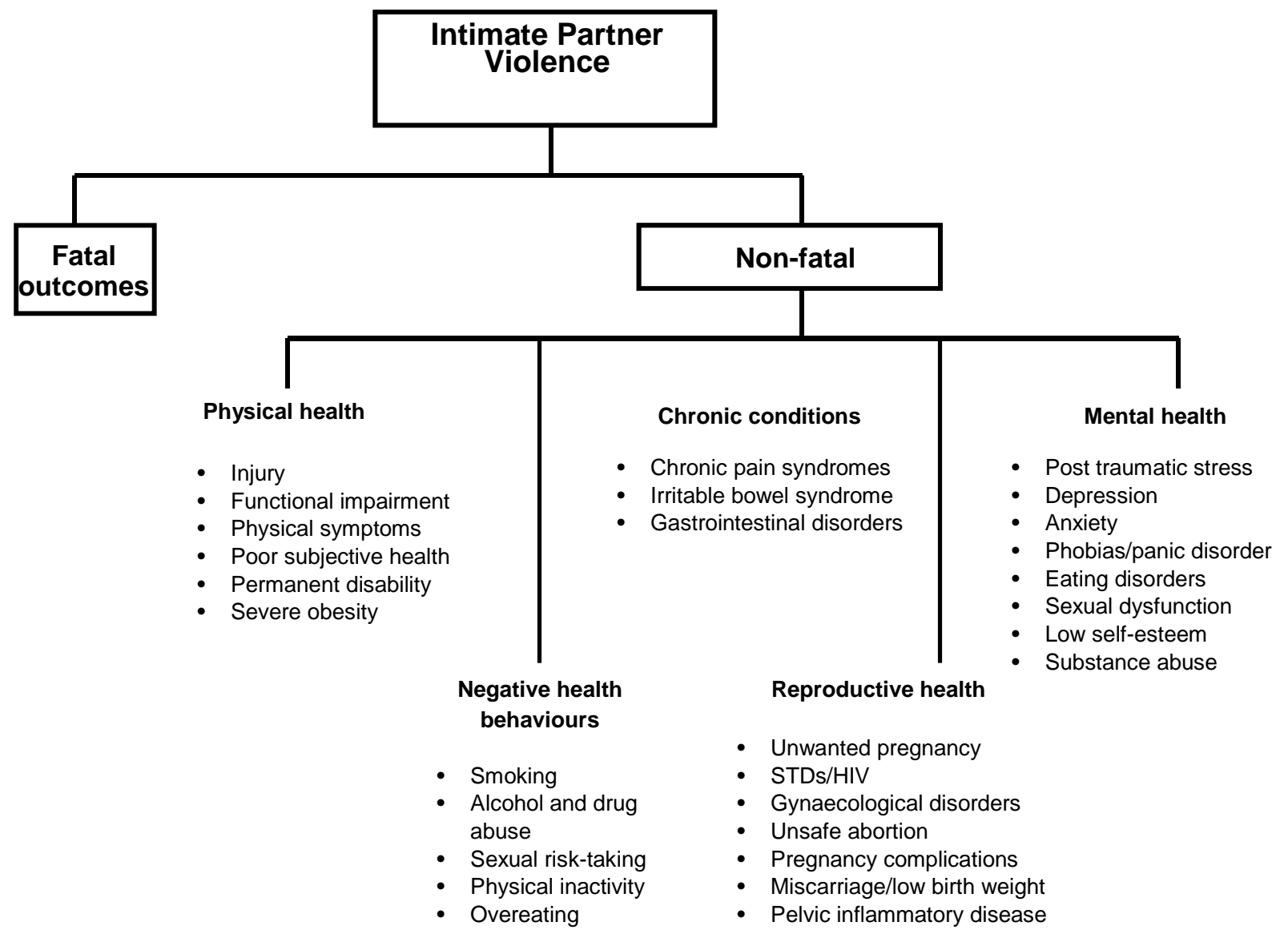

Population Reports. 2001.

\subsubsection{Mental health}

While many victims of IPV do not develop mental health conditions, for others, being abused regularly over a long period of time can result in mental distress. In one study $48 \%$ of the sample had "wanted help with mental health in the past 12 months". Data indicated that there was an increased risk of developing certain mental health problems as a result of being abused. Rates range from $17 \%$ to $72 \%$ of victims of IPV reporting depression across USA and UK studies, with rates of Post Traumatic Stress Disorder ranging from $33 \%$ to $88 \%$. Other mental illnesses have been linked to IPV including substance abuse, eating disorders and psychotic episodes. (Plichta \& Weisman, 1995; Stark, Flitcraft, \& Frazier, 1979 in http://www.snbw.org/).

In the Dunedin longitudinal study both female victims of severe IPV and male perpetrators reported one or more mental disorders. Figure 2.7 shows that women who 
experience IPV were more likely than non-abused women to report mental illness and that male perpetrators were more likely to be diagnosed with a mental illness than nonperpetrating men (Moffitt and Caspi, 1999).

Figure 2.7: Rates of mental illness among Dunedin perpetrators and victims of severe physical abuse

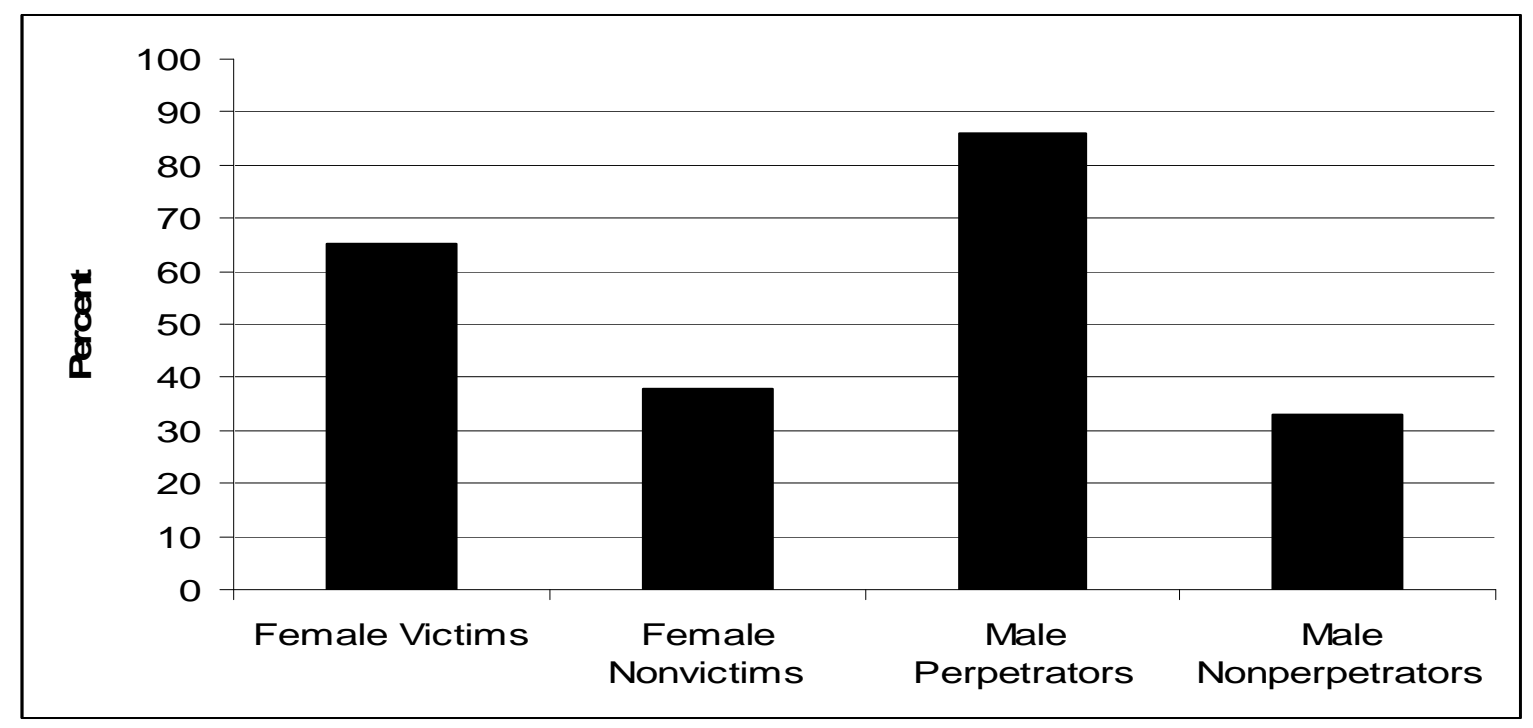

Moffitt and Caspi (1999).

\subsubsection{Physical health}

Physical injuries are often the most visible result of IPV. While common injuries are found to the neck, face and head there are also internal injuries or those hidden by clothing (Boyle, Robinson and Atkinson, 2004).

Many studies have shown an increase in physical injury experienced by victims of IPV, ranging from $40 \%$ to $72 \%$ of participants (Widom, 1989; Farrington, 1993; Moffitt and Henry, 1991. Table 2.10 reports Fanslow and Robinsons (2004) findings on IPV and health outcomes as reported by the women in their study. This table shows that there was a significant association between lifetime experience of IPV and a range of current negative health physical outcomes. 
Table 2.10: Associations of lifetime physical violence and health outcomes reported by ever partnered women

\begin{tabular}{|c|c|c|c|c|c|}
\hline $\begin{array}{l}\text { Current health problem } \\
\text { (past } 4 \text { weeks) }\end{array}$ & $\begin{array}{l}\text { Level of physical } \\
\text { violence }^{*}\end{array}$ & $\mathbf{N}$ & $\%$ & $\begin{array}{l}\text { OR }(95 \% \mathrm{Cl}) \text { from } \\
\text { logistic } \\
\text { regression } \dagger\end{array}$ & \begin{tabular}{|l} 
P value \\
from \\
logistic \\
regression
\end{tabular} \\
\hline \multirow{3}{*}{$\begin{array}{l}\text { Self-reported poor or very } \\
\text { poor health }\end{array}$} & No physical violence & 1814 & 2.3 & 1 & \multirow[t]{3}{*}{0.0002} \\
\hline & $\begin{array}{l}\text { Moderate } \\
\text { violence }\end{array}$ & 299 & 4.6 & $2.34(1.25-4.40)$ & \\
\hline & Severe violence & 555 & 8.6 & $2.73(1.64-4.53)$ & \\
\hline \multirow{3}{*}{$\begin{array}{l}\text { Some/many problems, or } \\
\text { unable to perform usual } \\
\text { activities }\end{array}$} & No physical violence & 1813 & 13.2 & 1 & \multirow[t]{3}{*}{$<0.0001$} \\
\hline & Moderate violence & 299 & 16.5 & $1.34(0.92-1.94)$ & \\
\hline & Severe violence & 554 & 26.0 & $1.94(1.46-2.59)$ & \\
\hline \multirow{3}{*}{$\begin{array}{l}\text { Many problems } \\
\text { walking/unable to walk }\end{array}$} & No physical violence & 1814 & 1.3 & 1 & \multirow[t]{3}{*}{0.005} \\
\hline & $\begin{array}{c}\text { Moderate physical } \\
\text { violence }\end{array}$ & 299 & 2.9 & $2.35(0.98-5.67)$ & \\
\hline & $\begin{array}{c}\text { Severe physical } \\
\text { violence }\end{array}$ & 555 & 6.0 & $2.95(1.54-5.66)$ & \\
\hline \multirow{3}{*}{$\begin{array}{l}\text { Moderate/severe/extreme } \\
\text { pain or discomfort }\end{array}$} & No physical violence & 1814 & 21.9 & 1 & \multirow[t]{3}{*}{$<0.0001$} \\
\hline & Moderate violence & 299 & 33.3 & $1.78(1.34-2.35)$ & \\
\hline & Severe violence & 554 & 37.8 & $2.10(1.64-2.69)$ & \\
\hline \multirow{3}{*}{$\begin{array}{l}\text { Some/many or extreme } \\
\text { memory or concentration } \\
\text { problems }\end{array}$} & No physical violence & 1813 & 11.0 & 1 & \multirow[t]{3}{*}{$<0.0001$} \\
\hline & Moderate violence & 299 & 18.0 & $1.82(1.26-2.62)$ & \\
\hline & Severe violence & 555 & 26.8 & $2.58(1.92-3.48)$ & \\
\hline \multirow[t]{3}{*}{ Dizziness } & No physical violence & 1813 & 11.1 & 1 & \multirow[t]{3}{*}{$<0.0001$} \\
\hline & Moderate violence & 299 & 19.1 & $1.80(1.24-2.61)$ & \\
\hline & Severe violence & 554 & 26.7 & $2.55(1.89-3.44)$ & \\
\hline \multirow[t]{3}{*}{ Vaginal discharge } & No physical violence & 1812 & 6.5 & 1 & \multirow[t]{3}{*}{0.008} \\
\hline & Moderate violence & 298 & 8.7 & $1.39(0.81-2.38)$ & \\
\hline & Severe violence & 551 & 11.5 & $1.86(1.25-2.77)$ & \\
\hline
\end{tabular}

* 'No physical violence' group contains a small proportion of women who had experienced sexual violence $(n=101,5.6 \%)$; †Logistic regression models included age, NZDep2001, ethnicity, educational status, household income, and location. Fanslow and Robinsons (2004). 


\subsubsection{Hospital Admissions}

Hospital admission rates give some indication of the amount of, or degree of, severity of IPV that women are facing. However factors such as accessibility to resources and cultural beliefs can affect who will admit themselves or be admitted to hospital. However of those women who do seek medical care, in the USA, it is estimated that $37 \%$ of women with violence-related injuries who sought medical care were injured by a current or former partner (UNICEF, 2000).

Fanslow and Robinson (2004) study of women found that those who had experienced IPV in the previous 12 months were more than twice as likely to contact a healthcare professional or be hospitalised than women who had not experienced IPV (see table 2.11).

Table 2.11: Women who had contact with healthcare professionals, or were hospitalised

\begin{tabular}{|l|c|c|c|c|c|}
\hline Variable & $\begin{array}{c}\text { Level of } \\
\text { physical } \\
\text { violence* }\end{array}$ & $\mathbf{N}$ & $\%$ & $\begin{array}{c}\text { OR (95\%Cl) from } \\
\text { logistic } \\
\text { regression† }\end{array}$ & $\begin{array}{c}\text { P value from } \\
\text { logistic } \\
\text { regression }\end{array}$ \\
\hline $\begin{array}{l}\text { Consulted health } \\
\text { professional in last } \\
4 \text { weeks }\end{array}$ & $\begin{array}{c}\text { No physical } \\
\text { violence }\end{array}$ & 1814 & 29.8 & 1 & $<0.0001$ \\
\cline { 2 - 5 } & $\begin{array}{c}\text { Moderate } \\
\text { violence }\end{array}$ & 299 & 36.2 & $1.34(1.01-1.78)$ & \\
\cline { 2 - 5 } & Severe violence & 554 & 44.5 & $1.86(1.47-2.36)$ & \\
\hline
\end{tabular}

* 'No physical violence' group contains a small proportion of women who had experienced sexual violence ( $n=101,5.6 \%)$; †Logistic regression models included age, NZDep2001, ethnicity, educational status, household income. Model for "consulted health professionals in last 4 weeks" also included location. Fanslow and Robinsons (2004).

In a study reported by Pritchard (2005) $11.3 \%$ of the sample reported physical abuse, of them $13 \%$ resulted in hospital treatment, while two point seven percent of men reported being physically assaulted with none of them requiring hospital treatment. These figures indicate that there are only a small number of victims seeking medical help and that women are more likely to seek medical help than men, it also may be a reflection of the level of harm, in that men are more likely to inflict greater physical harm and injury to female victims, than women do to male victims. 


\subsubsection{Mortality rates}

In the USA femicide (murder of a female intimate partner) is one of the leading causes of premature death amongst women. For African American femicide is the leading cause of death for women aged 15-45 years (West, 2004).

In a review of death cases by Mahoney et al (2001) available statistics indicated that $30 \%$ to $64 \%$ were femicide cases. In the USA in 1997 an estimate of at least 1,217 women were killed by their partner. Kaufman et al. (1998) estimated that in female murder cases almost $50 \%$ are a result of violence by a partner or husband.

Suicide attempts and completions are also reported at higher rates for victims of IPV. Fanslow and Robinson (2004) found that women who experienced moderate IPV were three times more likely to attempt suicide, while women who had experienced severe IPV were almost eight times more likely to attempt suicide (see table 2.12).

Table 2.12: Mental health effects of violence on women

\begin{tabular}{|c|c|c|c|c|c|}
\hline Variable & $\begin{array}{l}\text { Level of } \\
\text { physical } \\
\text { violence* }^{*}\end{array}$ & $\mathbf{N}$ & $\%$ & $\begin{array}{l}\text { OR }(95 \% \mathrm{Cl}) \text { from } \\
\text { logistic } \\
\text { regression } \dagger\end{array}$ & $\begin{array}{l}\text { P value from } \\
\text { logistic } \\
\text { regression }\end{array}$ \\
\hline \multirow[t]{3}{*}{$\begin{array}{l}\text { Suicidal } \\
\text { thoughts ever }\end{array}$} & $\begin{array}{c}\text { No physical } \\
\text { Violence }\end{array}$ & 1812 & 19.6 & 1 & \multirow[t]{3}{*}{$<0.0001$} \\
\hline & $\begin{array}{l}\text { Moderate } \\
\text { violence }\end{array}$ & 299 & 40.3 & $2.62(1.97-3.48)$ & \\
\hline & Severe violence & 553 & 52.3 & $3.97(3.10-5.10)$ & \\
\hline \multirow[t]{3}{*}{$\begin{array}{l}\text { Suicidal } \\
\text { attempts ever }\end{array}$} & $\begin{array}{c}\text { No physical } \\
\text { Violence }\end{array}$ & 1809 & 2.3 & 1 & \multirow[t]{3}{*}{$<0.0001$} \\
\hline & $\begin{array}{l}\text { Moderate } \\
\text { violence }\end{array}$ & 299 & 7.5 & $2.98(1.69-5.27)$ & \\
\hline & Severe violence & 552 & 20.9 & $7.63(4.79-12.15)$ & \\
\hline \multirow{3}{*}{$\begin{array}{l}\text { SRQ score } \\
\text { greater than } 7 \\
\text { (symptoms in } \\
\text { last } 4 \text { weeks) }\end{array}$} & $\begin{array}{c}\text { No physical } \\
\text { violence }\end{array}$ & 1814 & 9.4 & 1 & \multirow[t]{3}{*}{$<0.0001$} \\
\hline & $\begin{array}{l}\text { Moderate } \\
\text { violence }\end{array}$ & 299 & 22.0 & $2.66(1.87-3.78)$ & \\
\hline & Severe violence & 555 & 31.8 & $3.84(2.89-5.11)$ & \\
\hline
\end{tabular}


$\mathrm{SRQ}=$ self-reporting questionnaire; * 'No physical violence' group contains a small proportion of women who had experienced sexual violence ( $n=101,5.6 \%)$; †Logistic regression models included age, NZDep2001, ethnicity, educational status, household income, and location. Fanslow and Robinsons (2004).

\subsubsection{Stressors}

Stress on individuals and families is found to have a significant impact on the likelihood of IPV occurring throughout the literature. Work, life events, community and the ability of the couple to manage stress (particularly chronic stress) are all critical factors in relationship satisfaction and durability. Adults who are overworked and stressed, can find they have little time and energy left to focus on their relationship. The impact of certain risk factors then may be more of a reflection on how an individual copes with stress and the mechanisms available to reduce this stress rather than the actual factor (such as low income or unemployment).

An individual's ability to control stressors can create an environment of relative harmony while those unable to exert such control may revert to IPV to deal with their situation (Jasinski, 2001). The ability to deal with stressors and the type and levels of stress faced, significantly varies across SES, gender and age. Cunradi et al. (2002) suggests that those from lower socio-economic levels are affected at greater levels by negative life events and have fewer resources available to deal with the stress then those from higher SES backgrounds.

\subsection{Conclusion}

In conclusion, research around IPV has grown significantly since the 1970's with a shifting focus on the different types of violence experienced and on the way certain contextual and situational factors impact of experiences and levels of victimisation.

Victimisation surveys have become an accepted way of estimating incidence and prevalence rates for IPV by surveying representative samples of populations. The popularity of these types of surveys arose from the identification of the limitations of Police statistics in terms of victim reporting and Police recording.

In victimisation surveys participants are asked a series of screening questions that help define the crime/s being researched. The definitions and boundaries of behaviours 
used to define a crime in various studies often differ, making it problematic when making comparisons between victimisation rates from different studies, however these studies highlight the complexity of the factors and environments that victims are living in.

The NZNSCV (2001) showed that for IPV the prevalence rate was $25 \%$ for women while nearly $20 \%$ of men report having also experienced IPV over a lifetime and three percent of women in a current relationships reported having experienced at least one of these types of violence, while one point eight percent of men reported such an experience over a 12 month period.

Risk factors identified in the literature, and collected by the NZNSCV included:

- Demographic risk factors

$$
\begin{array}{ll}
\circ & \text { Age } \\
\circ & \text { Gender } \\
\circ & \text { Ethnicity }
\end{array}
$$

- Socioeconomic risk factors

- Socio-economic (NZSEI) group

○ Household tenure

$\circ$ Living situation

○ Number of people living in households

- Main income earner

- Employment status

- Marital status.

Other studies have identified other risk factors and behaviours that are associated with IPV including drug and alcohol use, child witnesses of violence and stress and show the inter-relationships between variables such as SES, employment, stress and education. The effects of IPV have also been shown to play a huge part in victims receiving health care, for both physical and mental issues as a result of victimisation. IPV can also lead to death as the violence escalates or as situations change, e.g. child birth, separation.

This thesis aims to build on the results seen overseas and in previous New Zealand studies, and to provide more New Zealand specific findings, with data from New Zealand participants, in New Zealand society and culture, including findings for New Zealand Māori and Pacific people. 


\section{Chapter Three}

\section{Description of the New Zealand National Survey of Crime Victims (NZNSCV) 2001.}

This section describes the survey methodology used for the New Zealand National Survey of Crime Victims 2001, including sample design and weightings.

Much of the information in this chapter was taken from the published technical report of this survey: 'Technical Report on the 2001 New Zealand National Survey of Crime Victims' prepared for the Ministry of Justice by Reilly (2003). For a more detailed explanation of the survey, see this publication.

\subsection{Description of the General Survey}

This research uses the data from the 2001 New Zealand National Survey of Crime Victims (NZNSCV). This survey explores the experience of victims of crime in New Zealand from a random sample of around 5000 New Zealanders aged 15 years and over and their experience of crime over the previous 12 months and violence by a partner over a lifetime.

The NZNSCV 2001 was commissioned by the Ministry of Justice in collaboration with the New Zealand Police, the Department of Corrections and the Ministry of Social Development. The project was undertaken by a consortium led by ACNielsen Ltd and also included researchers from Auckland and Victoria University.

The 2001 NZNSCV was the second survey in a series, with the first NZNSCV data collection being carried out in 1996. The continuation of these surveys allows comparisons to be made between years with a comparable data source

The aim of the NZNSCV survey was to provide a more stable picture of crime victimisation over time and to allow a better understanding of the nature and extent of crime and victimisation in New Zealand. As police crime statistics are affected by victim's readiness and ability to report a crime, crime surveys help us to provide another avenue for studying the incidence and prevalence of crime in New Zealand. 
This survey included questions, for the period of 1 January 2000 - 31 December 2000, about the type of offences experienced by the victim (respondent) and the impact these offences had on the victim as well as other demographics and victim related information.

Included also was a section asking 2526 women and 1721 men about their experience of physical violence by their heterosexual intimate partner.

\subsubsection{Survey Population}

The target population in the main survey was all non-institutionalised adults aged 15 years and over, living in permanent private dwellings. This represented approximately 2.6 million people, according to the New Zealand Census (2001).

The survey population cannot include the entire target population so the NZNSCV surveyors adopted the Statistics New Zealand's "Statistical Standard for Usual Residence 1999" as the definition of which people and households were included in the survey population in 2001.

Those excluded in the survey population were long-term residents of old peoples' homes, hospitals and psychiatric institutions; inmates of penal institutions; those members of the New Zealand armed forces who live in institutional settings; non-New Zealand diplomats and their non-New Zealand staff; members of non-New Zealand armed forces stationed in New Zealand; overseas visitors stationed in New Zealand for less than 12 months; and residents of offshore islands, except Waiheke Island.

\subsubsection{Sample size}

A final sample of 5,300 was collected with shortfalls in the Māori and Pacific booster samples which were balanced with increased sampling of the main population. The expected and actual sample sizes for the 2001 survey can be seen in table 3.1 . 
Table 3.1: Expected and actual sample sizes

\begin{tabular}{|l|l|l|}
\hline & Expected & Actual \\
\hline Total & $\mathbf{5 4 7 0}$ & $\mathbf{5 3 0 0}$ \\
\hline Main Sample & 4000 & 4101 \\
\hline Mãori booster & 610 & 500 \\
\hline Pacific booster & 860 & 699 \\
\hline
\end{tabular}

From Morris and Reilly (2003).

The data analysis in the NZNSCV (2001) is based on a sample of $n=5147$. One hundred and fifty three people were excluded as a result of data storage problems and these records had to be discarded.

The analysis in this thesis was based on $n=2903$ (currently partnered), and $n=3783$ (ever partnered). These numbers are lower than for the over all survey mainly because those that reported never having had a heterosexual partner were not asked this section.

Table 3.2 shows the breakdown by ethnicity used for analysis in this thesis. It differs from the 2001 NZNSCV report (Morris and Reilly, 2003) because of a different ethnic classification that was used to code ethnicity for the analysis in this thesis (see section 4.7.1.2 for more detail).

Table 3.2: Actual sample size used for this thesis, by ethnicity.

\begin{tabular}{|l|c|c|}
\hline Ethnicity & Lifetime analysis & $\mathbf{1 2}$ Month analysis \\
\hline NZ European & 2413 & 1897 \\
\hline Māori booster & 690 & 475 \\
\hline Pacific booster & 462 & 348 \\
\hline Other & 218 & 183 \\
\hline
\end{tabular}

The number of participants interviewed in the 2001 survey was relatively small in proportion to the New Zealand population $(0.17 \%$ overall, $0.3 \%$ for Pacific peoples), however the probability sampling procedures allow us to be able to generalise the result to the population as a whole with some confidence. 


\subsubsection{Response Rate}

A number of strategies were incorporated in the 2001 NZNSCV to facilitate maximum response rates and to gain a higher response rate than the $57 \%$ in 1996 . This was done by:

- carrying out wide spread media coverage through radio and newspapers, including Māori and Pacific media, before the fieldwork began

- distributing a signed letter from the Secretary of Justice to targeted households endorsing and informing the public about the up-coming survey

- increasing the number of "call-backs" allowed

- providing non-response training to help interviewers cope with this

- matching participant and interviewer ethnicity where possible in the booster samples.

For the 2001 NZNSCV the total response rate rose from $57 \%$ to $62 \%$ for the total sample (including the booster samples) and $65 \%$ for the main sample. However for Māori, the response rate was only $57 \%$ and for Pacific people, $53 \%$. This reflects the fact that while the contact rates were high, the conversion and response rates for the booster samples were still low.

So although the overall response rate was higher Morris and Reilly (2003) comment that the low response rate for the booster samples was disappointing. This could be partially explained by Young, Morris, Cameron and Haslett (1997) belief that as New Zealand is so heavily researched, and has a small population, certain groups feel overresearched and thus decline to be involved in future research. As pointed out, this 2001 NZNSCV took place in the same year as the census (and the several population surveys linked to the Census) which may have had a negative effect on the response rates.

\subsubsection{Time period}

The field work period ran from mid-July to the end of November in 2001. This survey period was divided in to quarters and the areas selected were assigned systematically to these quarters. This allowed preliminary response rates to be calculated during the course of the fieldwork. 


\subsection{Sample Design}

\subsubsection{Overview}

A national random sample of New Zealand households was surveyed using a complex sample design which included three separate samples: a sample of the general population (the main sample) and two booster samples for Māori and Pacific people.

A complex multi-stage design was used for each of these samples consisting of stratification, clustering and unequal selection probabilities. This is necessary for a face-to-face survey as it is a cost effective way to carry out field work while ensuring that the population as a whole has a known chance of being selected for the sample. This requirement is fundamental to the calculation of survey estimates that are reliable, and allows also for the calculation of margins of sampling error.

In the sample design, there were four stages involving the selection of each unit at successive stages. These were:

- areas

- households

- people

- incidents.

These modifications to the ideal simple-random sample are more practical when carrying out field work, while also providing unbiased survey results.

\subsubsection{Sample Frame}

Changes were made to improve the sample design from 1996 to the 2001 (current) survey, which although fairly minor, have improved the survey's robustness. The main change was in the methodology used for the self-completion section of the survey where Computer Assisted Self Interviewing (CASI) was introduced and replaced the paper surveys. This increased disclosure of IPV events which is important in that the sample frame can then be linked to official population statistics with more robust results, this will be discussed further in this chapter. 
ACNielsen developed and standardised a national sampling frame that is both reliable and replicable to produce statistically reliable data. Their sampling frame allows the survey data to project up to the total population rather than in simple percentages and also allows geographical areas to be broken down in to reasonably small and concise areas.

The 38,000 Statistics New Zealand meshblocks range from resident numbers between zero and 900 (although there is an average of 100 in each). This was found to be too small by ACNielsen for survey research purposes, while area units were seen as unable to meet ACNielsen's requirements for large numbers of areas in use at any one time. As a result of this, ACNielsen created "Nielsen Area Units" (NAU) that fit in size between Statistics New Zealand's meshblocks and their smaller area units. The NAU's contain almost 5000 units with seven meshblocks on average in each, averaging at about 700 people in 230 dwellings.

Some NAU's were omitted from the sample frame where there was low-density Māori or Pacific households, that is, where they contained few Māori or Pacific people as a proportion of the total population.

ACNielsen imposed quasi-random (or random) procedures for:

- the selection of area units within stratification grid cells

- selecting streets and household within area units

- selecting participants within dwellings.

\subsubsection{Area Unit Selection}

Chromy's method was used for the main sample in selecting NAU's within each stratum. "The number of area selected within each stratum was generally proportional to the number of permanent private dwellings in each stratum" (Reilly, 2003). Table 3.3 shows the number of area units selected by each stratum for the main sample and for the Māori and Pacific booster samples, where each stratum is a contiguous geographical region. 
Table 3.3: The number of area units selected by each stratum for the main sample, Māori and Pacific booster samples.

\begin{tabular}{|c|c|c|c|}
\hline Stratum & $\begin{array}{l}\text { Number of NAU's for } \\
\text { main sample }\end{array}$ & $\begin{array}{l}\text { Number of NAU's for } \\
\text { Māori booster sample }\end{array}$ & $\begin{array}{l}\text { Number of NAU's for } \\
\text { Pacific booster sample }\end{array}$ \\
\hline 1 & 204 & 28 & 122 \\
\hline 2 & 82 & 22 & 6 \\
\hline 3 & 16 & \multirow{2}{*}{24} & \multirow{2}{*}{8} \\
\hline 4 & 90 & & \\
\hline 5 & 76 & 10 & 26 \\
\hline 6 & 62 & \multirow{2}{*}{14} & \multirow{3}{*}{6} \\
\hline 7 & 22 & & \\
\hline 8 & 38 & 8 & \\
\hline 9 & 102 & 8 & \multirow{4}{*}{6} \\
\hline 10 & 24 & \multirow{2}{*}{4} & \\
\hline 11 & 24 & & \\
\hline 12 & 60 & 6 & \\
\hline Total & 800 & 124 & 174 \\
\hline
\end{tabular}

Reilly, 2003.

For the Māori and Pacific booster samples, strata were defined in the same way except where a low proportion of Māori or Pacific populations existed in those strata, those strata were combined.

\subsubsection{Household Selection}

The sampling procedure for households began with interviewers starting at a randomly selected point and from there-on calling in to every fourth dwelling using a predetermined walk pattern until the dwelling quota in that area was collected. In rural areas all dwellings were approached for both the main and the booster samples.

A "call-back" routine was established to maximise the likelihood of obtaining interviews in each NAU at designated dwellings. If no contact was made at the first call, interviewer's returned up to three visits in total. Visits were made at least once during the day and once during the evening throughout the week. 


\subsubsection{Participant Selection}

For every household visited the names and birth month of all residents over 15 years of age were listed. The person with the next birthday was selected as the respondent to be interviewed. For the Māori and Pacific booster samples, only those identified as Māori or Pacific by the door respondent were listed. If not all household members birth months were known by the doorstep respondent then the names were ordered alphabetically by first names, the closest name to the beginning of the alphabet was selected.

Once the person was selected to take part in the survey, this did not mean that they would necessarily agree to take part in the survey although contact had been made. Once the selected person had been advised of the nature and purpose of the survey they were then asked to grant consent for the interview to continue with them. Not all persons agreed to this. The following table (3.4) shows those that were contacted and the conversation and response rates at this point for the main and booster samples.

Table 3.4: Response rates for the NZNSCV (2001)

\begin{tabular}{|l|c|c|c|c|}
\hline & Total Sample & Main Sample & $\begin{array}{l}\text { Māori } \\
\text { Booster }\end{array}$ & $\begin{array}{l}\text { Pacific } \\
\text { Booster }\end{array}$ \\
\hline Contact rate & 93.3 & 92.7 & 95.3 & 94.9 \\
\hline $\begin{array}{l}\text { Conversion } \\
\text { rate }\end{array}$ & 66.2 & 69.5 & 59.3 & 55.6 \\
\hline Response rate & 61.8 & 64.5 & 56.5 & 52.8 \\
\hline
\end{tabular}

${ }^{*}$ Conversion rate is the number of people who are contacted and who are willing to participate in the survey. Morris and Reilly (2003).

\subsubsection{Incident Selection}

For participants who claimed to have been victimised many times in the previous 12 months, three of these incidents had to be selected as it was not practical to ask them to complete questions for every incident. The three incidents were randomly selected which allowed the construction of unbiased estimates as the data could be weighted. This process was the same for the Māori and Pacific booster samples. 
The incident selection increased the sample size for high priority offences (ie. assaults, threats, personal theft) with a chance of being selected three times more likely than for low priority offences (i.e. motor vehicle offence, household theft).

\subsubsection{Data Collection and Processing}

The 2001 NZNSCV employed the technique of structured interviews to collect survey data from the respondents, as in the 1996 NZNSCV. To avoid duplication of the same event being disclosed (for household events) only one interview was carried out per household, as a result limiting contamination. This was also done for efficacy reasons, to reduce the correlation between responses, as a result reducing the variance of the estimators.

Computer Assisted Personal Interviewing (CAPI) was used in the 2001 survey after criticism was made of the paper questionnaire in 1996. Both the British and Australian crime surveys used this technique which carried with it the advantages of handling complex sequencing involved in the NZNSCV, making the skipping procedures easier to manage. This allowed for fewer occurrences of missing data.

Computer Assisted Self Interviewing (CASI) was used for the section to measure violence committed by intimate partners. This allowed the participants to complete these sections on their own providing maximum confidentiality and privacy. Using CASI also reduces the likelihood of participants missing questions.

The one main criticism of this CASI system is some individuals' fear of computers. Findings from British Crime Survey suggested however that as little as three percent of participants refused to complete the self-completion section and of this three percent only $13 \%$ used the reason that it was a "dislike of computers" (Morris and Reilly, 2003. Pp 48).

\subsubsection{Questionnaire design and development}

\subsubsection{Alterations}

The questionnaire was modified from the 1996 NZNSCV after consultation with the Australian Bureau of Statistics (ABS). Changes were kept to a minimum to allow for maximum comparability between years, however some re-drafting, cutting of questions 
and the format and layout were altered. This was done ultimately to simplify the questionnaire and to reduce the burden to respondents while preserving the ability to compare data (for more information on the questions and sections that were altered refer to the NZNSCV report, Morris and Reilly, 2003).

\subsubsection{Questionnaire Sections}

The questionnaire was divided in to five sections:

1. perceptions of crime safety and worries towards crime, the knowledge and use of prevention strategies against crime

2. a screening section to indicate what offences they had been victims of since 1 January 2000

3. a detailed victim form to record the incidences of each of the incidents

4. demographic information collected about the participant and the household

5. a self-completion questionnaire with three sections including:

- violence by a heterosexual partner

- assault by other people known to the victim

○ unwanted sexual attention.

Section Five included screening questions to identify if the participant had been a victim in each of the categories.

\subsubsection{Victim Forms}

Victim forms were filled in by participants for up to three mentioned victimisations and covered issues such as loss or damage resulting from the victimisation, extent of any injury, emotional and practical consequences, whether they reported the incident to the Police, their view of the adequacy of Police response and also with any support groups. Information was also collected in order to ascertain whether or not the incident qualified for inclusion in calculations of incidence and prevalence rates.

\subsubsection{Self-completion Section - Violence by a Heterosexual Intimate Partner}

The section "violence by a heterosexual partner" was a self-completion section where participants used CASI to answer questions around their experience of violence by a heterosexual partner (if they identified being a victim of this type of crime). They provided information on the incidents of partner violence since 1 January 2000 with 
emphasis on the most recent incident. Information was included on the extent of their injuries (if any), the emotional impacts on them as victims, whether they had reported the incident to the Police, Police response and their perception of the adequacy of the Police, and whether they had accessed any victim support groups or agencies and their perception on the services support given to them.

\subsubsection{Pilot and Pre-Testing}

The NZNSCV 2001 was piloted to identify if there were any further areas that needed to be altered. The major function of the pilot was to test field logistical procedures and the inter-cluster variability. This was done to see what impact the design effects had on the average sampling error. The pilot was also used to look at respondent's ability to understand the questions, to comment on the layout, sequencing and sensitivity.

In the pilot, 20 NAUs were selected from the Auckland, Bay of Plenty and Canterbury regions including a spread of urban, small towns and rural locations. From the findings of the pilot, the survey questions were further cut back as length was the main issue identified as causing a substantial burden to respondents.

\subsubsection{Description of the Database}

The data collected by the New Zealand National Survey of Crime Victims 2001 was provided on CD-ROM for this thesis by the Ministry of Justice. The CD-ROM contained the data and a data dictionary. Hard copies were obtained providing information on the survey background and methodology, the NZNSCV technical report (Reilly, 2003) and the NZNSCV 2001 report (Morris and Reilly, 2003).

The data was in the form of a SAS dataset. All identifying information about the participants was removed from the dataset before being provided by the Ministry of Justice, including geographical identifiers. The dataset contained 5147 records, with individual and household weights (see section 4.7.7 for further details on the applied weights).

Approval to use the data was gained from the Ministry of Justice and the Victoria University of Wellington Human Ethics Committee. 


\section{Chapter Four}

\section{Statistical Theory}

Chapter Four describes the methodology used to analyse the data from the NZNSCV (2001). Firstly is a review of the theory for simple univariate survey data analysis techniques, followed by weighting calculations. The Chi-squared test of independence is explained followed by the log linear model and logistic regression theory. It should be noted that the weights attributed to variables were calculated by the Ministry of Justice and were supplied with the dataset.

Following this is a description of the methods used in this study, including data grouping and analysis. The actual analysis results are reported in Chapter Five.

Much of the information in this chapter was taken from the Agresti (2002). For a more detailed explanation of categorical data analysis, see this publication.

\subsection{Point Estimates}

\subsubsection{Estimators of point estimates}

For a selected variable, population totals and means can be calculated where the probability of selection is known for each respondent. The Horwitz-Thompson estimator for the population total $\hat{Y}_{H T}$ is:

$$
\hat{Y}_{H T}=\sum_{k=1}^{n} w_{k} y_{k}
$$

Where $\mathrm{n}$ is the sample size and $k=1 \ldots n, y_{k}$ are the responses and $w_{k}$ are the sample weights for each of the respondents. The variable $y_{k}$ can represent an indicator variable $\left(y_{k}=0\right.$ or 1$)$. 
The NZNSCV survey is concerned primarily with means or point estimates of rates. Within a population the Horwitz-Thompson estimator of the rate within the population $\hat{P}_{x}$ is:

$$
\hat{P}_{x}=\frac{\hat{Y}}{N}=\frac{\sum_{k=1}^{n} w_{k} y_{k}}{\sum_{k=1}^{n} w_{k}}
$$

Where $N$ is the (known) population total.

\subsubsection{Dealing with items of non-response}

Point estimates are formed using only those respondents who responded to each question. An item of non-response is assumed to be Missing Completely at Random. By excluding some respondents the population totals are affected as the benchmarked population is greater than the population total.

The Horwitz-Thompson estimator for the rate $\hat{P}_{x}$ within the population is:

$$
\hat{P}_{x}^{\prime}=\frac{\hat{Y}^{\prime}}{N^{\prime}}=\frac{\sum_{k=1}^{n^{\prime}} w_{k} y_{k}}{\sum_{k=1}^{n^{\prime}} w_{k}}
$$

Where the number of people who responded to the question is $n$ ', for each respondent $k=1 \ldots n^{\prime}, w_{k}$ are the sample weights and $N^{\prime}$ is the weighted population total, and the responses are $y_{k}$.

To calculate the population total $(\hat{Y})$ the rate $\hat{P}_{x}$ is multiplied by the benchmarked population size.

$$
\begin{aligned}
\hat{Y} & =\hat{P}_{x}^{\prime} \times \sum_{k=1}^{n} w_{k} \\
& =\hat{P}_{x} N .
\end{aligned}
$$




\subsubsection{Estimates for subdomains}

For population subdomains such as ethnicity, age and gender, rate estimates are calculated in the same way the total population estimates are calculated, but are summed for subdomains $x$. The rate estimate is calculated by:

$$
\hat{P}_{x}^{\prime}=\frac{\hat{Y}^{\prime}}{N^{\prime}}=\frac{\sum_{k=1}^{n^{\prime}} w_{k} y_{k} \delta_{k x}}{\sum_{k=1}^{n^{\prime}} w_{k} \delta_{k x}}
$$

where $\delta_{k x}=1$ if $k \in x$, and $\delta_{k x}=0$ if $k \notin x$.

\subsection{Calculation of Sampling Error}

Jack knifing is used to calculate a survey sample estimate variance when a variance cannot be calculated directly due to its complex nature. This process involves each response unit being dropped out of the sample one at a time, and recalculating the parameter of interest. In the case of the NZNSCV (2001) data, the NAU is the response unit that is deleted from each jack knife replicate. The distribution of these calculations (called replicated means) is used to calculate the variance (Efron, 1982).

For the jack knife procedure a separate set of weights is needed for each jack knife replicate, where each set is post-stratified.

Sampling error The jack-knifed variance estimate $\hat{\operatorname{Var}}(\hat{\theta})$ of the estimator $\hat{\theta}$ of the parameter $\theta$ can be used to estimate the sampling error (SE) for an approximately normal distribution:

$$
\hat{S E}(\hat{\theta})=\sqrt{\hat{\operatorname{Var}}(\hat{\theta})}
$$

Confidence intervals $95 \%$ confidence intervals for any parameter $\theta$ can be calculated using the sampling error: 


$$
\hat{\theta} \pm 1.96 \times \hat{S E}(\hat{\theta})
$$

Relative sampling error (RSE) The precision of the estimators are indicative of the relative sampling error and is defined as:

$$
R S E(\hat{\theta})=\frac{\hat{S E}(\hat{\theta})}{\hat{\theta}}
$$

Where an RSE is greater than 0.3, this indicates that caution should be taken when using the estimates as they may be unreliable.

\subsection{Weighting}

To be able to compare population totals and to allow for sampling bias, weights were applied to the data. Weights are used in the NZNSCV (2001) survey data to make adjustments for factors such as differential non-response, sample design, and sample skew to make the data more comparative to the known population (Morris and Reilly, 2003).

The 2001 NZNSCV sample design involved a hierarchy of four levels:

- the Nielsen Area Unit

- households

- people

- victimisation incidents.

Sub-sampling took place at each level requiring different weightings for analysis on:

- households

- people

- incidents.

\subsubsection{Household Weights}

Across the three samples (main, Māori and Pacific) household weights were calculated as the reciprocal of each household's probability of inclusion in the sample. For $i$, (The inclusion probability) $p_{i}^{1}$ was calculated as follows: 


$$
p_{i}^{1}=\sum_{s=1}^{3} p_{i}^{1, s} r_{i}^{1, s}
$$

Where $P_{i}^{1, s}$ is the probability that household $i$ was selected for sample $s$ and $r_{i}^{1, s}$ is the probability that household $i$ was eligible for sample $s$ (Reilly, 2003).

For each household within each NAU the selection probability is inversely proportional to the number of dwellings in that NAU due to the fixed number of dwellings selected in each NAU, thus the household selection proportion was constant for the main sample $P_{i}^{1,1}$. This calculation was:

$p_{i}^{1,1}=\frac{8 \times 800}{1272874}=0.0050201$.

For the Māori and Pacific booster sample a similar calculation was used where the "number of dwellings selected in each area was multiplied by the number of areas selected for that sample, divided by the number of eligible dwellings in the relevant sampling frame" (Reilly, 2003). Specifically this was:

$p_{i}^{1,2}=\frac{32 \times 124}{1164618}=0.0034071$ for Māori and

$p_{i}^{1,3}=\frac{32 \times 174}{311139}=0.0178955$ for Pacific booster samples.

\subsubsection{Person Weights}

Similar to the household weights, person (individual) weights were also calculated, the difference being that person weights were incompletely post-stratified by age, sex and ethnicity instead of by urbanisation. This was done to adjust for only one person in a household being surveyed.

Non-response was adjusted using the same adjustment factors as for the household non-response adjustment.

After incomplete post-stratification the final person weights ranged from 33.67 to 3357.91, averaging at 578.14. Incidence and prevalence calculations for personal 
offences used these person weights, and for the main and self-completion questionnaire analysis.

\subsection{Inference Testing}

\subsubsection{Chi-Squared Tests}

The chi-squared test of independence is used to assess the relationship between two or more categorical variables as presented in a contingency table. The chi-squared test compares the actual and expected values in each cell that would be expected under the assumptions of independence. What the chi-square test determines is if the difference between expected and observed values is replicated in the real population (Haslam and McGarty, 2003).

The chi-square statistic is calculated by:

$$
\chi^{2}=\Sigma \frac{\left(f_{o}-f_{e}\right)^{2}}{f_{e}}
$$

where $f_{o}=$ the observed cell count and

$f_{e}=$ the expected cell count which is (row total * column total/ $\mathrm{N}$ ).

The degrees of freedom $(d f)$ and sample size are used to determine if the sample differences were due to chance or that they reflected the population. The calculation for $d f$ is:

(number of rows-1) $\times$ (number of columns-1)

(Lewis-Beck, Bryman and Liao, 2004; Haslam and McGarty, 2003). 


\subsubsection{Chi-square limitations}

Chi-squared tests are not the most appropriate for complex survey data as they assume that the data is random, independent and identically distributed which is not usually the case. However they do allow us to get an initial idea of what explanatory variables might be related to the dependent variables. Note, as this is not the most reliable test to assess association, a logistic regression is the main test used in this thesis to draw conclusions from the data.

\subsection{Log-Linear Models}

Log-linear analysis is used to measure the relationship amongst discrete (categorical) variables. For three or more variables multi-way frequency analysis is used for tests of association (Tabachnick and Fidell, 1996). Where an additive regression-type equation is used, a log-linear model is developed. Log-linear models provide a powerful framework for the analysis of contingency tables. The assessment of the degree of association between two continuous variables is made using the correlation co-efficient. A log-linear model can be thought of as a model of expected frequencies in a contingency table, whose strength is in its ability to be applied to quite complicated contingency tables with several variables, which is why it is more then just an alternative to the $\chi^{2}$ test (Simkiss, Ebrahim and Waterston, 2006). For a $2 \times 2$ contingency table the log-linear model is:

$$
\ln \left(\pi_{i j}\right)=\lambda+\lambda_{i}^{R}+\lambda_{j}^{C}+\lambda_{i j}^{R C}
$$

Where the natural logarithm is represented by $" \ln \left(\right.$ )" and the $\lambda_{i}^{R}, \lambda_{j}^{C}$ and $\lambda_{i j}^{R C}$ are row, column and association parameters estimated from the data. To test for independence in the model is to test $\lambda_{i j}^{R C}=0$ for all pairs $(i, j)$. If row variables and column variables are not independent the row and column association is represented as $\lambda_{i j}^{R C}$. The logodds ratio for models with two or more categorical variables is:

$$
\ln \left(\frac{\pi_{11} \pi_{22}}{\pi_{12} \pi_{21}}\right)=\lambda_{11}^{R C}-\lambda_{12}^{R C}-\lambda_{21}^{R C}+\lambda_{22}^{R C}
$$


The full log-linear model for three variables is:

$$
\ln \left(\pi_{i j k}\right)=\lambda+\lambda_{i}^{R}+\lambda_{j}^{C}+\lambda_{k}^{M}+\lambda_{i j}^{R C}+\lambda_{i k}^{R M}+\lambda_{j k}^{R M}+\lambda_{i j k}^{R C M}
$$

To explore the association between $\mathrm{R}$ and $\mathrm{C}$ the log-odds ratio equation is used:

$$
\ln \left(\frac{\pi_{11 k} \pi_{22 k}}{\pi_{12 k} \pi_{21 k}}\right)=\ln \left(\pi_{11 k}\right)-\ln \left(\pi_{12 k}\right)-\ln \left(\pi_{21 k}\right)+\ln \left(\pi_{22 k}\right),
$$

which in turn can be written as:

$$
\ln \left(\frac{\pi_{11 k} \pi_{22 k}}{\pi_{12 k} \pi_{21 k}}\right)=\left(\lambda_{11}^{R C}-\lambda_{12}^{R C}-\lambda_{21}^{R C}+\lambda_{22}^{R C}\right)+\left(\lambda_{11 k}^{R C M}-\lambda_{12 k}^{R C M}-\lambda_{21 k}^{R C M}+\lambda_{22 k}^{R C M}\right)
$$

(Lewis-Beck et al. 2004).

Where the data set has a binary response variable (victim/not) and categorical variables for the explanatory variables then there is a choice between using a log-linear model or a logistic regression model. The logistic regression strength is that it allows for discrete categorical variables as well as explanatory variables and allows the dependent and independent variables to be seen as different in the model (Simkiss, Ebrahim, \& Waterston 2006).

\subsection{Regression}

This section summarises the theory of generalised linear models (GLM), with particular focus on logistic regression. Much of this section is adapted from Tabachnick and Fidell (1996).

\subsubsection{Generalised Linear Model (GLM)}

The relationship between a dependent variable and an explanatory variable are explored by using regression models. The significance of an explanatory variable in the model can be tested while controlling for other explanatory variables. The GLM can be represented by:

$$
g\left(\mu_{i}\right)=x_{i}^{T} \beta
$$


with means $\mu_{i}$ and $g$ is the link function, $\chi_{i}^{T}$ are the explanatory variables, and the unknown regression parameters are represented by $\beta$.

\subsubsection{Regression Models}

The choice of regression model relies on the dependent variables:

- a continuous variable requiring linear regression

- a count variable which requires the use of Poisson regression

- a binary variable which requires logistics regression.

This study used logistic regression which is appropriate because of the binary outcome with sparse explanatories being modelled at the individual level. Logistic regression is the method focused on in this section.

\subsection{Linear Regression}

A linear model can be can be used when the dependent variable is continuous. The general linear model is:

$$
E\left(Y_{i}\right)=\mu_{i}=x_{i}^{T} \beta \quad Y_{i} \sim N\left(\mu_{i}, \sigma^{2}\right) .
$$

\subsection{Poisson Regression}

When the dependent variable follows Poisson distribution Poisson regression is carried out. The GLM for this is:

$$
E\left(Y_{i}\right)=\mu_{i}=n_{i} e^{x_{i}^{T} \beta} \quad Y_{i} \sim \operatorname{Poisson}\left(\mu_{i}\right)
$$

where $Y_{i}$ is the independent random variable, $i$ denotes a particular sub-domain, the average number or rate of events is $\mu_{i}, n_{i}$ is the exposure, the explanatory variables are $x_{i}$ and the regression coefficient to be estimated is $\beta$ under the Poisson regression model the link function is the log function:

$$
\log \mu_{i}=\log n_{i}+x_{i}^{T} \beta
$$

(Dobson, 2002). 


\subsection{Logistic Regression}

Logistic Regression allows prediction of a dichotomous outcome, such as being a victim or not $(1,0)$, from a set of variables that can be discrete, continuous, dichotomous or a combination. Logistic regression provides the same results as the logit form of frequency analysis with a discrete dependent variable.

Logistic regression requires a less stringent set of statistical assumptions which account for the limited nature of the estimates. Logistic regression allows for the departure from assumptions of normal distribution, linearity or equal variance in each group.

The logistic regression model is slightly complex as it is non-linear where $\pi(x)$ (outcome variable, in this study being a victim of IPV or not) is the probability of an outcome variable which is based on a non-linear function of the best linear predictors (Lewis-Beck, Bryman and Liao, 2004). The logistic regression equation is:

$$
\pi(x)=\frac{\exp (\alpha+\beta x)}{1+\exp (\alpha+\beta x)}
$$

for $Y$ (binary response variable) and $X$ (explanatory variable), let $\pi(x)=p(Y=1 \mid X=x)=1-P(Y=0 \mid X=x)$, with a constant $\alpha$, coefficient $\beta$.

This linear regression equation, by taking a linear combination of the explanatory variable, fits an s-shaped curve and creates a logit or log of the odds:

$$
\log i t[\pi(x)]=\log \frac{\pi(x)}{1-\pi(x)}=\alpha+\beta x
$$

The logistic regression equation is therefore the probability of being in one group divided by the probability of being in the other group (Agresti, 2002).

If there is a single explanatory variable that is continuous, the model is:

$$
\log i t[\pi(x)]=\alpha+\beta x
$$


With the hypothesis of independence $H_{o}: \beta=0$, the model probability predicted has the value of:

$$
\hat{\pi}(x)=\frac{\exp (\alpha+\beta x)}{1+\exp (\alpha+\beta x)}
$$

which always lies between 0 and 1 .

The odds ratio is often used to interpret the results of the analysis when $x$ is at two different levels, this is given as:

$$
\frac{\operatorname{odds}(x=a)}{\operatorname{odds}(x=b)}=\frac{\frac{\hat{\pi}(x=a)}{1-\hat{\pi}(x=a)}}{\frac{\hat{\pi}(x=b)}{1-\hat{\pi}(x=b)}}=\exp \left(\alpha+\beta_{a}-\alpha-\beta_{b}\right)=\exp (\beta[a-b]) .
$$

Categorical variables are called 'factors' when they are explanatory and occur at different levels. If $A$ and $B$ are two categorical explanatory variables at levels $I$ and $J$, the value of $\pi\left(x_{i j}\right)$ is the probability of success when $\mathrm{A}$ is at level $i$ and $\mathrm{B}$ is at level $j$. The logistic regression model for categorical explanatory variables is:

$$
\log \left(\frac{\pi\left(x_{i j}\right)}{1-\left(x_{i j}\right)}\right)=\alpha+\beta x_{i}^{A}+\beta x_{i}^{B} .
$$

Assuming no interactions between explanatory variables, once the estimated parameters are known $\alpha, \beta x_{i}^{A}, \beta x_{i}^{B}$, we can calculate the predicted probability:

$$
\hat{\pi}\left(x_{i j}\right)=\frac{\exp \left(\alpha+\beta_{i} x_{i}^{A}+\beta_{j} x_{j}^{B}\right)}{1-\exp \left(\alpha+\beta_{i} x_{i}^{A}+\beta_{j} x_{j}^{B}\right)} .
$$




\subsubsection{Type of Models}

Comparisons need to be made between models when using logistic regression to ensure the model of choice is the one with the best fit with the minimum number of parameters.

\subsubsection{2 .1 Maximal model}

When there is a parameter for each observation $\pi(x)=y_{i}$ this is called the maximal model. Comparisons with other models are made against this maximal model:

$$
E\left[Y_{i}\right]=\pi(x)
$$

\subsection{Model with interaction terms}

A more complex regression model can occur when explanatory variables interact together. An example of an interaction included in the regression model containing two continuous explanatory variables $x_{i}$ and $v_{i}$ would be:

$$
\log i t[\pi(x)]=\alpha+\beta_{1} x_{i}+\beta_{2} v_{2}+\beta_{3} x_{i} v_{i}
$$

The interaction term $\beta_{3} x_{i} v_{i}$ should only be present in the model when $\beta_{1} x_{1}$ and $\beta_{2} v_{i}$, the main effect terms, are also present in the model.

\subsection{Model excluding interaction terms}

A less complicated model can be given when no interactions are present between explanatory variables:

$$
\log i t[\pi(x)]=\alpha+\beta_{1} x_{i}+\beta_{2} v_{i}
$$




\subsection{Null Model}

Where there is only one parameter, the intercept, then the null model has the form:

$$
\log i t[\pi(x)]=\alpha
$$

\subsubsection{Selection of a Model}

\subsubsection{Log-Likelihood}

Logistic regression can be used to compare models, the simplest model (with just one constant and no predictors) compared with a more complex model (that has a constant, all predictors and maybe some interaction terms between predictors). A goodness-of-fit test is used to choose the model that best predicts the outcome variable with the fewest predictors. A log-likelihood is calculated to test the goodnessof-fit which is based on the sum of the probabilities associated with the actual and predicted outcomes for each case:

$$
\text { Log-likelihood }=\sum_{i=1}^{n}\left[Y_{i} \log \left(\hat{Y}_{i}\right)+\left(1-\hat{Y}_{i}\right) \log \left(1-\hat{Y}_{i}\right)\right]
$$

\subsubsection{Individual Parameter Tests}

Testing and interpreting coefficients in logistic regression are carried out using maximum likelihood methods which in turn are used to evaluate the fit of the model. The statistical significance for each coefficient present in an acceptable model is evaluated using the Wald statistic where the coefficient is divided by its standard error (a $Z$ statistic):

$$
W_{j}=\frac{B_{j}}{S E_{B J}} .
$$




\subsubsection{Stepwise Logistic Regression}

Stepwise logistic regression selects a variable in a sequential manner that is deemed to be a key variable for explaining the model. Stepwise logistic regression can either take on a forward or backward movement and utilises the likelihood ratio test to decide which variables to keep in the model, or to drop from the model. This method permits the assessment of many models which may otherwise not have been looked at.

Forward selection is the most popular option where the initial model contains only the constant. From here explanatory variables are added one at a time until the cut-off level is reached and adding anymore variables to the model will not improve the model, that is that all variables that are left from the model have a significance level greater than 0.05. Backwards selection is the reverse where the initial model contains all the explanatory variables and from here deletes one variable at a time (deleting highest $p$ value first) until the point where no additional terms would significantly reduce the deviance $(<0.05)$ if added.

\subsubsection{Use of weights}

Research suggests that by using sampling weights in a logistic regression, it is only the intercept term that is affected. However there is an increased risk of bias if the dependent variable and the sampling probabilities are related therefore warranting caution when using un-weighted data.

In this thesis, however, all factors that were used to determine the individual weights (age, sex, ethnicity) were included in the regression model, making it justifiable to fit the regression without using weights.

\subsubsection{Assumptions of Logistic Regression}

Logistic regression is more flexible than other methods discussed and it is based on a set of different, less stringent assumptions. These are:

- that variables can take only two values, which are independent of each other

- the "error" terms are not continuous, homoskedastic, or normally distributed

- the predicted probabilities are constrained to behave linearly and not to be greater than zero 
(Lewis-Beck, Bryman and Liao, 2004; Tabachnick \& Fidell 1996).

However, other assumptions still apply including:

- meaningful coding so analysis of the output is meaningful

- inclusion of all relevant variables in the regression model so that the model best predicts the outcome variable

- exclusion of all irrelevant variables as they may be included in the regression model as a correlate of other outcome variables, effecting the standard errors of the regression coefficients for the outcome variable

- $\quad$ error terms are assumed to be independent (independent sampling)

- low error in the explanatory variables

- linearity is assumed between the independents and the log odds (logit) of the dependent

- multicollinearity cannot exist, where one independent variable is a linear function of another independent variable

- no outliers as they can significantly impact on the regression model

- large samples are required as the maximum likelihood estimation (MLE) used in regression modelling and relies on large-sample asymptotic normality

(Tabachnick and Fidell, 1996).

\subsubsection{Diagnostic tests}

Diagnostic tests need to be carried out for each model to ensure that logistic regression assumptions are met and a satisfactory model fit is found.

\subsubsection{Goodness-of-Fit Test}

By comparing the difference in two models a chi-square can be used where all the components in the smaller model are present in the bigger model:

$$
\chi^{2}=2[(\log \text {-likelihood for bigger model)-(log-likelihood for smaller model)] }
$$

where the degrees of freedom (df) is:

df (bigger model) - df (smaller model). 
This $\chi^{2}$ (goodness-of-fit) process is also used to evaluate predictors that are added to a smaller model. In general the log-likelihood increases / decreases as predictors are deleted / added. In comparing the models we look at how significant the log-likelihood increases/decreases as predictors are deleted / added.

This $\chi^{2}$ test statistic follows a chi-squared distribution $\chi^{2}(\mathrm{~N}-\mathrm{P})$, where $\mathrm{N}$ is the number of observations and $P$ is the number of parameters estimated. It is essentially measuring that the model holds $\left(H_{o}\right)$ vs the model does not hold $\left(H_{A}\right)$.

\subsubsection{Interpretation and Analysis of Residuals}

For each case, residuals are calculated and then standardised to be assessed on their fit to the model. Graphs can be plotted of these residuals to ensure no outliers are present and that the residuals are random.

Raw residuals are calculated simply as the difference between observed and expected value based on the model, this is shown as:

$$
\text { Residual }=y_{i}-n_{i} \hat{p}_{i}
$$

where the observed counts are $y_{i}$ in cell $i$, and the population counts are $n_{i}$, and the predicted probabilities from the model are $\hat{p}_{i}$.

However it is often more practical to use standardised residuals as the raw residuals do not account for group size differences. The formula for standardised residuals is:

$$
\text { Residuals }_{s t d}=\frac{y_{i}-n_{i} \hat{p}_{i}}{\sqrt{\operatorname{Var}\left(n_{i} \hat{p}_{i}\right.}}
$$

The calculated residuals are required to lie within \pm 3 standard deviations of the mean. There is an assumption that the data used on this calculation is not sparse. 


\subsubsection{Sparse data}

When a dependent variable has a low chance of occurring, sparse data can occur as many of the regression cells, $n_{i}$, have low or zero observations. When using techniques such as regression, results can mean that the model is over fitted meaning the data cannot support too many parameters. This has implications in that as you add more explanatory variable this can result in the fitted values becoming more like the observed values. This has implications on the parameter estimates which will undergo large changes. There are also problems with sparse data which can mean that a goodness-of-fit test is no longer usable.

\subsection{Methods}

All statistical analysis for this research was computed using the statistical computer software SAS v9.1. Graphs were produced in Excel. This section outlines the methods used for the analysis of this survey data.

\subsubsection{Ethnicity coding}

\subsubsection{Coding Ethnicity}

Classification of ethnicity was self-identified by the participant, where they were asked to identify one or more ethnic groups that they identified with. For analysis these responses were then classified in to groups for analysis. Two modes of classification can be used:

- total response output

- prioritised response output

(Statistics New Zealand, 1995).

The total response mode records each individual in as many ethnic groups as they identify with. The result is an ethnicity count for the survey higher than the actual participant count, as individuals can be recorded in more than one ethnic category.

In the prioritised response mode individuals are assigned to only one ethnic group. The hierarchical classification rule is applied. This means that each participant is counted only once and the number of participants in the survey is the same as the total sum of 
all the ethnic groups. This classification mode means that the size of each ethnic group will be underestimated, except the group 'Māori' where anyone that records Māori as one or more of their ethnicities, will be placed in this ethnic category (Ministry of Health, 2001b).

In this thesis prioritised classification was used, where individuals were coded by ethnicity using a hierarchical method. Ethnicity was prioritised in the following mutually exclusive categories:

- Māori : any reporting of Māori

- Pacific: reporting as Pacific, except where they report being Māori also

- NZ European: where state NZ European and do not report being Māori or Pacific

- Other: any other ethnicity where they did not report being Māori , Pacific or NZ European

- "Refused": those who did not report their ethnic group.

The overall number of respondents who responded to the lifetime and 12 month section differed (see discussion in Chapter Three). The following table (4.3) shows the number or respondents by ethnicity used in this thesis:

Table 4.3: Actual sample size used for this thesis, by ethnicity.

\begin{tabular}{|l|c|c|}
\hline Ethnicity & Lifetime analysis & $\mathbf{1 2}$ Month analysis \\
\hline NZ European & 2413 & 1897 \\
\hline Māori & 690 & 475 \\
\hline Pacific & 462 & 348 \\
\hline Other & 218 & 183 \\
\hline
\end{tabular}

\subsubsection{Sole versus Mixed Māori}

The table below (table 4.1) shows the elevated sole Māori rates in reporting ethnicity, this is compared to the Census (2001). This shows the low number of respondents in the NZNSCV (2001) who report as being sole Māori, which is significantly lower than those who responded in the Census (2001). This indicates that reporting by sole versus mixed ethnicity is incomplete as the people in the NZNSCV reported differently to the New Zealand population (as reported in the Census, 2001). This means that using sole Māori figures will add biases to the estimates (Allan, 2001). Hence the use 
of Māori as a single variable, including those that state only Māori as their ethnicity and those that include Māori and 'other' ethnicities when responding to the survey, was done in this analysis to minimise biases to the estimates.

Table 4.1: Māori - Lifetime Data

\begin{tabular}{|l|c|c|c|}
\hline Māori & Sole & Total & $\%$ \\
\hline NZNSCV & 185 & 484 & 38 \\
\hline Census 2001 & 294,726 & 231,801 & 56 \\
\hline
\end{tabular}

Table 4.2: Māori - 12 months Data

\begin{tabular}{|l|c|c|c|}
\hline Māori & Sole & Total & $\%$ \\
\hline NZNSCV & 263 & 755 & 35 \\
\hline Census 2001 & 294,726 & 231,801 & 56 \\
\hline
\end{tabular}

\subsubsection{Simple univariate analysis}

Weighted data was used when calculating point estimates so that the data represented the New Zealand population. All weights were provided by the Ministry of Justice in the dataset. The variances were calculated for the point estimates, and these variances were used to calculate the sampling error. For each point estimate $95 \%$ confidence intervals and relative sampling errors were calculated.

\subsubsection{Combining cells with low counts}

Due to small cell counts in some levels of the explanatory variables, some cells were combined. This was the case for the variables:

- age - 15-16 years and 17-24 years were combined

- ethnicity - Asian was included in 'other' as it was a small number of respondents and a diverse range of ethnic groups within the label 'Asian"

- number of people in the household - categories were combine for households with seven people or more

- number of people in the household under 16 years - categories were combined for households with four or more under 16 year olds. 
Low cell counts meant levels of victimisation were unable to be calculated, therefore some dependent variable sub-groups needed to be aggregated.

\subsubsection{Chi-squared test}

To test the relationships between the key variables and being a victim (or not), chisquared testing was carried out. The variable 'victim' was a dichotomous response (yes/no). All other variables were categorical to allow for this analysis. A list of output tables for each variable show which variables have a significant relationship with the dependent variable. The variables 'gender' and 'main income earner' were found to be not significant in explaining victimisation over the 12 month period but were significant factors over a lifetime, as a result these variables were left in the log linear analysis and logistic regression analysis along with all the other significant variables.

\subsubsection{Log linear model}

As the variables were discrete categorical variables, log linear modelling was used to measure the relationship between the variables. SAS v9.1 was used to calculate the log linear model. The procedure PROC CATMOD was used to carry out this analysis. All the variables were able to be put into this model to allow for the exclusion of variables that do not add value to the model in explaining being a victim. Multi-way frequency tables were produced and a model was identified as the best fit to the data.

This technique does not explicitly identify the dependent variable (in this case being a victim or not), however this relationship in the model can be made explicit as it was in this model.

\subsubsection{Logistic Regression analysis methodology}

Logistic regression was carried out to model the risk factors for intimate partner violence.

\subsubsection{Regression coefficients}

Following the log linear modelling, logistic regression was carried out. The log linear model and the logistic regression model provide a mathematically similar model but the 
logistic regression model allows us to more explicitly identify the dependent variable in the model (Lewis-Beck, Bryman and Liao, 2004).

SAS v9.1 was used to calculate the regression coefficients for each model. The procedure PROC REG was used to carry out the logistic regression analysis and the selection: STEPWISE was specified to fit a generalised linear model to the data. The options for using logit link and binomial distribution were specified for the logistic regression modelling. The SAS user guide (SAS Institute, 1990) was used as a reference for SAS programming.

\subsubsection{Use of sample weights}

As stated earlier, sampling weights can be ignored when using complex survey data in carrying out a logistic regression as it is only the intercept term that is affected (Prentice and Pyke 1979, cited in Lohr, 1999).

The sample design for the NZNSCV (2001) included one of the key explanatory variables, 'ethnicity', a key part of the sample selection process. The sample weights provided with the NZNSCV (2001) will be correlated with ethnicity, and although it is not expected that the weights will cause any bias in the results, this is also likely.

Weighs were not used in this analysis as the unweighted data was viewed to provide more conservative estimates in the regression analysis.

\subsubsection{Modelling Intimate Partner Violence against risk factors}

First a model was run with all explanatory variables. The Wald test was used to test risk factors. Interactions were tested using the stepwise procedure. Only those participants who had responses for every risk variable were included in the model.

The explanatory variables used were age, gender, ethnicity, living situation, household tenure, employment status, main income earner, marital status, number of people in the household, and number of people in the household under 16 years old, and NZSEI group.

The variable age was aggregated for 15-16 years and 17-24 year olds (new age variable 15-24 years old). The variable ethnicity was also combined with the category 
'Asian' being included in 'other' as it was a small number of respondents and a diverse range of ethnic groups within the label 'Asian'. Due to small cell counts some categories for 'number of people in the household' and 'number of people in the household under 16 years' were combined.

\subsubsection{Diagnostic tests}

Diagnostic plots were made for each model with both raw and standardised residuals, for regression cell count $n_{i}$. This was done to ensure there were no outliers in the models or any trends, meaning that the residuals appear to be random. Checking for linear trends is also necessary, so observed counts were graphed against fitted counts in each cell for each different subgroup. Residuals were sometimes re-plotted after cells with low counts were aggregated (where up to $70 \%$ of regression cells had no observation event). 


\section{Chapter Five}

\section{Results}

This chapter starts with the simple univariate analysis of victims of violence by an intimate partner (IPV) (with findings from NZNSCV, Morris and Reilly, 2003). This is followed by a discussion of significant risk factors for IPV identified from the logistic regression.

Section 5.1 presents data from the original survey (Morris and Reilly 2003) and sections 5.2 to 5.4 presents the analysis undertaken for this thesis. Full results of the analysis can be found in appendix $\mathrm{C}$ to $\mathrm{F}$.

\subsection{Intimate Partner Violence Victimisation}

\subsubsection{Life-time victimisation}

In the 2001 NZNSCV, four screening questions were used to determine if a participant was a victim of intimate partner violence over their lifetime. The specific screen questions used to identify intimate partner violence as victim in the NZNSCV (Morris and Reilly, 2003) were:

- Has any partner EVER actually used force or violence on you, such as deliberately hit, kicked, punched, grabbed or shoved you, or deliberately hit you with something, in a way that could have hurt you?

- Has any partner EVER threatened to use force or violence on you, such as threatened to hit, kick, push, grab or shove you, in a way that actually frightened you?

- Has any partner EVER deliberately destroyed, damaged or harmed something belonging to you, or threatened to do any of these things, in a way that actually frightened you?

- Has any partner EVER used a weapon against you, or threatened to use a weapon against you, such as a knife or gun or any other weapon? 
Figure 5.1 shows that for women, over $25 \%$ report having experienced one or more of these behaviours in their lifetime while nearly $20 \%$ of men report having also experienced one or more of these behaviours.

Figure 5.1: Prevalence of violence for males and females EVER experienced by a partner (in a heterosexual relationship).

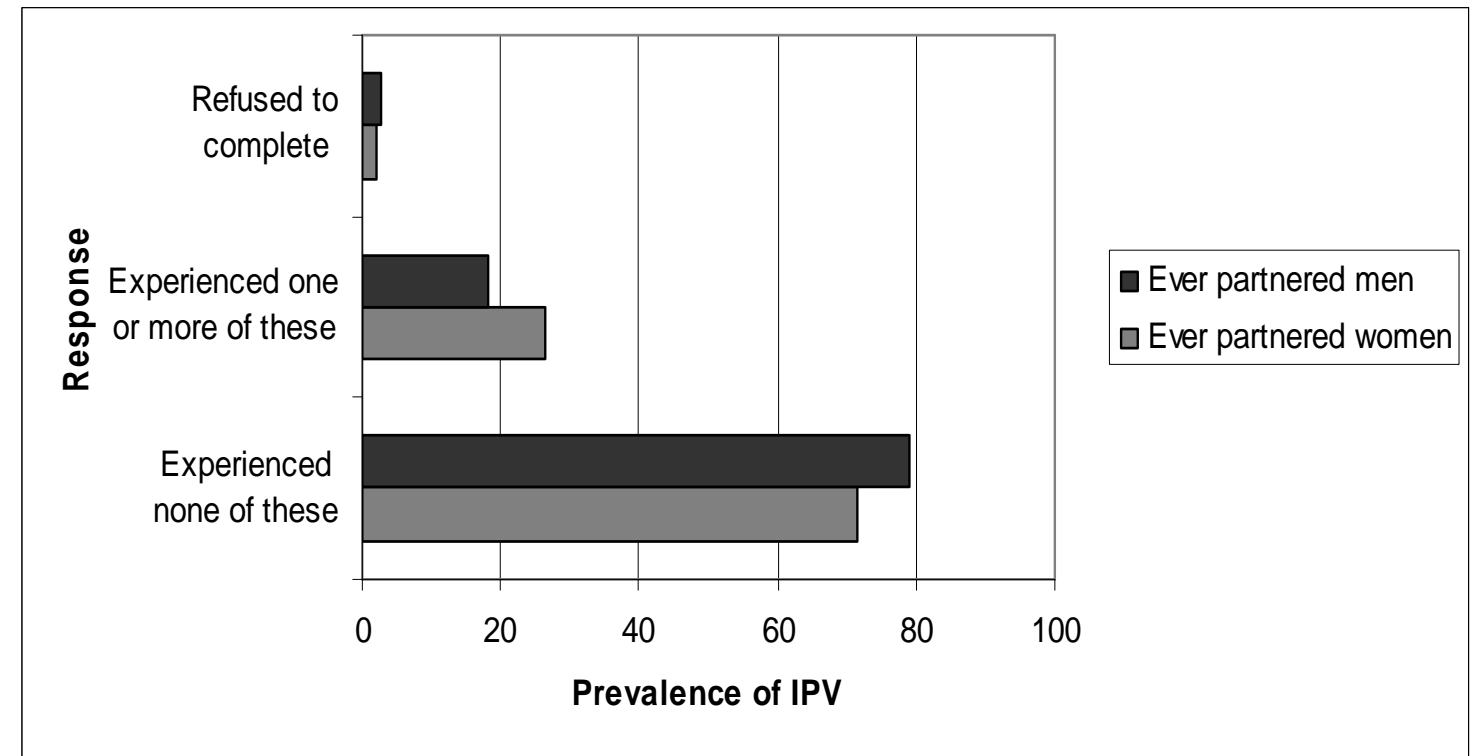

From NZNSCV, Morris and Reilly, 2003. The full results can be found in Table 2.1.

\subsubsection{Victimisation over Past 12 months}

The same four screening questions (in section 5.1.1) were used to determine whether a participant was a victim of partner violence in the past 12 months (2000). The question was changed so participants were asked about the 'previous 12 month period' instead of 'ever'.

- Since 1 January 2000, has a current partner actually used force or violence on you, such as deliberately hit, kicked, punched, grabbed or shoved you, or deliberately hit you with something, in a way that could have hurt you?

- Since 1 January 2000, has a current partner threatened to use force or violence on you, such as threatened to hit, kick, push, grab or shove you, in a way that actually frightened you?

- Since 1 January 2000, has a current partner deliberately destroyed, damaged or harmed something belonging to you, or threatened to do any of these things, in a way that actually frightened you? 
- Since 1 January 2000, has a current partner used a weapon against you, or threatened to use a weapon against you, such as a knife or gun or any other weapon?

Figure 5.2 shows the incidence and prevalence of violence experienced by heterosexual partners in 2000. The figures show that three percent of women in a current relationship reported having experienced at least one of these types of violent incidents, while one point eight percent of men reported such an experience.

Figure 5.2: Prevalence of violence for males and females by a current partner (in a heterosexual relationship) in 2000.

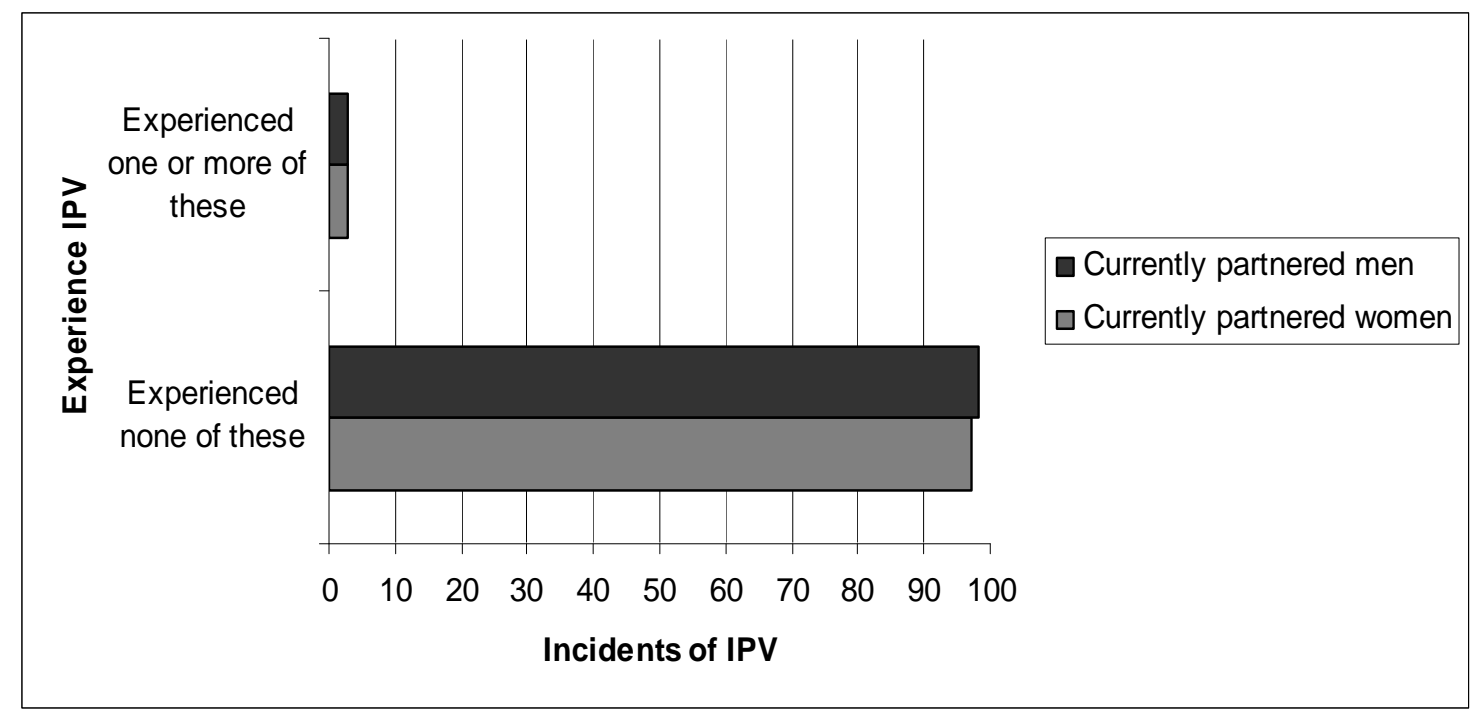

From NZNSCV, Morris and Reilly, 2003. The full results can be found in Table 2.5.

Table 5.1 shows the number of times a victim was assaulted by a current partner. Only one percent of people reported being assaulted by a partner but for over $40 \%$ of those that were assaulted they experienced more than one incident with nine point five percent reporting five or more assaults. This shows that repeat victimisation is high within the context of IPV (NZNSCV 2001). 
Table 5.1: Frequency of victimisation for assault by current partner in 2000

\begin{tabular}{|c|c|c|c|}
\hline Times Victimised & $\begin{array}{l}\text { Percent of all } \\
\text { people }\end{array}$ & $\begin{array}{l}\text { Percent of those } \\
\text { victimised }\end{array}$ & $\begin{array}{l}\text { Percent } \\
\text { victimisations }\end{array}$ \\
\hline 0 & 99.0 & NA & 25.7 \\
\hline 1 & 0.6 & 58.8 & 20.6 \\
\hline 2 & 0.2 & 23.6 & 5.4 \\
\hline 3 & 0.04 & 4.2 & 6.7 \\
\hline 4 & 0.04 & 3.9 & 41.5 \\
\hline 5 or more & 0.1 & 9.5 & \\
\hline Prevalence & 1.0 & & \\
\hline
\end{tabular}

Sample size (people): 5147. Morris and Reilly, 2003.

\subsubsection{Impact on Intimate Partner Violence}

\subsubsection{Reactions of the Victims}

In the survey, respondents were asked how the incidents affected them. Figure 5.3 shows that for women, the impact of IPV was much greater than for men, with over $60 \%$ of women reporting being affected "very much" or "quite a lot" compared with $33 \%$ of men. Men were more likely to report the incidents having "just a little effect" (58\%).

Figure 5.3: Overall effects of violence by current heterosexual partners on the victim where some reaction, by sex: percentages

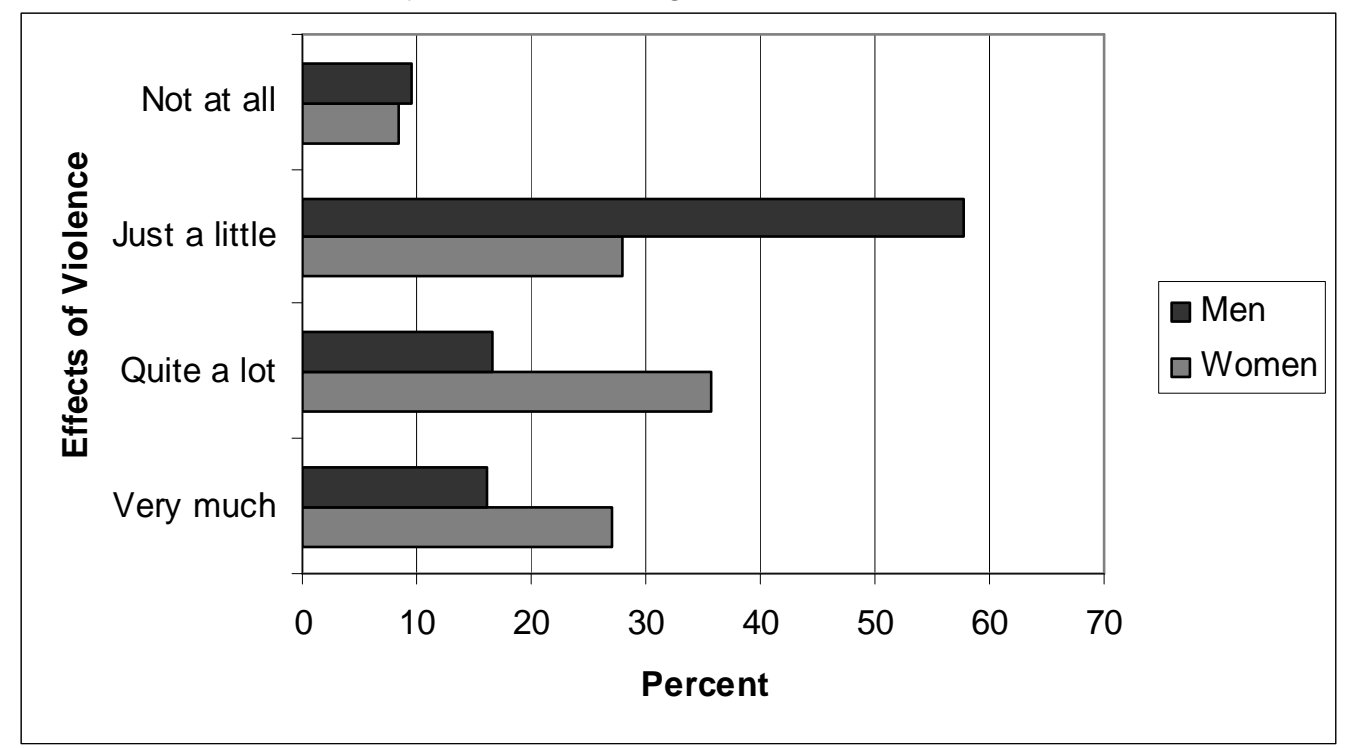

Morris and Reilly, 2003. 
Respondents were also asked what, if any, reaction they had to the IPV incident. Figure 5.4 shows victim's reactions to violent incidents that they experienced. Anger was the most common response to IPV by both men and women. The difference in reaction between males and females were seen by the second most reported reaction. For females this was that they cried (59.2\%), while significantly less men reported crying $(12.7 \%)$ as their reaction. For men however the second most reported reaction was shock at $41.7 \%$. Women were also more likely to report feeling 'fear for their children'. For men, they were much more likely to report increasing their use of alcohol, drugs and medications.

Overall for men, seven percent reported experiencing no reaction at all, compared to none of the females (zero percent). This could be explained by the men having experienced less serious violence. This figure highlights that although violence is reported at the same rate between men and women, for men and women their reactions to the violence are different (Morris and Reilly, 2003).

Figure 5.4: Victims' reactions to violent incidents by current heterosexual partners, by sex: percentages reporting each reaction

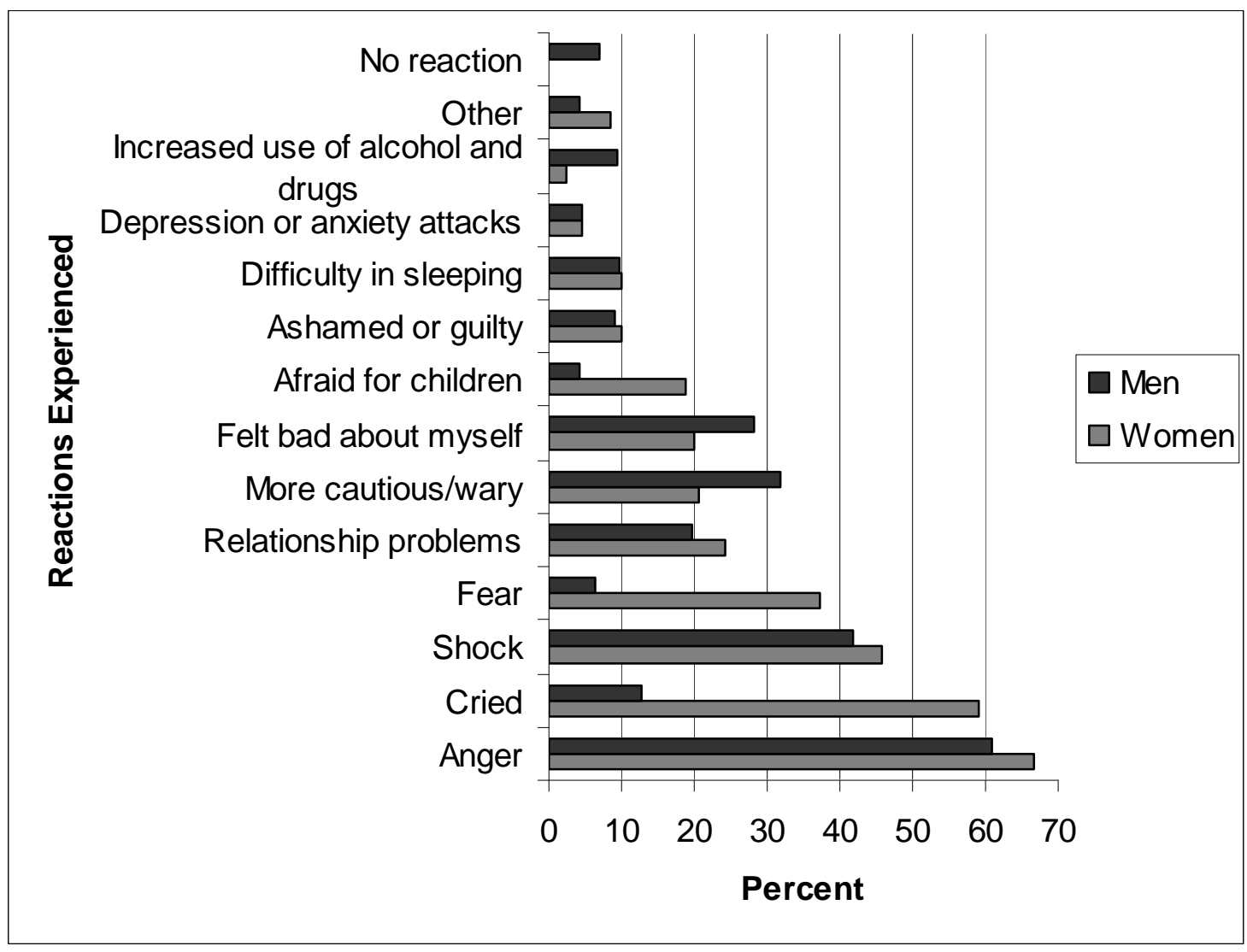

Note: multiple responses are possible. Morris and Reilly, 2003. 


\subsubsection{Type of injuries}

Injuries were reported for only one fifth of participants in the survey who experienced IPV. The most commonly reported injury was bruised or black eyes (over three quarters). Scratches were reported by only one quarter of participants and less than two percent reported broken bones and less than one percent reported internal injuries from IPV incidents. Only one fifth of these participants who experienced IPV reported seeking medical attention (Morris and Reilly, 2003).

\subsection{Risk factors for Intimate Partner Violence over a lifetime}

The following section gives descriptive results by demographic groups for IPV victims over a lifetime. Chi-square tests were carried out on the survey data to discover whether being a victim (1) or not $(0)$ is independent of other variables. These results only test one risk factor at a time using simple univariate analyses, without controlling for other factors. Some differences may be due to correlations between other variables. To allow for these correlations, a regression analysis was used. However statistical significance within a chi-square test does denote some confidence that the relationships between variables are more than random error. Chi-squared analysis provides information on the probability of dependence between variables; it does not provide information about the strength of an association (Lewis-Beck et al, 2004).

\subsubsection{Demographic risk factors}

\section{Age}

The results from the lifetime prevalence table (Table 2.2) show that younger age groups report higher levels of IPV violence. O'Donnell et al (2002), West (1998) and Mouzos and Makkai (2004) suggest that it would make sense for older people to report higher levels of IPV, as they have had a longer time period to experience violence, however this does not seem to be so in overseas data and in this New Zealand data.

Lifetime prevalence by age group showed that for those aged 15-24 years $(n=291)$, one third had experienced one or more of those behaviours listed. This figure rose to $53.7 \%$ for 25-39 year olds ( $n=1301)$. Thirty-four point six percent of 40-59 year olds $(n=1435)$ reported some form of violence, while only $12 \%$ of the 60 and over group 
$(\mathrm{n}=755)$ reported any violent events. Overall those aged under 60 years report higher rates of lifetime victimisation that those 60 years and older.

Results from the chi-square test indicate that this reported difference in lifetime prevalence for different age groups is significant with $\left(\chi^{2}(3)=151.83, p<.001\right)$. We can conclude that age is not independent of being a victim or not, that is that being a certain age will increase (or decrease) the risk of being a victim of intimate partner violence.

\section{Gender}

Women reported a higher prevalence of lifetime IPV than did men, $26.4 \%$ compared to $18.2 \%$ respectively (Morris and Reilly, 2003). Chi-squared analysis indicates that this reported rate of IPV between males and females is significant $\left(\chi^{2}(1)=84.09, p\right.$ $<.001)$. It would seem that gender is not independent of them being a victim or not.

\section{Ethnicity}

For Māori the reported rate of lifetime violence by a partner is much higher than for any other ethnic group. For Māori the prevalence of one or more violent behaviours was reported as 39.3\% while for New Zealand European, $21.4 \%$ reported partner violence. For both Pacific people and 'others' the reported level of lifetime violence was $17 \%$.

The chi-square test for ethnicity shows these differences to be highly significant between being a victim, or not, $\left(\chi^{2}(3)=128.81, p<.0001\right)$. Ethnicity is a factor associated with being a victim of intimate partner violence.

\section{Mixed versus sole-Māori}

Some research (Nickerson, 2004) supports a difference in findings of IPV when looking at those who self-identified at mixed versus sole Māori. For the lifetime prevalence data a chi-squared was carried out, no significant difference was found, $\left(\chi^{2}(1)=0.0008, p\right.$ $=0.9776$ ). Therefore we can conclude that being a victim, or not, is independent of identifying as sole Māori or mixed Māori. 


\subsubsection{Socioeconomic risk factors}

\section{Socio-economic (NZSEI) group}

Across the different socio-economic groups, little difference was seen in reported lifetime prevalence, except for those in the NZSEI 30-39 group who consistently reported higher rates of violent behaviours. The chi-squared results indicate that there is a significant difference between NZSEI groups and being a victim, $\left(\chi^{2}(6)=92.87, p\right.$ $<.0001)$. NZSEI group is not independent of the being a victim or not.

\section{Household tenure}

The results indicated that there is a significant difference between whether or not an individual owns or rents a house, and being a victim, $\left(\chi^{2}(2)=113.07, p<.0001\right)$. This indicates that level of household tenure is not independent of being a victim of intimate partner violence.

\section{Living situation}

Living situation refers to how the household is comprised. This variable has three subcategories: couples living with children, living alone or with extended family. These results indicate that there is a significant difference between living situation and being a victim, $\left(\chi^{2}(5)=411.56, p<.0001\right)$. We can conclude that living situation is not independent of them being a victim or not.

\section{Number of people living in households}

Research suggests that the more people living in a dwelling, and the more dependants that they have, the greater the risk of violence occurring (National Health Committee, 1998; Gray 2001).

Results indicate that there is a significant difference between the number living in a household and being a victim, $\left(\chi^{2}(6)=110.34, p<.0001\right)$. These results also indicate that there is a significant difference between the number of people under 16 years of 
age in a household $\chi^{2}(4)=72.08, p<.0001$. This suggests being a victim or not is not independent of the number of people living in the household.

\section{Main income earner}

Chi-squared results indicate that there is a significant difference between being the main income earner and being a victim, $\chi^{2}(1)=12.20, p=0.0005$. It seems that being the main income earner is not independent of them being a victim or not.

\section{Employment status}

Results from the chi-squared test indicate that there is a significant difference between employment status and being a victim, $\left(\chi^{2}(4)=225.93, p<.0001\right)$. It seems that employment status is related to being a victim or not.

\section{Marital status}

The variable marital status had four sub-categories: those in de-facto relationships, divorced or separated, legally married or single-never married. The results indicate that there is a significant difference between marital status and being a victim, $\left(\chi^{2}(3)=\right.$ 426.70, $p<.0001$ ), indicating that being a victim of IPV is not independent of marital status. 
Table 5.2: Summary of Risk factors for Intimate Partner Violence over a lifetime

\begin{tabular}{|c|c|c|c|}
\hline Variable & Significant & p-value & Comment \\
\hline Age & $\nabla$ & $p<.001$ & $\begin{array}{l}\text { The results for lifetime prevalence show } \\
\text { that younger age groups report higher } \\
\text { levels of violence. }\end{array}$ \\
\hline Gender & $\square$ & $p<.001$ & $\begin{array}{l}\text { Women reported a higher prevalence of } \\
\text { lifetime IPV than did men. }\end{array}$ \\
\hline Ethnicity & $\square$ & $p<.001$ & $\begin{array}{l}\text { For Māori the reported rate of lifetime } \\
\text { IPV by a partner is much higher than for } \\
\text { any other ethnic group. This was lowest } \\
\text { for Pacific and 'other' ethnic groups. }\end{array}$ \\
\hline $\begin{array}{l}\text { Mixed versus sole- } \\
\text { Māori }\end{array}$ & 冈 & $p=0.9776$ & $\begin{array}{l}\text { No difference was found between those } \\
\text { who self-identified as Māori (sole) and } \\
\text { those who identified as Māori and } \\
\text { another ethnicity (mixed). }\end{array}$ \\
\hline $\begin{array}{l}\text { Socio-economic } \\
\text { (NZSEI) group }\end{array}$ & $\square$ & $p<.001$ & $\begin{array}{l}\text { Those in the NZSEI30-39 group who } \\
\text { consistently reported higher rates of } \\
\text { IPV. }\end{array}$ \\
\hline Household tenure & $\square$ & $p<.001$ & $\begin{array}{l}\text { Reported household tenure was a } \\
\text { significant factor in reporting IPV } \\
\text { victimisation or not. }\end{array}$ \\
\hline Living situation & $\square$ & $\mathrm{p}<.001$ & $\begin{array}{l}\text { Solo parents with children were more } \\
\text { likely to report IPV than those living with } \\
\text { a partner and those living alone with no } \\
\text { children. }\end{array}$ \\
\hline $\begin{array}{l}\text { Number of people } \\
\text { living in households }\end{array}$ & $\square$ & $p<.001$ & $\begin{array}{l}\text { The more people living in a dwelling, } \\
\text { and the more dependants that they } \\
\text { have, the greater the risk of IPV } \\
\text { occurring. }\end{array}$ \\
\hline Main income earner & $\square$ & $p<.0005$ & $\begin{array}{l}\text { Where the respondent was the main } \\
\text { income earner (or not) this was reported } \\
\text { as a significant factor in IPV. }\end{array}$ \\
\hline Employment status & $\nabla$ & $p<.001$ & $\begin{array}{l}\text { Those who reported being on social } \\
\text { welfare benefit were more likely to } \\
\text { report IPV in their lifetime. }\end{array}$ \\
\hline Marital status & $\square$ & $p<.001$ & $\begin{array}{l}\text { Divorced or separated respondents } \\
\text { reported a higher rate of IPV than other } \\
\text { marital situations. }\end{array}$ \\
\hline
\end{tabular}




\subsection{Risk factors for Intimate Partner Violence over a 12 month period}

The following section gives descriptive results by demographic groups for IPV victims over a 12 month period (2000). Chi-square tests were carried out to discover whether being a victim (1) or not (0) is independent of other variables.

\subsubsection{Demographic risk factors}

\section{Age}

Results from the chi-square test showed a significant result between age and being a victim, $\left(\chi^{2}(3)=106.54, p<.001\right)$. Age is not independent of those who report being a victim or not.

\section{Gender}

Women reported a higher prevalence of IPV over a 12 month period than did men by more than twice as much. Of those who were 'currently partnered', $3 \%$ of women reported experiencing one or more violent behaviours, compared to $1.8 \%$ of men (NZNSCV, 2001). However Chi-squared results indicate that this reported rate of violence between males and females is not significantly different, $\left(\chi^{2}(1)=2.07, \mathrm{p}=\right.$ 0.15). Therefore, we can conclude that being a victim, or not, is independent of gender.

\section{Ethnicity}

The chi-square test for ethnicity and victimhood shows these differences to be highly significant, $\left(\chi^{2}(3)=71.21, \mathrm{p}<.0001\right)$. We can conclude that ethnicity is not independent with being a victim, or not, of intimate partner violence.

\section{Mixed versus sole-Māori}

For the 12 month prevalence data a chi-squared was carried out to see if there was a difference in victimisation between those who identified as sole Māori versus those who identified as Māori and another ethnicity (mixed). No significant difference was 
found, $\left(\chi^{2}(1)=0.0038, p=0.9508\right)$. Therefore we can conclude that being a victim, or not, is independent of identifying as sole Māori or mixed Māori.

\subsubsection{Socioeconomic risk factors}

\section{NZSEI group}

Results indicate that there is a significant difference between NZSEI groups and being a victim, $\left(\chi^{2}(6)=35.75, \mathrm{p}<.0001\right)$. We can conclude that being in a particular NZSEI group will increase (or decrease) the risk of being a victim of intimate partner violence.

\section{Household tenure}

The chi-squared results indicate that there is a difference between whether or not an individual owns or rents a house, and being a victim, $\left(\chi^{2}(2)=67.74, p<.0001\right)$. This indicates that level of household tenure is not independent of being a victim of intimate partner violence.

\section{Living situation}

These results indicate that there is a significant difference between living situation and being a victim, $\left(\chi^{2}(8)=42361.06, p<.0001\right)$. Therefore, we can conclude that living situation is not independent of the being a victim or not.

\section{Number of people living in households}

Research suggests (National Health Committee, 1998; Gray 2001) that the more people living in a dwelling and the more dependants of the respondents, the greater the risk for violence to occur. Results from the chi-square analysis support this with a significant difference between the number living in a household and being a victim, $\left(\chi^{2}(6)=42.69, \mathrm{p}<.0001\right)$. These results also indicate that there is a significant difference between the number of people under 15 years of age in a household $\left(\chi^{2}(4)\right.$ $=37.55, p<.0001)$. Therefore, we can conclude that the number of people living in a household is not independent of them being a victim or not. 


\section{Main income earner}

A chi-squared test was carried out to see if there is a relationship between reported intimate partner violence (in the previous 12 month period) and whether or not the respondent was the main income earner. Results $\left(\chi^{2}(1)=0.03, p=0.86\right)$ indicate that being the main income earner is independent of them being a victim or not.

\section{Employment status}

Results from the chi-squared test indicate that there is a significant difference between employment status and being a victim, $\left(\chi^{2}(4)=72.91, \mathrm{p}<.0001\right)$. Therefore, we can conclude that employment status is not independent of the being a victim or not

\section{Marital status}

Results of a chi-squared analysis indicate that there is a significant difference between marital status and being a victim, $\left(\chi^{2}(3)=113.24, p<.0001\right)$, implying that being a victim of partner violence has some dependence on marital status. 
Table 5.3: Summary of Risk factors for Intimate Partner Violence over a 12 month period

\begin{tabular}{|c|c|c|c|}
\hline Variable & Significant & $p$-value & Comment \\
\hline Age & $\nabla$ & $p<.001$ & $\begin{array}{l}\text { Results indicate that reported age } \\
\text { of respondents is significant, with } \\
\text { younger age groups reporting } \\
\text { higher rates of IPV. }\end{array}$ \\
\hline Gender & $\mathbf{x}$ & $p=0.15$ & $\begin{array}{l}\text { Results indicate that reported rates } \\
\text { of IPV between males and females } \\
\text { were similar over the } 12 \text { month } \\
\text { period. }\end{array}$ \\
\hline Ethnicity & $\nabla$ & $p<.001$ & $\begin{array}{l}\text { Differences were found in IPV } \\
\text { reporting between different ethnic } \\
\text { groups. }\end{array}$ \\
\hline $\begin{array}{l}\text { Mixed versus sole- } \\
\text { Māori }\end{array}$ & 可 & $p=0.9508$ & $\begin{array}{l}\text { No difference was found between } \\
\text { those who self-identified as Māori } \\
\text { (sole) and those who identified as } \\
\text { Māori and another ethnicity } \\
\text { (mixed). }\end{array}$ \\
\hline $\begin{array}{l}\text { Socio-economic } \\
\text { (NZSEI) group }\end{array}$ & $\square$ & $p<.001$ & $\begin{array}{l}\text { Reported IPV victimisation differed } \\
\text { significantly between NZSEI levels. }\end{array}$ \\
\hline Household tenure & $\square$ & $p<.0001$ & $\begin{array}{l}\text { Owning or renting a house was } \\
\text { shown to be significant in IPV } \\
\text { reporting. }\end{array}$ \\
\hline Living situation & $\nabla$ & $p<.0001$ & $\begin{array}{l}\text { Living situations was significant in } \\
\text { reporting of IPV. }\end{array}$ \\
\hline $\begin{array}{l}\text { Number of people } \\
\text { living in households }\end{array}$ & $\nabla$ & $p<.0001$ & $\begin{array}{l}\text { Number of people living in } \\
\text { households was significant in } \\
\text { reporting of IPV. }\end{array}$ \\
\hline Main income earner & 可 & $p=0.86$ & $\begin{array}{l}\text { No difference was found between } \\
\text { being the main income earner and } \\
\text { IPV reporting. }\end{array}$ \\
\hline Employment status & $\nabla$ & $p<.0001$ & $\begin{array}{l}\text { Employment status was significant } \\
\text { in reporting of IPV. }\end{array}$ \\
\hline Marital status & $\nabla$ & $p<.0001$ & $\begin{array}{l}\text { Marital status was significant in } \\
\text { reporting of IPV. }\end{array}$ \\
\hline
\end{tabular}




\subsection{Multivariate Analysis for Intimate Partner Violence Victims risk}

Using multivariate techniques mean that IPV can be tested across multiple dimensions at the same time as all the explanatory variables of interest are used in the model. Univariate methods can be used to test each explanatory variable against the dependent variables but this does not allow for interactions of the explanatory variables. So while variables may be significant on their own at explaining the dependent variable, when other variables are included in a multivariate model a significant univariate factor may not be significant in explaining the dependent variable in the model. For example, in this study employment status was found to be a significant factor in univariate testing $\left(\chi^{2}(4)=72.91, p<.0001\right)$. However when this variable was included in the regression model (multivariate technique), this variable was no longer found to be a significant predictor of being a victim of intimate partner violence.

\subsubsection{Log Linear results for lifetime and 12 month data}

Log linear modelling was used to test the relationship of the variables, and identifying the model that best predicts IPV victimisation. The significance level was set at the $5 \%$ significance level. Variables were entered into the model, with the best fit model identifying key variables as being significant in explaining IPV victimisation. See Appendix $E$ for the full log linear model results.

The results from the log linear model were the same as those for the Logistic regression model (see 5.4.2) which we would expect as both models are mathematically equivalent (Lewis-Beck, Bryman and Liao, 2004). For more discussion on the significant variables see sections 5.4.2.1 and 5.4.2.2. 


\subsubsection{Logistic Regression results}

To investigate IPV risk factors in New Zealand logistic regression was used. This technique was used as it allows for significance testing for explanatory variables while controlling for other variables in the model.

Model selection for this analysis was selected using the stepwise method. The Wald test was used to examine levels of each individual explanatory variable. The significance level was set at $5 \%$. Interaction terms were not included in the step-wise regression.

In this stage of the analysis IPV victimisation was used as the outcome dependent variable. Several socio-demographic variables were assessed to see which were significantly associated with IPV victimisation. The full logistic regression results are included in Appendix F.

From the existing literature on IPV, presented in chapter 2, several risk factors were identified as increasing the risk of being an IPV victim. These included gender, age, ethnicity, employment status, education, income, socio-economic status, alcohol and drugs, marital status and other stressors.

\subsubsection{Logistic Regression results for Lifetime prevalence}

Based on this analysis several risk factors were identified, consistent with the literature. The results from this analysis are shown in table 5.4. For each explanatory variable the baseline comparison group has an odds ratio of 1 .

From this analysis the significant risk factors for being a victim of IPV over a lifetime included:

- 25-39 year olds

- Māori

- female

- solo parent with child/ren

- social welfare/beneficiary/other

- divorced or separated. 
Of these factors, the highest risk factor was found for those aged 25-39 years old, and is also relatively high for 15-24 year olds and 40-59 year olds. Those aged 60 years and over were the least at risk for being victims. Māori were more at risk of being IPV victims than New Zealand/European, Pacific people and others.

Those who reported living as a solo parent with child/ren were more at risk of IPV than those living with a partner or other family members. Those who were on social welfare benefits were more at risk than those in paid employment, home duties or students, while those who reported as divorced or separated were at greater risk than those who were currently married, never married or in a defacto relationship. 
Table 5.4: Risk factors for victimisation over a lifetime: logistic regression results

\begin{tabular}{|c|c|c|c|}
\hline \multicolumn{2}{|c|}{ Explanatory Variable } & \multirow{2}{*}{$\begin{array}{c}\text { Odds Ratio } \\
1.92(1.13-3.27)\end{array}$} & \multirow{2}{*}{$\begin{array}{c}p \text {-value } \\
0.89\end{array}$} \\
\hline Age & $15-24$ & & \\
\hline & $25-39$ & $3.10(1.98-4.87)$ & $<.0001$ \\
\hline & $40-59$ & $2.47(1.61-3.78)$ & 0.01 \\
\hline & 60 and over & 1.00 & \\
\hline \multirow[t]{4}{*}{ Ethnicity } & Māori & $2.2(1.48-3.29)$ & $<.0001$ \\
\hline & New Zealand/ European & $1.34(0.92-1.95)$ & 0.22 \\
\hline & Pacific people & $0.76(0.49-1.17)$ & $<.0001$ \\
\hline & Other & 1.00 & \\
\hline \multirow[t]{2}{*}{ Gender } & Female & $1.71 \quad(1.44-2.04)$ & $<.0001$ \\
\hline & Male & 1.00 & \\
\hline \multirow{6}{*}{$\begin{array}{l}\text { Living } \\
\text { situation }\end{array}$} & One person living alone & $0.61(0.43-0.86)$ & 0.63 \\
\hline & Flatmates/others & $0.57(0.36-0.90)$ & 0.97 \\
\hline & Extended family/whanau & $0.53(0.37-0.78)$ & 0.59 \\
\hline & $\begin{array}{l}\text { Couple without } \\
\text { children/children not } \\
\text { living with them }\end{array}$ & $0.35(0.22-0.53)$ & $<.0001$ \\
\hline & Couple with Children & $0.53(0.35-0.79)$ & 0.48 \\
\hline & $\begin{array}{l}\text { Solo parent with } \\
\text { child/ren }\end{array}$ & 1.00 & \\
\hline \multirow[t]{5}{*}{$\begin{array}{l}\text { Employment } \\
\text { status }\end{array}$} & $\begin{array}{l}\text { Currently in paid } \\
\text { employment }\end{array}$ & $0.96 \quad(0.71-1.31)$ & 0.05 \\
\hline & Home duties & $0.95(0.65-1.41)$ & 0.19 \\
\hline & $\begin{array}{l}\text { Social welfare } \\
\text { beneficiary }\end{array}$ & $1.57(1.09-2.27)$ & 0.00 \\
\hline & Retired & $1.24(0.73-2.11)$ & 0.60 \\
\hline & Other & 1.00 & \\
\hline \multirow[t]{4}{*}{$\begin{array}{l}\text { Marital } \\
\text { status }\end{array}$} & Divorced/separated & $1.50(0.72-1.46)$ & $<.0001$ \\
\hline & Defacto relationship & $1.02(0.72-1.46)$ & 0.22 \\
\hline & Legally married & $0.43(0.30-0.62)$ & $<.0001$ \\
\hline & Single/never married & 1.00 & \\
\hline
\end{tabular}

NB. The odds ratios are expressed with respect to the reference level. One reference level is chosen within each group. 
Other explanatory variables were fitted into this model including the main income earner, the number of people living in the household, number of dependents in the household and their NZSEI group but were found not to be significant in explaining victimisation in this model.

\subsubsection{Logistic Regression results for 12 Month Period (2000)}

Several risk factors were identified as being significant in accounting for IPV over a 12 month period. There was some difference between the risk factors over a 12 month period and those over a lifetime. The results from this analysis are shown in Table 5.5. For each explanatory variable the baseline comparison group has an odds ratio of one.

From this analysis the significant risk factors for being a victim of IPV over a 12 month period included:

- 15-24 year olds

- Māori

- Not specified NZSEI group (beneficiaries, students, housewives)

- 6 or more persons living in the household

- not owning or renting a house

- defacto relationship.

Of these factors, the highest risk was for those aged 15-24 years old, and is also relatively high for 25-59 year olds. Consistent with the lifetime prevalence model those aged 60 years and over were the least at risk for being victims. Māori were more at risk of being subjected to IPV than New Zealand European, Pacific people and others.

Those who reported being in a defacto relationship were more at risk of IPV than those who reported being married, single or never married. Those living with six or more people in their household were more at risk than those with fewer people. Those who were in the 'not specified' socio-economic bracket (beneficiaries, students, housewives) were at a slightly greater risk of victimisation, while those who did not own or rent a house were at greater risk than those who did. Other explanatory variables were fitted in this model including employment status, main income earner, gender, living situation and number of dependents living in the household, but were found not to be significant in explaining IPV victimisation in this 12 month victimisation model. 
Table 5.5: Risk factors for victimisation over a 12 month period: logistic regression results

\begin{tabular}{|c|c|c|c|}
\hline \multicolumn{2}{|c|}{ Explanatory Variable } & \multirow{2}{*}{$\begin{array}{l}\text { Odds Ratio } \\
10.31(2.20-48.40)\end{array}$} & \multirow{2}{*}{$\frac{p \text {-value }}{0.001}$} \\
\hline Age & $15-24$ & & \\
\hline & $25-39$ & $6.51 \quad(1.49-28.56)$ & 0.05 \\
\hline & $40-59$ & $4.58(1.06-19.89)$ & 0.71 \\
\hline & 60 and over & 1.00 & \\
\hline \multirow[t]{4}{*}{ Ethnicity } & Māori & $\begin{array}{l}3.43(1.17- \\
10.11)\end{array}$ & 0.0002 \\
\hline & New Zealand/European & $1.80(0.62-5.18)$ & 0.73 \\
\hline & Pacific people & $1.28 \quad(0.40-4.06$ & 0.28 \\
\hline & Other & 1.00 & \\
\hline \multirow[t]{7}{*}{ NZSEI group } & NZSEI 10-29 & $0.33(0.14-0.80)$ & 0.03 \\
\hline & NZSEI 30-39 & $0.63(0.30-1.33)$ & 0.92 \\
\hline & NSZEI 40-49 & $0.97(0.46-2.02)$ & 0.02 \\
\hline & NZSEI 50-59 & $0.52(0.22-1.20)$ & 0.49 \\
\hline & NZSEI 60-74 & $0.45(0.19-1.07)$ & 0.25 \\
\hline & NZSEI 75-90 & $0.73(0.25-2.15)$ & 0.67 \\
\hline & Not Specified & 1.00 & \\
\hline \multirow[t]{3}{*}{ Household tenure } & Rented & 1.00 & \\
\hline & Owned & $0.51(0.33-0.79)$ & 0.01 \\
\hline & Other & $1.40(0.43-4.55)$ & 0.26 \\
\hline \multirow[t]{7}{*}{$\begin{array}{l}\text { Number of people living } \\
\text { in the household }\end{array}$} & 1 Person & $0.78(0.20-3.20)$ & 1.00 \\
\hline & 2 Persons & $0.36(0.15-0.90)$ & 0.002 \\
\hline & 3 Persons & $0.81(0.45-1.90)$ & 0.86 \\
\hline & 4 Persons & $0.92(0.41-2.08)$ & 0.41 \\
\hline & 5 Persons & $0.67(0.27-1.66)$ & 0.56 \\
\hline & 6 Persons & $1.23(0.49-3.30)$ & 0.12 \\
\hline & 7 Persons or more & 1.00 & 0.0002 \\
\hline \multirow[t]{4}{*}{ Marital status } & Divorced/separated & $1.18(0.35-3.97)$ & 0.02 \\
\hline & Defacto relationship & $0.64(0.32-1.30)$ & 0.69 \\
\hline & Legally married & $0.31(0.14-0.66)$ & 0.0001 \\
\hline & Single/never married & 1.00 & \\
\hline
\end{tabular}

NB. The odds ratios are expressed with respect to the reference level. One reference level is chosen within each group. 


\section{Chapter Six}

\section{Discussion}

This study investigated risk factors that are associated with being more or less likely to be a victim of intimate partner violence in New Zealand.

This chapter discusses the methods of analysis used in this study and the findings of the research, in the context of the literature already available in this area.

\subsection{Method}

\subsubsection{Statistical Analysis}

The initial statistical analysis of the survey data included the calculation of chi-squared tests for reported IPV victimisation by different demographic groups. Low cell counts meant that levels of IPV victimisation were unable to be reported separately and some dependent variable sub-groups needed to be aggregated for the purpose of reporting.

Some univariate analysis was performed to identify variables that had relationships with the independent variable of being a victim. Multivariate analysis was also preformed including a log linear model and logistic regression. These techniques meant that estimates could be calculated for the significance of an explanatory variable while controlling for other factors. The strength of the logistic regression method is that it is able to distinguish between significant risk factors.

The regression analysis was used to investigate the risk factors for victimisation reported over a lifetime and reported in the previous 12 month period (2000). Explanatory variables were selected from previous research that identified key variables for analysis. Wald tests were used to test whether variables would be significant in the model.

Through the stepwise logistic regression, main income earner, the number of people living in the household, number of dependents in the household and their NZSEI group were left out of the model for lifetime victimisation as they did not add to explaining IPV 
victimisation when other variables were present. For the previous 12 months IPV victimisation, the variables employment status, main income earner, gender, number of people living in the household and number of dependents in the household were left out of the stepwise logistic regression model.

Diagnostic graphs were plotted each time a regression model was fitted. As expected, standardised residuals were not satisfactory because the low cell counts in some cells. Where cells were not combined and cell counts were low, then the observed probability in the cell was one, this led to large standardised residuals being calculated. When this occurred aggregated data was graphed.

\subsubsection{Violence by a Partner section of survey}

A number of improvements were made to the 1996 NZNSCV to allow for more robust data. The main change was in the methodology used for the self-completion section of the survey where Computer Assisted Self Interviewing (CASI) was introduced and replaced the paper surveys for the violence by a heterosexual partner section. The increase in disclosure in the intimate partner violence section adds to the support that using CASI produces more reliable figures, and allows for more robust analysis. This was achieved through CASI as there was:

- a decrease in missing information

- an increase in confidentiality and privacy.

In the British Crime Survey (Mirlees-Black et al, 1996) there was a reported ten-times higher reported prevalence rate with laptop computers than with a paper-based survey. In the 1996 NZNSCV (Morris, 1997) there was a large amount of missing data, this amount significantly dropped by using CASI with automatic skipping procedures, layout and format.

\subsection{Results}

\subsubsection{Risk factors for Intimate Partner Violence}

Results from NZNSCV show that rates of IPV over a lifetime were reported to be significantly higher amongst Māori, people aged 25-39, females, solo parents, those on social welfare benefits, and divorced or separated participants. For those reporting IPV 
in the previous 12 months, higher rates of IPV were found for those aged 15-24 years, Māori, lower NZSEI groups, those with six or more people living in their household, defacto relationships and those who do not own or rent a house.

\subsubsection{Gender}

Much research has shown differences in the reported rate of IPV between males and females (Johnson and Bunge, 2001; Rennison, 2003; Tjaden and Thoennes, 2000). Results from this survey show that for women, lifetime prevalence of IPV occurs at a significantly higher rate than for men. This effect is emphasised when looking at Māori women who report even higher rates of IPV over their lifetime.

However gender did not appear to be a significant factor in this study for those reporting IPV by a current partner in the past 12 months (2000). Moffit and Caspi (1999) reported findings from the Dunedin Multidisciplinary Health and Development study that men were as likely to report violence by their partner as women. This has also been noted in the research by Goodyear-Smith (2004) and National Family Violence Survey (1975, 1985 in Straus and Gelles, 1986) which recorded the same rate of victimisation between both men and women when referring to a shorter survey period. This quote from a participant in this survey highlights the reporting of women's violence towards their intimate partner:

"My girlfriend threatens to seriously hurt me when I annoy her and most of the time she hits me first".

This lack of a difference in reporting between males and females supports the research which shows that men and women are more similar in rates of aggressive behaviours in relationships (Taylor and Pittman 2005 cited in Pritchard, 2005). However this similarity in rates of aggression of mutual couple violence is not an indication of severity of harm where gender differences are more consistently found.

Moffitt and Caspi (1999) report that regardless of whether women and men are victims at the same rate or not, women are reported to inflict just one third of injuries in IPV cases and one quarter of IPV deaths. Mirrlees-Black and Byron (1999) add support to this argument. When splitting reported IPV into chronic (three or more incidents) versus intermittent (one to two incidents) levels of violence they found that men and women reported similar rates of intermittent violence (10\% and $11 \%$ respectively), but for 
chronic levels of violence $12 \%$ of women reported violence compared to only five percent of men. Romans et al (2007) also found that women were more likely to experience severe physical violence such as strangling and beatings.

Research also suggests that there is a significant difference in the impact of violence on women compared to the impact on men as victims. In the NZNSCV more women reported being affected "very much" or "quite a lot" by their most recent incidence of violence and women were more likely to report being afraid for themselves and their children. Mirrless-Black and Byron (1999) also suggested that men were less upset by their experience while Tjaden and Thoennes (2000) also reported women feeling greater levels of fear, time off from work and increased use of the Health and Justice system.

\subsubsection{Age}

Results from this study found that for lifetime prevalence 25-39 year olds were at a greater risk of being a victim of IPV, while for those who experienced IPV in the past 12 months those belonging to the age group 15-24 years, were significantly more likely to be victims by a current partner.

Findings that those in younger age groups are more at risk of IPV have been identified in other research. O'Donnell et al. (2000) and West (1998) found a greater likelihood of victimisation in under 30 year olds in their work while Mouzos and Makkai (2004) also found IPV rates to be higher in younger males and even more so in younger females.

Pritchard (2005) discussed that the rate of violence in young dating couples is estimated at approximately $30 \%$, and is shown to be linked to cohabiting at a young age (amongst other variables), perhaps explaining the findings in this study that those in younger age groups are more likely to report IPV and aggression in their current relationships.

From the Dunedin Cohort study (in Moffitt and Caspi, 1999) 48\% of couples at age 21 reported having been involved in physical partner violence. Those aged 21 who had young children were shown to be more likely than other young people to report IPV victimisation. 
Other reasons for these differences in age may be explained by reporting practices. It would make sense that those who experience victimisation over a lifetime would be those in older age groups as they would have had more years to experience such events, however the differences may be in reporting practises, where those in older age groups are less willing to report incidents of IPV for reasons of loyalty, shame or embarrassment, or simply due to memory loss or repressions of memories (Morris and Reilly, 2003), or that older people are less aware of IPV as a social issue and are less likely to define their experiences as IPV (Lievore and Mayhew, 2007). While this is a possible explanation, it may be simply that those who are younger cohorts are actually more at risk than those who are older.

\subsubsection{Ethnicity}

\subsection{Māori}

The experience Māori have of violence in their families is complex as it occurs not only within a historical context through the process of colonisation, but also occurs within the context of today's socio-economic climate. There has been much research conducted overseas that provides statistical support indicating a link between ethnicity and increased IPV rates (Meares, 2001; Hughes, 2004: Fergusson, 2003).

In New Zealand, figures vary on the proportion of Māori who are victims of IPV, but most of the literature indicates that Māori are more likely than non-Māori to be victims of IPV. This was found in the current study where Māori were twice as likely to be victims of IPV over a lifetime and three and a half times more likely over the past twelve month period (2000).

Results from other studies support these findings. Fergusson (2003) found that Māori were two to four times more likely to be involved in violent behaviour. Possible explanations for the difference in rates of IPV for Māori include their experience of loss of land, change in language, loss of identity, the impact of urbanisation. These all lead to heightened stress and pressure which can lead to an increase in the likelihood of dysfunction in those families and communities (Balzer et al, 1997; Duff, 1993; Walker, 1996; Fergusson, 2003). Figures from Women's Refuge (2007) report that for 2006 Māori represented $42 \%$ of the women that used the Refuge, and although Pakeha women using the refuge was reported at $43 \%$, the proportion of Māori in the population make the $42 \%$ more significant. 
In Balzer et al's (1997) study, talking with New Zealand Māori, these factors such as low self-esteem and dysfunctional backgrounds were not the cause of violence in their families although participants stated these factors contributed to an increased likelihood of violence, "without a doubt". However Balzer et al's (1997) participants stated it is still the individual that must be accountable for their violent behaviours and this accountability should not be minimalised by explaining violence through culture.

The definition of ethnicity is also problematic when measuring differences in IPV rates. Apparent difference may be an artefact of how an individual identifies their ethnicity.

In this study it was investigated whether there was a difference in reporting of IPV between those who identified themselves as sole Māori versus mixed Māori. Previous research (Nickerson, 2004) has found differences in how people self-identify when answering ethnicity questions. No difference was found in this study between rates of IPV for those who self-identified as mixed and sole Māori. This is consistent with Kukutai (2003) who found that sole Māori and mixed Māori were not sufficiently distinctive from each other and that more difference lies between those that descend from Māori and either do or do not identify as being Māori.

\subsection{Pacific}

Results from this thesis showed that Pacific people have lower reported incidents of IPV than all other ethnic groups in New Zealand over a lifetime. From the results from the 1996 NZNSCV's for IPV prevalence Young et al (1997) noted that Pacific reporting was very low. These results were reanalysed to include those who identified as multiple ethnicities and the difference did not change. Compared with the 2001 data, prevalence for Pacific was significantly higher (than 1996). This was found for all ethnic groups and may account for the change in methodology which was designed to allow for greater disclosure. The number of Pacific people surveyed in 2001 was also greater than in 1996, providing more reliable figures for analysis.

Figures from Women's Refuge (2007) show that only eight percent of women who used the Refuge in 2006 were Pacific people, compared to 42\% Māori and 43\% Pakeha women. 
In a study by Paterson et al (2007), with a cohort of Pacific mothers living in New Zealand, they reported that $21 \%$ of participants reported 'minor' physical violence by their partner while $11 \%$ reported 'severe' levels of physical violence by their partner over the previous 12 month period. The overall victimisation rate for the Pacific participants was $22.9 \%$.

However differences in specific Pacific groups have also been shown. Paterson et al (2007) found that Samoan women reported higher rates of IPV compared to other Pacific groups. In this thesis specific Pacific groups were to small in respondent numbers to yield any meaningful results, by combining all the Pacific groups together this may lose some of the variance in responses by sub-groups and a larger sample of some Pacific groups may skew the results.

\subsubsection{New Zealand Socioeconomic Index (NZSEI) Group}

NZSEl is a measure that reflects the socio-economic status (SES) of people, based on the main income earner's occupation (in the household). In this study NZSEI level was not found to be a significant factor in the likelihood of victimisation over a lifetime but was for those who reported victimisation in the previous 12 months (2000). Table 5.5 shows that for the previous 12 months those in the 'unspecified' group and those in the middle of the NZSEI range reported higher victimisation.

Much research suggest that the stress experienced in lower socio-economic status household causes an increase in the experience of IPV, with limited access to resources and employment and increased feelings of hopelessness, IPV seems to be more common (West, 1998; Unicef, 2000; Hotaling and Sugarman, 1986).

However low SES is not seen in the literature as a causal factor in victimisation statistics but is shown to increase the risk of such experiences Cunradi et al, 2002; Garrison et al. 1993).

In this study a reason for not finding NZSEI levels as a significant factor for those reporting victimisation over a lifetime may be that current NZSEI was recorded which may be at a higher level than in the past when the reported IPV victimisation was occurring. 


\subsubsection{Employment Status}

Employment status was found to be a significant predictor in explaining IPV over a lifetime with those who reported as being on social welfare benefits being most at risk of reporting IPV. Employment status was not found to be a significant predictor in reporting of IPV in the past 12 months.

Many studies have looked at male employment status (Kaufman 1998, Balzer et al, 1997) and found it to be a significant factor in IPV reporting. In this study it asked for the participant's employment status, so an explanation for the difference in these results could be due to the high number of females answering the survey and female unemployment has not been shown to be as likely to be associated with increased IPV rates (Dowd et al 1996, O'Donnell et al 2002).

\subsubsection{Main Income Earner}

Main income earner was a variable that identified if the respondent was the main income earner or not in their household. It was not found to be a significant predictor of IPV over a lifetime or in the previous 12 months. So while research has identified that families in low incomes are more at risk of IPV (Cunradi et al 2002; Kaufman et al 1998; O'Donnell 2002) this study suggests that IPV is not dependent on who earns the main income for the family, but that low SES status (including low income) is a significant factor in experiencing IPV, which is consistent with other studies (O'Donnell et al 2002; Kaufman et al, 1998).

\subsubsection{Living Situation}

Living situation was found to be significant over a lifetime but not over a 12 month period in reporting of IPV. For the lifetime data, solo parents with children were up to twice as likely to report IPV as those living with their partner, living with their partner and children and those living with extended family or living alone.

\subsubsection{Over Crowding}

The number of people living in the respondent's household was found to be a significant factor for IPV for 12 month data while the number of dependents (under 16 years of age) was not found to be significant in predicting IPV victimisation over the 12 
month period or over a lifetime. This finding is consistent with a body of research showing that overcrowding is associated with an increase in stress, poverty and an increase in the likelihood of IPV (World Health Organisation, 2002; Shirley, Adair, \& Anderson, 2000; Māori Women's Housing Project Report, 1991).

No official measurement for household overcrowding exists in New Zealand, but Statistics New Zealand classify overcrowding as "relates to situations where the number of people residing in a household exceeds the capability of the household to provide adequate shelter and services to its members."

In health research, overcrowding and low income are important indicators as they are highly correlated with negative social outcomes and especially mental and physical health (National Health Committee, 1998; Gray 2001). In a Ministry of Health report, overcrowding was found to be a significant contributor to health status, especially for Pacific people. Income was also a significant contributor to these outcomes..

\subsubsection{Marital Status}

This survey found that for lifetime prevalence of IPV being divorced or separated was a significant factor in the likelihood of IPV; this was also the case for reported IPV in the past 12 months. This finding that being divorced or separated was a significant factor in the likelihood of IPV may be that individuals have had a longer history of violence and were able to break out of the relationships they were in. Violence has also been found to escalate after separation which may be a factor in increased reporting of IPV for those divorced or separated. Separation can be a time when women are at their most vulnerable both physically and psychologically and it can be a time when IPV worsens or can even be a trigger for new violence to begin (Lievore and Mayhew, 2007).

\subsubsection{Intimate Partner Violence victimisation comparison with 1996}

Both the 2001 and 1996 NZNSCV asked about participant's experience of violence by a heterosexual partner. Although some methodological changes were made between 1996 and 2001, care has been taken in making comparisons.

Overall, women were far more likely to experience IPV over their lifetime than men, regardless of age or ethnicity, although Māori men were also found to have experienced high levels of some of the IPV behaviours discussed. In 2001, the disclosure of IPV for women and men was much higher than in 1996. This could be an 
indication of an increase in IPV incidences in New Zealand, or as a result of the change in methodology between 1996 and 2001. Either explanation means the results in 2001 are more reliable than previous. While a significant difference between male and female victimisation was found in 2001, the difference was not as great in 1996.

For ethnicity, Māori were significantly more likely to report IPV in 1996 than non-Māori. This was found in 2001 also, but across all ethnicities victimisation reports rose significantly. This again could be explained by methodological differences between surveys, or an actual increase in victimisation. A larger sample of Pacific people also allowed for more robust estimates in the 2001 survey. While there was an overall increase in victimisation, this survey probably still continues to under estimate the true nature of this crime, although the 2001 figures provide more reliable figures.

\subsubsection{Comparison with previous New Zealand surveys}

\subsubsection{Lifetime Experience}

A number of New Zealand studies have measured lifetime prevalence rates of violence by a partner (Fanslow and Robinson, 2004; Koziol-McLain et al 2004; Morris and Reilly, 2003). These figures vary across surveys which is most likely to be the effect of different measurements and definitions of IPV.

In the NZNSCV (2001), participants were asked if they had experienced an event of violence by a heterosexual partner in their lifetime. The NZNSCV (2001) found that over a lifetime more than $25 \%$ of females and nearly $20 \%$ of males had experienced IPV.

Findings from Leibrich et al (1995) showed that 35\% of men in their study used physical violence and $62 \%$ of the males in the study reported using psychological abuse against female partners.

The Dunedin Longitudinal Study (in Moffitt and Caspi, 1999), found that $27 \%$ of women and $24 \%$ of men reported being physically abused by their partner over a lifetime and by matching couple-responses they found that between $70 \%$ to $80 \%$ of partners reports of IPV were agreed on by the other partner. 
More recently Fanslow and Robinson (2004) reported that over a lifetime $32 \%$ of women reported physical violence and $16 \%$ reported experiencing sexual violence over the previous year (2003).

\subsubsection{Experience over a 12 month period}

In the NZNSCV (2001), participants were asked if they had experienced an event of violence by a heterosexual partner in the previous 12 months beginning 1 January 2000. Of those who currently had partners only three percent reported at least one of these types of violence.

Other studies have found similar findings in rates of IPV. The Youth 2000 survey of 9699 year nine to 13 students around New Zealand reported rates of students experiencing adults in their home physically hurting each other over the last 12 months was six percent with just over one percent of the sample reporting that the adults in their home had physically hurt each other three or more times in the last 12 months (Fleming et al, 2007).

\subsection{Survey Limitations}

The results from this study are based on survey data, which means that results are subject to non-sampling errors due to survey data coming from a sample of New Zealanders and not the whole of New Zealand (census). Sampling errors are also likely, due to survey design and analysis. Confidence intervals were calculated to the $95 \%$ level to account for sampling errors.

The response rate in 2001 was higher than in 1996 with an overall response rate of $62 \%$ (see Chapter Three). Broken down, this equates to a $65 \%$ response rate for the main sample, 57\% for Māori and 53\% for Pacific. In the 1996 survey the response rate was "barely adequate" at $57 \%$ for the overall sample, so $62 \%$ was a welcome increase; however for Māori and Pacific the 2001 response rates are still quite low. Low response rates affect the reliability of the findings and make comparisons between data more problematic. In 2001, non-response strategies were put in place to lift the response rate including:

- tv advertising

- sending out letters 
- languages

- call backs.

These appeared to have had some impact on response rates overall, however some groups were not fully represented in the sample (see table 6.1). For the overall sample, seven percent were aged between 15-24 years compared to $14 \%$ of the New Zealand population (Statistics New Zealand, 2007). Of this seven percent, nine point one percent refused to complete the IPV section. Ever-partnered males answering the IPV section was only $40 \%$ of this sample compared with $49 \%$ of the New Zealand population (Statistics New Zealand, 2007).

This may be as a result of differential response, whereby some groups in the population are more likely to respond to surveys. This effect can be measured, but in this survey no data was kept or was available to identify the characteristics of those in the population that did not want to respond or were not able to be contacted.

Table 6.1: Difference in response rates for certain variables in the NZNSCV (2001) compared to the New Zealand population.

\begin{tabular}{|l|c|c|}
\hline Variable & $\begin{array}{c}\text { Overall Sample } \\
\text { (NZNSCV, 2001). }\end{array}$ & $\begin{array}{c}\text { New Zealand } \\
\text { population (Census, } \\
\text { 2006). }\end{array}$ \\
\hline 15-24 years & $7 \%$ & $14 \%$ \\
\hline Ever partnered males & $40 \%$ & $49 \%$ \\
\hline
\end{tabular}

The target population for the survey was all non-institutionalised adults aged 15 years and over, living in permanent private dwellings, excluding groups such as those that are homeless or living in shelters, key groups when estimating IPV. The impact of this omission of those not living in residential settings can be seen when looking at the Women's Refuge figures for 2006 that show that 28,845 women and children used the Refuge, any who were in the Refuge at the time of the survey would not be included in the sample frame, thus missing a number of cases of intimate partner violence leading to under-reporting of IPV. This sample design also excludes those living in military institutions, again a group that has a significantly higher reported IPV rate (Griffin and Morgan, 1988; Bohannon, Dosser, and Lindley, 1995; Cronin, 1995; Heyman and Neidig, 1999; McCarroll, Thayer, Liu, Newby, Norwood and Fullerton, 2000). 
Young et al's (1997) belief is that as New Zealand is so heavily researched, and has a proportionally small population, certain groups feel over-researched and thus decline to be involved in future research.

While CASI was used for the IPV self-completion section, this section came at the end of a long survey on crime and it could be that some participants simply pressed 'no' to avoid having to spend too much longer on the survey. If this is so, the data still continues to under-estimate IPV experienced in New Zealand.

\subsubsection{Disclosure of Intimate Partner Violence}

Talking about their experiences of violence, especially by loved ones in an intimate partner setting, can be very hard to do, and capturing data on sensitive subjects like this can be problematic when people are not willing to disclose their personal or private matters. Where people do respond, their sensitivity to IPV reporting can lead to individuals giving inaccurate responses.

So while there is still, most likely, an underestimate of IPV from this survey, the increase in reporting of incidents can be somewhat attributed to the methodological changes in the 2001 survey. The use of CASI for this section, can allow for participants to respond with an increase in confidentiality and privacy.

\subsubsection{Definition of Intimate Partner Violence}

How participants define IPV can limit the response to the survey. While the four parts of IPV are clearly defined to include certain behaviors and actions, how an individual defines their own experiences may not match. Adams, Towns and Gavey (1995) show that people in abusive relationships can see the behaviors that we define as abusive, as being normal and therefore not labeling these events as acts of violence. Individual's may also over report on incidents by over-defining situations or recalling a longer period than that being asked about. The extent of these inaccuracies in reporting cannot be calculated in this survey but it is assumed in the analysis that responses given by participants are correct and accurate. 


\subsubsection{Continuum of Control}

A major criticism of Police statistics on IPV is the mis-reporting of incidents as well as a lack of reporting on the level or seriousness/impact of IPV. The inclusion of questions in the 1996 and 2001 survey on the impact of violence to victims goes some way to answer this by identifying the reaction and implications on violence to that individual. More is needed to define the true seriousness of the reported offences and where they sit on the continuum of controlling behaviour.

Data that looks at who initiated the incident, whether it was an act of self-defence or whether it was mutual couple violence, where both couples are violent, or if it is one partner against the other (instrumental violence) will provide a better perspective on the extent of the violence and the relationship that sits within that violent partnership.

This quote gives some indication of the complexity of committing violence, where this women reports mutual violence:

"We were having an argument when he pushed me and I pushed him back".

\subsection{Policy Implications}

The complexity of IPV means that no one strategy will reduce the incidents in all situations. Intimate partner violence can occur in different social contexts, and the strategies needed would require an understanding of the degree to which that society or community sanctions IPV (UNICEF, 2000).

Considering the interconnectedness between factors such as social structure, power relations and economic systems, strategies and interventions must be designed with these in mind. Strategies with multiple layers, that address IPV while also providing immediate services to victims, ensure a potential to eliminate victimisation and will be sustainable (UNICEF, 2000).

Such strategies are useful and necessary to be able to alter circumstances and lower the risk to victims in vulnerable situations and to enable them to prepare strategies to deal with impending situations. By identifying which demographic characteristics 
contribute to increased risk of being a victim of IPV we can inform developers of social policy and intervention programmes (O'Donnell et al, 2002).

\subsubsection{Ethnic Specific Policy}

With the need for multiple, contextualised, specific strategies, identifying what will work for different ethnic groups in New Zealand is also a major public and policy issue that needs to be addressed.

\subsubsection{Māori Specific}

Te Rito, New Zealand Family Violence Prevention Strategy (Ministry of Social Development, 2002) identifies the continued need to address violence in Māori families, as the rates for violence by intimate partners remains high.

Prevention initiatives for violence within families need to be complemented by strategies that incorporate Māori beliefs and realities, to ensure equal access for Māori and address the principles in the Treaty of Waitangi. For Māori, violence prevention needs to be placed in a holistic context, both in concept, structure and activity. This was identified in an evaluation of Māori family violence prevention programmes that looked at already existing Māori programmes, and the common themes and activities running through them (DHB toolkit).

\subsubsection{Pacific Specific}

For Pacific people, there are few existing specific IPV prevention programmes. Again, findings into what Pacific people want show that there needs to be a range of programmes and strategies that are culturally based, but importantly, recognise the diversity within the Pacific population in New Zealand (Ministry of Health, 2001a). More access to mainstream services is also a priority area seen by Pacific people. There also needs to be a focus on the differences experienced by Pacific people that are New Zealand born, as well as those that are born out of New Zealand and have migrated to New Zealand (Ministry of Health, 2001a). 


\subsubsection{Alcohol and Drugs}

A key factor in reducing aggression and violence is found by decreasing alcohol and substance abuse. By limiting alcohol and drug taking, positive impacts are seen in couple and family relationships. Intimate partners drug and alcohol use was not measured in this thesis as a risk factor as it was not collected in the NZNSCV (2001), however when participants were asked about their reaction to IPV nearly ten percent of men and two point five percent of women reported increased drug and alcohol use as a result of IPV (Morris and Reilly, 2003).

Other research outlined in this study shows the link between alcohol and drug use and its effects on IPV. In a study by Fals-Stewart (2003) a group of men with a history of violence were referred to a drug and alcohol treatment programme. On the days the participants drank alcohol they were eleven times more likely to hit their partners than on the days they did not drink. These findings were shown in a study of young couples who were eight times more likely to hit each other on days they drank alcohol, than on days they did not drink (Relationship Services in Prichard, 2005).

\subsubsection{Levels of Stress}

Another key variable not measured in the NZNSCV (2001) was that of stress. Levels of stress can be impacted on in a number of ways such as a lack of economic resource, poverty and health. Amato, Johnson, Booth and Rogers (2003) found that increased economic resources were associated with increased relationship quality. This has led to the argument that interventions designed to support couple relationships should target contextual variables. Research looking at stable relationships suggests that the provision of child care, higher wages, affordable housing, improved access to health care and safer neighbourhoods are all contextual variables that can contribute to relationship satisfaction and stability in a positive way (Bradbury \& Karney, 2004).

\subsubsection{Changing Attitudes and Behaviours}

Public awareness campaigns have been identified as a needed component of an IPV prevention programme (Ministry of Health, 2001a; Ministry of Social Development, 2001). Well-designed community-based campaigns are a more effective way to change attitudes and behaviours towards the phenomenon of violence in intimate partner 
relationships. A current example of this is the Campaign for Action on Family Violence (the Campaign, The Ministry of Social Development).

The Campaign aims to increase awareness of violence within families in New Zealand, to promote a greater propensity to act on violence within families and to create a social climate that supports change. This social marketing Campaign is an example of how Government policy can aid in supporting a community to reduce the incidents of IPV in New Zealand, and helping New Zealanders to collectively change the norms around IPV, where it happens and to whom, and what is and is not acceptable (Ministry of Social Development, 2007).

\subsection{Conclusion}

Intimate partner violence is a significant issue in New Zealand. In 2006 alone Police reported an increase of family violence call outs reaching more than 71,000 (Women's Refuge, 2007). Reported rates of IPV over a lifetime are at approximately $26 \%$ for women $18 \%$ for men and over a 12 month period at three percent for women and one point eight percent for men (in the adult population over 15 years) (Morris and Reilly, 2003).

This thesis set out to answer the following research questions:

1. What factors are strong predictors for intimate partner violence victimisation?

2. Does victim ethnicity factored out when variables such as SES, income and/or employment status are taken into account?

The 2001 NZNSCV confirmed the people's experiences of violence by intimate partners is more common than violence by a stranger and the population groups at most significant risk of IPV are young Māori women.

This thesis analysed complex survey data from NZNSCV (2001), resulting in the use of appropriate multivariate statistical techniques, including log linear modeling and logistic regression. 
The NZNSCV (2001) suggests that since 1996 there has been an increase in IPV rates, and the figure disclosed by victims in this survey are much higher than the number of offenses reported by the Police in official statistics and is consistent with a number of other New Zealand population studies (Leibrich et al, 1995; Morris, 1997; Moffitt and Caspi, 1999; Fleming et al, 2007 Falser and Robinson, 2004). This survey also reemphasised the finding that most New Zealanders do not experience IPV or any crime in general, but that for a minority of New Zealanders, victimisation is a regular occurrence and these few individuals experience the majority of crime, especially if they are young Māori females.

Variables of interest that came out of the literature, which were not measured in the NZNSCV (2001), were levels of situational stress and the impact of drugs and alcohol on incidents of IPV.

The level of stress on a couple's ability to resolve conflict in a positive way can lead to conflict resolution using violence. Understanding the stages in a couple's relationship can also be important when looking at IPV with research identifying crucial life stages that increase stress and can increase the occurrence of IPV, especially for first time parents (Bradbury, 2003).

Another key factor in reducing IPV is reducing alcohol and substance abuse. Limiting alcohol and drug taking has a positive impact on couple and family relationships. Collecting data on this in future surveys will provide a fuller picture of factors surrounding victimisation and perpetration.

Future work can be done to build on these results to further improve our knowledge and understanding of the phenomenon of violence in our families in New Zealand. Key factors identified in the literature such as drug and alcohol abuse are ones that are beneficial to investigate and measure in victimisation surveys, as well as looking at the specific context in New Zealand such as:

- the impact of repeal of Section 59 in the Crimes Act

- Government campaigns and policy

- the Taskforce for Action on Family Violence initiatives 
It is also important to look at the impact that these initiatives and programmes have on:

- beliefs that inhibit propensity to act

- beliefs and attitudes that contribute to the problem of underreporting of IPV

- prevalence of IPV

- experiences of victims

- community and family attitudes towards IPV.

Thus in answer to the research questions we see that:

1. The strong predictors for IPV are Māori, people aged 25-39, females, solo parents, over-crowding, those on social welfare benefits, and divorced or separated for lifetime victimisation, and aged 15-24 years, Māori, lower NZSEI groups, solo parents with children, defacto relationships and those who do not own or rent a house for 12 month prevalence of IPV.

2. Ethnicity is strongly significant in explaining victimisation even when other variables are factored into the model. In particular Māori reported to be twice as likely to be victims of IPV over a lifetime and three-and-a-half times more likely over the past 12 month period (Morris and Riley), this was not as different when other factors where factored in, however Māori remained at a significantly higher rate of reporting IPV.

In conclusion the results from this thesis provide further evidence of the risk factors found to increase the likelihood of intimate partner violence victimisation, but also highlight the complexity of this area and the other aspects of an individual's life and situations that may be impacting on their experiences. 


\section{References}

Adams, P., Towns, A. and Nicola, G. (1995). Dominance and Entitlement: the rhetoric men use to discuss their violence towards women. Discourse and Society, 6(3):387406.

Agresti, A. (2002). Categorical Data Analysis. Second edition. Wiley-Interscience: Canada.

Ahlborg, T. and Strandmark, M. (2006). Factors influencing the quality of intimate relationships six months after delivery: First-time parents' own views and coping strategies. Journal of Psychometric Obstetrics and Gynecology, 27(3):163-172.

Allan, J. (2001). Review of the Measurement of Ethnicity, Classification and Issues. Statistics New Zealand.

Amato, P., Johnson, D., Booth, A. and Rogers, S. (2003). Continuity and change in marital quality between 1980 and 2000. Journal of Marriage and Family, 65:1-22.

Balzar, R., Haimona, D., Henare, M. and Matchitt, V. (1997). Māori Family Violence in Aotearoa. Te Puni Kokiri, Wellington.

Barak, G., Leighton, P. and Flavin, J. ( 2006 ). Class Race Gender and Crime: the social realitites of Justice in America. Second edition. Rowman \& Littlefield.

Barnett, O.W. and LaViolette, A.D. (1993). It Could Happen to Anyone. Why Battered Women Stay. SAGE Publications, London.

Barwick, H., Gray, A. and Macky, R. (2000). Domestic Violence Act 1995: Process Evaluation. The Ministry of Justice, Wellington.

Bohannon, J. R., Dosser, D. A., \& Lindley, S. E. (1995). Using couple data to determine domestic violence rates: An attempt to replicate previous work. Violence and Victims, 10(2), 133-141. 
Boyle, A., Robinson S. and Atkinson, P. (2004) Domestic violence in emergency medicine patients. Emergency Medicine Journal, 21:9-13.

Bradbury, T. (2003). Paper presented at Strengthening Families Conference, Wellington, December. In Pritchard, R. (2007). Healthy Family Relationships: A review of the research literature to contribute to the Campaign for Action on Family Violence Project. The Ministry of Social Development, Wellington.

Bradbury, T. and Karney, B. (2004). Understanding and altering the longitudinal course of marriage. Journal of Marriage and Family, 66: 862-879. In Pritchard, R. (2007). Healthy Family Relationships: A review of the research literature to contribute to the Campaign for Action on Family Violence Project. The Ministry of Social Development, Wellington.

Brown, M.P. and Hendricks, J.E. Wife Abuse. In Jackson, N.A. and Oates, G.C. (1998). Violence in Intimate Relationships: Examining Sociological and Psychological Issues. Butterworth-Heinemann, Boston.

Charles, P. and Perreira, K. (2007). Intimate Partner Violence During Pregnancy and 1Year Post-Partum. Journal of Family Violence, 22 (7):609-619.

Cleveland, H.H., Herrera, V.M. and Stuewig, J. (2003). Abusive Males and Abused Females in Adolescent Relationships: Risk Factor Similarity and Dissimilarity and the Role of Relationship Seriousness. Journal of Family Violence, 18(6):325-339.

Cunradi, C.B., Caetano, R. and Schafer, J. (2002). Socio-economic Predictors of Intimate Partner Violence Among White, Black and Hispanic Couples in the United States. Journal of Family Violence. 17(4):377-389.

Cram, F., Pihama, L., Jenkins, K. and Karehana, M. (2002). Evaluation of Programmes for Māori Adult Protected Persons under the Domestic Violence Act 1995. The International Research institute for Māori and Indigenous Education. The University of Auckland.

Cronin, C. (1995). Adolescent reports of parental spousal violence in military and civilian families. Journal of Interpersonal Violence, 10(1), 117-122. 
Dal Grande, E., Hickling, J., Taylor, A. and Woollacott, T. (2003). Domestic Violence in South Australia: A population survey of males and females. Australian and New Zealand Journal of Public Health, 27(5): 543-550.

Dearwater, S.R., Coben, J.H., Campbell, J.C., Nah, G., Glass, N. and McLoughlin, E. (1998). Prevalence of intimate partner abuse in women treated at community hospital emergency departments. Journal of the American Medical Association, 280(5):433438.

Dobson, A.J. (2002). An introduction to Generalized Linear Models. Chapman \& Hall, Boca Raton, $2^{\text {nd }}$ edition.

Dowd, M., Langley, J., Koepsell, T., Soderberg, R. and Rivara, F. (1996). Hospitalizations for injury in New Zealand: Prior injury as a risk factor for assaultive injury. American Journal of Public Health, 86(7): 929-934.

Downs. W.R., Miller, B.A. and Panek, D.D. (1993). Differential patterns of partner-towoman violence: A comparison of samples of community, alcohol-abusing, and battered women. Journal of Family Violence, 8(2): 1573-2851.

Duff, A. (1993). Māori: The crisis and the challenge. Harper Collins, Auckland.

Elliott, D.S., D. Huizinga, and B.J. Morse. (1985). The Dynamics of Delinquent Behavior: A National Survey Progress Report. Institute of Behavioral Sciences, University of Colorado.

Efron, B. (1982). The Jackknife, the Bootstrap, and other Resampling Plans, In Society of Industrial and Applied Mathematics CBMS-NSF Monographs, 38.

Fagan, J. and A. Browne. (1994). Violence Between Spouses and Intimates. In Reiss and J.A. Roth. Understanding and Preventing Violence, 3:115-292. Washington, DC: National Academy Press.

Fals-Stewart, W. (2003). The Occurrence of Partner Aggression on days of Alcohol Consumption: A longitudinal diary study. Journal of Consulting and Clinical Psychology, 71: 41-52. 
Fanslow, J. and Robinson, E. (2004). Violence against women in New Zealand: prevalence and health consequences. Social and Community Health, School of Population Health, University of Auckland, Auckland, New Zealand. New Zealand Medical Journal, $117: 1206$.

Farrington, D.P. (1993). Motivations for Conduct Disorder and Delinquency. Development and Psychopathology, 5:225-241. In World Health Organisation. World Report on Violence and Health. World Health Organisation, Geneva.

Fergusson, D.M. (2003). Ethnicity and interpersonal violence in a New Zealand birth cohort. In Hawkins and Darnell. (Ed). Violent Crimes: Assessing Race and Ethnic Differences. Cambridge University Press, 138-153.

Fleming, T.M., Watson, P.D., Robinson, E., Ameratunga, S., Dixon, R., Clark, T.C., and Crengle, S. (2007). Violence and New Zealand Young People: Findings of Youth 2000 - A National Secondary School Youth Health and Wellbeing Survey. The University of Auckland.

Fogarty., Burge. and McCord. (2002). Communicating With Patients about Intimate Partner Violence: Screening and Interviewing Approaches Communicating with Special Populations, 34(5): 369-375.

Garrison, R.J., Gold, R.S., Wilson, P.W.F. and Kannel, W.B. (1993). Educational attainment and coronary heart disease: The Framingham Offspring Study. Preventative. Medicine, 22:54-64.

Giles, D.C. (2002). Advanced Research Methods in Psychology. Routledge: New York.

Giles-Sims, J. The Aftermath of Partner Violence. In Jasinski, J.L. and Williams, L.M. (1998). Partner violence: A comprehensive review of 20 years of research. SAGE Publications, London.

Goodyear-Smith, F. (2004). Recognising and Responding to Partner Abuse: Challenging the key facts. New Zealand Medical Journal, 117:1202. 
Gottman, J., Coan, J., Carrere, S., and Swanson, C. (1998). Predicting marital happiness and stability from newlywed interactions. Journal of Marriage and the Family, 60: 5-22.

Gray, A. (2001). Definitions of Crowding and the Effects of Crowding on Health: A Literature Review. Ministry of Social Policy, Wellington.

Griffin, W. A., \& Morgan, A. R. (1988). Conflict in maritally distressed military couples. American Journal of Family Therapy, 16(1), 14-22.

Golding. (1996). Sexual assault history and limitations in physical functioning in two general population samples. Research in Nursing and Health, 19:33-44.

Haslam, S.A. and McGarty, C. (2003). Research Methods and Statistics in Psychology. SAGE Publications, London.

Hendricks, J. (1992). Domestic Violence Legislation in the United States: A Survey of the States. In Intimate Violence, 213-226.

Heyman, R. E., \& Neidig, P. H. (1999). A comparison of spousal aggression prevalence rates in U.S. Army and civilian representative samples. Journal of Consulting and Clinical Psychology, 67(2), 239-242.

Hotaling, G.T. and Sugarman, D.B. (1986). An analysis of risk markers in husband to wife violence: the current state of knowledge. Violence and Victims, 1(2):101-24.

Hughes, C. (2004). Domestic Violence Statistics: What can they tell us? Te Awatea Research Centre's Newsletter. Te Awatea Review, University of Canterbury. 12(2).

Injury Centre CDC (2003). Cost of Intimate Partner Violence Against Women in the United States. Department of Health and Human Services. United States. Available online: http://www.cdc.gov/ncipc/pub-res/interpersonalviolence_cost/ 02 _ introduction .htm .

Jasinski, J.L. (2001). Theoretical Explanations for Violence against Women. In Renzetti, C.M., Edleson, J.L. and Kennedy-Bergan, R. (2001). Sourcebook on Violence Against Women. Sage Publications : London. 
Johnson, H. Rethinking Survey Research on Violence against Women. In Dobash, R.E. and Dobash, R.P. (1998). Rethinking Violence Against Women. SAGE Publications, London.

Johnson, H. and Bunge, V.P. (2001). Prevalence and consequences of spousal assault in Canada. Canadian Journal of Criminology, 43: 27-45.

Kaslow, N., Thompson, M.P., Meadows, L., Jacobs, D., Chance, S. and Gibb, B. (1998). Factors that mediate or moderate the link between partner abuse and suicidal behavior in African American women. Journal of Consulting and Clinical Psychology, 66: 533-40.

Kessler, R.C., McGonagle, K.A., Zhao, S., Nelson, C.B., Hughes, M. and Eshleman, S. (1994). Lifetime and 12-month prevalence of DSM-III-R psychiatric disorders in the United States: results from the National Comorbidity Survey. Archives of General Psychiatry, 51: 8-19.

Kaukinen, C. (2004). Status Compatibility, Physical Violence, and Emotional Abuse in Relationships. Journal of Marriage and Family, 66:452-471.

Kaufman Kantor, G. and Jasinski, J.L. Dynamics and Risk Factors in Partner Violence. In Jasinski, J.L. and Williams, L.M. (1998). Partner violence: A comprehensive review of 20 years of research. Sage Publications: London.

Koziol-McLain, J., Gardiner, J., Batty, P., Rameka, M., Fyfe, E. and Giddings, L. (2004). Prevalence of intimate partner violence among women presenting to an urban adult and paediatric emergency care department [Electronic version]. New Zealand Medical Journal, 117:1-8.

Kukutai, T. (2003). The Dynamics of Ethnicity Reporting: Māori in New Zealand a discussion paper prepared for Te Puni Kokiri, University of Waikato, 28-42.

Leibrich, J., Paulin, J. and Ransom, P. (1995). Hitting Home: men speak about male partner abuse of women. Wellington: Department of Justice.

Lewis-Beck, M.S., Bryman, A. and Liao, T.F. (2004). The SAGE Encyclopedia of Social Science Research Methods. Volume 1-3. SAGE Publications: London. 
Lievore, D. and Mayhew, P. (2007). The Scale and Nature of Family Violence in New Zealand. Wellington: Ministry of Social Development.

Lohr ,S.L. (1999). Sampling: design and analysis. Pacific Grove, Duxbury Press, California.

McCarroll, J. E., Thayer, L. E., Liu, X., Newby, J. H., Norwood, A. E., Fullerton, C. S. (2000). Spouse abuse recidivism in the U.S. Army by gender and military status. Journal of Consulting and Clinical Psychology, 68(3), 521-525.

McNeil, H., Von Dadelzen, S., Gray, A., Duituturanga, E., Good, R. and Ash, R. (1988). Attitudes to family violence: $A$ study across three cultures. Department of Social Welfare, Wellington.

McWilliams, M. Violence against women in societies under stress. In Dobash, R.E. and Dobash, R.P. (1998). Rethinking Violence Against Women. SAGE Publications, London.

Mahoney, P., Williams, L.M. and West, C.M. Violence Against Women by Intimate Relationship Partners. In ReNew Zealandetti, C.M., Edleson, J.L. and KennedyBergan, R. (2001). Sourcebook on Violence Against Women. SAGE Publications, London.

Malley-Morrison, K. and Hines, D.A. (2004). Family violence in a cultural perspective: defining, understanding and combating abuse. SAGE publications, London.

Māori Women's Housing Project Report. (1991). For the Sake of Decent Shelter, Wellington.

Margolin, G., Burman, R.S. and O'Brien, M. (1990). Margolin's "Domestic Conflict Scale" or "Conflict Inventory". The Domestic Conflict Instrument. University of Southern California, Los Angeles.

Martin, A.J., Berenson, K.R., Griffing, S., Sage, R.E., Madry, L., Bingham, L.E. and Primm, B.J. (2000). The Process of Leaving and Abusive Relationship: The Role of Risk Assessment and Decision-Certainty. Journal of Family Violence, 15(2): 109-122. 
Mayhew, P. and Reilly, J. (2007). The New Zealand Crime and Safety Survey 2006. Ministry of Justice.

Meares, T. L. (2001). Crime and Ethnicity (Including Race). In Prevention of Crime and Delinquency. International Encyclopedia of the Social \& Behavioral Sciences.

Miller, Cohen, and Rossman. (1993). Victim costs of violent crime and resulting injuries. Health Affairs, 12(4):186-97.

Ministry of Health. (2001a). Interpersonal Violence: DHB toolkit. To reduce violence in interpersonal relationships, families, schools and communities. New Zealand Health Strategy.

Ministry of Health. (2001b). Monitoring Ethnic Inequalities in Health Public Health Intelligence Occasional Bulletin No 4.

Ministry of Justice. (1996). A summary of the crime victims and women's safety surveys. Available online: www.justice.govt.nz/pubs/reports/1996/victims/Default.htm.

Ministry of Socail Development. (2007). Community Action Toolkit to Prevent Family Violence.

Ministry of Social Development. (2002). Te Rito: New Zealand Family Violence Prevention Strategy. Wellington: Ministry of Social Development. Available online: http://www.msd.govt.nz/documents/publications/sector-policy/te-rito.pdf.

Mirrlees-Black and Byron. (1999). Domestic Violence: Findings from the BCS SelfCompletion Questionnaire. Research Findings No. 86, Home Office, London.

Mirrlees-Black, C., Mayhew, P. and Percy, A. (1996). The 1996 British Crime Survey. Home Office Statistical Bulletin 19/96. Home Office, London.

Moffit, T. and Caspi, A. (1999). Findings about Partner Violence from the Dunedin Multidisciplinary Health and Development Study. National Institute of Justice Research. United States Department of Justice, Washington. 
Moffitt, T.E. and Henry, B. Neuropsychological studies of juvenile delinquency and juvenile violence. In Milner, J.S. Neuropsychology of aggression: 1991:131-146. In World Health Organisation (2002). World Report on Violence and Health. World Health Organisation, Geneva.

Morris, A. and Reilly, J. (2003). New Zealand National Survey of Crime Victims 2001. Ministry of Justice.

Morris, A. (1997). Women's Safety Survey. Ministry of Justice, Wellington.

Mouzos, J. and Makkai, T. (2004). Women's Experiences of Male Violence: Findings from the Australian Component of the International Violence Against Women Survey (IVAWS). Canberra: Australian Institute of Criminology. Research and Public Policy Series, 56.

Mukherjee, S. (1999). Ethnicity and crime: an Australian research study. Australian Institute of Criminology. A report prepared for the Department of Immigration and Multicultural Affairs

Mulroney, J. (2003). Australian Statistics on Domestic Violence. Australian Domestic and Family Violence Clearinghouse.

Murrell, A., Christoff, K. and Henning, K. (2007). Characteristics of Domestic Violence Offenders: Associations with Childhood Exposure to Violence. Journal of Family Violence, 2(7): $523-532$.

National Health Committee. (1998). The Social, Cultural and Economic Determinants of Health in New Zealand: Action to Improve Health, National Advisory Committee on Health and Disability, National Health Committee, Wellington.

Nickerson, (2004). Mental Health Service Use in New Zealand: an initial explanatory analysis of the National Data Collection. Unpublished project report. Victoria University of Wellington.

O'Donnell, C., Smith, A. and Madison, J.R. (2002). Using Demographic Risk Factors to Explain Variations in the Incidence of Violence against Women. Journal of Interpersonal violence, 17(12): 1239-1262. 
Paterson, J., Percival, T., Schluter, P., Sundborn, G., Abbott, M., Carter, S., CowleyMalcolm, E., Borrows, J., Gao, W. and the PIF Study Group. (2007). Living in New Zealand Intimate Partner Violence within a Cohort of Pacific Mothers. Journal of Interpersonal Violence, 22: 698.

Pickup, F., Williams, S., and Sweetman, C. (2001). Ending Violence against Women. A challenge for development and humanitarian work. Oxfam, United Kingdon.

Plichta, S.B. and Weisman, C.S. (1995). Spouse and partner abuse, use of health services, and unmet need for medical care in US women. Journal of Women's Health, 4(1): 45-53.

Population Reports. (2001). Violence Against Women. Issues in World Health. Johns Hopkins School of Public Health. Available online: http://www.jhuccp.org.

Pritchard, R. (2005). A review of the recent literature on intimate partner violence and common couple violence, and interventions/treatment programmes that seek to reduce partner aggression including by female perpetrators. For the Taskforce for Action on Family Violence. Unpublished.

Pritchard, R. (2007). Healthy Family Relationships: A review of the research literature to contribute to the Campaign for Action on Family Violence Project. The Ministry of Social Development, Wellington.

Reilly, J. (2003). Technical report on the 2001 New Zealand National Survey of Crime Victims. The Ministry of Justice, Wellington.

Rennison, C. M. (2003). Crime Data Brief: Intimate Partner Violence, 1993-2001 U.S. Department of Justice Office of Justice Programs.

Romans, S., Forte, T., Cohen, M.M., Du Mont, J., and Hyman. (2007). Who Is Most at Risk for Intimate Partner Violence? A Canadian Population-Based Study. Journal of Interpersonal Violence, 22(12):1495-1514.

SAS Institute. (1990). SAS/STAT user's guide, version 6. 4th ed. Cary, N.C: SAS Institute. 
Shirley, I., Adair, V. and Anderson, A. (2000). The Determinants of Good Childhood Outcomes:A Report for the Social Policy Agency, Auckland.

Simkiss, D., Ebrahim, G.J. and Waterston. A.J.R. (Eds) (2006). Research Methods: Multivariate Analysis. Journal of Tropical Paediatrics. Oxford Journals.

Stark, E. and Flitcraft, A. (1988). Women and Children at Risk: A Feminist Perspective on Child Abuse. International Journal of Health Services, 18(1): 97-118.

Statistics New Zealand. (1995, 2007). Population Statistics, 1996, 2001. Available online: http://www.stats.govt.nz/default.htm.

Straus, M.A. (1979). Measuring Intrafamily Conflict and Violence: The Conflict Tactics Scales. Journal of Marriage and the Family, 41: 75-88.

Straus, M.A. and Gelles, R.J. (1986). Societal Change and Change in Family Violence From 1975 to 1986 as Revealed by Two National Studies. Journal of Marriage and the Family, 48: 465-479.

Straus, M. and Gelles, R. (1990). Physical Violence in American Families. New Brunswick, New Jersey.

Tabachnick, B.G. and Fidell, L.S. (1996). Using Multivariate Statistics. $3^{\text {rd }}$ Ed. HarperCollins College Publishers, New York.

Tipu, M. (2003). When enough is enough. Breaking the cycle of domestic violence. Reprinted with permission from the Ngai Tahu magazine.

Tjaden, P. and Thoennes, N. (2000). Extent, Nature and Consequences of Intimate Partner Violence. Findings from the National Violence against Women Survey, National Institute of Justice, Washington.

Unicef. (2000). Domestic Violence against women and girls. In Innocenti Digest, 6.

Van Dijk and Mayhew. (1992). Criminal Victimisation in the Industralised World: Key Findings of the 1989 and 1992 International Crime Surveys. Ministry of Justice, The Netherlands. 
Vest, J.R., Catlin, T.K., Chen, J.J. and Brownson, R.C. (2002). Multistate analysis of factors associated with intimate partner violence. American Journal of Preventive Medicine, 22(3): 156-164.

Walker, R. (1996). Nga Pepa a Ranginui: The Walker papers. Penguin, Auckland.

West, C.M. Lifting the "Political Gag Order": Breaking the Silence Around Partner Violence in Ethnic Minority Families. In Jasinski, J.L. and Williams, L.M. (1998). Partner violence: A comprehensive review of 20 years of research. SAGE Publications, London.

West, C.M. (2004). Black Women and Intimate Partner Violence. Journal of Interpersonal violence, 19(12): 1487-1493.

Widom, C.S. (1989). Child abuse, neglect, and violent criminal behavior. Criminology,. In World Health Organisation. World Report on Violence and Health. World Health Organisation, Geneva.

Women's Refuge. (2007). Appeal Media Release. Published: Saturday, 14 July 2007 Appeal Media Release Women's Refuge.

World Health Organisation. (2002). World Report on Violence and Health. World Health Organisation, Geneva.

Young, J. (1999). The Exclusive Society: Social Exclusion, Crime and Difference in Late Modernity.

Young, W., Morris, A., Cameron, N. and Haslett, S. (1997). The New Zealand National Survey of Crime Victims 1996. Department of Justice, Wellington. 


\section{Glossary}

Area Units are aggregations of meshblocks with unique names. Area units within urban areas normally contain 3,000-5,000 population. (Statistics New Zealand, 2007).

Blue-collar crime is crime by a type of offender with low socioeconomic status and/or an occupation of manual labour or similar.

Call-backs are the number of times a household is contacted before the household is abandoned as a possible respondent.

CAPI is 'Computer Assisted Personal Interviewing' where interviewers enter respondent's responses directly into a computer.

CASI is "Computer Assisted Self Interviewing" where the respondent is given the computer to enter their own responses, allowing for more sensitive subjects to be answered anonymously.

Chromy's Method was used in the NZNSCV where the number of area selected within each stratum is generally proportional to the number of permanent private dwellings in each stratum (Reilly, 2003).

Common Couple Violence is more common in relationships where violence in occurring, it does tend to be more mild to moderate in nature, while instrumental violence tends to be more severe in harm.

Dark-figure of crime is crimes that remain unknown to Police, and are therefore not part of the Police count

Femicide when a male murders his intimate female partner or ex-partner.

Incidents are specific criminal acts involving one or more victims and offenders. For example, if two people were victimised at the same time and place, this would result in two victims but only one incident. 
Incidence rates give the average number of victimisations experienced per household or individual in a specified timeframe.

Instrumental violence is violence perpetrated by men with the intention to punish and control their partner.

Life-time prevalence is the proportion of individuals in the population who have ever experienced victimisation in their lifetime

Intimate Partner Violence is defined as violence in a heterosexual intimate relationship

Meshblock "is the smallest geographic unit for which statistical data is collected and processed by Statistics New Zealand. A meshblock is a defined geographic area, varying in size from part of a city block to large areas of rural land". (Statistics New Zealand, 2007).

Mutual Violence is where both the male and female intimate partner are violent towards each other.

NAU's are Nielsen Area Units which fit in size between Statistics New Zealand's meshblocks and their smaller area units. The NAU's contain almost 5000 units with seven meshblocks on average in each, averaging at about 700 people in 230 dwellings.

NZNSCV is the New Zealand National Survey of Crime Victims carried out in 2001 by the Ministry of Justice. A representative sample of New Zealand talking about their experience of victimisation.

NZSEI (New Zealand Socioeconomic Index) "scale reflects the socio-economic status of people, based on the occupation of the main income earner in their household. Each participant in the 2001 NEW NZNSCV was given a score between 10 and 90 based on this occupation" (Morris and Reilly, 2003).

NZSEI unspecified "if the main income earner did not have an occupation (e.g. s/he was a beneficiary or student), if the occupation was unspecified because of a 'don't know' response or a refusal, or if it was not specified in enough detail to code (e.g. 
'retired' was noted with no indication of the previous occupation). Most of those coded in this category were students, housewives and beneficiaries rather than refusals or 'don't know' responses".

Prevalence is the number of participant who have been victimized by an intimate partner at some point during their lifetime or during a set survey period. For example, if a person had experienced five acts of domestic violence then the prevalence would be one but the incidence would be counted as five.

Prevalence rates give the percentage of households or individuals victimised once or more in a specified timeframe.

Victimisation Survey is a survey that measures the extent of victimisation and crime through a survey.

White-collar crime is crime by a type of offender with high socioeconomic status and/or an occupation of trust or is a type of offence for example, economic crime. 
Appendix

A Section of the NZNSCV (2001) on violence by a heterosexual partner

B Derived Variables

C Results from Chi-Square

D Results from Chi-Square - Mixed vs. Sole- Māori

E Results from Log Linear Model

F Results from Logistic Regression 
Appendix A - Victimisation section from the New Zealand National Survey of Crime Victims 2001 Questionnaire

This appendix presents the section 'violence by a heterosexual partner' from the NZNSCV 2001 (Ministry of Justice, 2001). 


\section{SECTION 1: VIOLENCE BY YOUR PARTNER}

Q258 We are particularly interested in learning more about people's experience of violence at the hands of their partners. Other research has told us that this is much more common than violence by strangers. We need to know if this is so in New Zealand too. These questions only apply to a partner of the opposite sex. Answer them if you have ever been in a marital or similar partnership with a partner of the opposite sex. Questions relating to partners of the same sex are dealt with in Section 2.

Ever been in a marital/ partnership of opposite sex. $1 \rightarrow$ Continue with Q252

Never been in a marital/ partnership of opposite sex

Q252 Has any partner EVER deliberately destroyed, damaged or barmed something belonging to you, or threatened to do any of these things, in a way that actually frightened you?

Yes

No

Q253 Has any partner EVER actually used force or violence on you, such as deliberately bit, kicked, pushed, grabbed or shoved you, or deliberately bit you with something, in a way that could have burt you?

Yes

No 
Q254 Has any partwer EVER threatened to use force or violence on you, such as tbreatened to bit, kick, push, grab or shove you, in a way that actually frightened you?

Yes
No

Q255 Has any partner EVER used a weapon against you, or tbreatened to use a weapon against you, such as a knife or a gun or any other weapon?

Yes
No

No 2
Q258 These next questions also only apply to a partner of the opposite sex.
Answer them if you are in a marital or similar partnership at the present time and answer them about your current partner.

\section{Continue - in a marriage/ partnership AT PRESENT.}

Not in a partnership/ marriage AT PRESENT
$1 \rightarrow$ Continue with Q259

$2 \rightarrow$ Go to Section 2 on page 13

Q259 Since 1st January 2000, has your CURRENT partner deliberately destroyed, damaged or barmed sometbing belonging to you, or threatened to do any of these things, in a way that actually frightened you?

Yes

No

Not prepared to say

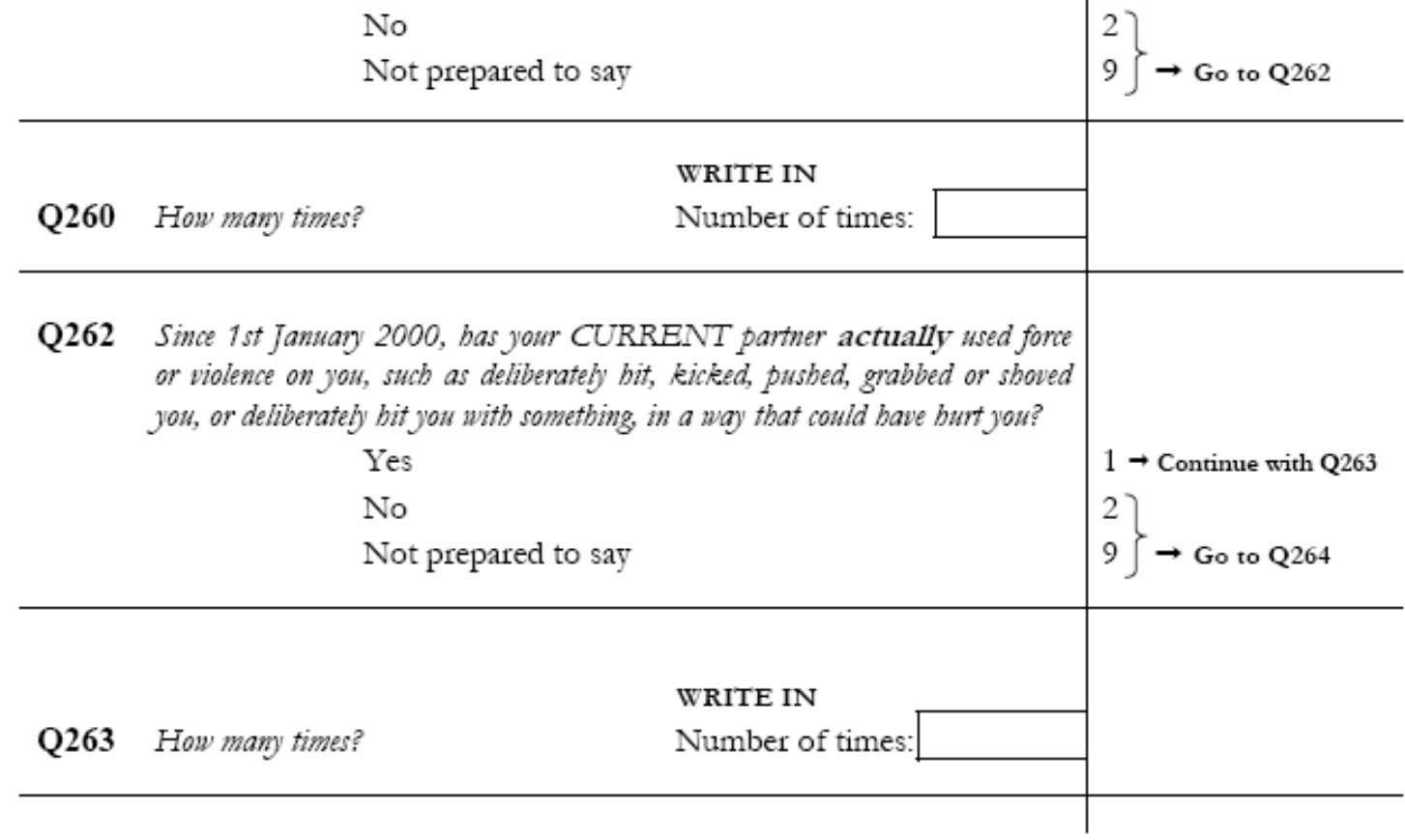


Q264 Since 1st January 2000, bas your CURRENT partner threatened to use force or violence on you, such as threatened to bit, kick, push, grab or shove you, in a way that actually frightened you?

Yes

$1 \rightarrow$ Continue with Q265

No

Not prepared to say

2

$9\} \rightarrow$ Go to Q266

WRITE IN

Q265 How many times?

Number of times:

Q266 Since 1 January 2000, bas your CURRENT partner used a weapon against you, or threatened to use a weapon against you, such as a knife or a gun or any other weapon?

Yes

$1 \rightarrow$ Continue with Q267

No

Not prepared to say

2

$9\} \rightarrow$ Go to Q272

WRITE IN

Q267 How many times?

Number of times:

IF YOU ANSWERED 'YES' TO EITHER Q259/ 262/ 264/ 266 CONTINUE WITH Q272, ELSE GO TO SECTION TWO VIOLENCE BY PEOPLE YOU KNOW WELL (on page 13).

Q272 We would like to know more about what was the MOST RECENT incident of this type since January 2000. Could you please briefly describe this MOST RECENT incident?

Please be as detailed as possible. WRITE IN YOUR ANSWER BELOW

Q273 The following questions relate to the MOST RECENT incident you bave just described at $Q^{272}$.

In what year did the incident bappen?

2000

2001

Q275 During this incident, did your partner bave a weapon or sometbing they used or threatened to use as a weapon?

Yes

No

Not prepared to say 


\begin{tabular}{|c|c|c|}
\hline Q276 & $\begin{array}{l}\text { What was the weapon? } \\
\text { PLEASE SELECT ALL THAT APPLY } \\
\qquad \begin{array}{l}\text { A bottle or a drinking glass } \\
\text { A knife or screwdriver or other stabbing weapon ..... } \\
\text { A stick or club or other hitting weapon.................. } \\
\text { A gun } \\
\text { Other (please specify below) }\end{array}\end{array}$ & $\begin{array}{l}\text { CIRCLE } \\
\text { THAT APPLY ALL } \\
01 \\
02 \\
03 \\
04 \\
37\end{array}$ \\
\hline Q278 & $\begin{array}{l}\text { Were you pbysically injured in any way? } \\
\qquad \begin{array}{l}\text { Yes } \\
\text { No } \\
\text { Not prepared to say }\end{array}\end{array}$ & 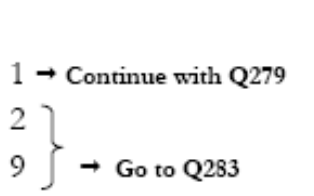 \\
\hline Q279 & $\begin{array}{l}\text { In what way were you pbysically injured? } \\
\text { PLEASE SELECT ALL THAT APPLY } \\
\qquad \begin{array}{l}\text { Bruises/ black eyes } \\
\text { Scratches } \\
\text { Cuts } \\
\text { Broken bones } \\
\text { Internal injuries } \\
\text { Other (please specify below) }\end{array}\end{array}$ & $\begin{array}{l}\text { CIRCLE } \\
\text { THAT APPLY ALL } \\
01 \\
02 \\
03 \\
04 \\
05 \\
37\end{array}$ \\
\hline Q281 & $\begin{array}{l}\text { As a result of what bappened did you get attention from a doctor or murse? } \\
\text { Yes } \\
\text { No }\end{array}$ & $\begin{array}{l}1 \rightarrow \text { Continue with Q282 } \\
2 \rightarrow \text { Go to Q283 }\end{array}$ \\
\hline Q282 & $\begin{array}{l}\text { Did you need to stay overnight in bospital? } \\
\qquad \text { Yes } \\
\text { No }\end{array}$ & $\begin{array}{l}1 \\
2\end{array}$ \\
\hline Q283 & $\begin{array}{l}\text { Was your partner affected at all by alcobol or drugs when the incident } \\
\text { bappened? } \\
\qquad \begin{array}{l}\text { Yes } \\
\text { No } \\
\text { Don't know }\end{array}\end{array}$ & $\begin{array}{l}1 \\
2 \\
9\end{array}$ \\
\hline
\end{tabular}


Q284 People react to these things in different ways. Did you bave any of the following reactions affer the incident?

PLEASE SELECT ALL THAT APPLY

CIRCLE ALI

I was angry

THAT APPLY

I was shocked

017

$02 \mid$

I was afraid $\quad 03 \mid$

I experienced difficulty sleeping $\quad 04$ |

I cried $\quad 05$ |

I had depression or anxiety attacks ......................................... 06

I had relationship problems

$07 \mid \rightarrow$ Continue

I was ashamed or guilty

08 $\quad$ with Q286

I felt bad about myself

09 |

I have been more cautious / aware .......................................... 10

I have been afraid for the children ............................................. $11 \mid$

I increased my use of alcohol or drugs or medication............... 12 |

Other (please specify below)

37 |

No reaction

38 」

Q286 Would you say you were affected by the incident very much, quite a lot, just a little, or not at all?

Very much

Quite a lot

Just a little

Not at all

Don't know 


\section{Appendix B - Derived Variables}

This chapter describes the derived variables used in the analysis for this thesis. This includes the categories recorded in the NZNSCV (2001) questionnaire, as well as detail on any variables that were derived during the analysis in this thesis.

Low cell counts meant levels of victimisation were unable to be calculated, therefore some dependent variable sub-groups needed to be aggregated.

Age Respondents were asked to specify which age bracket they belonged to. Age was grouped in the following bands: 15-16 years, 17-24 years, 25-39 years, 40-49 years, 60-69 years, $70+$ years or refused.

For the chi squared tests and regression analysis the categories 15-16 years and 1724 years were combined and become one category 15-24 years.

Ethnicity The ethnicity of respondents was prioritised into one of five categories: Maori, Pacific, NZ European, others and refused.

The category 'Asian' was included in 'other' as it was a small number of respondents and a diverse range of ethnic groups within the label 'Asian". This allowed more robust estimates.

Gender Respondents were asked to identify their gender as either male or female.

Living situation Respondents were asked to describe their household based on the following categories: One person living alone, Flatmates/others, Extended family/whanau, Couple without children/children not living with them, Couple with Children or Solo parent with child/ren 
Employment status Respondents were asked to describe their employment status by identifying which if the following categories described them. The options were: Currently in paid employment, Home duties, Social welfare beneficiary or Retired/other.

Marital status Respondents were asked to identify their current marital status. The "current situation" respondents could be categorised in to were: Divorced/separated/, Defacto relationship, Legally married or Single/never married.

Main income earner Respondents were asked if they were the main income earner in the household (yes or no response).

Number of people living in the household/Number of dependents in the household Respondents were asked for the total number of people living in the household at the tome of the interview, and the number if those living in the household aged under 15 years (classified as dependents).

For the number of people in the household, categories were combined for households with seven people or more. For the number of people in the household under 16 years, categories were combined for households with four or more under 16 year olds.

NZSEI group is a scale that reflects the socio-economic status of people based on the occupation of the main income earner in their household. is given a score between 10 and 90 based on this occupation. These scores were then grouped into seven ranges for presentation of the data in tables. The higher the score, the higher the socioeconomic status (Morris and Reilly, 2003).

Intimate partner was established by asking respondents if they had EVER been in a marital/partnership of the opposite sex or if they had NEVER been in a marital/partnership with the opposite sex. Those that answered yes to having ever been in a relationship were asked to continue answering the section on 'violence by your partner'. Those that answered that they had not ever been in a relationship carried on to the next section (violence by someone you know).

Experience IPV in the previous 12 months The specific screen questions used to identify intimate partner violence as victim in the NZNSCV (Morris and Reilly, 2003) were: 
- Since 1 January 2000, has a current partner actually used force or violence on you, such as deliberately hit, kicked, punched, grabbed or shoved you, or deliberately hit you with something, in a way that could have hurt you?

- Since 1 January 2000, has a current partner threatened to use force or violence on you, such as threatened to hit, kick, push, grab or shove you, in a way that actually frightened you?

- Since 1 January 2000, has a current partner deliberately destroyed, damaged or harmed something belonging to you, or threatened to do any of these things, in a way that actually frightened you?

- Since 1 January 2000, has a current partner used a weapon against you, or threatened to use a weapon against you, such as a knife or gun or any other weapon?

Experience IPV in their lifetime The specific screen questions used to identify intimate partner violence as victim in the NZNSCV (Morris and Reilly, 2003) were:

- Has any partner EVER actually used force or violence on you, such as deliberately hit, kicked, punched, grabbed or shoved you, or deliberately hit you with something, in a way that could have hurt you?

- Has any partner EVER threatened to use force or violence on you, such as threatened to hit, kick, push, grab or shove you, in a way that actually frightened you?

- Has any partner EVER deliberately destroyed, damaged or harmed something belonging to you, or threatened to do any of these things, in a way that actually frightened you?

- Has any partner EVER used a weapon against you, or threatened to use a weapon against you, such as a knife or gun or any other weapon? 


\section{Appendix C - Results from Chi-Square}

This appendix presents results of univariate analysis of intimate partner violence in New Zealand. These results are discussed fully in chapter five. 


\section{Lifetime}

\begin{tabular}{|c|c|c|c|c|c|c|c|c|c|}
\hline \multirow{6}{*}{$\begin{array}{c}\text { Frequency } \\
\text { Percent } \\
\text { Row Pct } \\
\text { Col Pct }\end{array}$} & \multicolumn{9}{|c|}{ Table of Victim by NZSEI Group } \\
\hline & \multirow[t]{2}{*}{ Victim } & \multicolumn{7}{|c|}{ NZSEI Group: NZ Socio-Economic Index - Grouped) } & \multirow[t]{2}{*}{ Total } \\
\hline & & $\begin{array}{c}\text { NZSEI } \\
\text { Not } \\
\text { specified }\end{array}$ & $\begin{array}{c}\text { NZSEI } \\
10-29\end{array}$ & $\begin{array}{c}\text { NZSEI } \\
30-39\end{array}$ & $\begin{array}{c}\text { NZSEI } \\
40-49\end{array}$ & $\begin{array}{c}\text { NZSEI } \\
50-59\end{array}$ & $\begin{array}{c}\text { NZSEI } \\
60-74\end{array}$ & $\begin{array}{l}\text { NZSEI } \\
75-90\end{array}$ & \\
\hline & 0 & $\begin{array}{l}117 \\
3.09 \\
4.21 \\
48.95\end{array}$ & $\begin{array}{l}477 \\
12.61 \\
17.15 \\
74.30\end{array}$ & $\begin{array}{l}488 \\
12.90 \\
17.55 \\
71.98\end{array}$ & $\begin{array}{l}581 \\
15.36 \\
20.89 \\
73.17\end{array}$ & $\begin{array}{l}514 \\
13.59 \\
18.48 \\
76.72\end{array}$ & $\begin{array}{l}437 \\
11.55 \\
15.71 \\
78.88\end{array}$ & $\begin{array}{l}167 \\
4.41 \\
6.01 \\
81.07\end{array}$ & $\begin{array}{l}2781 \\
73.51\end{array}$ \\
\hline & 1 & $\begin{array}{l}122 \\
3.22 \\
12.18 \\
51.05\end{array}$ & $\begin{array}{l}165 \\
4.36 \\
16.47 \\
25.70\end{array}$ & $\begin{array}{l}190 \\
5.02 \\
18.96 \\
28.02\end{array}$ & $\begin{array}{l}213 \\
5.63 \\
21.26 \\
26.83\end{array}$ & $\begin{array}{l}156 \\
4.12 \\
15.57 \\
23.28\end{array}$ & $\begin{array}{l}117 \\
3.09 \\
11.68 \\
21.12\end{array}$ & $\begin{array}{l}39 \\
1.03 \\
3.89 \\
18.93\end{array}$ & $\begin{array}{l}1002 \\
26.49\end{array}$ \\
\hline & Total & $\begin{array}{l}239 \\
6.32\end{array}$ & $\begin{array}{l}642 \\
16.97\end{array}$ & $\begin{array}{l}678 \\
17.92\end{array}$ & $\begin{array}{l}794 \\
20.99\end{array}$ & $\begin{array}{l}670 \\
17.71\end{array}$ & $\begin{array}{l}554 \\
14.64\end{array}$ & $\begin{array}{l}206 \\
5.45\end{array}$ & $\begin{array}{l}3783 \\
100.00\end{array}$ \\
\hline
\end{tabular}

\begin{tabular}{|c||c||c||c||}
\hline Statistic & DF & Value & Prob \\
\hline \hline Chi-Square & 6 & 92.8734 & $<.0001$ \\
\hline \hline Likelihood Ratio Chi-Square & 6 & 84.7181 & $<.0001$ \\
\hline \hline Mantel-Haenszel Chi-Square & 1 & 46.9197 & $<.0001$ \\
\hline \hline Phi Coefficient & & 0.1567 & \\
\hline \hline Contingency Coefficient & & 0.1548 & \\
\hline \hline Cramer's V & & 0.1567 & \\
\hline \hline
\end{tabular}

Sample Size $=3783$ 


\begin{tabular}{|c|c|c|c|c|c|c|c|c|}
\hline \multirow{7}{*}{$\begin{array}{l}\text { Frequency } \\
\text { Percent } \\
\text { Row Pct } \\
\text { Col Pct }\end{array}$} & \multicolumn{8}{|c|}{ Table of Victim by Living Situation } \\
\hline & \multirow[t]{2}{*}{ Victim } & \multicolumn{6}{|c|}{ Living Situation } & \multirow[t]{2}{*}{ Total } \\
\hline & & $\begin{array}{l}\text { Couple } \\
\text { with } \\
\text { children }\end{array}$ & $\begin{array}{c}\text { Couple } \\
\text { without } \\
\text { children/ } \\
\text { children } \\
\text { not living } \\
\text { in the } \\
\text { household }\end{array}$ & $\begin{array}{c}\text { Extended } \\
\text { family/whanau } \\
\text { /other } \\
\text { combination }\end{array}$ & $\begin{array}{c}\text { Flatmates/ } \\
\text { Others }\end{array}$ & $\begin{array}{l}\text { One } \\
\text { person } \\
\text { living } \\
\text { alone }\end{array}$ & $\begin{array}{c}\text { Solo } \\
\text { parent } \\
\text { with } \\
\text { child/ren }\end{array}$ & \\
\hline & 0 & $\begin{array}{l}1040 \\
27.51 \\
37.41 \\
76.08\end{array}$ & $\begin{array}{l}1036 \\
27.40 \\
37.27 \\
87.28\end{array}$ & $\begin{array}{l}289 \\
7.64 \\
10.40 \\
71.01\end{array}$ & $\begin{array}{l}87 \\
2.30 \\
3.13 \\
62.14\end{array}$ & $\begin{array}{l}221 \\
5.85 \\
7.95 \\
60.05\end{array}$ & $\begin{array}{l}107 \\
2.83 \\
3.85 \\
34.29\end{array}$ & $\begin{array}{l}2780 \\
73.53\end{array}$ \\
\hline & 1 & $\begin{array}{l}327 \\
8.65 \\
32.67 \\
23.92\end{array}$ & $\begin{array}{l}151 \\
3.99 \\
15.08 \\
12.72\end{array}$ & $\begin{array}{l}118 \\
3.12 \\
11.79 \\
28.99\end{array}$ & $\begin{array}{l}53 \\
1.40 \\
5.29 \\
37.86\end{array}$ & $\begin{array}{l}147 \\
3.89 \\
14.69 \\
39.95\end{array}$ & $\begin{array}{l}205 \\
5.42 \\
20.48 \\
65.71\end{array}$ & $\begin{array}{l}1001 \\
26.47\end{array}$ \\
\hline & Total & $\begin{array}{l}1367 \\
36.15\end{array}$ & $\begin{array}{l}1187 \\
31.39\end{array}$ & $\begin{array}{l}407 \\
10.76\end{array}$ & $\begin{array}{l}140 \\
3.70\end{array}$ & $\begin{array}{l}368 \\
9.73\end{array}$ & $\begin{array}{l}312 \\
8.25\end{array}$ & $\begin{array}{l}3781 \\
100.00\end{array}$ \\
\hline & \multicolumn{8}{|c|}{ Frequency Missing = 2} \\
\hline
\end{tabular}

\begin{tabular}{|c||c||c||c||}
\hline Statistic & DF & Value & Prob \\
\hline \hline Chi-Square & 5 & 411.5603 & $<.0001$ \\
\hline \hline Likelihood Ratio Chi-Square & 5 & 389.5443 & $<.0001$ \\
\hline \hline Mantel-Haenszel Chi-Square & 1 & 265.5082 & $<.0001$ \\
\hline \hline Phi Coefficient & & 0.3299 & \\
\hline \hline Contingency Coefficient & & 0.3133 & \\
\hline \hline Cramer's V & & 0.3299 & \\
\hline \hline
\end{tabular}

Effective Sample Size $=3781$

Frequency Missing = 2 


\begin{tabular}{|c|c|c|c|c|}
\hline \multirow{2}{*}{$\begin{array}{c}\text { Frequency } \\
\text { Percent } \\
\text { Row Pct } \\
\text { Col Pct }\end{array}$} & \multicolumn{4}{|c|}{ Table of Victim by Gender } \\
\hline & \multirow[t]{2}{*}{ Victim } & \multicolumn{2}{|c|}{ Gender } & \multirow[t]{2}{*}{ Total } \\
\hline & & Male & Female & \\
\hline & 0 & $\begin{array}{l}1323 \\
34.97 \\
47.57 \\
81.07\end{array}$ & $\begin{array}{l}1458 \\
38.54 \\
52.43 \\
67.78\end{array}$ & $\begin{array}{l}2781 \\
73.51\end{array}$ \\
\hline & 1 & $\begin{array}{l}309 \\
8.17 \\
30.84 \\
18.93\end{array}$ & $\begin{array}{l}693 \\
18.32 \\
69.16 \\
32.22\end{array}$ & $\begin{array}{l}1002 \\
26.49\end{array}$ \\
\hline & Total & $\begin{array}{l}1632 \\
43.14\end{array}$ & $\begin{array}{l}2151 \\
56.86\end{array}$ & $\begin{array}{l}3783 \\
100.00\end{array}$ \\
\hline
\end{tabular}

\begin{tabular}{|c||c||c||c||}
\hline \hline Statistic & DF & Value & Prob \\
\hline \hline Chi-Square & 1 & 84.0949 & $<.0001$ \\
\hline \hline Likelihood Ratio Chi-Square & 1 & 86.1218 & $<.0001$ \\
\hline \hline Continuity Adj. Chi-Square & 1 & 83.4140 & $<.0001$ \\
\hline \hline Mantel-Haenszel Chi-Square & 1 & 84.0727 & $<.0001$ \\
\hline \hline Phi Coefficient & & 0.1491 & \\
\hline \hline Contingency Coefficient & & 0.1475 & \\
\hline \hline Cramer's V & & 0.1491 & \\
\hline \hline
\end{tabular}

\begin{tabular}{|c||l||}
\hline \multicolumn{2}{|c|}{ Fisher's Exact Test } \\
\hline \hline Cell (1,1) Frequency (F) & 1323 \\
\hline \hline Left-sided $\operatorname{Pr}<=$ F & 1.0000 \\
\hline \hline Right-sided $\operatorname{Pr}>=$ F & $1.225 \mathrm{E}-20$ \\
\hline \hline & \\
\hline \hline Table Probability (P) & $1.273 \mathrm{E}-20$ \\
\hline \hline Two-sided Pr <= P & $2.023 \mathrm{E}-20$ \\
\hline
\end{tabular}

Sample Size $=3783$ 


\begin{tabular}{|c|c|c|c|c|c|c|}
\hline \multirow{2}{*}{$\begin{array}{c}\text { Frequency } \\
\text { Percent } \\
\text { Row Pct } \\
\text { Col Pct }\end{array}$} & \multicolumn{6}{|c|}{ Table of Victim by Age } \\
\hline & \multirow[t]{2}{*}{ Victim } & \multicolumn{4}{|c|}{ Age } & \multirow[t]{2}{*}{ Total } \\
\hline & & $15-24$ & $25-39$ & $40-59$ & $\begin{array}{c}60 \text { and } \\
\text { over }\end{array}$ & \\
\hline & 0 & $\begin{array}{l}194 \\
5.13 \\
6.98 \\
66.67\end{array}$ & $\begin{array}{l}846 \\
22.37 \\
30.43 \\
65.03\end{array}$ & $\begin{array}{l}1066 \\
28.19 \\
38.35 \\
74.29\end{array}$ & $\begin{array}{l}674 \\
17.82 \\
24.24 \\
89.27\end{array}$ & $\begin{array}{l}2780 \\
73.51\end{array}$ \\
\hline & 1 & $\begin{array}{l}97 \\
2.56 \\
9.68 \\
33.33\end{array}$ & $\begin{array}{l}455 \\
12.03 \\
45.41 \\
34.97\end{array}$ & $\begin{array}{l}369 \\
9.76 \\
36.83 \\
25.71\end{array}$ & $\begin{array}{l}81 \\
2.14 \\
8.08 \\
10.73\end{array}$ & $\begin{array}{l}1002 \\
26.49\end{array}$ \\
\hline & Total & $\begin{array}{l}291 \\
7.69\end{array}$ & $\begin{array}{l}1301 \\
34.40\end{array}$ & $\begin{array}{l}1435 \\
37.94\end{array}$ & $\begin{array}{l}755 \\
19.96\end{array}$ & $\begin{array}{l}3782 \\
100.00\end{array}$ \\
\hline & \multicolumn{6}{|c|}{ Frequency Missing = 1} \\
\hline
\end{tabular}

\begin{tabular}{|c||c||c||c||}
\hline Statistic & DF & Value & Prob \\
\hline \hline Chi-Square & 3 & 151.8264 & $<.0001$ \\
\hline \hline Likelihood Ratio Chi-Square & 3 & 167.8844 & $<.0001$ \\
\hline Mantel-Haenszel Chi-Square & 1 & 128.9643 & $<.0001$ \\
\hline \hline Phi Coefficient & & 0.2004 & \\
\hline \hline Contingency Coefficient & & 0.1965 & \\
\hline \hline Cramer's V & & 0.2004 & \\
\hline \hline
\end{tabular}

Effective Sample Size $=3782$

Frequency Missing = 1 


\begin{tabular}{||c||c||l||l|l||||}
\hline \hline \multirow{2}{|c||}{$\begin{array}{c}\text { Frequency } \\
\text { Percent } \\
\text { Row Pct } \\
\text { Col Pct }\end{array}$} \\
\cline { 3 - 6 }
\end{tabular}

\begin{tabular}{|c||c||c||c||}
\hline Statistic & DF & Value & Prob \\
\hline \hline Chi-Square & 3 & 128.8072 & $<.0001$ \\
\hline \hline Likelihood Ratio Chi-Square & 3 & 120.1162 & $<.0001$ \\
\hline Mantel-Haenszel Chi-Square & 1 & 80.9156 & $<.0001$ \\
\hline \hline Phi Coefficient & & 0.1845 & \\
\hline \hline Contingency Coefficient & & 0.1815 & \\
\hline \hline Cramer's V & & 0.1845 & \\
\hline \hline
\end{tabular}

Sample Size $=3783$ 


\begin{tabular}{|c|c|c|c|c|c|}
\hline \multirow{6}{*}{$\begin{array}{c}\text { Frequency } \\
\text { Percent } \\
\text { Row Pct } \\
\text { Col Pct }\end{array}$} & \multicolumn{5}{|c|}{ Table of Victim by Household Tenure } \\
\hline & \multirow[t]{2}{*}{ Victim } & \multicolumn{3}{|c|}{ Household Tenure } & \multirow[t]{2}{*}{ Total } \\
\hline & & Rented & $\begin{array}{c}\text { Owned } \\
\text { (including a } \\
\text { mortgage) }\end{array}$ & Other & \\
\hline & 0 & $\begin{array}{l}752 \\
19.88 \\
27.04 \\
62.67\end{array}$ & $\begin{array}{l}1972 \\
52.13 \\
70.91 \\
78.97\end{array}$ & $\begin{array}{l}57 \\
1.51 \\
2.05 \\
66.28\end{array}$ & $\begin{array}{l}2781 \\
73.51\end{array}$ \\
\hline & 1 & $\begin{array}{l}448 \\
11.84 \\
44.71 \\
37.33\end{array}$ & $\begin{array}{l}525 \\
13.88 \\
52.40 \\
21.03\end{array}$ & $\begin{array}{l}29 \\
0.77 \\
2.89 \\
33.72\end{array}$ & $\begin{array}{l}1002 \\
26.49\end{array}$ \\
\hline & Total & $\begin{array}{l}1200 \\
31.72\end{array}$ & $\begin{array}{l}2497 \\
66.01\end{array}$ & $\begin{array}{l}86 \\
2.27\end{array}$ & $\begin{array}{l}3783 \\
100.00\end{array}$ \\
\hline
\end{tabular}

\begin{tabular}{|c||c||c||c||}
\hline Statistic & DF & Value & Prob \\
\hline \hline Chi-Square & 2 & 113.0686 & $<.0001$ \\
\hline \hline Likelihood Ratio Chi-Square & 2 & 109.8188 & $<.0001$ \\
\hline \hline Mantel-Haenszel Chi-Square & 1 & 15.7750 & $<.0001$ \\
\hline \hline Phi Coefficient & & 0.1729 & \\
\hline \hline Contingency Coefficient & & 0.1704 & \\
\hline \hline Cramer's V & & 0.1729 & \\
\hline \hline
\end{tabular}

Sample Size $=3783$ 


\begin{tabular}{|c|c|c|c|c|c|c|c|}
\hline \multirow{6}{*}{$\begin{array}{c}\text { Frequency } \\
\text { Percent } \\
\text { Row Pct } \\
\text { Col Pct }\end{array}$} & \multicolumn{7}{|c|}{ Table of Victim by Employment Status } \\
\hline & \multirow[t]{2}{*}{ Victim } & \multicolumn{5}{|c|}{ Employment Status } & \multirow[t]{2}{*}{ Total } \\
\hline & & $\begin{array}{l}\text { Currently in } \\
\text { Paid } \\
\text { Employment }\end{array}$ & $\begin{array}{l}\text { Home } \\
\text { Duties }\end{array}$ & Retired & $\begin{array}{c}\text { Social } \\
\text { Welfare/ } \\
\text { Beneficiary }\end{array}$ & $\begin{array}{l}\text { Student } \\
\text { or } \\
\text { Other }\end{array}$ & \\
\hline & 0 & $\begin{array}{l}1581 \\
41.79 \\
56.85 \\
74.58\end{array}$ & $\begin{array}{l}284 \\
7.51 \\
10.21 \\
74.74\end{array}$ & $\begin{array}{l}533 \\
14.09 \\
19.17 \\
88.98\end{array}$ & $\begin{array}{l}196 \\
5.18 \\
7.05 \\
47.12\end{array}$ & $\begin{array}{l}187 \\
4.94 \\
6.72 \\
69.78\end{array}$ & $\begin{array}{l}2781 \\
73.51\end{array}$ \\
\hline & 1 & $\begin{array}{l}539 \\
14.25 \\
53.79 \\
25.42\end{array}$ & $\begin{array}{l}96 \\
2.54 \\
9.58 \\
25.26\end{array}$ & $\begin{array}{l}66 \\
1.74 \\
6.59 \\
11.02\end{array}$ & $\begin{array}{l}220 \\
5.82 \\
21.96 \\
52.88\end{array}$ & $\begin{array}{l}81 \\
2.14 \\
8.08 \\
30.22\end{array}$ & $\begin{array}{l}1002 \\
26.49\end{array}$ \\
\hline & Total & $\begin{array}{l}2120 \\
56.04\end{array}$ & $\begin{array}{l}380 \\
10.04\end{array}$ & $\begin{array}{l}599 \\
15.83\end{array}$ & $\begin{array}{l}416 \\
11.00\end{array}$ & $\begin{array}{l}268 \\
7.08\end{array}$ & $\begin{array}{l}3783 \\
100.00\end{array}$ \\
\hline
\end{tabular}

\begin{tabular}{|c||c||c||c||}
\hline Statistic & DF & Value & Prob \\
\hline \hline Chi-Square & 4 & 225.9297 & $<.0001$ \\
\hline \hline Likelihood Ratio Chi-Square & 4 & 221.0550 & $<.0001$ \\
\hline \hline Mantel-Haenszel Chi-Square & 1 & 24.3695 & $<.0001$ \\
\hline \hline Phi Coefficient & & 0.2444 & \\
\hline \hline Contingency Coefficient & & 0.2374 & \\
\hline \hline Cramer's V & & 0.2444 & \\
\hline \hline
\end{tabular}

Sample Size $=3783$ 


\begin{tabular}{|c|c|c|c|c|}
\hline \multirow{2}{*}{$\begin{array}{c}\text { Frequency } \\
\text { Percent } \\
\text { Row Pct } \\
\text { Col Pct }\end{array}$} & \multicolumn{4}{|c|}{ Table of Victim by Main Income Earner for household } \\
\hline & \multirow[t]{2}{*}{ Victim } & \multicolumn{2}{|c|}{ Main Income Earner for household } & \multirow[t]{2}{*}{ Total } \\
\hline & & Yes & No & \\
\hline & 0 & $\begin{array}{l}1626 \\
42.98 \\
58.47 \\
71.47\end{array}$ & $\begin{array}{l}1155 \\
30.53 \\
41.53 \\
76.59\end{array}$ & $\begin{array}{l}2781 \\
73.51\end{array}$ \\
\hline & 1 & $\begin{array}{l}649 \\
17.16 \\
64.77 \\
28.53\end{array}$ & $\begin{array}{l}353 \\
9.33 \\
35.23 \\
23.41\end{array}$ & $\begin{array}{l}1002 \\
26.49\end{array}$ \\
\hline & Total & $\begin{array}{l}2275 \\
60.14\end{array}$ & $\begin{array}{l}1508 \\
39.86\end{array}$ & $\begin{array}{l}3783 \\
100.00\end{array}$ \\
\hline
\end{tabular}

\begin{tabular}{|c||c||c||c||}
\hline Statistic & DF & Value & Prob \\
\hline \hline Chi-Square & 1 & 12.2044 & 0.0005 \\
\hline \hline Likelihood Ratio Chi-Square & 1 & 12.3236 & 0.0004 \\
\hline \hline Continuity Adj. Chi-Square & 1 & 11.9430 & 0.0005 \\
\hline Mantel-Haenszel Chi-Square & 1 & 12.2012 & 0.0005 \\
\hline \hline Phi Coefficient & & -0.0568 & \\
\hline Contingency Coefficient & & 0.0567 & \\
\hline \hline Cramer's V & & -0.0568 & \\
\hline \hline
\end{tabular}

\begin{tabular}{|c||l||}
\hline \multicolumn{2}{|c|}{ Fisher's Exact Test } \\
\hline \hline Cell (1,1) Frequency (F) & 1626 \\
\hline \hline Left-sided $\operatorname{Pr}<=$ F & $2.592 \mathrm{E}-04$ \\
\hline \hline Right-sided $\mathrm{Pr}>=$ F & 0.9998 \\
\hline \hline & \\
\hline Table Probability (P) & $6.445 \mathrm{E}-05$ \\
\hline \hline Two-sided Pr <= P & $4.661 \mathrm{E}-04$ \\
\hline
\end{tabular}

Sample Size $=3783$ 


\begin{tabular}{|c|c|c|c|c|c|c|}
\hline \multirow{6}{*}{$\begin{array}{c}\text { Frequency } \\
\text { Percent } \\
\text { Row Pct } \\
\text { Col Pct }\end{array}$} & \multicolumn{6}{|c|}{ Table of Victim by Marital Status } \\
\hline & \multirow[t]{2}{*}{ Victim } & \multicolumn{4}{|c|}{ Marital Status } & \multirow[t]{2}{*}{ Total } \\
\hline & & $\begin{array}{c}\text { Defacto } \\
\text { Relationship }\end{array}$ & $\begin{array}{l}\text { Divorced/ } \\
\text { Sep }\end{array}$ & $\begin{array}{c}\text { Legal } \\
\text { Married }\end{array}$ & $\begin{array}{c}\text { Single- } \\
\text { Never } \\
\text { Married }\end{array}$ & \\
\hline & 0 & $\begin{array}{l}347 \\
9.17 \\
12.48 \\
63.90\end{array}$ & $\begin{array}{l}240 \\
6.34 \\
8.63 \\
48.00\end{array}$ & $\begin{array}{l}1954 \\
51.65 \\
70.26 \\
84.92\end{array}$ & $\begin{array}{l}240 \\
6.34 \\
8.63 \\
54.67\end{array}$ & $\begin{array}{l}2781 \\
73.51\end{array}$ \\
\hline & 1 & $\begin{array}{l}196 \\
5.18 \\
19.56 \\
36.10\end{array}$ & $\begin{array}{l}260 \\
6.87 \\
25.95 \\
52.00\end{array}$ & $\begin{array}{l}347 \\
9.17 \\
34.63 \\
15.08\end{array}$ & $\begin{array}{l}199 \\
5.26 \\
19.86 \\
45.33\end{array}$ & $\begin{array}{l}1002 \\
26.49\end{array}$ \\
\hline & Total & $\begin{array}{l}543 \\
14.35\end{array}$ & $\begin{array}{l}500 \\
13.22\end{array}$ & $\begin{array}{l}2301 \\
60.82\end{array}$ & $\begin{array}{l}439 \\
11.60\end{array}$ & $\begin{array}{l}3783 \\
100.00\end{array}$ \\
\hline
\end{tabular}

\begin{tabular}{|c||c||c||c||}
\hline Statistic & DF & Value & Prob \\
\hline \hline Chi-Square & 3 & 426.7043 & $<.0001$ \\
\hline \hline Likelihood Ratio Chi-Square & 3 & 414.8004 & $<.0001$ \\
\hline \hline Mantel-Haenszel Chi-Square & 1 & 41.3600 & $<.0001$ \\
\hline \hline Phi Coefficient & & 0.3358 & \\
\hline \hline Contingency Coefficient & & 0.3184 & \\
\hline \hline Cramer's V & & 0.3358 & \\
\hline \hline
\end{tabular}

Sample Size $=3783$ 


\begin{tabular}{|c|c|c|c|c|c|c|c|c|c|}
\hline \multirow{6}{*}{$\begin{array}{c}\text { Frequency } \\
\text { Percent } \\
\text { Row Pct } \\
\text { Col Pct }\end{array}$} & \multicolumn{9}{|c|}{ Table of Victim by Number living in the Household } \\
\hline & \multirow[t]{2}{*}{ Victim } & \multicolumn{7}{|c|}{ Number living in the Household } & \multirow[t]{2}{*}{ Total } \\
\hline & & $\begin{array}{c}1 \\
\text { Person }\end{array}$ & $\begin{array}{c}2 \\
\text { Persons }\end{array}$ & $\begin{array}{c}3 \\
\text { Persons }\end{array}$ & $\begin{array}{c}4 \\
\text { Persons }\end{array}$ & $\begin{array}{c}5 \\
\text { Persons }\end{array}$ & $\begin{array}{c}6 \\
\text { Persons }\end{array}$ & $\begin{array}{l}7 \text { or } \\
\text { more }\end{array}$ & \\
\hline & 0 & $\begin{array}{l}223 \\
5.89 \\
8.02 \\
60.27\end{array}$ & $\begin{array}{l}1122 \\
29.66 \\
40.35 \\
82.44\end{array}$ & $\begin{array}{l}455 \\
12.03 \\
16.36 \\
67.41\end{array}$ & $\begin{array}{l}508 \\
13.43 \\
18.27 \\
70.46\end{array}$ & $\begin{array}{l}247 \\
6.53 \\
8.88 \\
70.17\end{array}$ & $\begin{array}{l}114 \\
3.01 \\
4.10 \\
70.37\end{array}$ & $\begin{array}{l}112 \\
2.96 \\
4.03 \\
78.87\end{array}$ & $\begin{array}{l}2781 \\
73.51\end{array}$ \\
\hline & 1 & $\begin{array}{l}147 \\
3.89 \\
14.67 \\
39.73\end{array}$ & $\begin{array}{l}239 \\
6.32 \\
23.85 \\
17.56\end{array}$ & $\begin{array}{l}220 \\
5.82 \\
21.96 \\
32.59\end{array}$ & $\begin{array}{l}213 \\
5.63 \\
21.26 \\
29.54\end{array}$ & $\begin{array}{l}105 \\
2.78 \\
10.48 \\
29.83\end{array}$ & $\begin{array}{l}48 \\
1.27 \\
4.79 \\
29.63\end{array}$ & $\begin{array}{l}30 \\
0.79 \\
2.99 \\
21.13\end{array}$ & $\begin{array}{l}1002 \\
26.49\end{array}$ \\
\hline & Total & $\begin{array}{l}370 \\
9.78\end{array}$ & $\begin{array}{l}1361 \\
35.98\end{array}$ & $\begin{array}{l}675 \\
17.84\end{array}$ & $\begin{array}{l}721 \\
19.06\end{array}$ & $\begin{array}{l}352 \\
9.30\end{array}$ & $\begin{array}{l}162 \\
4.28\end{array}$ & $\begin{array}{l}142 \\
3.75\end{array}$ & $\begin{array}{l}3783 \\
100.00\end{array}$ \\
\hline
\end{tabular}

\begin{tabular}{|c||c||c||c||}
\hline Statistic & DF & Value & Prob \\
\hline \hline Chi-Square & 6 & 110.3353 & $<.0001$ \\
\hline \hline Likelihood Ratio Chi-Square & 6 & 112.0368 & $<.0001$ \\
\hline \hline Mantel-Haenszel Chi-Square & 1 & 1.7207 & 0.1896 \\
\hline \hline Phi Coefficient & & 0.1708 & \\
\hline \hline Contingency Coefficient & & 0.1683 & \\
\hline \hline Cramer's V & & 0.1708 & \\
\hline \hline
\end{tabular}

Sample Size $=3783$ 


\begin{tabular}{|c|c|c|c|c|c|c|c|}
\hline \multirow{7}{*}{$\begin{array}{c}\text { Frequency } \\
\text { Percent } \\
\text { Row Pct } \\
\text { Col Pct }\end{array}$} & \multicolumn{7}{|c|}{$\begin{array}{c}\text { Table of Victim by Number living in the Household } \\
\text { under } 16 \text { years of age }\end{array}$} \\
\hline & \multirow[t]{2}{*}{ Victim } & \multicolumn{5}{|c|}{$\begin{array}{l}\text { Number living in the Household } \\
\text { under } 16 \text { years of age }\end{array}$} & \multirow[t]{2}{*}{ Total } \\
\hline & & $\begin{array}{c}0 \\
\text { Persons }\end{array}$ & $\begin{array}{c}1 \\
\text { Person }\end{array}$ & $\begin{array}{l}2 \\
\text { Persons }\end{array}$ & $\begin{array}{l}3 \\
\text { Persons }\end{array}$ & $\begin{array}{l}4 \text { or } \\
\text { more }\end{array}$ & \\
\hline & 0 & $\begin{array}{l}1628 \\
43.05 \\
58.56 \\
79.03\end{array}$ & $\begin{array}{l}420 \\
11.11 \\
15.11 \\
67.63\end{array}$ & $\begin{array}{l}436 \\
11.53 \\
15.68 \\
67.49\end{array}$ & $\begin{array}{l}189 \\
5.00 \\
6.80 \\
65.63\end{array}$ & $\begin{array}{l}107 \\
2.83 \\
3.85 \\
64.07\end{array}$ & $\begin{array}{l}2780 \\
73.51\end{array}$ \\
\hline & 1 & $\begin{array}{l}432 \\
11.42 \\
43.11 \\
20.97\end{array}$ & $\begin{array}{l}201 \\
5.31 \\
20.06 \\
32.37\end{array}$ & $\begin{array}{l}210 \\
5.55 \\
20.96 \\
32.51\end{array}$ & $\begin{array}{l}99 \\
2.62 \\
9.88 \\
34.38\end{array}$ & $\begin{array}{l}60 \\
1.59 \\
5.99 \\
35.93\end{array}$ & $\begin{array}{l}1002 \\
26.49\end{array}$ \\
\hline & Total & $\begin{array}{l}2060 \\
54.47\end{array}$ & $\begin{array}{l}621 \\
16.42\end{array}$ & $\begin{array}{l}646 \\
17.08\end{array}$ & $\begin{array}{l}288 \\
7.62\end{array}$ & $\begin{array}{l}167 \\
4.42\end{array}$ & $\begin{array}{l}3782 \\
100.00\end{array}$ \\
\hline & \multicolumn{7}{|c|}{ Frequency Missina $=1$} \\
\hline
\end{tabular}

\begin{tabular}{|c||c||c||c||}
\hline Statistic & DF & Value & Prob \\
\hline \hline Chi-Square & 4 & 72.0808 & $<.0001$ \\
\hline \hline Likelihood Ratio Chi-Square & 4 & 71.7830 & $<.0001$ \\
\hline \hline Mantel-Haenszel Chi-Square & 1 & 57.9361 & $<.0001$ \\
\hline \hline Phi Coefficient & & 0.1381 & \\
\hline \hline Contingency Coefficient & & 0.1368 & \\
\hline \hline Cramer's V & & 0.1381 & \\
\hline \hline
\end{tabular}

Effective Sample Size $=3782$

Frequency Missing = 1 


\begin{tabular}{|c|c|c|c|c|c|c|}
\hline \multirow{6}{*}{$\begin{array}{c}\text { Frequency } \\
\text { Percent } \\
\text { Row Pct } \\
\text { Col Pct }\end{array}$} & \multicolumn{6}{|c|}{ Table of Victim by Ethnicity } \\
\hline & \multirow[t]{2}{*}{ Victim } & \multicolumn{4}{|c|}{ Ethnicity } & \multirow[t]{2}{*}{ Total } \\
\hline & & Māori & $\begin{array}{c}\mathrm{NZ} \\
\text { European }\end{array}$ & Pacific & other & \\
\hline & Not a Victim & $\begin{array}{l}420 \\
14.47 \\
15.15 \\
88.42\end{array}$ & $\begin{array}{l}1844 \\
63.52 \\
66.50 \\
97.21\end{array}$ & $\begin{array}{l}330 \\
11.37 \\
11.90 \\
94.83\end{array}$ & $\begin{array}{l}179 \\
6.17 \\
6.46 \\
97.81\end{array}$ & $\begin{array}{l}2773 \\
95.52\end{array}$ \\
\hline & Victim & $\begin{array}{l}55 \\
1.89 \\
42.31 \\
11.58\end{array}$ & $\begin{array}{l}53 \\
1.83 \\
40.77 \\
2.79\end{array}$ & $\begin{array}{l}18 \\
0.62 \\
13.85 \\
5.17\end{array}$ & $\begin{array}{l}4 \\
0.14 \\
3.08 \\
2.19\end{array}$ & $\begin{array}{l}130 \\
4.48\end{array}$ \\
\hline & Total & $\begin{array}{l}475 \\
16.36\end{array}$ & $\begin{array}{l}1897 \\
65.35\end{array}$ & $\begin{array}{l}348 \\
11.99\end{array}$ & $\begin{array}{l}183 \\
6.30\end{array}$ & $\begin{array}{l}2903 \\
100.00\end{array}$ \\
\hline
\end{tabular}

\begin{tabular}{|c||c||c||c||}
\hline Statistic & DF & Value & Prob \\
\hline \hline Chi-Square & 3 & 71.2102 & $<.0001$ \\
\hline \hline Likelihood Ratio Chi-Square & 3 & 57.1909 & $<.0001$ \\
\hline \hline Mantel-Haenszel Chi-Square & 1 & 23.9934 & $<.0001$ \\
\hline \hline Phi Coefficient & & 0.1566 & \\
\hline \hline Contingency Coefficient & & 0.1547 & \\
\hline \hline Cramer's V & & 0.1566 & \\
\hline \hline
\end{tabular}

Sample Size $=2903$ 


\begin{tabular}{|c|c|c|c|c|c|c|c|c|c|}
\hline \multirow{6}{*}{$\begin{array}{c}\text { Frequency } \\
\text { Percent } \\
\text { Row Pct } \\
\text { Col Pct }\end{array}$} & \multicolumn{9}{|c|}{ Table of Victim by NZ Socio-Economic Index - Grouped } \\
\hline & \multirow[t]{2}{*}{ Victim } & \multicolumn{7}{|c|}{ NZSEIG: NZ Socio-Economic Index - Grouped) } & \multirow[t]{2}{*}{ Total } \\
\hline & & $\begin{array}{c}\text { NZSEI } \\
\text { Not } \\
\text { specified }\end{array}$ & $\begin{array}{c}\text { NZSEI } \\
10-29\end{array}$ & $\begin{array}{c}\text { NZSEI } \\
30-39\end{array}$ & $\begin{array}{c}\text { NZSEI } \\
40-49\end{array}$ & $\begin{array}{c}\text { NZSEI } \\
50-59\end{array}$ & $\begin{array}{c}\text { NZSEI } \\
60-74\end{array}$ & $\begin{array}{c}\text { NZSEI } \\
75-90\end{array}$ & \\
\hline & 0 & $\begin{array}{l}90 \\
3.10 \\
3.25 \\
86.54\end{array}$ & $\begin{array}{l}455 \\
15.67 \\
16.41 \\
97.22\end{array}$ & $\begin{array}{l}489 \\
16.84 \\
17.63 \\
94.22\end{array}$ & $\begin{array}{l}601 \\
20.70 \\
21.67 \\
93.91\end{array}$ & $\begin{array}{l}512 \\
17.64 \\
18.46 \\
97.15\end{array}$ & $\begin{array}{l}462 \\
15.91 \\
16.66 \\
97.26\end{array}$ & $\begin{array}{l}164 \\
5.65 \\
5.91 \\
96.47\end{array}$ & $\begin{array}{l}2773 \\
95.52\end{array}$ \\
\hline & 1 & $\begin{array}{l}14 \\
0.48 \\
10.77 \\
13.46\end{array}$ & $\begin{array}{l}13 \\
0.45 \\
10.00 \\
2.78\end{array}$ & $\begin{array}{l}30 \\
1.03 \\
23.08 \\
5.78\end{array}$ & $\begin{array}{l}39 \\
1.34 \\
30.00 \\
6.09\end{array}$ & $\begin{array}{l}15 \\
0.52 \\
11.54 \\
2.85\end{array}$ & $\begin{array}{l}13 \\
0.45 \\
10.00 \\
2.74\end{array}$ & $\begin{array}{l}6 \\
0.21 \\
4.62 \\
3.53\end{array}$ & $\begin{array}{l}130 \\
4.48\end{array}$ \\
\hline & Total & $\begin{array}{l}104 \\
3.58\end{array}$ & $\begin{array}{l}468 \\
16.12\end{array}$ & $\begin{array}{l}519 \\
17.88\end{array}$ & $\begin{array}{l}640 \\
22.05\end{array}$ & $\begin{array}{l}527 \\
18.15\end{array}$ & $\begin{array}{l}475 \\
16.36\end{array}$ & $\begin{array}{l}170 \\
5.86\end{array}$ & $\begin{array}{l}2903 \\
100.00\end{array}$ \\
\hline
\end{tabular}

\begin{tabular}{|c||c||c||c||}
\hline Statistic & DF & Value & Prob \\
\hline \hline Chi-Square & 6 & 35.7521 & $<.0001$ \\
\hline \hline Likelihood Ratio Chi-Square & 6 & 30.1194 & $<.0001$ \\
\hline \hline Mantel-Haenszel Chi-Square & 1 & 7.6743 & 0.0056 \\
\hline \hline Phi Coefficient & & 0.1110 & \\
\hline \hline Contingency Coefficient & & 0.1103 & \\
\hline \hline Cramer's V & & 0.1110 & \\
\hline \hline
\end{tabular}

Sample Size $=2903$ 


\begin{tabular}{|c|c|c|c|c|c|c|c|c|}
\hline \multirow{2}{*}{$\begin{array}{c}\text { Frequency } \\
\text { Percent } \\
\text { Row Pct } \\
\text { Col Pct }\end{array}$} & \multicolumn{8}{|c|}{ Table of Victim by Living Situation } \\
\hline & \multirow[t]{2}{*}{ Victim } & \multicolumn{6}{|c|}{ Living Situation } & \multirow[t]{2}{*}{ Total } \\
\hline & & $\begin{array}{l}\text { Couple } \\
\text { with } \\
\text { children }\end{array}$ & $\begin{array}{l}\text { Couple } \\
\text { without } \\
\text { children/ } \\
\text { children not } \\
\text { living in the } \\
\text { household }\end{array}$ & $\begin{array}{c}\text { Extended } \\
\text { family/whanau/ } \\
\text { other } \\
\text { combination }\end{array}$ & $\begin{array}{c}\text { Flatmates/ } \\
\text { Others }\end{array}$ & $\begin{array}{l}\text { One } \\
\text { person } \\
\text { living } \\
\text { alone }\end{array}$ & $\begin{array}{c}\text { Solo } \\
\text { parent } \\
\text { with } \\
\text { child/ren }\end{array}$ & \\
\hline & 0 & $\begin{array}{l}1235 \\
42.56 \\
44.55 \\
94.71\end{array}$ & $\begin{array}{l}1152 \\
39.70 \\
41.56 \\
98.29\end{array}$ & $\begin{array}{l}259 \\
8.92 \\
9.34 \\
93.17\end{array}$ & $\begin{array}{l}47 \\
1.62 \\
1.70 \\
87.04\end{array}$ & $\begin{array}{l}43 \\
1.48 \\
1.55 \\
91.49\end{array}$ & $\begin{array}{l}36 \\
1.24 \\
1.30 \\
76.60\end{array}$ & $\begin{array}{l}2772 \\
95.52\end{array}$ \\
\hline & 1 & $\begin{array}{l}69 \\
2.38 \\
53.08 \\
5.29\end{array}$ & $\begin{array}{l}20 \\
0.69 \\
15.38 \\
1.71\end{array}$ & $\begin{array}{l}19 \\
0.65 \\
14.62 \\
6.83\end{array}$ & $\begin{array}{l}7 \\
0.24 \\
5.38 \\
12.96\end{array}$ & $\begin{array}{l}4 \\
0.14 \\
3.08 \\
8.51\end{array}$ & $\begin{array}{l}11 \\
0.38 \\
8.46 \\
23.40\end{array}$ & $\begin{array}{l}130 \\
4.48\end{array}$ \\
\hline & Total & $\begin{array}{l}1304 \\
44.93\end{array}$ & $\begin{array}{l}1172 \\
40.39\end{array}$ & $\begin{array}{l}278 \\
9.58\end{array}$ & $\begin{array}{l}54 \\
1.86\end{array}$ & $\begin{array}{l}47 \\
1.62\end{array}$ & $\begin{array}{l}47 \\
1.62\end{array}$ & $\begin{array}{l}2902 \\
100.00\end{array}$ \\
\hline & \multicolumn{8}{|c|}{ Frequency Missing = 1} \\
\hline
\end{tabular}

\begin{tabular}{|c||c||c||c||}
\hline Statistic & DF & Value & Prob \\
\hline \hline Chi-Square & 5 & 76.8793 & $<.0001$ \\
\hline \hline Likelihood Ratio Chi-Square & 5 & 60.3938 & $<.0001$ \\
\hline \hline Mantel-Haenszel Chi-Square & 1 & 17.6156 & $<.0001$ \\
\hline \hline Phi Coefficient & & 0.1628 & \\
\hline \hline Contingency Coefficient & & 0.1606 & \\
\hline \hline \multicolumn{2}{|c|}{ Cramer's V } & 0.1628 & \\
\hline \hline $\begin{array}{c}\text { WARNING: 25\% of the cells have expected counts less } \\
\text { than 5. Chi-Square may not be a valid test. }\end{array}$ \\
\hline \hline
\end{tabular}

Effective Sample Size $=2902$

Frequency Missing = 1 


\begin{tabular}{|c|c|c|c|c|}
\hline \multirow{2}{*}{$\begin{array}{c}\text { Frequency } \\
\text { Percent } \\
\text { Row Pct } \\
\text { Col Pct }\end{array}$} & \multicolumn{4}{|c|}{ Table of Victim by Gender } \\
\hline & \multirow[t]{2}{*}{ Victim } & \multicolumn{2}{|c|}{ Gender } & \multirow[t]{2}{*}{ Total } \\
\hline & & Male & Female & \\
\hline & 0 & $\begin{array}{l}1266 \\
43.61 \\
45.65 \\
96.13\end{array}$ & $\begin{array}{l}1507 \\
51.91 \\
54.35 \\
95.02\end{array}$ & $\begin{array}{l}2773 \\
95.52\end{array}$ \\
\hline & 1 & $\begin{array}{l}51 \\
1.76 \\
39.23 \\
3.87\end{array}$ & $\begin{array}{l}79 \\
2.72 \\
60.77 \\
4.98\end{array}$ & $\begin{array}{l}130 \\
4.48\end{array}$ \\
\hline & Total & $\begin{array}{l}1317 \\
45.37\end{array}$ & $\begin{array}{l}1586 \\
54.63\end{array}$ & $\begin{array}{l}2903 \\
100.00\end{array}$ \\
\hline
\end{tabular}

\begin{tabular}{|c||c||c||c||}
\hline Statistic & DF & Value & Prob \\
\hline \hline Chi-Square & 1 & 2.0674 & 0.1505 \\
\hline \hline Likelihood Ratio Chi-Square & 1 & 2.0878 & 0.1485 \\
\hline Continuity Adj. Chi-Square & 1 & 1.8164 & 0.1777 \\
\hline \hline Mantel-Haenszel Chi-Square & 1 & 2.0667 & 0.1505 \\
\hline Phi Coefficient & & 0.0267 & \\
\hline \hline Contingency Coefficient & & 0.0267 & \\
\hline \hline Cramer's V & 0.0267 & \\
\hline \hline
\end{tabular}

\begin{tabular}{||c||l|}
\hline \multicolumn{2}{|c|}{ Fisher's Exact Test } \\
\hline \hline Cell (1,1) Frequency (F) & 1266 \\
\hline \hline Left-sided $\mathrm{Pr}<=$ F & 0.9373 \\
\hline \hline Right-sided $\mathrm{Pr}>=$ F & 0.0884 \\
\hline \hline Table Probability (P) & 0.0257 \\
\hline \hline Two-sided Pr <= P & 0.1762 \\
\hline \hline
\end{tabular}

Sample Size $=2903$ 


\begin{tabular}{|c|c|c|c|c|c|c|}
\hline \multirow{7}{*}{$\begin{array}{c}\text { Frequency } \\
\text { Percent } \\
\text { Row Pct } \\
\text { Col Pct }\end{array}$} & \multicolumn{6}{|c|}{ Table of Victim by Age } \\
\hline & \multirow[t]{2}{*}{ Victim } & \multicolumn{4}{|c|}{ Age } & \multirow[t]{2}{*}{ Total } \\
\hline & & $15-24$ & 25-39 & $40-59$ & $\begin{array}{c}60 \\
\text { and over }\end{array}$ & \\
\hline & 0 & $\begin{array}{l}143 \\
4.93 \\
5.16 \\
83.14\end{array}$ & $\begin{array}{l}916 \\
31.56 \\
33.04 \\
93.18\end{array}$ & $\begin{array}{l}1081 \\
37.25 \\
39.00 \\
97.12\end{array}$ & $\begin{array}{l}632 \\
21.78 \\
22.80 \\
99.68\end{array}$ & $\begin{array}{l}2772 \\
95.52\end{array}$ \\
\hline & 1 & $\begin{array}{l}29 \\
1.00 \\
22.31 \\
16.86\end{array}$ & $\begin{array}{l}67 \\
2.31 \\
51.54 \\
6.82\end{array}$ & $\begin{array}{l}32 \\
1.10 \\
24.62 \\
2.88\end{array}$ & $\begin{array}{l}2 \\
0.07 \\
1.54 \\
0.32\end{array}$ & $\begin{array}{l}130 \\
4.48\end{array}$ \\
\hline & Total & $\begin{array}{l}172 \\
5.93\end{array}$ & $\begin{array}{l}983 \\
33.87\end{array}$ & $\begin{array}{l}1113 \\
38.35\end{array}$ & $\begin{array}{l}634 \\
21.85\end{array}$ & $\begin{array}{l}2902 \\
100.00\end{array}$ \\
\hline & \multicolumn{6}{|c|}{ Frequency Missing = 1} \\
\hline
\end{tabular}

\begin{tabular}{|c||c||c||c||}
\hline Statistic & DF & Value & Prob \\
\hline \hline Chi-Square & 3 & 106.5424 & $<.0001$ \\
\hline \hline Likelihood Ratio Chi-Square & 3 & 99.0075 & $<.0001$ \\
\hline Mantel-Haenszel Chi-Square & 1 & 92.3322 & $<.0001$ \\
\hline \hline Phi Coefficient & & 0.1916 & \\
\hline \hline Contingency Coefficient & & 0.1882 & \\
\hline \hline Cramer's V & & 0.1916 & \\
\hline \hline
\end{tabular}

Effective Sample Size $=2902$

Frequency Missing = 1 


\begin{tabular}{|c|c|c|c|c|c|}
\hline \multirow{6}{*}{$\begin{array}{c}\text { Frequency } \\
\text { Percent } \\
\text { Row Pct } \\
\text { Col Pct }\end{array}$} & \multicolumn{5}{|c|}{ Table of Victim by Household Tenure } \\
\hline & \multirow[t]{2}{*}{ Victim } & \multicolumn{3}{|c|}{ Household Tenure } & \multirow[t]{2}{*}{ Total } \\
\hline & & Rented & $\begin{array}{c}\text { Owned } \\
\text { (including a } \\
\text { mortgage) }\end{array}$ & Other & \\
\hline & 0 & $\begin{array}{l}660 \\
22.74 \\
23.80 \\
90.16\end{array}$ & $\begin{array}{l}2054 \\
70.75 \\
74.07 \\
97.44\end{array}$ & $\begin{array}{l}59 \\
2.03 \\
2.13 \\
93.65\end{array}$ & $\begin{array}{l}2773 \\
95.52\end{array}$ \\
\hline & 1 & $\begin{array}{l}72 \\
2.48 \\
55.38 \\
9.84\end{array}$ & $\begin{array}{l}54 \\
1.86 \\
41.54 \\
2.56\end{array}$ & $\begin{array}{l}4 \\
0.14 \\
3.08 \\
6.35\end{array}$ & $\begin{array}{l}130 \\
4.48\end{array}$ \\
\hline & Total & $\begin{array}{l}732 \\
25.22\end{array}$ & $\begin{array}{l}2108 \\
72.61\end{array}$ & $\begin{array}{l}63 \\
2.17\end{array}$ & $\begin{array}{l}2903 \\
100.00\end{array}$ \\
\hline
\end{tabular}

\begin{tabular}{|c||c||c||c||}
\hline Statistic & DF & Value & Prob \\
\hline \hline Chi-Square & 2 & 67.7408 & $<.0001$ \\
\hline \hline Likelihood Ratio Chi-Square & 2 & 58.8473 & $<.0001$ \\
\hline \hline Mantel-Haenszel Chi-Square & 1 & 11.5505 & 0.0007 \\
\hline \hline Phi Coefficient & & 0.1528 & \\
\hline \hline Contingency Coefficient & & 0.1510 & \\
\hline \hline Cramer's V & & 0.1528 & \\
\hline \hline
\end{tabular}

Sample Size $=2903$ 


\begin{tabular}{|c|c|c|c|c|c|c|c|}
\hline \multirow{6}{*}{$\begin{array}{c}\text { Frequency } \\
\text { Percent } \\
\text { Row Pct } \\
\text { Col Pct }\end{array}$} & \multicolumn{7}{|c|}{ Table of Victim by Employment Status } \\
\hline & \multirow[t]{2}{*}{ Victim } & \multicolumn{5}{|c|}{ Employment Status } & \multirow[t]{2}{*}{ Total } \\
\hline & & $\begin{array}{l}\text { Currently in } \\
\text { Paid } \\
\text { Employment }\end{array}$ & $\begin{array}{l}\text { Home } \\
\text { Duties }\end{array}$ & Retired & $\begin{array}{c}\text { Social } \\
\text { Welfare/ } \\
\text { Beneficiary }\end{array}$ & $\begin{array}{c}\text { Student } \\
\text { or } \\
\text { Other }\end{array}$ & \\
\hline & 0 & $\begin{array}{l}1622 \\
55.87 \\
58.49 \\
95.36\end{array}$ & $\begin{array}{l}336 \\
11.57 \\
12.12 \\
94.92\end{array}$ & $\begin{array}{l}515 \\
17.74 \\
18.57 \\
99.23\end{array}$ & $\begin{array}{l}135 \\
4.65 \\
4.87 \\
88.24\end{array}$ & $\begin{array}{l}165 \\
5.68 \\
5.95 \\
93.75\end{array}$ & $\begin{array}{l}2773 \\
95.52\end{array}$ \\
\hline & 1 & $\begin{array}{l}79 \\
2.72 \\
60.77 \\
4.64\end{array}$ & $\begin{array}{l}18 \\
0.62 \\
13.85 \\
5.08\end{array}$ & $\begin{array}{l}4 \\
0.14 \\
3.08 \\
0.77\end{array}$ & $\begin{array}{l}18 \\
0.62 \\
13.85 \\
11.76\end{array}$ & $\begin{array}{l}11 \\
0.38 \\
8.46 \\
6.25\end{array}$ & $\begin{array}{l}130 \\
4.48\end{array}$ \\
\hline & Total & $\begin{array}{l}1701 \\
58.59\end{array}$ & $\begin{array}{l}354 \\
12.19\end{array}$ & $\begin{array}{l}519 \\
17.88\end{array}$ & $\begin{array}{l}153 \\
5.27\end{array}$ & $\begin{array}{l}176 \\
6.06\end{array}$ & $\begin{array}{l}2903 \\
100.00\end{array}$ \\
\hline
\end{tabular}

\begin{tabular}{|c||c||c||c||}
\hline Statistic & DF & Value & Prob \\
\hline \hline Chi-Square & 4 & 37.3735 & $<.0001$ \\
\hline \hline Likelihood Ratio Chi-Square & 4 & 40.0478 & $<.0001$ \\
\hline \hline Mantel-Haenszel Chi-Square & 1 & 0.4907 & 0.4836 \\
\hline \hline Phi Coefficient & & 0.1135 & \\
\hline \hline Contingency Coefficient & & 0.1127 & \\
\hline \hline Cramer's V & & 0.1135 & \\
\hline \hline
\end{tabular}

Sample Size $=2903$ 


\begin{tabular}{|c|c|c|c|c|}
\hline \multirow{3}{*}{$\begin{array}{c}\text { Frequency } \\
\text { Percent } \\
\text { Row Pct } \\
\text { Col Pct }\end{array}$} & \multicolumn{4}{|c|}{ Table of Victim by Main Income Earner for household } \\
\hline & \multirow[t]{2}{*}{ Victim } & \multicolumn{2}{|c|}{ Main Income Earner for household } & \multirow[t]{2}{*}{ Total } \\
\hline & & Yes & No & \\
\hline & 0 & $\begin{array}{l}1471 \\
50.67 \\
53.05 \\
95.46\end{array}$ & $\begin{array}{l}1302 \\
44.85 \\
46.95 \\
95.59\end{array}$ & $\begin{array}{l}2773 \\
95.52\end{array}$ \\
\hline & 1 & $\begin{array}{l}70 \\
2.41 \\
53.85 \\
4.54\end{array}$ & $\begin{array}{l}60 \\
2.07 \\
46.15 \\
4.41\end{array}$ & $\begin{array}{l}130 \\
4.48\end{array}$ \\
\hline & Total & $\begin{array}{l}1541 \\
53.08\end{array}$ & $\begin{array}{l}1362 \\
46.92\end{array}$ & $\begin{array}{l}2903 \\
100.00\end{array}$ \\
\hline
\end{tabular}

\begin{tabular}{|c||c||c||c||}
\hline \multicolumn{1}{|c||}{ Statistic } & DF & Value & Prob \\
\hline \hline Chi-Square & 1 & 0.0318 & 0.8584 \\
\hline \hline Likelihood Ratio Chi-Square & 1 & 0.0318 & 0.8584 \\
\hline \hline Continuity Adj. Chi-Square & 1 & 0.0078 & 0.9295 \\
\hline \hline Mantel-Haenszel Chi-Square & 1 & 0.0318 & 0.8584 \\
\hline \hline Phi Coefficient & & -0.0033 & \\
\hline \hline Contingency Coefficient & & 0.0033 & \\
\hline \hline Cramer's V & & -0.0033 & \\
\hline \hline
\end{tabular}

Sample Size $=2903$

\begin{tabular}{||c||l|}
\hline \multicolumn{2}{|c|}{ Fisher's Exact Test } \\
\hline \hline Cell (1,1) Frequency (F) & 1471 \\
\hline \hline Left-sided $\mathrm{Pr}<=$ F & 0.4654 \\
\hline \hline Right-sided $\mathrm{Pr}>=$ F & 0.6051 \\
\hline \hline Table Probability (P) & 0.0705 \\
\hline \hline Two-sided Pr <= P & 0.9284 \\
\hline \hline
\end{tabular}




\begin{tabular}{|c|c|c|c|c|c|c|}
\hline \multirow{6}{*}{$\begin{array}{c}\text { Frequency } \\
\text { Percent } \\
\text { Row Pct } \\
\text { Col Pct }\end{array}$} & \multicolumn{6}{|c|}{ Table of Victim by Marital Status } \\
\hline & \multirow[t]{2}{*}{ Victim } & \multicolumn{4}{|c|}{ Marital Status } & \multirow[t]{2}{*}{ Total } \\
\hline & & $\begin{array}{c}\text { Defacto } \\
\text { Relationship }\end{array}$ & $\begin{array}{l}\text { Divorced/ } \\
\text { Separated }\end{array}$ & $\begin{array}{c}\text { Legal } \\
\text { Married }\end{array}$ & $\begin{array}{c}\text { Single- } \\
\text { Never } \\
\text { Married }\end{array}$ & \\
\hline & 0 & $\begin{array}{l}459 \\
15.81 \\
16.55 \\
89.13\end{array}$ & $\begin{array}{l}34 \\
1.17 \\
1.23 \\
87.18\end{array}$ & $\begin{array}{l}2210 \\
76.13 \\
79.70 \\
97.61\end{array}$ & $\begin{array}{l}70 \\
2.41 \\
2.52 \\
82.35\end{array}$ & $\begin{array}{l}2773 \\
95.52\end{array}$ \\
\hline & 1 & $\begin{array}{l}56 \\
1.93 \\
43.08 \\
10.87\end{array}$ & $\begin{array}{l}5 \\
0.17 \\
3.85 \\
12.82\end{array}$ & $\begin{array}{l}54 \\
1.86 \\
41.54 \\
2.39\end{array}$ & $\begin{array}{l}15 \\
0.52 \\
11.54 \\
17.65\end{array}$ & $\begin{array}{l}130 \\
4.48\end{array}$ \\
\hline & Total & $\begin{array}{l}515 \\
17.74\end{array}$ & $\begin{array}{l}39 \\
1.34\end{array}$ & $\begin{array}{l}2264 \\
77.99\end{array}$ & $\begin{array}{l}85 \\
2.93\end{array}$ & $\begin{array}{l}2903 \\
100.00\end{array}$ \\
\hline
\end{tabular}

\begin{tabular}{|c|c|c|c|}
\hline Statistic & DF & Value & Prob \\
\hline Chi-Square & 3 & 113.2373 & $<.0001$ \\
\hline Likelihood Ratio Chi-Square & 3 & 88.1860 & $<.0001$ \\
\hline Mantel-Haenszel Chi-Square & 1 & 42.3893 & $<.0001$ \\
\hline Phi Coefficient & & 0.1975 & \\
\hline Contingency Coefficient & & 0.1938 & \\
\hline Cramer's V & & 0.1975 & \\
\hline \multicolumn{4}{|c|}{$\begin{array}{l}\text { WARNING: } 25 \% \text { of the cells have expected counts less } \\
\text { than } 5 . \text { Chi-Square may not be a valid test. }\end{array}$} \\
\hline
\end{tabular}

Sample Size $=2903$ 


\begin{tabular}{|c|c|c|c|c|c|c|c|c|c|}
\hline \multirow{6}{*}{$\begin{array}{c}\text { Frequency } \\
\text { Percent } \\
\text { Row Pct } \\
\text { Col Pct }\end{array}$} & \multicolumn{9}{|c|}{ Table of Victim by Number living in the Household } \\
\hline & \multirow[t]{2}{*}{ Victim } & \multicolumn{7}{|c|}{ Number living in the Household } & \multirow[t]{2}{*}{ Total } \\
\hline & & $\begin{array}{c}1 \\
\text { Person }\end{array}$ & $\begin{array}{c}2 \\
\text { Persons }\end{array}$ & $\begin{array}{c}3 \\
\text { Persons }\end{array}$ & $\begin{array}{c}4 \\
\text { Persons }\end{array}$ & $\begin{array}{c}5 \\
\text { Persons }\end{array}$ & $\begin{array}{c}6 \\
\text { Persons }\end{array}$ & $\begin{array}{l}7 \text { or } \\
\text { more }\end{array}$ & \\
\hline & 0 & $\begin{array}{l}43 \\
1.48 \\
1.55 \\
91.49\end{array}$ & $\begin{array}{l}1168 \\
40.23 \\
42.12 \\
98.40\end{array}$ & $\begin{array}{l}477 \\
16.43 \\
17.20 \\
94.08\end{array}$ & $\begin{array}{l}565 \\
19.46 \\
20.38 \\
93.39\end{array}$ & $\begin{array}{l}284 \\
9.78 \\
10.24 \\
94.67\end{array}$ & $\begin{array}{l}125 \\
4.31 \\
4.51 \\
91.24\end{array}$ & $\begin{array}{l}111 \\
3.82 \\
4.00 \\
92.50\end{array}$ & $\begin{array}{l}2773 \\
95.52\end{array}$ \\
\hline & 1 & $\begin{array}{l}4 \\
0.14 \\
3.08 \\
8.51\end{array}$ & $\begin{array}{l}19 \\
0.65 \\
14.62 \\
1.60\end{array}$ & $\begin{array}{l}30 \\
1.03 \\
23.08 \\
5.92\end{array}$ & $\begin{array}{l}40 \\
1.38 \\
30.77 \\
6.61\end{array}$ & $\begin{array}{l}16 \\
0.55 \\
12.31 \\
5.33\end{array}$ & $\begin{array}{l}12 \\
0.41 \\
9.23 \\
8.76\end{array}$ & $\begin{array}{l}9 \\
0.31 \\
6.92 \\
7.50\end{array}$ & $\begin{array}{l}130 \\
4.48\end{array}$ \\
\hline & Total & $\begin{array}{l}47 \\
1.62\end{array}$ & $\begin{array}{l}1187 \\
40.89\end{array}$ & $\begin{array}{l}507 \\
17.46\end{array}$ & $\begin{array}{l}605 \\
20.84\end{array}$ & $\begin{array}{l}300 \\
10.33\end{array}$ & $\begin{array}{l}137 \\
4.72\end{array}$ & $\begin{array}{l}120 \\
4.13\end{array}$ & $\begin{array}{l}2903 \\
100.00\end{array}$ \\
\hline
\end{tabular}

\begin{tabular}{|c||c||c||c||}
\hline Statistic & DF & Value & Prob \\
\hline \hline Chi-Square & 6 & 42.5986 & $<.0001$ \\
\hline \hline Likelihood Ratio Chi-Square & 6 & 46.8150 & $<.0001$ \\
\hline \hline Mantel-Haenszel Chi-Square & 1 & 24.8113 & $<.0001$ \\
\hline \hline Coni Coefficient & & 0.1211 & \\
\hline \hline Cramer's V & & 0.1211 & \\
\hline \hline
\end{tabular}

Sample Size $=2903$ 


\begin{tabular}{|c|c|c|c|c|c|c|c|}
\hline \multirow{3}{*}{$\begin{array}{c}\text { Frequency } \\
\text { Percent } \\
\text { Row Pct } \\
\text { Col Pct }\end{array}$} & \multicolumn{7}{|c|}{ Table of Victim by Number living in the Household under 16 years old } \\
\hline & \multirow[t]{2}{*}{ Victim } & \multicolumn{5}{|c|}{ Number living in the Household under 16 years old } & \multirow[t]{2}{*}{ Total } \\
\hline & & $\begin{array}{c}0 \\
\text { Persons }\end{array}$ & $\begin{array}{c}1 \\
\text { Person }\end{array}$ & $\begin{array}{c}2 \\
\text { Persons }\end{array}$ & $\begin{array}{c}3 \\
\text { Persons }\end{array}$ & $\begin{array}{l}4 \text { or } \\
\text { more }\end{array}$ & \\
\hline & 0 & $\begin{array}{l}1512 \\
52.08 \\
54.53 \\
97.42\end{array}$ & $\begin{array}{l}441 \\
15.19 \\
15.90 \\
94.03\end{array}$ & $\begin{array}{l}482 \\
16.60 \\
17.38 \\
94.14\end{array}$ & $\begin{array}{l}217 \\
7.48 \\
7.83 \\
93.13\end{array}$ & $\begin{array}{l}121 \\
4.17 \\
4.36 \\
88.32\end{array}$ & $\begin{array}{l}2773 \\
95.52\end{array}$ \\
\hline & 1 & $\begin{array}{l}40 \\
1.38 \\
30.77 \\
2.58\end{array}$ & $\begin{array}{l}28 \\
0.96 \\
21.54 \\
5.97\end{array}$ & $\begin{array}{l}30 \\
1.03 \\
23.08 \\
5.86\end{array}$ & $\begin{array}{l}16 \\
0.55 \\
12.31 \\
6.87\end{array}$ & $\begin{array}{l}16 \\
0.55 \\
12.31 \\
11.68\end{array}$ & $\begin{array}{l}130 \\
4.48\end{array}$ \\
\hline & Total & $\begin{array}{l}1552 \\
53.46\end{array}$ & $\begin{array}{l}469 \\
16.16\end{array}$ & $\begin{array}{l}512 \\
17.64\end{array}$ & $\begin{array}{l}233 \\
8.03\end{array}$ & $\begin{array}{l}137 \\
4.72\end{array}$ & $\begin{array}{l}2903 \\
100.00\end{array}$ \\
\hline
\end{tabular}

\begin{tabular}{|c||c||c||c||}
\hline Statistic & DF & Value & Prob \\
\hline \hline Chi-Square & 4 & 37.5479 & $<.0001$ \\
\hline \hline Likelihood Ratio Chi-Square & 4 & 34.0918 & $<.0001$ \\
\hline \hline Mantel-Haenszel Chi-Square & 1 & 33.0907 & $<.0001$ \\
\hline \hline Phi Coefficient & & 0.1137 & \\
\hline \hline Contingency Coefficient & & 0.1130 & \\
\hline \hline Cramer's V & & 0.1137 & \\
\hline \hline
\end{tabular}

Sample Size $=2903$ 
Appendix D - Results from Chi-Square - Mixed vs. SoleMāori 


\section{Lifetime}

\begin{tabular}{|c|c|c|c|c|}
\hline \multirow{2}{*}{$\begin{array}{c}\text { Frequency } \\
\text { Percent } \\
\text { Row Pct } \\
\text { Col Pct }\end{array}$} & \multicolumn{4}{|c|}{ Table of Māori by Victim } \\
\hline & \multirow[t]{2}{*}{ Māori } & \multicolumn{2}{|c|}{ Victim } & \multirow[t]{2}{*}{ Total } \\
\hline & & 0 & 1 & \\
\hline & Mixed & $\begin{array}{l}151 \\
20.00 \\
57.41 \\
34.79\end{array}$ & $\begin{array}{l}112 \\
14.83 \\
42.59 \\
34.89\end{array}$ & $\begin{array}{l}263 \\
34.83\end{array}$ \\
\hline & Sole_ & $\begin{array}{l}283 \\
37.48 \\
57.52 \\
65.21\end{array}$ & $\begin{array}{l}209 \\
27.68 \\
42.48 \\
65.11\end{array}$ & $\begin{array}{l}492 \\
65.17\end{array}$ \\
\hline & Total & $\begin{array}{l}434 \\
57.48\end{array}$ & $\begin{array}{l}321 \\
42.52\end{array}$ & $\begin{array}{l}755 \\
100.00\end{array}$ \\
\hline
\end{tabular}

\begin{tabular}{|c||c||c|c||}
\hline \multicolumn{1}{|c||}{ Statistic } & DF & Value & Prob \\
\hline \hline Chi-Square & 1 & 0.0008 & 0.9776 \\
\hline \hline Likelihood Ratio Chi-Square & 1 & 0.0008 & 0.9776 \\
\hline \hline Continuity Adj. Chi-Square & 1 & 0.0000 & 1.0000 \\
\hline \hline Mantel-Haenszel Chi-Square & 1 & 0.0008 & 0.9776 \\
\hline \hline Phi Coefficient & & -0.0010 & \\
\hline \hline Contingency Coefficient & & 0.0010 & \\
\hline \hline Cramer's V & & -0.0010 & \\
\hline
\end{tabular}

\begin{tabular}{||c||l||}
\hline \multicolumn{2}{|c|}{ Fisher's Exact Test } \\
\hline \hline Cell (1,1) Frequency (F) & 151 \\
\hline \hline Left-sided $\operatorname{Pr}<=$ F & 0.5192 \\
\hline \hline Right-sided $\mathrm{Pr}>=$ F & 0.5424 \\
\hline \hline & \\
\hline \hline Table Probability (P) & 0.0615 \\
\hline \hline Two-sided Pr <= P & 1.0000 \\
\hline \hline
\end{tabular}




\begin{tabular}{|c|c|c|c|c|}
\hline \multirow{2}{*}{$\begin{array}{c}\text { Frequency } \\
\text { Percent } \\
\text { Row Pct } \\
\text { Col Pct }\end{array}$} & \multicolumn{4}{|c|}{ Table of Māori by Victim } \\
\hline & \multirow[t]{2}{*}{ Māori } & \multicolumn{2}{|c|}{ Victim } & \multirow[t]{2}{*}{ Total } \\
\hline & & 0 & 1 & \\
\hline & Mixed & $\begin{array}{l}163 \\
33.68 \\
88.11 \\
38.17\end{array}$ & $\begin{array}{l}22 \\
4.55 \\
11.89 \\
38.60\end{array}$ & $\begin{array}{l}185 \\
38.22\end{array}$ \\
\hline & Sole_ & $\begin{array}{l}264 \\
54.55 \\
88.29 \\
61.83\end{array}$ & $\begin{array}{l}35 \\
7.23 \\
11.71 \\
61.40\end{array}$ & $\begin{array}{l}299 \\
61.78\end{array}$ \\
\hline & Total & $\begin{array}{l}427 \\
88.22\end{array}$ & $\begin{array}{l}57 \\
11.78\end{array}$ & $\begin{array}{l}484 \\
100.00\end{array}$ \\
\hline
\end{tabular}

\begin{tabular}{|c||c||c|c||}
\hline \hline Statistic & DF & Value & Prob \\
\hline \hline Chi-Square & 1 & 0.0038 & 0.9508 \\
\hline \hline Likelihood Ratio Chi-Square & 1 & 0.0038 & 0.9508 \\
\hline \hline Continuity Adj. Chi-Square & 1 & 0.0000 & 1.0000 \\
\hline \hline Mantel-Haenszel Chi-Square & 1 & 0.0038 & 0.9508 \\
\hline \hline Phi Coefficient & & -0.0028 & \\
\hline \hline Contingency Coefficient & & 0.0028 & \\
\hline \hline Cramer's V & & -0.0028 & \\
\hline \hline
\end{tabular}

\begin{tabular}{||c||l||}
\hline \multicolumn{2}{|c||}{ Fisher's Exact Test } \\
\hline \hline Cell (1,1) Frequency (F) & 163 \\
\hline \hline Left-sided $\mathrm{Pr}<=$ F & 0.5297 \\
\hline \hline Right-sided $\mathrm{Pr}>=$ F & 0.5851 \\
\hline \hline Table Probability (P) & 0.1148 \\
\hline \hline Two-sided Pr <= P & 1.0000 \\
\hline
\end{tabular}

Sample Size $=484$ 


\section{Appendix E - Results from Log Linear Model}

This appendix presents selected results from the log linear analysis of risk factors of

intimate partner violence. These results are discussed further in Chapter Five (specifically 5.4.1). 


\section{Lifetime}

\begin{tabular}{|c||l||l|l||}
\hline \hline \multicolumn{3}{|c|}{ Data Summary } \\
\hline \hline Response & Victim & Response Levels & 2 \\
\hline \hline Weight Variable & COUNT & Populations & 2537 \\
\hline \hline Data Set & ETHNICITYLIFETIME_FREQ & Total Frequency & 3779 \\
\hline \hline Frequency Missing & 4 & Observations & 2730 \\
\hline \hline
\end{tabular}

\begin{tabular}{||c|l||}
\hline \hline \multicolumn{2}{|c|}{ Response Profiles } \\
\hline \hline Response & Victim \\
\hline \hline $\mathbf{1}$ & 0 \\
\hline \hline 2 & 1 \\
\hline
\end{tabular}

Maximum Likelihood Analysis

Maximum likelihood computations converged.

\begin{tabular}{|c||l||l|l||}
\hline \multicolumn{3}{|c|}{ Maximum Likelihood Analysis of Variance } \\
\hline \hline Source & DF & Chi-Square & Pr > ChiSq \\
\hline \hline Intercept & 1 & 25.51 & $<.0001$ \\
\hline \hline ethnicity & 3 & 52.42 & $<.0001$ \\
\hline \hline Age & 3 & 25.75 & $<.0001$ \\
\hline \hline LivingSituation & 5 & 9.54 & 0.0895 \\
\hline \hline Q220_ & 1 & 28.34 & $<.0001$ \\
\hline \hline Q224_ & 2 & 5.57 & 0.0616 \\
\hline \hline EmploymentStatus & 4 & 7.16 & 0.1275 \\
\hline \hline Q230_ & 1 & 0.25 & 0.6181 \\
\hline \hline MaritalStatus & 3 & 72.74 & $<.0001$ \\
\hline \hline NolnHHold & 6 & 6.48 & 0.3721 \\
\hline \hline NoU16inHHold & 4 & 6.48 & 0.1663 \\
\hline \hline nzseigp & 6 & 12.12 & 0.0594 \\
\hline \hline Likelihood Ratio & $2 \mathrm{E3}$ & 2760.55 & 0.0002 \\
\hline \hline & & \\
\hline \hline
\end{tabular}




\begin{tabular}{|c|c|c|c|c|c|}
\hline \multicolumn{6}{|c|}{ Analysis of Maximum Likelihood Estimates } \\
\hline Parameter & & Estimate & $\begin{array}{c}\text { Standard } \\
\text { Error }\end{array}$ & $\begin{array}{l}\text { Chi- } \\
\text { Square }\end{array}$ & $\mathrm{Pr}>\mathrm{ChiSq}$ \\
\hline Intercept & & 0.6884 & 0.1363 & 25.51 & $<.0001$ \\
\hline \multirow[t]{3}{*}{ ethnicity } & Māori & -0.5583 & 0.0882 & 40.11 & $<.0001$ \\
\hline & NZ European & -0.1434 & 0.0789 & 3.30 & 0.0691 \\
\hline & Pacific & 0.5402 & 0.1169 & 21.36 & $<.0001$ \\
\hline \multirow[t]{3}{*}{ Age } & $15-24$ & 0.0819 & 0.1350 & 0.37 & 0.5443 \\
\hline & 25-39 & -0.3975 & 0.0879 & 20.46 & $<.0001$ \\
\hline & $40-59$ & -0.2823 & 0.0849 & 11.05 & 0.0009 \\
\hline \multirow[t]{5}{*}{ LivingSituation } & Couple with chil & 0.3417 & 0.2361 & 2.09 & 0.1478 \\
\hline & Couple without c & 0.4463 & 0.2618 & 2.91 & 0.0882 \\
\hline & Extended family/ & 0.1862 & 0.2368 & 0.62 & 0.4316 \\
\hline & Flatmates/Others & 0.0951 & 0.2604 & 0.13 & 0.7150 \\
\hline & One person livin & -0.7822 & 0.9853 & 0.63 & 0.4273 \\
\hline Q220_ & Male & 0.2630 & 0.0494 & 28.34 & $<.0001$ \\
\hline \multirow[t]{2}{*}{ Q224_ } & Rented & 0.0536 & 0.1012 & 0.28 & 0.5966 \\
\hline & Owned (including & 0.2218 & 0.0977 & 5.15 & 0.0233 \\
\hline \multirow[t]{4}{*}{ EmploymentStatus } & Currently in Pai & 0.0693 & 0.0841 & 0.68 & 0.4101 \\
\hline & Home Duties & 0.2004 & 0.1286 & 2.43 & 0.1191 \\
\hline & Retired & -0.1414 & 0.1917 & 0.54 & 0.4606 \\
\hline & Social Welfare/B & -0.2410 & 0.1195 & 4.07 & 0.0437 \\
\hline Q230_ & Yes & 0.0279 & 0.0560 & 0.25 & 0.6181 \\
\hline \multirow[t]{3}{*}{ MaritalStatus } & Defacto Reln & -0.0805 & 0.1046 & 0.59 & 0.4414 \\
\hline & Divorced/Sep & -0.5226 & 0.1198 & 19.02 & $<.0001$ \\
\hline & Legal Married & 0.7485 & 0.1006 & 55.39 & $<.0001$ \\
\hline \multirow[t]{2}{*}{ NolnHHold } & 1 Person & 0.5581 & 1.0203 & 0.30 & 0.5844 \\
\hline & 2 Persons & -0.1415 & 0.2419 & 0.34 & 0.5584 \\
\hline
\end{tabular}




\begin{tabular}{|c|c|c|c|c|c|}
\hline \multicolumn{6}{|c|}{ Analysis of Maximum Likelihood Estimates } \\
\hline \multirow[t]{5}{*}{ Parameter } & & Estimate & $\begin{array}{l}\text { Standard } \\
\text { Error }\end{array}$ & $\begin{array}{l}\text { Chi- } \\
\text { Square }\end{array}$ & $\mathrm{Pr}>\mathrm{ChiSq}$ \\
\hline & 3 Persons & -0.3352 & 0.2091 & 2.57 & 0.1090 \\
\hline & 4 Persons & -0.2382 & 0.2057 & 1.34 & 0.2468 \\
\hline & 5 Persons & -0.1830 & 0.2277 & 0.65 & 0.4214 \\
\hline & 6 Persons & -0.0752 & 0.2769 & 0.07 & 0.7860 \\
\hline \multirow[t]{4}{*}{ NoU16inHHold } & 0 Persons & 0.3676 & 0.1546 & 5.65 & 0.0174 \\
\hline & 1 Person & 0.1478 & 0.1244 & 1.41 & 0.2349 \\
\hline & 2 Persons & 0.0689 & 0.1115 & 0.38 & 0.5368 \\
\hline & 3 Persons & -0.0824 & 0.1532 & 0.29 & 0.5907 \\
\hline \multirow[t]{6}{*}{ nzseigp } & NZSEI Not specif & -0.3010 & 0.1520 & 3.92 & 0.0476 \\
\hline & NZSEI 10-29 & 0.1884 & 0.1012 & 3.46 & 0.0628 \\
\hline & NZSEI 30-39 & -0.0718 & 0.0939 & 0.59 & 0.4443 \\
\hline & NZSEI 40-49 & -0.1562 & 0.0895 & 3.05 & 0.0807 \\
\hline & NZSEI 50-59 & 0.0446 & 0.0993 & 0.20 & 0.6537 \\
\hline & NZSEI 60-74 & 0.1032 & 0.1079 & 0.92 & 0.3387 \\
\hline
\end{tabular}




\section{Months}

The CATMOD Procedure

\begin{tabular}{|c|c|c|c|}
\hline \multicolumn{4}{|c|}{ Data Summary } \\
\hline Response & Victim & Response Levels & 2 \\
\hline Weight Variable & COUNT & Populations & 1827 \\
\hline Data Set & VICTIMS_12MTHS_FREQ & Total Frequency & 2901 \\
\hline Frequency Missing & 2 & Observations & 1854 \\
\hline
\end{tabular}

\begin{tabular}{|c|l||}
\hline \multicolumn{2}{|c|}{ Response Profiles } \\
\hline \hline Response & Victim \\
\hline \hline $\mathbf{1}$ & 0 \\
\hline \hline 2 & 1 \\
\hline
\end{tabular}

\begin{tabular}{|c||}
\hline \hline Maximum Likelihood Analysis \\
\hline \hline Maximum likelihood computations converged. \\
\hline
\end{tabular}

\begin{tabular}{|c||l|l||l||}
\hline \multicolumn{3}{|c|}{ Maximum Likelihood Analysis of Variance } \\
\hline \hline Source & DF & Chi-Square & Pr > ChiSq \\
\hline \hline Intercept & 1 & 48.84 & $<.0001$ \\
\hline \hline ethnicity & 3 & 14.91 & 0.0019 \\
\hline \hline Age & 3 & 15.15 & 0.0017 \\
\hline \hline LivingSituation & 5 & 5.90 & 0.3165 \\
\hline \hline Q220_ & 1 & 0.35 & 0.5557 \\
\hline \hline Q224_ & 2 & 9.71 & 0.0078 \\
\hline \hline EmploymentStatus & 4 & 4.58 & 0.3332 \\
\hline \hline Q230_ & 1 & 0.21 & 0.6452 \\
\hline \hline MaritalStatus & 3 & 8.97 & 0.0297 \\
\hline \hline NolnHHold & $5 *$ & 8.28 & 0.1413 \\
\hline \hline NoU16inHHold & 4 & 2.45 & 0.6527 \\
\hline \hline nzseigp & 6 & 13.66 & 0.0337 \\
\hline \hline
\end{tabular}




\begin{tabular}{|c||l||l|l||}
\hline \multicolumn{3}{|c|}{ Maximum Likelihood Analysis of Variance } \\
\hline \hline Source & DF & Chi-Square & Pr > ChiSq \\
\hline \hline Likelihood Ratio & $2 \mathrm{E} 3$ & 747.29 & 1.0000 \\
\hline
\end{tabular}

Note: Effects marked with '*' contain one or more redundant or restricted parameters.

\begin{tabular}{|c|c|c|c|c|c|}
\hline \multicolumn{6}{|c|}{ Analysis of Maximum Likelihood Estimates } \\
\hline Parameter & & Estimate & $\begin{array}{l}\text { Standard } \\
\text { Error }\end{array}$ & $\begin{array}{l}\text { Chi- } \\
\text { Square }\end{array}$ & $\mathrm{Pr}>\mathrm{ChiSq}$ \\
\hline Intercept & & 2.6360 & 0.3772 & 48.84 & $<.0001$ \\
\hline \multirow[t]{3}{*}{ ethnicity } & Māori & -0.6958 & 0.1979 & 12.36 & 0.0004 \\
\hline & NZ European & -0.0659 & 0.1984 & 0.11 & 0.7397 \\
\hline & Pacific & 0.3038 & 0.2594 & 1.37 & 0.2415 \\
\hline \multirow[t]{3}{*}{ Age } & $15-24$ & -1.2860 & 0.3321 & 14.99 & 0.0001 \\
\hline & 25-39 & -0.7129 & 0.2884 & 6.11 & 0.0134 \\
\hline & $40-59$ & -0.3696 & 0.2777 & 1.77 & 0.1832 \\
\hline \multirow[t]{5}{*}{ LivingSituation } & Couple with chil & 0.2585 & 0.5691 & 0.21 & 0.6497 \\
\hline & Couple without c & -0.3369 & 0.7338 & 0.21 & 0.6462 \\
\hline & Extended family/ & 0.00940 & 0.5388 & 0.00 & 0.9861 \\
\hline & Flatmates/Others & -0.1629 & 0.5973 & 0.07 & 0.7851 \\
\hline & One person livin & 1.2565 & 2.5647 & 0.24 & 0.6242 \\
\hline Q220_ & Male & 0.0703 & 0.1193 & 0.35 & 0.5557 \\
\hline \multirow[t]{2}{*}{ Q224_ } & Rented & -0.0746 & 0.2319 & 0.10 & 0.7477 \\
\hline & Owned (including & 0.5885 & 0.2317 & 6.45 & 0.0111 \\
\hline \multirow[t]{4}{*}{ EmploymentStatus } & Currently in Pai & 0.1645 & 0.2173 & 0.57 & 0.4491 \\
\hline & Home Duties & 0.4175 & 0.2893 & 2.08 & 0.1490 \\
\hline & Retired & -1.2220 & 0.5914 & 4.27 & 0.0388 \\
\hline & Social Welfare/B & 0.3077 & 0.3246 & 0.90 & 0.3431 \\
\hline Q230_ & Yes & -0.0574 & 0.1247 & 0.21 & 0.6452 \\
\hline MaritalStatus & Defacto Reln & -0.2440 & 0.2603 & 0.88 & 0.3485 \\
\hline
\end{tabular}




\begin{tabular}{|c|c|c|c|c|c|}
\hline \multicolumn{6}{|c|}{ Analysis of Maximum Likelihood Estimates } \\
\hline Parameter & & Estimate & $\begin{array}{c}\text { Standard } \\
\text { Error }\end{array}$ & $\begin{array}{l}\text { Chi- } \\
\text { Square }\end{array}$ & $\mathrm{Pr}>\mathrm{ChiSq}$ \\
\hline & Divorced/Sep & 0.1058 & 0.4935 & 0.05 & 0.8302 \\
\hline & Legal Married & 0.4650 & 0.2711 & 2.94 & 0.0863 \\
\hline \multirow[t]{6}{*}{ NolnHHold } & 1 Person & -1.5848 & 2.3866 & 0.44 & 0.5067 \\
\hline & 2 Persons & 1.2324 & 0.8307 & 2.20 & 0.1379 \\
\hline & 3 Persons & -0.0947 & 0.6291 & 0.02 & 0.8803 \\
\hline & 4 Persons & -0.2205 & 0.5621 & 0.15 & 0.6948 \\
\hline & 5 Persons & 0.3633 & 0.5096 & 0.51 & 0.4760 \\
\hline & 6 Persons & & & & . \\
\hline \multirow[t]{4}{*}{ NoU16inHHold } & 0 Persons & 0.2879 & 0.3564 & 0.65 & 0.4192 \\
\hline & 1 Person & 0.3098 & 0.2828 & 1.20 & 0.2732 \\
\hline & 2 Persons & 0.1983 & 0.2409 & 0.68 & 0.4104 \\
\hline & 3 Persons & -0.1256 & 0.3327 & 0.14 & 0.7058 \\
\hline \multirow[t]{6}{*}{ nzseigp } & NZSEI Not specif & -0.3554 & 0.3592 & 0.98 & 0.3224 \\
\hline & NZSEI 10-29 & 0.6429 & 0.2910 & 4.88 & 0.0272 \\
\hline & NZSEI 30-39 & -0.0561 & 0.2085 & 0.07 & 0.7878 \\
\hline & NZSEI 40-49 & -0.5054 & 0.1937 & 6.81 & 0.0091 \\
\hline & NZSEI 50-59 & 0.1745 & 0.2632 & 0.44 & 0.5074 \\
\hline & NZSEI 60-74 & 0.2614 & 0.2755 & 0.90 & 0.3427 \\
\hline
\end{tabular}




\section{Appendix F - Results from Logistic Regression}

This appendix presents selected results from the logistic regression analysis of risk factors of intimate partner violence. These results are discussed further in Chapter Five (specifically 5.4.2).

In all these tables are:

Parameter estimate is the estimated odds ratio.

SE is the parameter estimate's standard error

Wald tests the significance of individual coefficients for all independent variables.

Odds the odds ratio tests for statistical independent of the dependent variables. This is calculated from the parameter estimate by odds=exp (parameter)

Lower, Upper gives the confidence interval, at 95\%, for the odds ratio.

P-value gives the $p$-value for the Wald test. 


\section{Lifetime}

\begin{tabular}{|c||l||}
\hline \multicolumn{2}{|c|}{ Model Information } \\
\hline \hline Data Set & WORK.ETHNICITYLIFETIME \\
\hline \hline Response Variable & Victim \\
\hline \hline Number of Response Levels & 2 \\
\hline \hline Model & binary logit \\
\hline \hline Optimization Technique & Fisher's scoring \\
\hline \hline
\end{tabular}

\begin{tabular}{||c||c|}
\hline Number of Observations Read & 3783 \\
\hline \hline Number of Observations Used & 3779 \\
\hline
\end{tabular}

\begin{tabular}{||c||l||l||}
\hline \hline \multicolumn{3}{|c|}{ Response Profile } \\
\hline \hline $\begin{array}{c}\text { Ordered } \\
\text { Value }\end{array}$ & Victim & $\begin{array}{c}\text { Total } \\
\text { Frequency }\end{array}$ \\
\hline \hline $\mathbf{1}$ & 0 & 2778 \\
\hline \hline 2 & 1 & 1001 \\
\hline
\end{tabular}

\begin{tabular}{|c|c|c|c|c|c|c|c|c|}
\hline \multicolumn{9}{|c|}{ Summary of Stepwise Selection } \\
\hline \multirow[t]{2}{*}{ Step } & \multicolumn{2}{|l|}{ Effect } & \multirow[t]{2}{*}{ DF } & \multirow{2}{*}{$\underset{\text { In }}{\text { Number }}$} & \multirow{2}{*}{$\begin{array}{l}\text { Score } \\
\text { Chi- } \\
\text { Square }\end{array}$} & \multirow{2}{*}{$\begin{array}{l}\text { Wald } \\
\text { Chi- } \\
\text { Square }\end{array}$} & \multirow[t]{2}{*}{$\mathrm{Pr}>\mathrm{ChiSq}$} & \multirow{2}{*}{$\begin{array}{c}\text { Variable } \\
\text { Label }\end{array}$} \\
\hline & Entered & Removed & & & & & & \\
\hline 1 & MaritalStatus & & 3 & 1 & 426.1910 & & $<.0001$ & \\
\hline 2 & LivingSituation & & 5 & 2 & 104.2398 & & $<.0001$ & \\
\hline 3 & ethnicity & & 3 & 3 & 57.6055 & & $<.0001$ & \\
\hline 4 & Q220_ & & 1 & 4 & 43.3701 & & $<.0001$ & D5 Sex \\
\hline 5 & Age & & 3 & 5 & 45.2019 & & $<.0001$ & \\
\hline 6 & EmploymentStatus & & 4 & 6 & 14.7511 & & 0.0052 & \\
\hline
\end{tabular}




\begin{tabular}{|c||c||c||l||}
\hline \multicolumn{4}{|c|}{ Type 3 Analysis of Effects } \\
\hline \hline Effect & DF & $\begin{array}{c}\text { Wald } \\
\text { Chi-Square }\end{array}$ & Pr > ChiSq \\
\hline \hline LivingSituation & 5 & 26.6198 & $<.0001$ \\
\hline \hline EmploymentStatus & 4 & 14.6401 & 0.0055 \\
\hline \hline MaritalStatus & 3 & 78.5068 & $<.0001$ \\
\hline \hline ethnicity & 3 & 55.4821 & $<.0001$ \\
\hline \hline Age & 3 & 31.8605 & $<.0001$ \\
\hline \hline Q220_ & 1 & 36.3349 & $<.0001$ \\
\hline \hline
\end{tabular}

\begin{tabular}{|c|c|c|c|c|c|c|}
\hline \multicolumn{7}{|c|}{ Analysis of Maximum Likelihood Estimates } \\
\hline Parameter & & DF & Estimate & $\begin{array}{l}\text { Standard } \\
\text { Error }\end{array}$ & $\begin{array}{l}\text { Wald } \\
\text { Chi- } \\
\text { Square }\end{array}$ & $\mathrm{Pr}>\mathrm{ChiSq}$ \\
\hline Intercept & & 1 & -0.9315 & 0.0799 & 136.0709 & $<.0001$ \\
\hline LivingSituation & $\begin{array}{l}\text { Couple with } \\
\text { children }\end{array}$ & 1 & -0.0764 & 0.1075 & 0.5049 & 0.4774 \\
\hline LivingSituation & $\begin{array}{c}\text { Couple without } \\
\text { children/children } \\
\text { not liv }\end{array}$ & 1 & -0.4989 & 0.1241 & 16.1513 & $<.0001$ \\
\hline LivingSituation & $\begin{array}{l}\text { Extended } \\
\text { family/whanau/other } \\
\text { combination }\end{array}$ & 1 & -0.0608 & 0.1124 & 0.2928 & 0.5884 \\
\hline LivingSituation & Flatmates/Others & 1 & 0.00676 & 0.1634 & 0.0017 & 0.9670 \\
\hline LivingSituation & $\begin{array}{l}\text { One person living } \\
\text { alone }\end{array}$ & 1 & 0.0636 & 0.1309 & 0.2361 & 0.6271 \\
\hline EmploymentStatus & $\begin{array}{l}\text { Currently in Paid } \\
\text { Employment }\end{array}$ & 1 & -0.1557 & 0.0785 & 3.9309 & 0.0474 \\
\hline EmploymentStatus & Home Duties & 1 & -0.1638 & 0.1248 & 1.7210 & 0.1896 \\
\hline EmploymentStatus & Retired & 1 & 0.0992 & 0.1885 & 0.2771 & 0.5986 \\
\hline EmploymentStatus & $\begin{array}{c}\text { Social } \\
\text { Welfare/Beneficiary }\end{array}$ & 1 & 0.3365 & 0.1137 & 8.7599 & 0.0031 \\
\hline MaritalStatus & Defacto Reln & 1 & 0.1250 & 0.1024 & 1.4913 & 0.2220 \\
\hline MaritalStatus & Divorced/Sep & 1 & 0.5067 & 0.1180 & 18.4302 & $<.0001$ \\
\hline
\end{tabular}




\begin{tabular}{|c|c|c|c|c|c|c|}
\hline \multicolumn{7}{|c|}{ Analysis of Maximum Likelihood Estimates } \\
\hline Parameter & & DF & Estimate & $\begin{array}{c}\text { Standard } \\
\text { Error }\end{array}$ & $\begin{array}{l}\text { Wald } \\
\text { Chi- } \\
\text { Square }\end{array}$ & $\mathrm{Pr}>\mathrm{ChiSq}$ \\
\hline MaritalStatus & Legal Married & 1 & -0.7354 & 0.0980 & 56.3195 & $<.0001$ \\
\hline ethnicity & Māori & 1 & 0.5876 & 0.0869 & 45.6715 & $<.0001$ \\
\hline ethnicity & NZ European & 1 & 0.0918 & 0.0746 & 1.5128 & 0.2187 \\
\hline ethnicity & Pacific & 1 & -0.4803 & 0.1101 & 19.0345 & $<.0001$ \\
\hline Age & $15-24$ & 1 & -0.0187 & 0.1311 & 0.0204 & 0.8866 \\
\hline Age & 25-39 & 1 & 0.4600 & 0.0840 & 30.0207 & $<.0001$ \\
\hline Age & $40-59$ & 1 & 0.2311 & 0.0828 & 7.7932 & 0.0052 \\
\hline Q220_ & Female & 1 & 0.2695 & 0.0447 & 36.3349 & $<.0001$ \\
\hline
\end{tabular}

\begin{tabular}{|c|c|c|c|}
\hline \multicolumn{4}{|l|}{ Odds Ratio Estimates } \\
\hline \multirow{2}{*}{$\begin{array}{c}\text { Effect } \\
\text { LivingSituation Couple with children vs Solo parent } \\
\text { with child/ren }\end{array}$} & \multirow{2}{*}{$\begin{array}{c}\text { Point } \\
\text { Estimate } \\
0.526\end{array}$} & \multicolumn{2}{|c|}{$\begin{array}{l}95 \% \text { Wald } \\
\text { Confidence } \\
\text { Limits }\end{array}$} \\
\hline & & 0.352 & 0.786 \\
\hline $\begin{array}{l}\text { LivingSituation Couple without children/children not liv } \\
\text { vs Solo parent with child/ren }\end{array}$ & 0.345 & 0.223 & 0.533 \\
\hline $\begin{array}{l}\text { LivingSituation Extended family/whanau/other } \\
\text { combination vs Solo parent with child/ren }\end{array}$ & 0.534 & 0.365 & 0.783 \\
\hline $\begin{array}{l}\text { LivingSituation Flatmates/Others vs Solo parent with } \\
\text { child/ren }\end{array}$ & 0.572 & 0.363 & 0.901 \\
\hline $\begin{array}{l}\text { LivingSituation One person living alone vs Solo parent } \\
\text { with child/ren }\end{array}$ & 0.605 & 0.427 & 0.858 \\
\hline $\begin{array}{l}\text { EmploymentStatus Currently in Paid Employment vs } \\
\text { Student or Other }\end{array}$ & 0.961 & 0.707 & 1.307 \\
\hline EmploymentStatus Home Duties vs Student or Other & 0.954 & 0.645 & 1.409 \\
\hline EmploymentStatus Retired vs Student or Other & 1.240 & 0.729 & 2.112 \\
\hline $\begin{array}{c}\text { EmploymentStatus Social Welfare/Beneficiary vs } \\
\text { Student or Other }\end{array}$ & 1.573 & 1.091 & 2.266 \\
\hline MaritalStatus Defacto Reln vs Single-Never Married & 1.022 & 0.715 & 1.459 \\
\hline
\end{tabular}




\begin{tabular}{|c|c|c|c|}
\hline \multicolumn{4}{|l|}{ Odds Ratio Estimates } \\
\hline \multirow{2}{*}{$\begin{array}{c}\text { Effect } \\
\text { MaritalStatus Divorced/Sep vs Single-Never Married }\end{array}$} & \multirow{2}{*}{$\begin{array}{c}\begin{array}{c}\text { Point } \\
\text { Estimate }\end{array} \\
1.496\end{array}$} & \multicolumn{2}{|c|}{$\begin{array}{l}95 \% \text { Wald } \\
\text { Confidence } \\
\text { Limits }\end{array}$} \\
\hline & & 1.090 & 2.054 \\
\hline MaritalStatus Legal Married vs Single-Never Married & 0.432 & 0.301 & 0.621 \\
\hline ethnicity Māori vs other & 2.196 & 1.468 & 3.286 \\
\hline ethnicity NZ European vs other & 1.338 & 0.917 & 1.952 \\
\hline ethnicity Pacific vs other & 0.755 & 0.485 & 1.174 \\
\hline Age $15-24$ vs 60 and over & 1.923 & 1.130 & 3.271 \\
\hline Age $25-39$ vs 60 and over & 3.103 & 1.978 & 4.868 \\
\hline Age $40-59$ vs 60 and over & 2.468 & 1.612 & 3.780 \\
\hline Q220_Female vs Male & 1.714 & 1.439 & 2.043 \\
\hline
\end{tabular}

\begin{tabular}{|c|c|c|c|}
\hline \multicolumn{4}{|c|}{$\begin{array}{l}\text { Association of Predicted Probabilities and Observed } \\
\text { Responses }\end{array}$} \\
\hline Percent Concordant & 75.6 & Somers' D & 0.521 \\
\hline Percent Discordant & 23.4 & Gamma & 0.526 \\
\hline Percent Tied & 1.0 & Tau-a & 0.203 \\
\hline Pairs & 2780778 & c & 0.761 \\
\hline
\end{tabular}


12 Months

\begin{tabular}{|c||l||}
\hline \multicolumn{2}{|c||}{ Model Information } \\
\hline \hline Data Set & WORK.VICTIMS_12MTHS \\
\hline \hline Response Variable & Victim \\
\hline \hline Number of Response Levels & 2 \\
\hline \hline Model & binary logit \\
\hline \hline Optimization Technique & Fisher's scoring \\
\hline \hline
\end{tabular}

\begin{tabular}{||c||c||}
\hline Number of Observations Read & 2903 \\
\hline \hline Number of Observations Used & 2901 \\
\hline
\end{tabular}

\begin{tabular}{|c||c||c|}
\hline \multicolumn{3}{|c|}{ Response Profile } \\
\hline \hline $\begin{array}{c}\text { Ordered } \\
\text { Value }\end{array}$ & Victim & $\begin{array}{c}\text { Total } \\
\text { Frequency }\end{array}$ \\
\hline \hline $\mathbf{1}$ & 0 & 2771 \\
\hline \hline 2 & 1 & 130 \\
\hline
\end{tabular}

Stepwise Selection Procedure

\begin{tabular}{|c|c|c|c|c|c|c|c|}
\hline \multirow[t]{2}{*}{ Step } & \multicolumn{2}{|l|}{ Effect } & \multirow[t]{2}{*}{ DF } & \multirow{2}{*}{$\underset{\text { In }}{\text { Number }}$} & \multirow{2}{*}{$\begin{array}{l}\text { Score } \\
\text { Chi- } \\
\text { Square }\end{array}$} & \multirow{2}{*}{$\begin{array}{l}\text { Wald } \\
\text { Chi- } \\
\text { Square }\end{array}$} & \multirow[t]{2}{*}{$\mathrm{Pr}>\mathrm{ChiSq}$} \\
\hline & Entered & Removed & & & & & \\
\hline 1 & Marital Status & & 3 & 1 & 113.3592 & & $<.0001$ \\
\hline 2 & Age & & 3 & 2 & 34.5716 & & $<.0001$ \\
\hline 3 & ethnicity & & 3 & 3 & 22.5903 & & $<.0001$ \\
\hline 4 & $\begin{array}{l}\text { Household } \\
\text { Tenure }\end{array}$ & & 2 & 4 & 9.1927 & & 0.0101 \\
\hline 5 & $\begin{array}{l}\text { NZ Socio- } \\
\text { Economic Index - } \\
\text { Grouped }\end{array}$ & & 6 & 5 & 14.1092 & & 0.0284 \\
\hline 6 & $\begin{array}{l}\text { Number in the } \\
\text { household }\end{array}$ & & 6 & 6 & 13.3816 & & 0.0374 \\
\hline
\end{tabular}




\begin{tabular}{|c||c||c||l||}
\hline \multicolumn{4}{|c|}{ Type 3 Analysis of Effects } \\
\hline \hline Effect & DF & $\begin{array}{c}\text { Wald } \\
\text { Chi-Square }\end{array}$ & Pr > ChiSq \\
\hline Q224_ & 2 & 10.5304 & 0.0052 \\
\hline \hline Marital Status & 3 & 15.8192 & 0.0012 \\
\hline \hline Number in the household & 6 & 12.8472 & 0.0455 \\
\hline \hline ethnicity & 3 & 16.0867 & 0.0011 \\
\hline \hline Age & 3 & 11.2762 & 0.0103 \\
\hline \hline $\begin{array}{c}\text { NZ Socio-Economic } \\
\text { Index - Grouped }\end{array}$ & 6 & 13.8100 & 0.0318 \\
\hline \hline
\end{tabular}

\begin{tabular}{|c|c|c|c|c|c|c|}
\hline \multicolumn{7}{|c|}{ Analysis of Maximum Likelihood Estimates } \\
\hline Parameter & & DF & Estimate & $\begin{array}{c}\text { Standard } \\
\text { Error }\end{array}$ & $\begin{array}{l}\text { Wald } \\
\text { Chi- } \\
\text { Square }\end{array}$ & Pr $>$ ChiSq \\
\hline Intercept & & 1 & -2.5911 & 0.3299 & 61.6745 & $<.0001$ \\
\hline $\begin{array}{l}\text { Household } \\
\text { Tenure }\end{array}$ & Other & 1 & 0.4494 & 0.3956 & 1.2909 & 0.2559 \\
\hline $\begin{array}{l}\text { Household } \\
\text { Tenure }\end{array}$ & $\begin{array}{c}\text { Owned } \\
\text { (including a } \\
\text { mortgage) }\end{array}$ & 1 & -0.5628 & 0.2282 & 6.0837 & 0.0136 \\
\hline Marital Status & Defacto Reln & 1 & -0.0817 & 0.2065 & 0.1565 & 0.6924 \\
\hline Marital Status & Divorced/Sep & 1 & 0.5301 & 0.4139 & 1.6404 & 0.0200 \\
\hline Marital Status & Legal Married & 1 & -0.8132 & 0.2142 & 14.4112 & 0.0001 \\
\hline $\begin{array}{l}\text { Number in the } \\
\text { household }\end{array}$ & 1 Person & 1 & -0.00105 & 0.5333 & 0.0000 & 0.9984 \\
\hline $\begin{array}{l}\text { Number in the } \\
\text { household }\end{array}$ & 2 Persons & 1 & -0.7766 & 0.2521 & 9.4926 & 0.0021 \\
\hline $\begin{array}{l}\text { Number in the } \\
\text { household }\end{array}$ & 3 Persons & 1 & 0.0381 & 0.2141 & 0.0316 & 0.8589 \\
\hline $\begin{array}{l}\text { Number in the } \\
\text { household }\end{array}$ & 4 Persons & 1 & 0.1598 & 0.1943 & 0.6765 & 0.4108 \\
\hline $\begin{array}{l}\text { Number in the } \\
\text { household }\end{array}$ & 5 Persons & 1 & -0.1517 & 0.2617 & 0.3359 & 0.5622 \\
\hline $\begin{array}{l}\text { Number in the } \\
\text { household }\end{array}$ & 6 Persons & 1 & 0.4860 & 0.3094 & 2.4672 & 0.1162 \\
\hline
\end{tabular}




\begin{tabular}{|c|c|c|c|c|c|c|}
\hline \multicolumn{7}{|c|}{ Analysis of Maximum Likelihood Estimates } \\
\hline Parameter & & DF & Estimate & $\begin{array}{l}\text { Standard } \\
\text { Error }\end{array}$ & $\begin{array}{l}\text { Wald } \\
\text { Chi- } \\
\text { Square }\end{array}$ & $\mathrm{Pr}>\mathrm{ChiSq}$ \\
\hline ethnicity & Māori & 1 & 0.7186 & 0.1950 & 13.5845 & 0.0002 \\
\hline ethnicity & NZ European & 1 & 0.0675 & 0.1955 & 0.1192 & 0.7299 \\
\hline ethnicity & Pacific & 1 & -0.2713 & 0.2525 & 1.1552 & 0.2825 \\
\hline Age & $15-24$ & 1 & 0.9007 & 0.2777 & 10.5229 & 0.0012 \\
\hline Age & 25-39 & 1 & 0.4419 & 0.2249 & 3.8613 & 0.0494 \\
\hline Age & $40-59$ & 1 & 0.0895 & 0.2398 & 0.1393 & 0.7090 \\
\hline $\begin{array}{l}\text { NZ Socio- } \\
\text { Economic Index } \\
\text { - Grouped }\end{array}$ & NZSEI 10-29 & 1 & -0.6216 & 0.2873 & 4.6805 & 0.0305 \\
\hline $\begin{array}{l}\text { NZ Socio- } \\
\text { Economic Index } \\
\text { - Grouped }\end{array}$ & NZSEI 30-39 & 1 & 0.0200 & 0.2040 & 0.0096 & 0.9219 \\
\hline $\begin{array}{l}\text { NZ Socio- } \\
\text { Economic Index } \\
\text { - Grouped }\end{array}$ & NZSEI 40-49 & 1 & 0.4470 & 0.1873 & 5.6986 & 0.0170 \\
\hline $\begin{array}{l}\text { NZ Socio- } \\
\text { Economic Index } \\
\text { - Grouped }\end{array}$ & NZSEI 50-59 & 1 & -0.1784 & 0.2572 & 0.4810 & 0.4880 \\
\hline $\begin{array}{l}\text { NZ Socio- } \\
\text { Economic Index } \\
\text { - Grouped }\end{array}$ & NZSEI 60-74 & 1 & -0.3133 & 0.2698 & 1.3484 & 0.2456 \\
\hline $\begin{array}{l}\text { NZ Socio- } \\
\text { Economic Index } \\
\text { - Grouped }\end{array}$ & NZSEI 75-90 & 1 & 0.1632 & 0.3846 & 0.1801 & 0.6713 \\
\hline
\end{tabular}




\begin{tabular}{|c|c|c|c|}
\hline \multicolumn{4}{|c|}{ Odds Ratio Estimates } \\
\hline \multirow{2}{*}{$\begin{array}{c}\text { Effect } \\
\text { Q224_Other vs Rented }\end{array}$} & \multirow{2}{*}{$\begin{array}{r}\begin{array}{c}\text { Point } \\
\text { Estimate }\end{array} \\
1.399\end{array}$} & \multicolumn{2}{|c|}{$\begin{array}{l}\text { 95\% Wald } \\
\text { Confidence } \\
\text { Limits }\end{array}$} \\
\hline & & 0.430 & 4.551 \\
\hline Q224_Owned (including a mortgage) vs Rented & 0.509 & 0.330 & 0.784 \\
\hline MaritalStatus Defacto Reln vs Single-Never Married & 0.640 & 0.316 & 1.296 \\
\hline $\begin{array}{c}\text { MaritalStatus Divorced/Sep vs Single-Never } \\
\text { Married }\end{array}$ & 1.180 & 0.351 & 3.969 \\
\hline $\begin{array}{c}\text { MaritalStatus Legal Married vs Single-Never } \\
\text { Married }\end{array}$ & 0.308 & 0.144 & 0.658 \\
\hline NolnHHold 1 Person vs 7 or more & 0.782 & 0.191 & 3.202 \\
\hline NolnHHold 2 Persons vs 7 or more & 0.360 & 0.145 & 0.896 \\
\hline NolnHHold 3 Persons vs 7 or more & 0.813 & 0.347 & 1.902 \\
\hline NolnHHold 4 Persons vs 7 or more & 0.918 & 0.405 & 2.082 \\
\hline NolnHHold 5 Persons vs 7 or more & 0.672 & 0.273 & 1.657 \\
\hline NolnHHold 6 Persons vs 7 or more & 1.272 & 0.491 & 3.298 \\
\hline ethnicity Māori vs other & 3.433 & 1.166 & 10.108 \\
\hline ethnicity NZ European vs other & 1.790 & 0.619 & 5.178 \\
\hline ethnicity Pacific vs other & 1.276 & 0.401 & 4.057 \\
\hline Age $15-24$ vs 60 and over & 10.307 & 2.195 & 48.399 \\
\hline Age $25-39$ vs 60 and over & 6.514 & 1.486 & 28.555 \\
\hline Age $40-59$ vs 60 and over & 4.579 & 1.055 & 19.884 \\
\hline nzseigp NZSEI 10-29 vs NZSEI Not specified & 0.331 & 0.137 & 0.803 \\
\hline nzseigp NZSEI 30-39 vs NZSEI Not specified & 0.629 & 0.298 & 1.329 \\
\hline nzseigp NZSEI 40-49 vs NZSEI Not specified & 0.965 & 0.461 & 2.019 \\
\hline nzseigp NZSEI 50-59 vs NZSEI Not specified & 0.516 & 0.221 & 1.203 \\
\hline nzseigp NZSEI 60-74 vs NZSEI Not specified & 0.451 & 0.189 & 1.073 \\
\hline nzseigp NZSEI 75-90 vs NZSEI Not specified & 0.726 & 0.246 & 2.145 \\
\hline
\end{tabular}




\begin{tabular}{|c|c|c|c|}
\hline \multicolumn{4}{|c|}{$\begin{array}{c}\text { Association of Predicted Probabilities and } \\
\text { Observed Responses }\end{array}$} \\
\hline Percent Concordant & 80.9 & Somers' D & 0.628 \\
\hline Percent Discordant & 18.1 & Gamma & 0.635 \\
\hline Percent Tied & 1.1 & Tau-a & 0.054 \\
\hline Pairs & 360230 & c & 0.814 \\
\hline
\end{tabular}

